Universidade de São Paulo

Instituto de Física

\title{
Detecção de chuveiros atmosféricos iniciados por hádrons massivos.
}

\author{
Washington Rodrigues de Carvalho Junior
}

Orientadora: Profa. Dra. Ivone Freire da Mota e Albuquerque

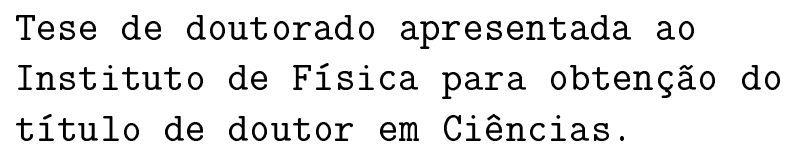

Banca Examinadora:

Profa. Dra. Ivone Freire da Mota e Albuquerque (IFUSP)

Prof. Dr. Philippe Gouffon (IFUSP)

Prof. Dr. Jorge Ernesto Horvath (IAG/USP)

Prof. Dr. João Ramos Torres de Melo Neto (UFRJ)

Profa. Dra. Carola Dobrigkeit Chinelatto (UNICAMP)

São Paulo 


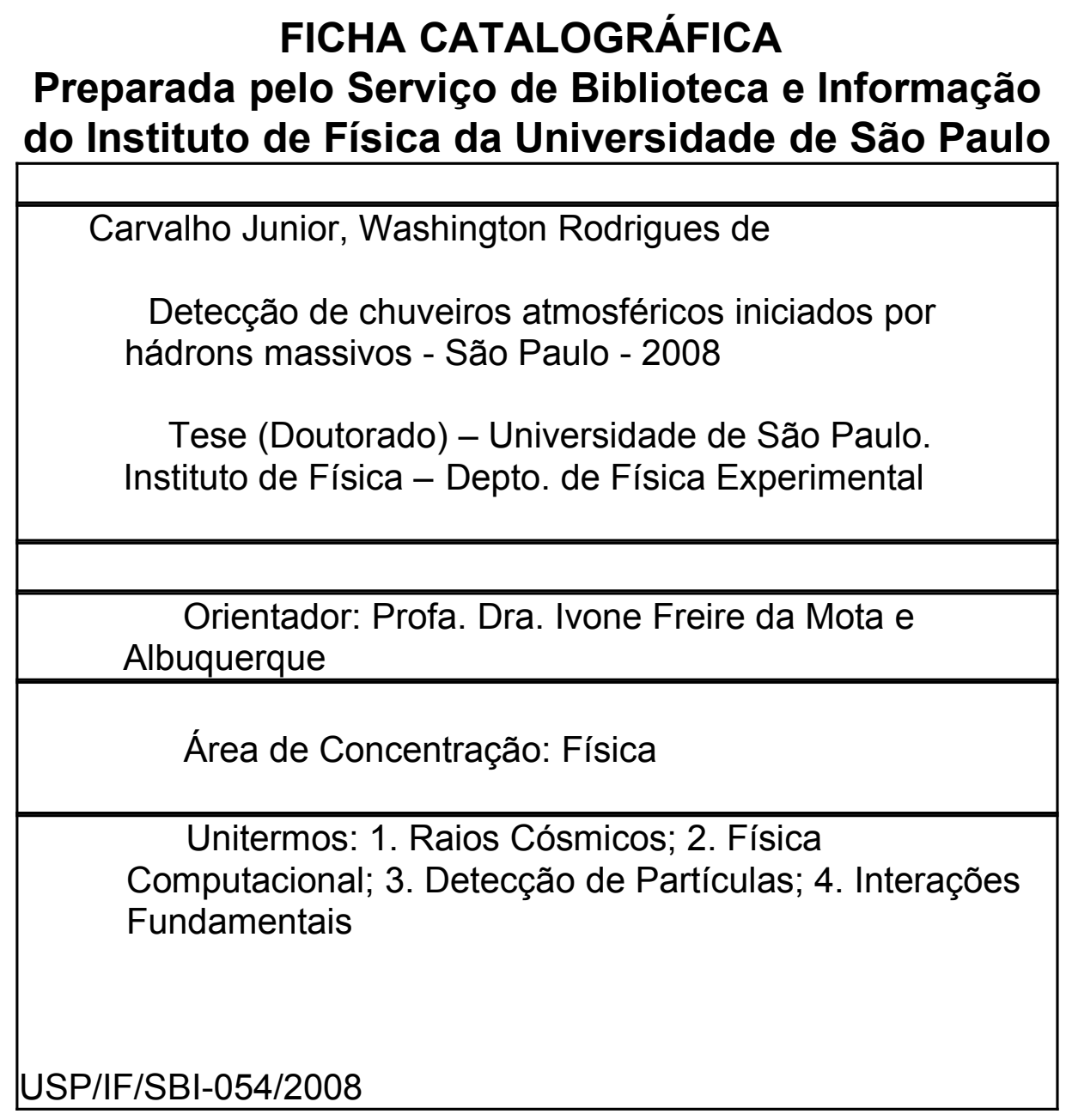


"One never notices what has been done; one can only see what remains to be done."

Marie Curie 


\section{Agradecimentos}

Ao Prof. Dr. Vitor de Souza, pelas explicações sobre o funcionamento e simulação de telescópios de fluorescência e pelas ricas e esquentadas discussões durante nossa colaboração.

À minha orientadora Profa. Dra. Ivone Albuquerque, pela quase infinita disponibilidade e paciência.

Ao Dr. Zwinglio de Oliveira Guimarães, ao Prof. Dr. Philippe Gouffon e ao amigo Diogo Tridapalli, pelas conversas que geraram algumas idéias apresentadas nesse trabalho.

À Fundação de Amparo à Pesquisa do Estado de São Paulo, pelo apoio financeiro que tornou possível este trabalho. 


\section{Resumo}

Nesta tese investigamos uma possível componente de partículas previstas por modelos além do modelo padrão da física de partículas, como por exemplo o massive gluino LSP, nos raios cósmicos de altíssimas energias (UHECR). Nosso objetivo é determinar os sinais experimentais em telescópios de fluorescência devidos a hádrons exóticos massivos e neutros, genericamente denominados de UHECRons. Para simular chuveiros iniciados por essa classe de partículas, alteramos o pacote Aires de simulação de chuveiros atmosféricos e o modelo hadrônico Sibyll. Estes chuveiros foram utilizados como entrada em simulações de telescópios de fluorescência por nós desenvolvidas, obtendo-se assim as distribuições dos observáveis desses chuveiros exóticos. A partir da comparação entre as características de chuveiros iniciados uhecrons e prótons, desenvolvemos métodos para a separação de sinais entre esses dois tipos de partículas. Esses métodos podem ser utilizados em uma análise inicial, com o intuito de procurar por sinais de partículas exóticas nos dados reais de observatórios de UHECR. 


\section{Abstract}

In this thesis we investigate a possible component of particles predicted by models beyond the standard model of particle physics, like the massive gluino LSP, in the ultra high energy cosmic rays (UHECR). Our objective is to determine the experimental signals on fluorescence telescopes due to exotic massive and neutral hadrons, generically called UHECRons. To simulate showers initiated by this class of particle, we altered the shower simulation package Aires and the hadronic model Sibyll. These showers were used as input in our simulations of fluorescence telescopes, thus obtaining the distribuitons of the observables for these exotic showers. By comparing the characteristics of showers initiated by uhecrons and protons, we developed methods to distinguish the signals between these two particles. These methods can be used in an initial analysis in order to look for signals of exotic particles in the real data of UHECR observatories. 


\section{Sumário}

1 Introdução $\quad 15$

1.1 Raios Cósmicos de altíssimas energias (UHECR) . . . . . . . . . . . . 17

1.1.1 Propagação dos UHECR . . . . . . . . . . . . . . . . . . . 19

1.1.2 Fontes e aceleração . . . . . . . . . . . . . . . 26

1.1.3 O enigma dos UHECR . . . . . . . . . . . . . . . 31

1.2 Chuveiros Atmosféricos Extensos (EAS) . . . . . . . . . . . . . . . 34

1.3 Simulação do EAS . . . . . . . . . . . . . . . . . . . 46

1.3.1 Interações hadrônicas: Sibyll . . . . . . . . . . . . . . . . . . . . 48

1.4 Deteç̧ão do EAS . . . . . . . . . . . . . . . . . 53

1.4.1 Técnica experimental de Fluorescência (FD) . . . . . . . . . 56

1.4.2 Técnica experimental de Superfície (SD) . . . . . . . . 65

2 Simulação da deteç̧ão e reconstrução de eventos pelo método FD. 69

$\begin{array}{lll}3 & \text { Simulação de EAS produzidos por uhecrons } & 77\end{array}$

3.0.3 Interações do UHECRON e alterações no Sibyll . . . . . . . . . . 77

3.0.4 Alterações no Aires . . . . . . . . . . . . . . . . . 82

4 Resultados e Análise $\quad 83$

4.1 Características de chuveiros iniciados por uhecrons. . . . . . . . . . . . 83

4.1.1 Características intrínsecas de EAS iniciados por uhecrons. . . . . 84

4.1.2 Características detectáveis de EAS iniciados por uhecrons. . . . . 93 
4.2 Método para separação de prótons e uhecrons . . . . . . . . . . . 105

5 Discussão e conclusão

Apêndices

128

A Shower Tools.

A.1 Sistemas de coordenadas utilizados na simulação . . . . . . . . . . . . . . 129

A.2 Classe Energy Deposition . . . . . . . . . . . . . . . . . . . 131

A.2.1 Leitura dos dados do perfil de deposição de energia . . . . . . . . 131

A.2.2 Transformações entre profundidade atmosférica vertical e slant . . 133

A.2.3 Transformação da inclinação zenital do chuveiro . . . . . . . . . 133

A.2.4 Ajuste da função Gaisser-Hillas ao perfil longitudinal de deposição

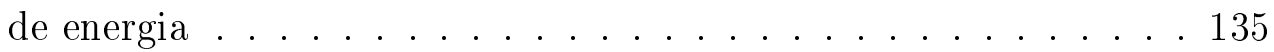

A.2.5 Integração da função GH e missing energy . . . . . . . . . . . . . 137

A.3 Classe Longitudinal Profile . . . . . . . . . . . . . . . . . . . . . . . . . . 140

A.4 Classe Shower Geometry . . . . . . . . . . . . . . . . 141

A.4.1 Geração da geometria do chuveiro. . . . . . . . . . . . . . 141

A.4.2 Determinação da parte visível do chuveiro. . . . . . . . . . . . . . 142

A.5 Classe PMT . . . . . . . . . . . . . . . . . . 145

A.5.1 Simulação do campo de visão das fotomultiplicadoras do telescópio e cálculo da energia depositada na atmosfera. . . . . . . . . . . 146

A.5.2 Cálculo do número de fótons de fluorescência emitidos e transporte através da atmosfera. . . . . . . . . . . . . . . . . . 149

A.5.3 Eficiência do telescópio, inclusão do fundo, simulação da eletrônica e trigger. . . . . . . . . . . . . . . . . . . . 151

A.5.4 Reconstrução da geometria . . . . . . . . . . . . . . . 155

A.5.5 Reconstrução da energia . . . . . . . . . . . . . . . . . 157

A.6 Classe EventManager . . . . . . . . . . . . . . . . . . . . 158 
A.6.1 Variáveis armazenadas . . . . . . . . . . . . . . . . . . 159 


\section{Capítulo 1}

\section{Introdução}

Nesta tese investigamos uma possível componente de partículas previstas por modelos além do modelo padrão da física de partículas (SM) nos raios cósmicos de altíssimas energias (UHECR). Nosso objetivo é determinar os sinais experimentais devido a hádrons exóticos massivos, denominados de UHECRons[1], em telescópios de fluorescência (FD). Estes hádrons são capazes de se propagar pelo fundo cósmico de microondas (CMB) com uma perda de energia muito menor que a de hádrons normais.

Nossa investigação se dá em dois níveis: primeiro uma análise das características das interações do uhecron na atmosfera, permitindo o desenvolvimento de simulações de chuveiros atmosféricos extensos (EAS) iniciados por este tipo de partícula, seguida pela determinação das características destes chuveiros "exóticos" e seus sinais em detetores de UHECR. Estes sinais são determinados utilizando-se os chuveiros de uhecrons como entrada de simulações Monte Carlo dos procressos de detecção e reconstrução de eventos por telescópios de fluorescência. Esta segunda etapa expande de forma original a investigação realizada por Albuquerque, Farrar e Kolb [2].

Através da comparação dos sinais em detetores de fluorescência de chuveiros iniciados por uhecrons e partículas usuais, como prótons e ferro, após a simulação completa da detecção e reconstrução de eventos, desenvolvemos métodos para separar esses dois tipos de chuveiro. Esses métodos podem ser utilizados para procurar por sinais de uhecrons 
em dados reais de observatórios de UHECR.

Modelos de extensão do SM propõem partículas com as características de uhecrons (ver capítulo 3). Como exemplo, temos um cenário de supersimetria, que propõe o heavy gluino como a partícula supersimétrica mais leve (LSP)[3]. Uma análise[4] dos dados experimentais do CDF determinou que a massa desta partícula está entre 25 e $35 G e V$. Entre outros candidatos compatíveis com o uhecron estão algumas classes de WIMPless dark matter [5], na região de massas entre $10 \mathrm{GeV}$ e $50 \mathrm{GeV}$. Muitos desses modelos serão testados no LHC e assim pode haver uma complementaridade entre esse experimento e observatórios de raios cósmicos, pois nada impede que esse tipo de partícula, com massas até 50GeV, sejam primários de chuveiros atmosféricos extensos (EAS).

A seguir descrevemos a organização desta tese de doutorado. O capítulo 1 apresenta uma revisão da área de UHECR. Discutimos a astrofísica relevante para os UHECR na seção1.1. Na seção 1.2 descrevemos a física relacionada com o processo de criação de chuveiros atmosféricos extensos, enquanto que a seção 1.3 descreve os principais métodos atuais de simulação de EAS. Finalmente, a seção 1.4 discute com algum detalhe os principais métodos de detecção e reconstrução de chuveiros na região de energia dos UHECR.

O capítulo 2 descreve o ferramental por nós desenvolvido[6] para a simulação da detecção e reconstrução de eventos pelo método de fluorescência. Mostramos também os resultados de alguns testes dessas simulações.

O capítulo 3 descreve o modelo de uhecron que está sendo utilizado, bem como as alterações efetuadas nos pacotes Sibyll[7] e Aires[8] para a simulação de chuveiros criados por uhecrons.

O capítulo 4 mostra nossa análise dos resultados obtidos. A seção 4.1 mostra uma comparação entre as características de chuveiros iniciados por uhecrons e partículas usuais, antes e após a inclusão dos efeitos de detecção e reconstrução de eventos, enquanto que a seção 4.2 descreve os métodos por nós desenvolvidos para a separação de uhecrons e prótons, baseados em seus sinais em telescópios de fluorescência. 
Finalmente, o capítulo 5 apresenta uma discussão final sobre o trabalho.

\subsection{Raios Cósmicos de altíssimas energias (UHECR)}

Os raios cósmicos foram descobertos pelo físico austríaco Victor Hess em 1912. Em uma série de vôos com balões equipados com câmaras de ionização, ele verificou que a intensidade da radiação aumentava com a altitude. Ele interpretou esse resultado como uma evidência de que a atmosfera terrestre é constantemente bombardeada por radiação ionizante. Desde então, nossa compreensão dos raios cósmicos foi bastante desenvolvida por vários físicos, entre eles Pierre Auger, que descobriu os chuveiros atmosféricos extensos (seção 1.2). A figura 1.1 mostra o espectro dos raios cósmicos e algumas de suas características. Pode-se observar a rápida variação do fluxo com a energia.

A parte mais energética do espectro, com energia acima de $\sim 5 \times 10^{19} \mathrm{eV}$, compõe os raios cósmicos de altíssimas energias (UHECR). As energias destas partículas são várias ordens de grandeza maiores do que as que podem ser alcançadas em aceleradores terrestres. Desse modo, os UHECR podem permitir a investigação dessa região de ultra alta energia.

Por outro lado, o fluxo nessa região do espectro de energia é extremamente baixo, por volta de 1 evento $/ \mathrm{km}^{2}$ século. A composição dessas partículas, bem como a maneira como são aceleradas e os objetos astrofísicos de onde se originam, ainda estão sendo intensamente investigados.

Neste capítulo abordaremos características importantes das partículas nessa parte do espectro. Descreveremos como a degradação de energia dos UHECR ao atravessar o fundo cósmico de microondas (CMB) e a ausência de bons candidatos a fontes em regiões próximas à Terra do ponto de vista astrofísico, juntamente com o fluxo medido por alguns experimentos nessa região de energia, dão origem ao enigma dos UHECR. 


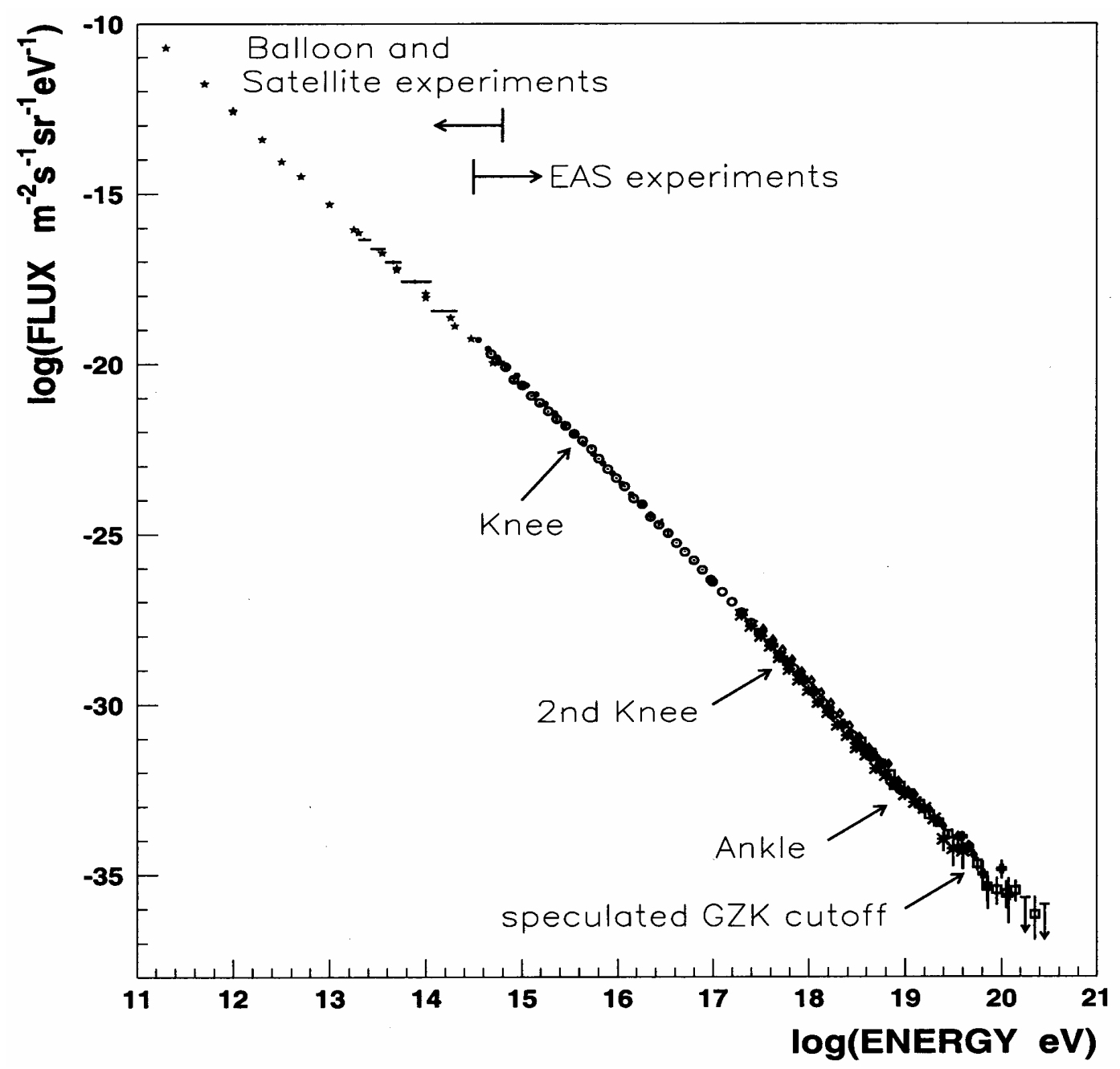

Figura 1.1: Espectro observado dos raios cósmicos. Figura extraída de [9]. 


\subsubsection{Propagação dos UHECR}

Em 1966, logo após a descoberta da radiação cósmica de fundo em microondas (CMB), Greisen[10] e, simultaneamente, Zatsepin e Kuzmin[11, 12] mostraram que essa radiação de fundo teria conseqüências importantes na propagação dos raios cósmicos, tornando o universo opaco para partículas com energia acima de $\sim 5 \times 10^{19} \mathrm{eV}$.

No caso de nucleons, o processo dominante é a fotoprodução de píons com o CMB:

$$
N+\gamma \rightarrow \pi+N
$$

onde $N$ é um nucleon.

No referencial de repouso (REST) de um UHECR composto por um nucleon, os fótons do CMB são vistos como raios- $\gamma$ com energia acima do limiar $E_{\gamma}^{\text {rest, lim de foto- }}$ produção de píons:

$$
E_{\gamma}^{r e s t, l i m} \equiv m_{\pi}+\frac{m_{\pi}^{2}}{2 m_{N}} \simeq 150 M e V
$$

onde $m_{\pi}$ e $m_{N}$ são as massas do píon e do nucleon, respectivamente. A seção de choque

total para esse processo em função da energia $E_{\gamma}^{r e s t}$ do fóton no referencial de repouso do nucleon é mostrada na figura 1.2. Próximo ao limiar, a seção de choque apresenta uma ressonância, associada à produção de um único píon através da produção e decaimento de um $\Delta^{+}$. A longa cauda após a ressonância é dominada por produção múltipla de píons.

Para relacionar o sistema de repouso do raio cósmico (REST) com o sistema do laboratório cósmico (LAB), definido como o sistema onde o CMB é isotrópico, podemos utilizar as transformações de Lorentz. A figura 1.3 mostra a relação entre os sistemas LAB e o sistema de repouso (REST) de uma partícula de energia $E$ e massa $M$ se movendo na direção $z$ no sistema LAB, e um fóton do CMB de energia $\epsilon$ incidindo com uma direção $(\theta, \phi)$ sobre o raio cósmico.

O quadrivetor $p^{\mu}$ do fóton no sistema LAB e $p^{\mu^{\prime}}$ no sistema REST podem ser descritos 


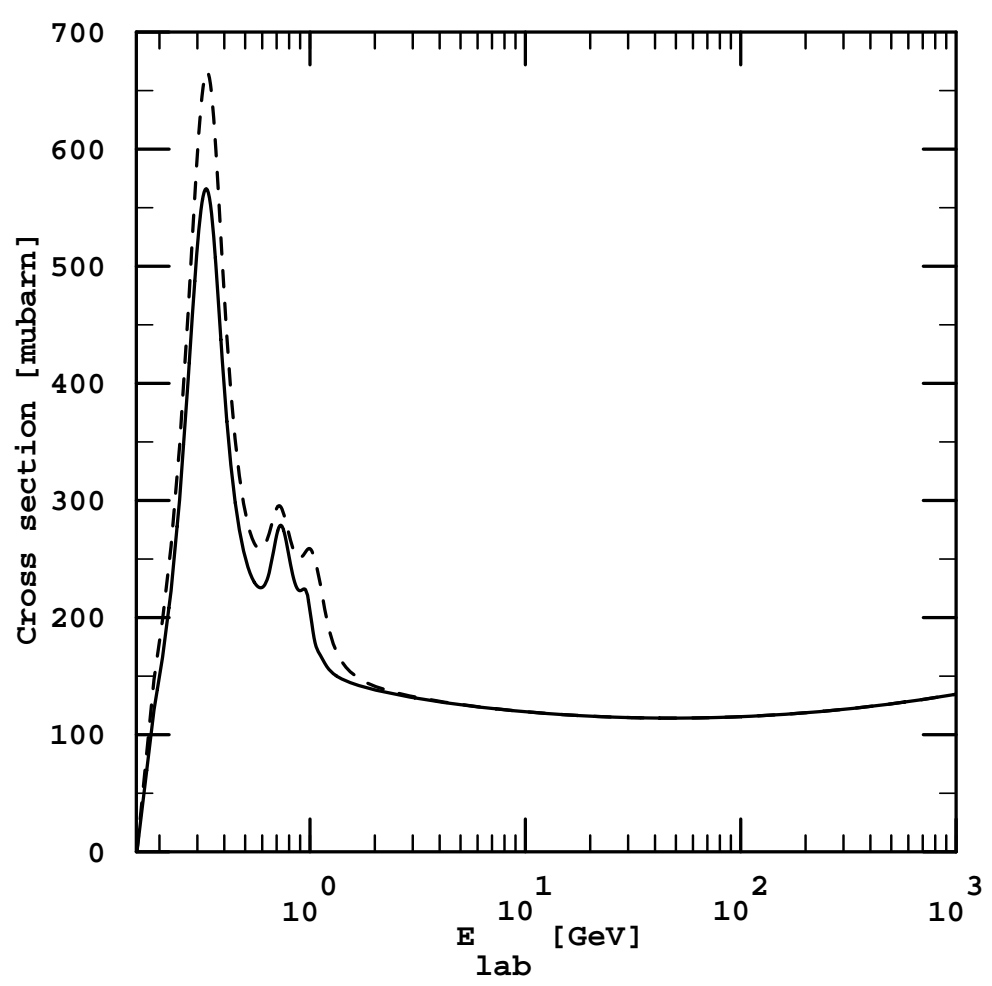

Figura 1.2: Seção de choque total para fotoprodução de píons no caso de prótons (linha cheia) e nêutrons (linha tracejada) em função da energia do fóton no sistema de repouso do nucleon. O primeiro pico, próximo ao limiar, é devido à ressonância associada à produção do $\Delta^{+}$. Figura extraída de [13].
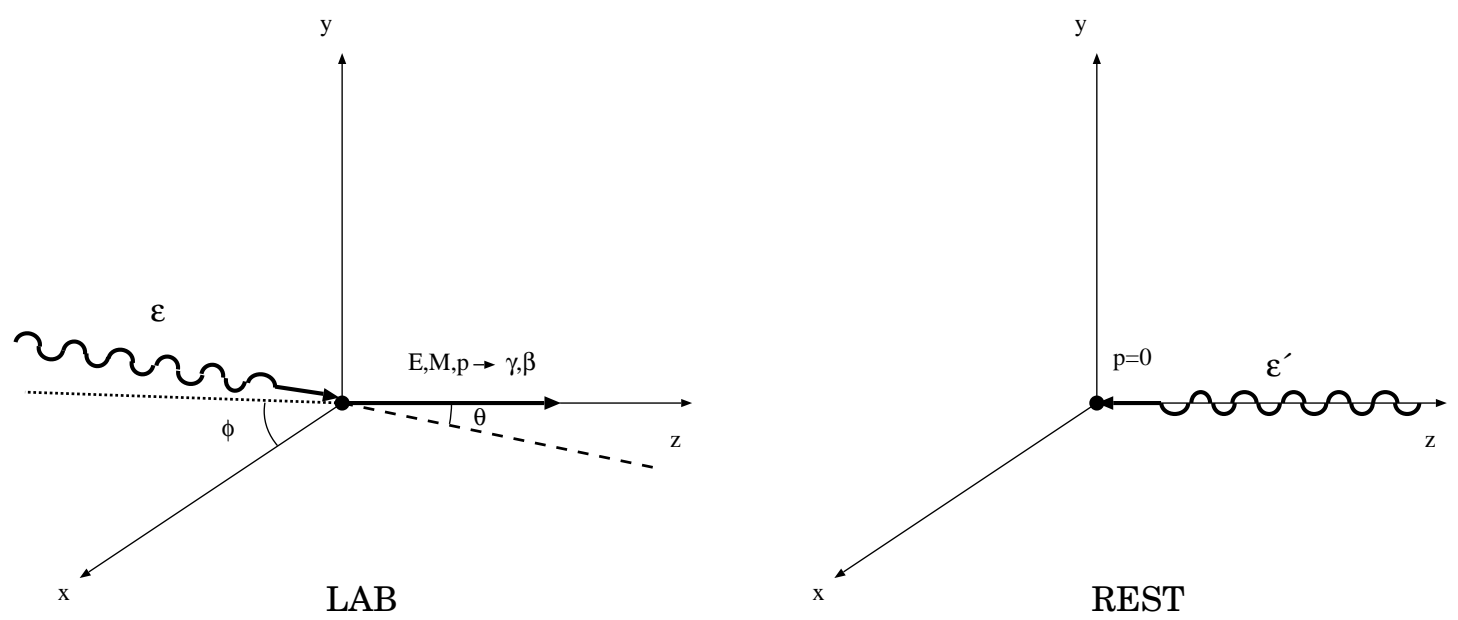

Figura 1.3: Relação entre os sistemas LAB e REST para uma partícula de energia $E$ e massa $M$ se movendo na direção $z$ no sistema LAB, e um fóton do CMB de energia $\epsilon$ incidindo com uma direção $(\theta, \phi)$ sobre o raio cósmico. 
por:

$$
\begin{aligned}
p^{\mu} & =(\epsilon, \epsilon \sin \theta \cos \phi, \epsilon \sin \theta \sin \phi, \epsilon \cos \theta), \\
p^{\mu^{\prime}} & =\left(\epsilon^{\prime}, \epsilon^{\prime} \sin \theta^{\prime} \cos \phi^{\prime}, \epsilon^{\prime} \sin \theta^{\prime} \sin \phi^{\prime}, \epsilon^{\prime} \cos \theta^{\prime}\right) .
\end{aligned}
$$

Aplicando as transformações de Lorentz sobre $p^{\mu}(1.3)$, temos:

$$
p^{\mu^{\prime}}=(\gamma(\epsilon-\beta \epsilon \cos \theta), \epsilon \sin \theta \cos \phi, \epsilon \sin \theta \sin \phi, \gamma(\epsilon \cos \theta-\beta \epsilon))
$$

e igualando 1.4 a 1.5, obtemos então:

$$
\begin{array}{r}
\epsilon^{\prime}=\gamma \epsilon(1-\beta \cos \theta)=\frac{E}{M} \epsilon(1-\beta \cos \theta), \\
\phi=\phi^{\prime}, \\
\cos \theta^{\prime}=\frac{\cos \theta-\beta}{1-\beta \cos \theta} .
\end{array}
$$

Assim, substituindo o limiar $E^{\text {rest,lim }}$ (Eq. 1.2) como $\epsilon^{\prime}$ em 1.6, obtemos o limiar $E_{N}^{l a b, l i m}$ para a energia do nucleon no sistema LAB:

$$
E_{N}^{l a b, l i m}=\frac{m_{\pi}}{(1-\beta \cos \theta) \epsilon}\left(m_{N}+\frac{m_{\pi}}{2}\right) \simeq 6.8 \times 10^{16}\left(\frac{\epsilon}{1 e V}\right)^{-1}\left(\frac{2}{1-\beta \cos \theta}\right) e V
$$

Como a energia do nucleon é extremamente alta, temos que $\beta \simeq 1$. Logo, da Eq. 1.8, obtemos $\theta \simeq \pi$, isto é, embora no sistema LAB os fótons do CMB sejam isotrópicos, no referencial REST os choques frontais são uma excelente aproximação. A energia dos fótons do $\mathrm{CMB}$ seguem uma distribuição de corpo negro com $T \simeq 2.7 K$, o que leva a uma energia típica da ordem de $\epsilon \sim 10^{-3} \mathrm{eV}$. Substituindo esses valores de $\epsilon, \theta$ e $\beta$ em 1.9, obtemos o limiar $E_{N}^{l a b, l i m} \simeq 6.8 \times 10^{19} \mathrm{eV}$ para a fotoprodução de píons. Vale lembrar que esta é apenas uma estimativa, já que devido à distribuição de energia dos fótons do CMB, é possível ocorrer a fotoprodução de píons abaixo desse limiar devido 
aos fótons mais energéticos dessa distribuição de corpo negro.

O comprimento de interação para a fotoprodução de píons pode ser estimada através da seção de choque para energias acima da ressonância $\Delta$ (Fig. 1.2) e a densidade $n_{\gamma}$ de fótons do CMB:

$$
\lambda=\left(\sigma n_{\gamma}\right)^{-1} \simeq 1.8 \times 10^{25} \mathrm{~cm} \simeq 6 M p c
$$

para $\sigma \simeq 135 \mu$ barn e $n_{\gamma} \simeq 410 \mathrm{~cm}^{-3}$.

Além do comprimento de interação, outro fator importante é a alta inelasticidade do processo de fotoprodução de píons, fazendo com que o próton incidente perca por volta de $20 \%$ de sua energia a cada interação. Essa alta inelasticidade, juntamente com o baixo comprimento de interação, faz com que a degradação de energia de prótons acima do limiar de fotoprodução de píons seja muito grande, limitando o alcance de prótons de altíssimas energias. A figura 1.4 mostra a taxa de perda de energia para prótons.

Aharonian e Cronin[15] investigaram a propagação de prótons pelo CMB utilizando métodos Monte Carlo. Como resultado (ver fig. 1.5), mostraram que após uma distância de aproximadamente $100 \mathrm{Mpc}$, a energia do próton é praticamente independente da sua energia inicial e é menor que $10^{20} \mathrm{eV}$.

Abaixo do limiar de fotoprodução de píons, o processo dominante é a criação de pares no CMB, seguido pela perda adiabática (redshift) devido à expansão do universo. Porém, acima do limiar de fotoprodução de píons, estes processos constituem uma contribuição pequena para a perda de energia, como pode ser visto na figura 1.4.

No caso de núcleos, a situação é um pouco diferente. O processo de perda de energia dominante acima de $10^{19} \mathrm{eV}$ é a fotodesintegração no CMB e no fundo infravermelho (IRB), devido à ressonância dipolar gigante. A energias mais baixas, o principal mecanismo é a criação de pares. Cálculos recentes indicam que o comprimento de atenuação é da ordem de $\sim 10 M p c$ a $10^{20} \mathrm{eV}[13]$. Desse modo, como no caso de nucleons, as fontes não poderiam estar a mais de algumas dezenas de $M p c$. Além das perdas devido à foto- 


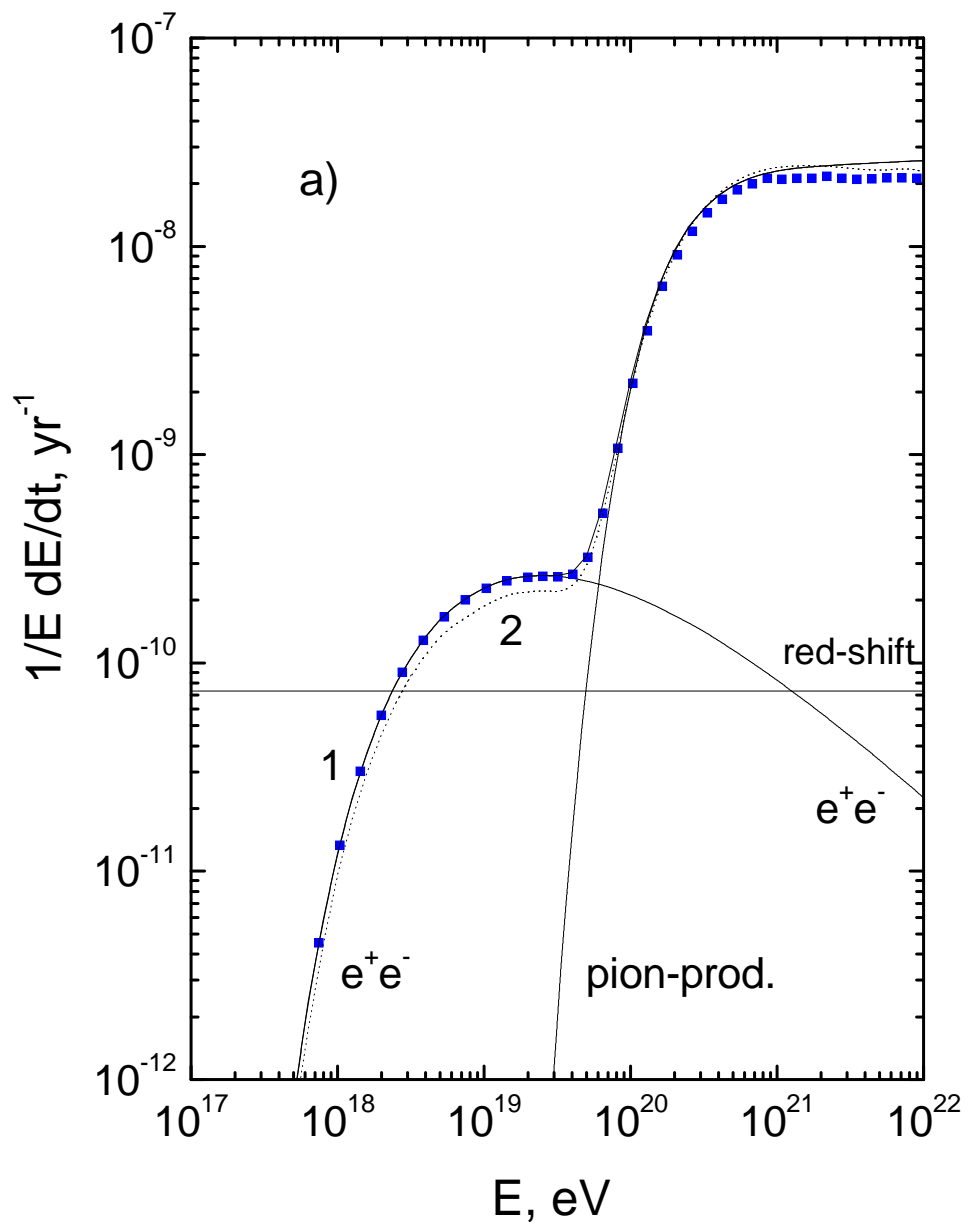

Figura 1.4: Taxa de perda de energia para prótons em $z=0$. A linha "red-shift" representa a perda adiabática de energia. Para $E=6.05 \times 10^{19} \mathrm{eV}$ as perdas devido à fotoprodução de píons e criação de pares são iguais. Figura extraída de [14].

desintegração, os núcleos estão sujeitos aos mesmos processos de perda de energia que nucleons. Porém os limiares se alteram de acordo com a massa do núcleo, substituindo $m_{N}$ pela massa do núcleo na equação 1.9 .

Como no caso de nucleons e núcleos, a propagação de fótons também é governada pelas suas interações com os fundos cósmicos de fótons. O processo dominante é a absorção devido à criação de pares com os fundos IRB, CMB, fundo universal de rádio (URB) e óptico: $\left(\gamma+\gamma_{b} \rightarrow e^{+}+e^{-}\right)$. O limiar para a produção de pares por raios gama em fótons de fundo de energia $\epsilon$ é[17]: 


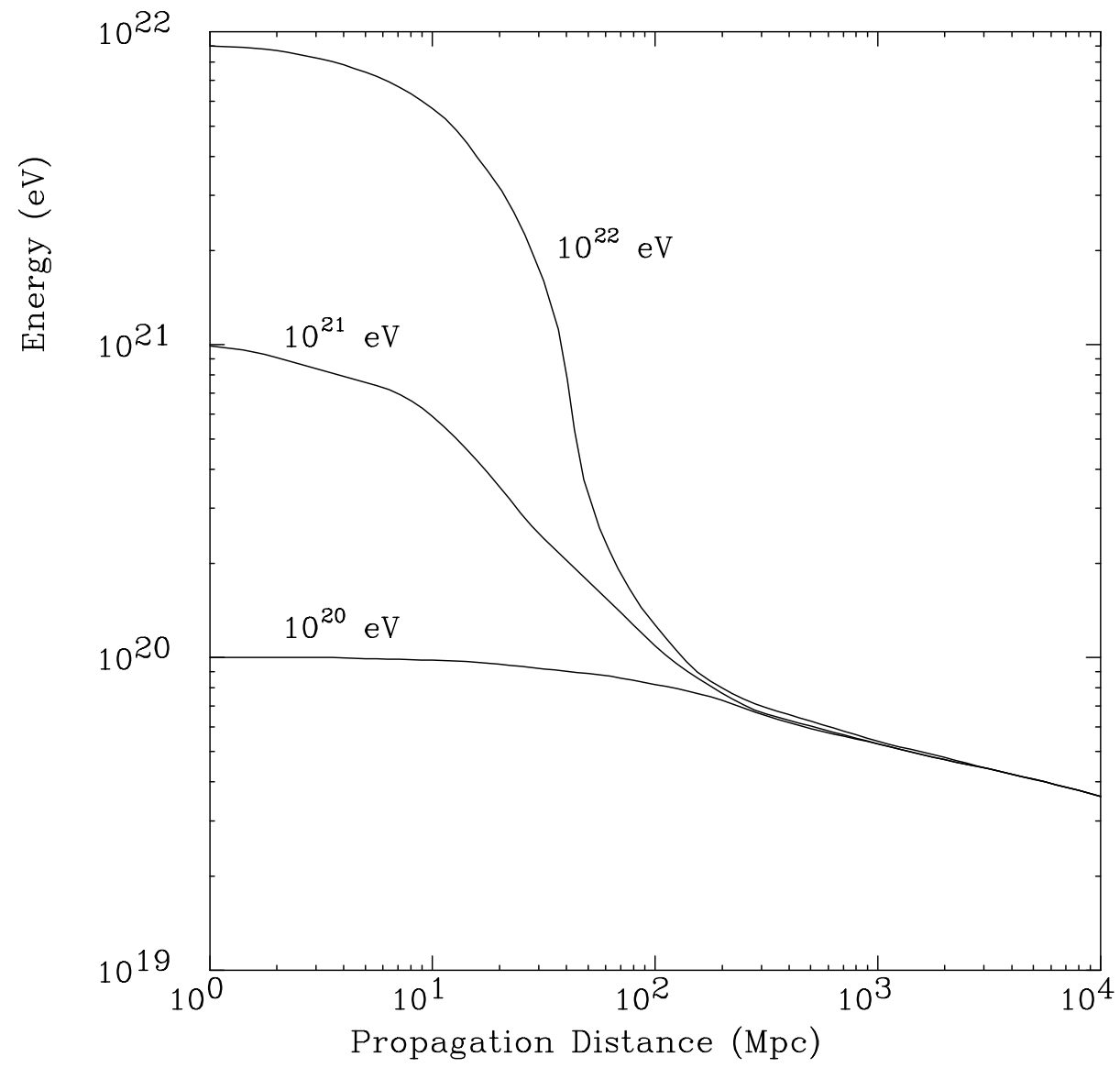

Figura 1.5: Energia média em função da distância (tempo) de propagação para prótons com energia inicial indicada. Figura extraída de [15].

$$
E_{t h r}=\frac{m_{e}^{2}}{\epsilon} \cong 2.6 \cdot 10^{11}\left(\frac{\epsilon}{e V}\right)^{-1} e V .
$$

Como a seção de choque desse processo é maior na região próxima ao limiar, os alvos mais eficientes para raios gama de energia $E$ são fótons de fundo de energia $\epsilon \sim m_{e}^{2} / E$. No caso de fótons de altíssimas energias, temos $\nu \sim 100 \mathrm{MHz}$, assim fótons do fundo de rádio (URB) são importantes nesse processo. Na região de energia entre $10^{12} \mathrm{eV} \mathrm{e}$ $10^{22} \mathrm{eV}$, o comprimento de atenuação é menor que $100 \mathrm{Mpc}$ [18], tornando o universo opaco para fótons em escalas cosmológicas.

Elétrons e pósitrons não podem constituir os UHECR, pois perdem a maior parte de sua energia ao atravessar os campos magnéticos cósmicos. A altas energias $(E \sim$ 


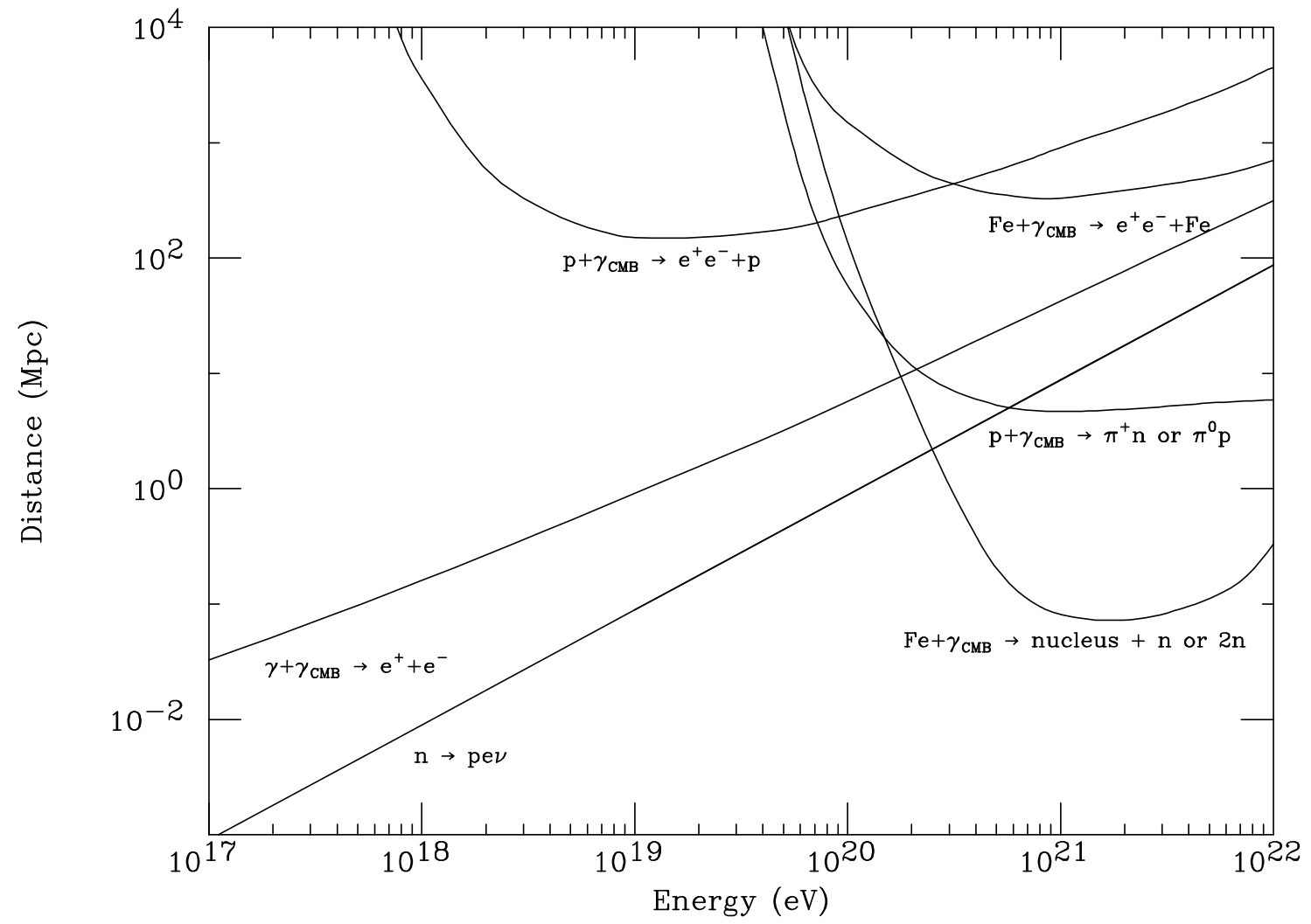

Figura 1.6: Panorama das interações das partículas primárias de raios cósmicos com o CMB. As curvas marcadas como " $p+\gamma_{C M B} \rightarrow e^{+} e^{-}+\mathrm{p}$ " e "Fe+ $+\gamma_{C M B} \rightarrow e^{+} e^{-}+\mathrm{Fe}$ " são comprimentos de atenuação. A curva marcada como " $p+\gamma_{C M B} \rightarrow \pi^{+} \mathrm{n}$ ou $\pi^{0}$ p" é o caminho livre médio para fotoprodução de píons no CMB. A curva marcada "Fe+ $+\gamma_{C M B} \rightarrow$ núcleo $+\mathrm{n}$ ou $2 \mathrm{n}$ " é o caminho livre médio para reações fotonucleares onde o ferro perde um ou dois nucleons. A curva marcada " $\gamma+\gamma_{C M B} \rightarrow e^{+} e^{-"}$ é o caminho livre médio para a interação de um fóton de alta energia com o CMB. "n $\rightarrow$ pev" é o comprimento de decaimento médio para nêutrons. Figura extraída de [16].

$\left.10^{19} \mathrm{eV} / B_{n G}\right)$, onde $B_{n G}$ é o campo magnético em $n G$, o processo dominante é a perda de energia por radiação síncrotron, que pode ser expressa como[18]:

$$
-\frac{d E}{d t}=\frac{4 \alpha^{2}}{3 m_{e}^{2}}<B^{2}>\left(\frac{E}{m_{e}}\right)^{2},
$$

onde $m_{e}$ é a massa do elétron e $E$ é a energia do elétron ou pósitron. Em um campo da ordem de $1 n G$, essa perda é da ordem de $3 \times 10^{18} \mathrm{eV}$ em $100 \mathrm{kpc}$ para um elétron de $100 \mathrm{EeV}[18]$. Outro processo relevante no caso de elétrons é o processo Compton Inverso. 
Ainda outro fator importante na propagação de raios cósmicos é a sua deflexão devido aos campos magnéticos extra-galáticos (EGMF). A deflexão $\theta(E, r)$ de uma partícula de energia $E$ devido a um EGMF $B$ com um comprimento de coerência $l_{c}$ em uma distância percorrida $r \gtrsim l_{c}$ pode ser dada por[19]:

$$
\theta(E, r) \simeq\left(\frac{2 r l_{c}}{9}\right)^{\frac{1}{2}} r_{L}^{-1}
$$

onde $r_{L}$ é o raio de Larmor que, para uma partícula de carga $Z e$ e energia $E$, pode ser dado por:

$$
r_{L} \simeq \frac{E}{Z e B}
$$

e assim podemos obter[20]:

$$
\theta(E, r) \simeq 0.8^{\circ} Z\left(\frac{E}{10^{20} e V}\right)^{-1}\left(\frac{r}{10 M p c}\right)^{\frac{1}{2}}\left(\frac{l_{c}}{1 M p c}\right)^{\frac{1}{2}}\left(\frac{B}{10^{-9} G}\right)
$$

Desse modo, partículas de altíssimas energias possuem uma deflexão pequena e, em princípio, apontariam na direção da fonte que as produziu.

Todos os processos de perda de energia de UHECR fazem com que o universo visível, no caso de partículas conhecidas, seja restrito a uma esfera com um raio da ordem de $\sim 50 M p c$, chamada de esfera GZK, restringindo as fontes às proximidades de nossa galáxia do ponto de vista astrofísico.

\subsubsection{Fontes e aceleração}

Os mecanismos de aceleração das partículas dos UHECR ainda não são bem determinados. Porém, podemos dividir esses mecanismos em duas classes distintas: mecanismos Bottom-up e mecanismos Top-down.

Nos mecanismos Bottom-up, a energia é transferida aos UHECR através da interação com campos eletromagnéticos. Esses mecanismos não descartam a possibilidade de que os UHECR sejam em si compostos por partículas além do modelo padrão. Os 
mecanismos Bottom-up podem ser divididos em diretos e estocásticos/difusos. Nos mecanismos diretos, a aceleração se dá de uma só vez em regiões de altíssimos campos elétricos, gerados nas proximidades de condutores magnetizados em alta rotação, como por exemplo estrelas de nêutrons ou objetos supermassivos[21], como discos de acreção de buracos negros. Nos mecanismos estocásticos, as partículas ganham energia através de muitas interações com regiões de campos magnéticos dinâmicos (espelhos magnéticos) ou em regiões com intensas ondas de choque (nuvens de plasma magnetizado), como por exemplo em remanescentes de supernovas (SNRs) ou hot spots de rádiogaláxias. Esses processos, como o Diffusive Shock Acceleration Mechanism (DSAM) no caso de aceleração em ondas de choque, são variantes dos mecanismos de Fermi.

Nos mecanismos Top-down, os raios cósmicos seriam gerados através do decaimento de partículas massivas. Tais partículas poderiam ser relíquias meta-estáveis de algum campo primordial ou partículas extremamente instáveis, produzidas pela radiação, interação ou colapso de defeitos topológicos [18]. O decaimento destas partículas produz uma cascata de fótons de alta energia, neutrinos e léptons leves, com uma pequena fração de prótons e nêutrons, parte dos quais se torna os UHECR.

Os mecanismos Top-down foram intensamente pesquisados nos últimos anos, pois pareciam ser uma opção viável aos problemas encontrados nos mecanismos de aceleração Bottom-up tradicionais. No entanto, a maioria dos modelos Top-down prevêem um grande fluxo de fótons de altíssima energia[22, 23] $\left(E>10^{19} \mathrm{eV}\right)$, o que é descartado experimentalmente já que, segundo resultados recentes do Auger[24], a fração fotônica dos UHECR acima de $10^{19} \mathrm{eV}$ é no máximo $2 \%$, com um nível de confiança de $95 \%$. Desse modo, mecanismos Top-down não parecem ser uma solução viável para a origem dos UHECR.

\section{Possíveis fontes dos UHECR}

Independentemente dos detalhes do mecanismo de aceleração, direta ou estocástica, Hillas[21] mostrou que a energia máxima que pode ser alcançada por uma partícula de 
carga $Z e$ em uma região de tamanho $R$ e campo magnético $B$ é dada por:

$$
E_{\text {max }} \cong \beta Z\left(\frac{B}{1 \mu G}\right)\left(\frac{R}{1 k p c}\right) 10^{18} \mathrm{eV}
$$

onde $\beta$ é a velocidade da onda de choque ou a eficiência do mecanismo de aceleração.

A equação 1.16 pode ser entendida em termos de uma relação entre o ganho de energia da partícula em uma região com campo magnético $B$ (perpendicular à velocidade da partícula) de tamanho $R$, e a capacidade dessa região confinar tal partícula, com um raio de Larmor da ordem de $E_{15} / Z B_{\mu G}$, onde $E_{15}$ é a energia da partícula em unidades de $10^{15} \mathrm{eV}$ e $B_{\mu G}$ é o campo da região em $\mu G$. Essa é uma condição necessária mas não suficiente. Desse modo podemos avaliar possíveis fontes aceleradoras em termos de seu campo magnético e seu tamanho. A figura 1.7 é conhecida como diagrama de Hillas e mostra limites de campo magnético e tamanho do objeto astrofísico para acelerar partículas a $10^{20} \mathrm{eV}$. Objetos abaixo da linha diagonal não são capazes de acelerar determinada partícula ( $\mathrm{p} \operatorname{com} \beta=1, \mathrm{p} \operatorname{com} \beta=1 / 300$ ou Fe $\operatorname{com} \beta=1$ ) a essa energia.

Do diagrama de Hillas (Fig.1.7) vemos que estrelas de nêutrons girantes (pulsares), satisfazem a condição necessária mas não suficiente dada pela equação 1.16. Nesse caso, as partículas são aceleradas diretamente através da diferença de potencial induzida pela configuração do campo magnético girante da estrela de nêutrons. Porém, a perda de energia por radiação síncrotron em um sistema compacto como um pulsar é muito grande. Desse modo, acredita-se que seja muito difícil acelerar partículas em pulsares além de $\sim 10^{15} \mathrm{eV}[25]$.

Outro candidato a fonte dos UHECR são os núcleos galáticos ativos (AGN). Esse termo é usado para identificar uma gama de objetos, caracterizados pela presença de um buraco negro massivo central alimentado por um disco de acreção. A presença de jatos é uma característica de vários $\mathrm{AGNs}^{1}$. Quando a matéria do fluxo de acreção está prestes a acabar, a AGN deixa de ser ativa, tornando-se um quasar inativo. Estimativas

\footnotetext{
${ }^{1}$ Esse tipo de objeto recebe várias denominações diferentes, dependendo do ângulo de visão em relação ao jato.
} 


\section{Hillas-plot (candidate sites for $\mathrm{E}=100 \mathrm{EeV}$ )}

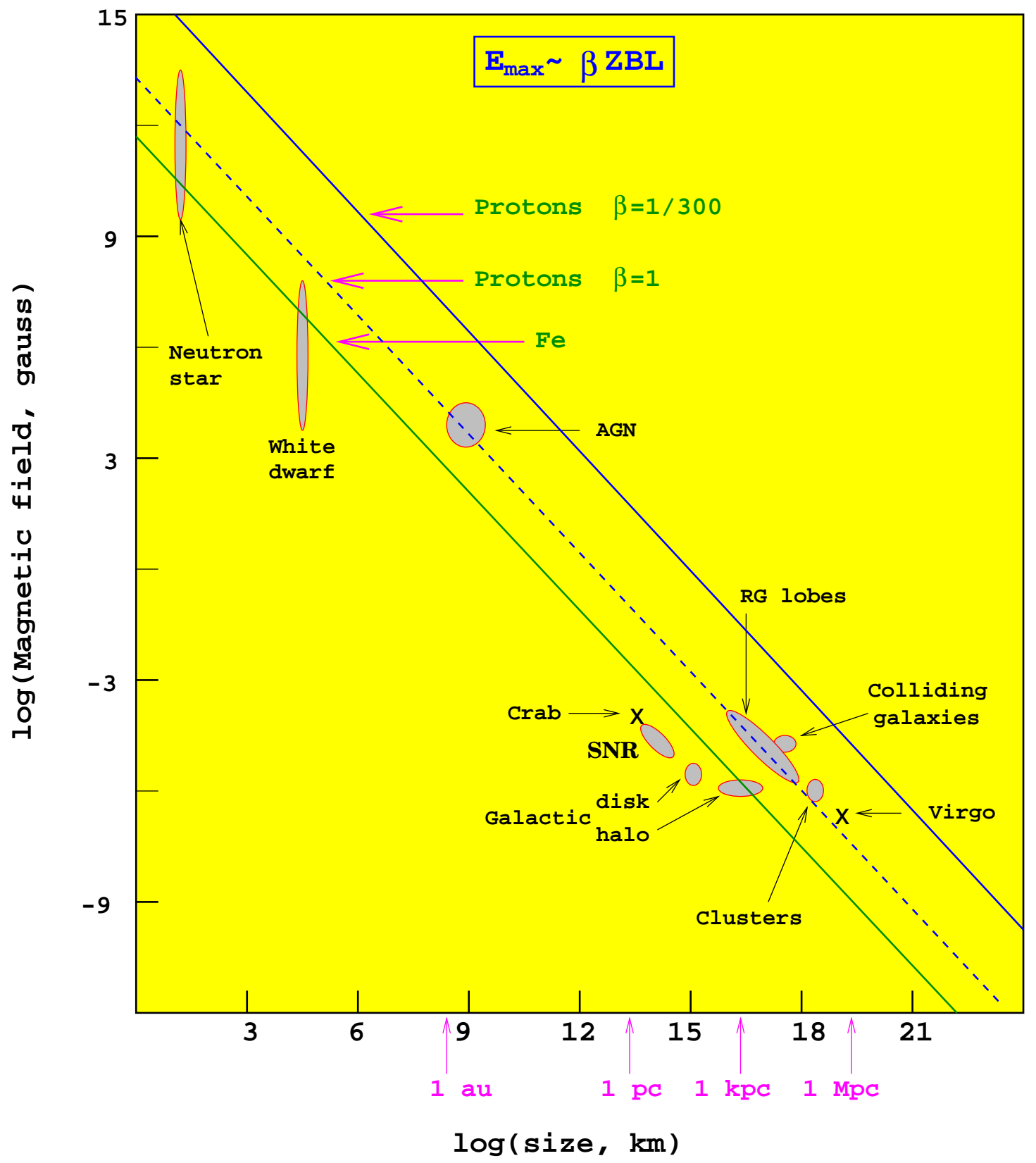

Figura 1.7: Diagrama de Hillas mostrando limites de Campo Magnético e tamanho do objeto astrofísico para acelerar partículas a $10^{20} \mathrm{eV}$. Objetos abaixo da linha diagonal não são capazes de acelerar determinada partícula $(\mathrm{p} \operatorname{com} \beta=1, \mathrm{p} \operatorname{com} \beta=1 / 300 \mathrm{ou}$ Fe $\operatorname{com} \beta=1)$. Figura extraída de [18]. 
do tamanho e do campo da região central de AGNs levam a $R \sim 0.02 p c$ e $B \sim 5 G[13]$, e obtemos assim uma energia de corte $E_{c} \sim 10^{19} \mathrm{eV}$ segundo o DSAM, valor esse que pode ter uma incerteza de algumas ordens de grandeza. Desse modo, a parte central das AGNs poderia, em princípio, ser a fonte de UHECR até algumas vezes $10^{19} \mathrm{eV}$. Por outro lado, a energia das partículas aceleradas é degradada por fotoprodução de píons devido à alta densidade de energia nessa região. Outras perdas de energia são devido à emissão síncrotron e processos Compton. Norman et al[26] concluem que prótons ou núcleos pesados não conseguem sair da região central de AGNs com energia muito maior que $10^{16} \mathrm{eV}$. Assim, as regiões centrais de AGNs não parecem ser fontes prováveis para os UHECR. Para eliminar esses problemas de perda de energia, a região de aceleração deve estar mais afastada da região central da AGN, onde a densidade de radiação é muito menor.

Ainda outro candidato a fonte dos UHECR são os chamados hot spots de galáxias de rádio Fanaroff-Riley tipo II. O poderoso jato ejetado da AGN supre de energia um gigantesco lóbulo de rádio. O hot spot observado no fim dos jatos é interpretado como uma região onde há uma onda de choque. Essa região é ideal para a aceleração de prótons a altíssimas energias, já que o campo magnético é intenso e a densidade de radiação é pequena, minimizando as perdas de energia. Dependendo do campo magnético no hot spot, que é uma grandeza com grande incerteza, seria possível acelerar partículas até $10^{21} \mathrm{eV}$. Desse modo, os hot spots poderiam ser a fonte dos UHECR acima de $10^{20} \mathrm{eV}$. O grande problema com esse tipo de fonte é sua distância à Terra. Não são conhecidos hot spots dentro dos 50Mpc[27] exigidos pelo corte GZK. Além disso, UHECRs dessa energia teriam uma rigidez magnética muito grande (eq. 1.15), porém as direções de chegada desses eventos não apontam para nenhum desses objetos dentro de um raio de $100 M p c$. Desse modo, embora se acredite que os hot spots de galáxias de rádio sejam capazes de produzir UHECR acima de $10^{20} \mathrm{eV}$, estes chegariam à Terra com energias abaixo de algumas dezenas de EeVs. Elbert e Sommers[27] sugeriram a possibilidade de que campos magnéticos muito mais intensos do que os que se acredita existir no 
meio intergalático poderiam curvar sensivelmente a trajetória de UHECRs carregados. Assim, a distância em linha reta à fonte deveria ser ainda menor que 50Mpc. Por outro lado, os fótons provenientes da fonte e observados atualmente teriam sido produzidos até 15 milhões de anos após a emissão dos UHECR carregados. Então, embora não se observem hot spots a menos de $50 \mathrm{Mpc}$ atualmente, esse poderia não ser o caso há 15 milhões de anos.

Outra possibilidade, que é a efetivamente investigada nesta tese de doutorado, é que os UHECR com energias acima de $10^{20} \mathrm{eV}$ seriam compostos por partículas que sofrem uma menor degradação de energia durante sua propagação através do CMB. Desse modo, poderiam ser provenientes de fontes muito mais distantes.

Além dos candidatos a fontes citados aqui, existem muitos outros, como os Gamma Ray Bursters (GRB), intensamente pesquisados no momento.

\subsubsection{O enigma dos UHECR}

Como discutido na seção 1.1.1, a descoberta do CMB trouxe repercussões importantes para a investigação de UHECR, devido à compreensão de que o universo torna-se opaco para partículas de energia $E \gtrsim 5 \times 10^{19} \mathrm{eV}$.

Isso implica que o espectro de energia dos raios cósmicos na Terra deve ter uma queda abrupta em torno desse valor, conhecida como corte GZK. Por outro lado, vários eventos de energia $E>5 \times 10^{19} \mathrm{eV}$ foram detectados por alguns observatórios de UHECR. O evento mais energético já detectado, de energia $E=3.2 \times 10^{20} \mathrm{eV}$, foi observado pela colaboração Fly's Eye em 1991[28]. Esse evento tem uma energia muito acima do limite esperado para o fim do espectro dos raios cósmicos na Terra. Várias buscas de fontes relacionadas com esse evento foram efetuadas, entre elas a de Elbert e Sommers [27]. Apesar de nenhuma fonte compatível com a direção ter sido encontrada dentro da esfera GZK, foram encontradas possíveis fontes a distâncias maiores. Outros experimentos, como o AGASA[29], reportaram um excesso de eventos acima do corte GZK, indicando uma continuação do espectro além do limite esperado. 
A presença desses eventos se tornou um enigma, conhecido como o enigma dos UHECR, que pode ser encapsulado nas seguintes questões: De onde vêm os UHECR? Como são produzidos? Quais são suas fontes? Qual sua composição? Algumas investigações procuravam alternativas para explicar a produção dos UHECR, como os mecanismos Top-Down (seção 1.1.2). Outras procuravam alternativas para a composição dos UHECR, como é o caso do uhecron, que poderiam circundar as dificuldades de propagação pelo CMB.

Chung, Farrar e Kolb[1] sugeriram que raios cósmicos com energia acima do corte $G Z K$ poderiam ser hádrons massivos e estáveis, ao invés de nucleons. Estas partículas, previstas por modelos além do SM, poderiam se propagar através do CMB com uma perda de energia muito menor que nucleons, e assim, poderiam ter sido produzidas a maiores distâncias. Eles cunharam o nome uhecron para descrever genericamente partícula estáveis, neutras e massivas, que poderiam em princípio explicar a ausência do corte GZK no espectro dos UHECR. Devido à sua menor perda de energia, essas partículas poderiam ter se originado em fontes muito mais distantes que o limite de 100Mpc esperado no caso de hádrons comuns.

Albuquerque, Kolb e Farrar[2] analisaram a compatibilidade entre o evento do Fly's Eye e um uhecron. Nesta tese de doutorado, expandimos e generalizamos esse trabalho através da inclusão de efeitos devido à detecção e reconstrução de eventos, além da criação de métodos para a separação de sinais de uhecrons e hádrons normais em telescópios de fluorescência.

Resultados experimentais recentes são relevantes para o esclarecimento do enigma dos UHECR. A colaboração HiRes publicou artigos[30, 31] reportando a observação de uma quebra no espectro, identificada como o corte GZK[30]. A figura 1.8 mostra a razão entre o número de eventos efetivamente observados acima da quebra no espectro e o número de eventos esperados para um ajuste tipo lei de potência à parte final do espectro, antes da quebra, que seria o número esperado de eventos, caso não houvesse o corte GZK. Dessa integral do espectro é possível obter $E_{1 / 2}=10^{19.73 \pm 0.07}$, onde $E_{1 / 2}$ se 
refere à energia na qual a integral do espectro cai à metade do valor esperado no caso da ausência do corte GZK.

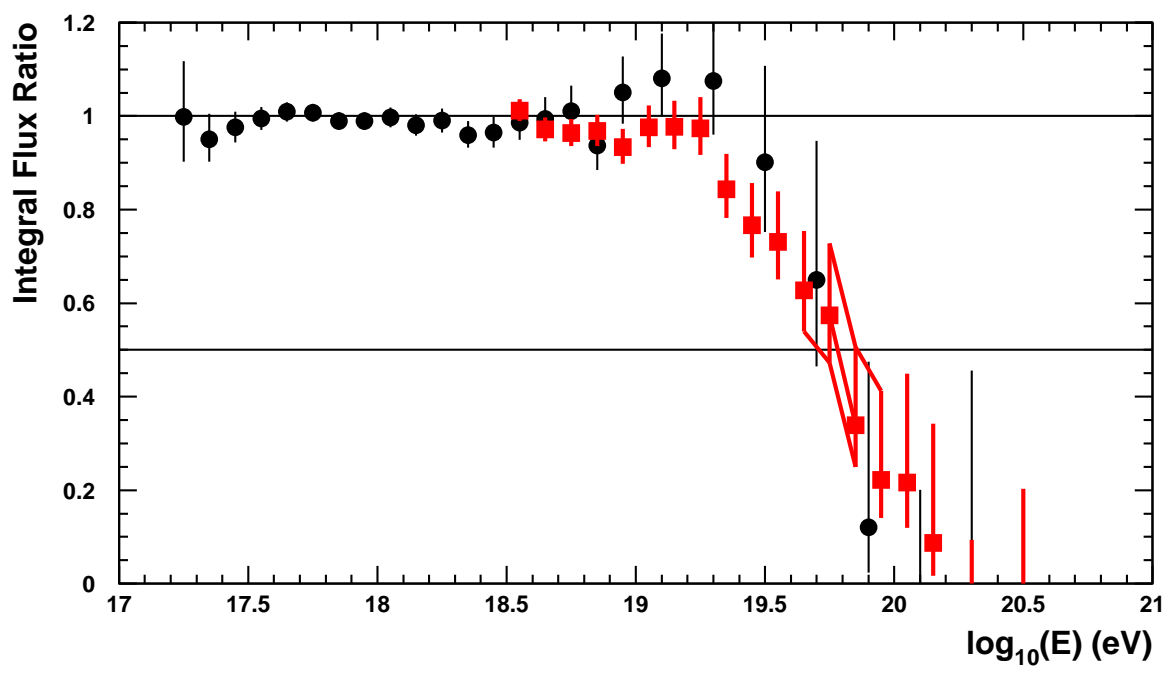

Figura 1.8: Integral dos dois espectros monoculares do HiRes dividido por um ajuste da parte final do espectro, antes do corte. Apenas os valores do HiRes-I(vermelho) são utilizados para a estimativa de $E_{1 / 2}$. Figura extraída de [31].

Os resultados do Auger[32, 33, 34], já com uma estatística muito maior que os experimentos anteriores, também são compatíveis com a presença do corte GZK. No entanto, esta colaboração espera um número ainda maior de dados para determinar conclusivamente a presença desse corte. A figura 1.9 mostra a razão entre o espectro reconstruído pelo SD do Auger e um espectro $\propto E^{-2.6}$ em função da energia.

Recentemente, esta mesma colaboração[35, 36] determinou uma provável correlação entre as direções de chegada de eventos trans-GZK $\left(E>6 \times 10^{19} \mathrm{eV}\right)$ e as posições de núcleos ativos de galáxias (AGNs) próximas à Terra (até $\sim 75 M p c$ ). O principal resultado desses trabalhos é a anisotropia dos UHECR, não estabelecendo porém as AGNs como fontes.

Assim, parece que a observação experimental do corte GZK está se estabelecendo. É importante ressaltar que a presença do corte GZK não elimina a possibilidade de detecção dos uhecrons, possibilidade esta que é analisada nesta tese, no caso específico de telescópios de fluorescência. 


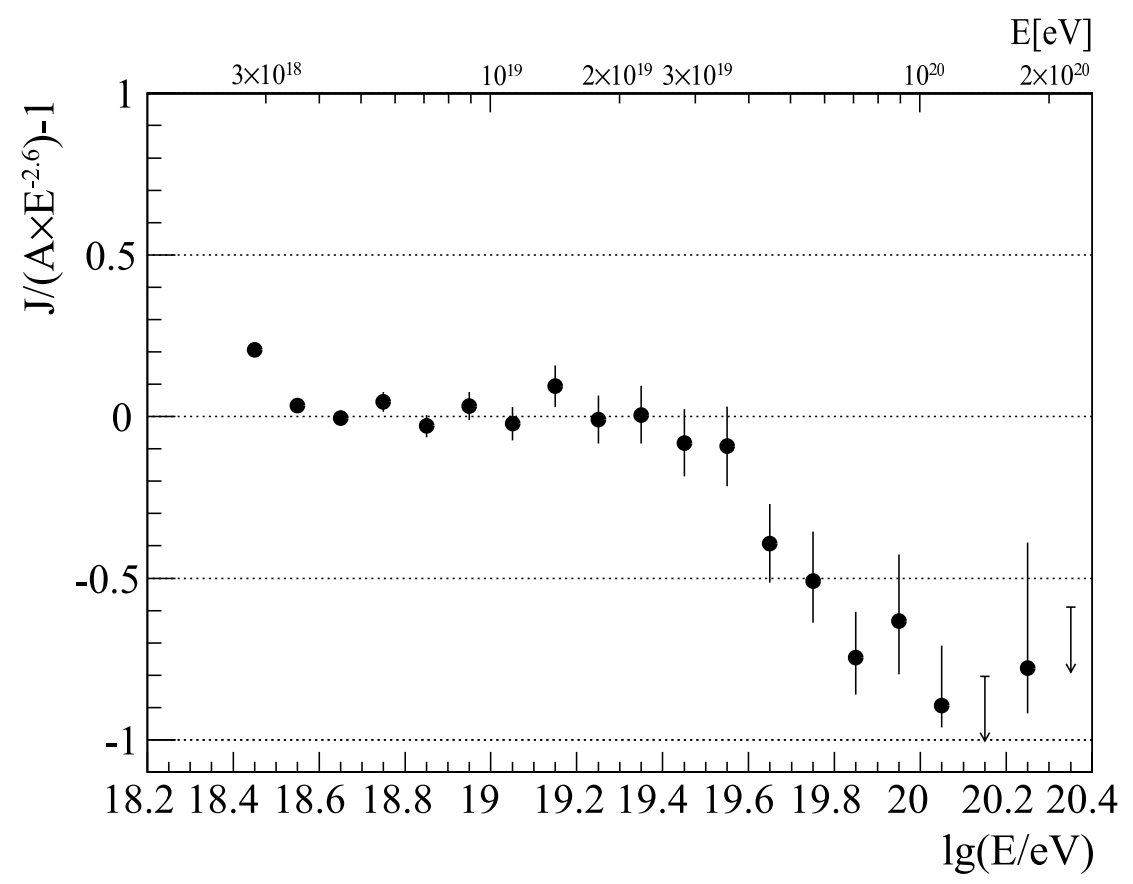

Figura 1.9: Razão entre o espectro reconstruído pelo SD do Auger e um espectro $\propto E^{-2.6}$ em função da energia. Figura extraída de [32].

\subsection{Chuveiros Atmosféricos Extensos (EAS)}

A figura 1.10 mostra um chuveiro criado por um próton de $10 \mathrm{GeV}$ em uma câmara de nuvens contendo placas de chumbo. Quando da primeira interação desse próton com um núcleo de chumbo (provavelmente na sétima placa), várias partículas são criadas e estas, por sua vez, criam ainda outras partículas, formando um chuveiro. Podemos observar características importantes do desenvolvimento do chuveiro, como o número de partículas, que cresce e depois decresce à medida que este atravessa cada vez mais chumbo, a distribuição lateral das partículas em relação ao eixo do chuveiro, bem como algumas partículas, múons, que apresentam trajetórias retilíneas e se aprofundam muito mais na câmara. Exceto pela escala $(0.5 \mathrm{~m} \times 0.3 \mathrm{~m})$, as características do chuveiro mostrado na figura 1.10 são semelhantes às características de um chuveiro criado por uma partícula de alta energia ao entrar na atmosfera terrestre.

Ao contrário dos calorímetros artificiais, geralmente homogêneos, a atmosfera é um calorímetro natural inomogêneo. Suas propriedades, como por exemplo a densidade e a 


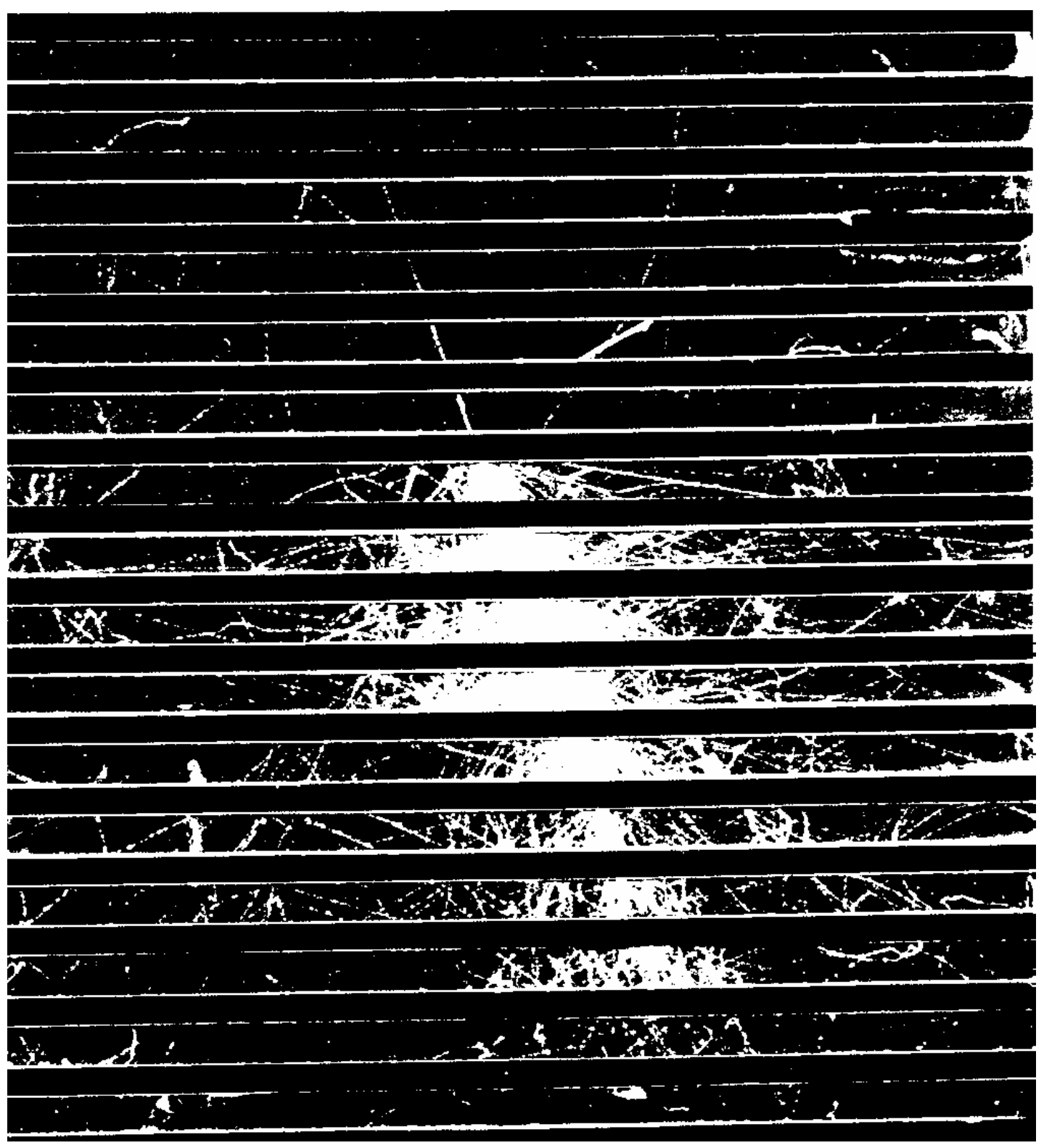

Figura 1.10: Cascata (ou chuveiro) produzido por um próton de $10 \mathrm{GeV}$ em uma câmara de núvens contendo placas de chumbo. Figura extraída de [9]. 
pressão, são fortemente dependentes da altitude. Essas variações podem ser entendidas e aproximadas utilizando-se modelos atmosféricos, como por exemplo a US atmosphere $19^{76}$ [37]. Por outro lado, outras características atmosféricas variam no tempo, como a quantidade de aerossóis presentes e as características de atenuação e espalhamento moleculares, tornando-se fontes de incertezas nas características desse gigantesco calorímetro.

Devido à variação da densidade com a altitude, uma grandeza que pode descrever naturalmente essa variação é a profundidade atmosférica vertical $X_{v}$ :

$$
X_{v}(h)=\int_{h}^{\infty} \rho_{a t m}(z) d z
$$

onde $\rho_{a t m}(z)$ é a densidade atmosférica a uma altura $z$. Por outro lado, para descrever adequadamente a quantidade de matéria atravessada por partículas na atmosfera, cuja direção não é necessariamente vertical, utiliza-se a profundidade atmosférica ao longo dessa direção, chamada profundidade atmosférica slant $X_{s}$, que depende da inclinação zenital $\theta$ da direção sobre a qual ela é medida. Podemos relacionar uma profundidade atmosférica vertical $X_{v}$ com uma profundidade atmosférica slant $X_{s}$, da seguinte forma (ver Fig. 1.11):

$$
X_{s}=\frac{X_{v}}{\cos \theta}
$$

Esta expressão não leva em conta a curvatura terrestre, porém, para $\theta \lesssim 80^{\circ}$, o erro associado com essa aproximação é menor que $4 \%$.

Um EAS é uma cascata de partículas iniciada pela partícula primária, o raio cósmico, ao entrar na atmosfera e interagir com um núcleo do ar. Espacialmente, um EAS é um disco fino e largo de partículas que se move através da atmosfera a uma velocidade próxima à da luz, com um tempo de evolução da ordem de $\mu s$. A figura 1.12 mostra a simulação do desenvolvimento de um EAS[38]. Um esquema do desenvolvimento de um EAS é mostrado na figura 1.13. Se o primário for um nucleon ou um núcleo, a cascata é iniciada por uma interação hadrônica. Através de subseqüentes interações são criadas 


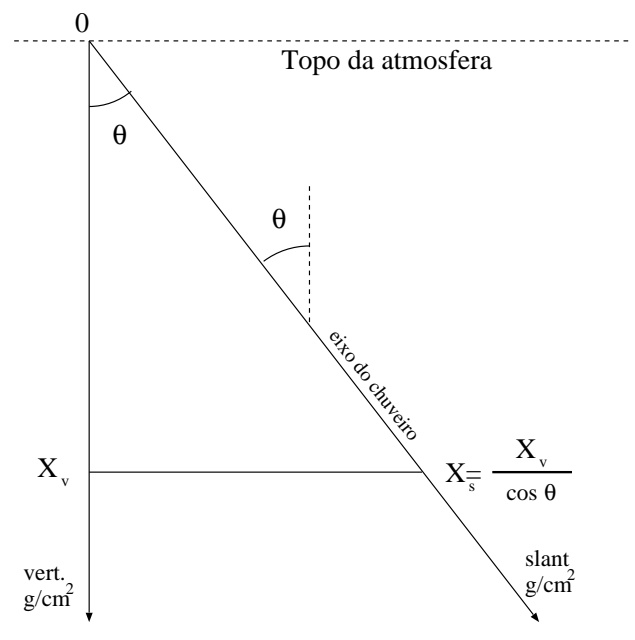

Figura 1.11: Relação entre profundidade atmosférica vertical (vertical $\mathrm{g} / \mathrm{cm}^{2}$ ) e profundidade atmosférica slant ( slant $\mathrm{g} / \mathrm{cm}^{2}$ ).

novas gerações de hádrons. Porém, em cada geração, aproximadamente $30 \%$ da energia é transferida para uma cascata eletromagnética, alimentada pelo rápido decaimento dos mésons $\pi^{0}$. Após o desenvolvimento completo do chuveiro, aproximadamente $90 \%$ da energia do primário é dissipada por ionização causada pela cascata eletromagnética.

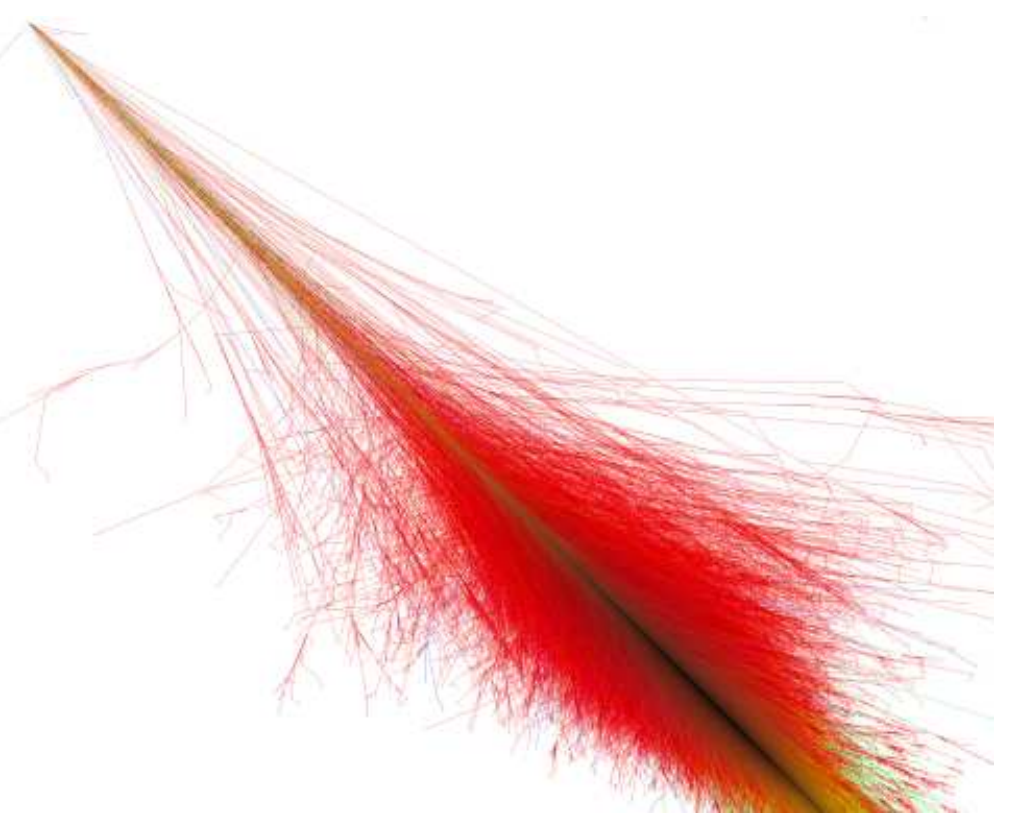

Figura 1.12: Simulação de um EAS produzido por um próton de $10^{15} \mathrm{eV}$. As cores representam diferentes partículas: vermelho=elétrons, pósitrons e gamas, verde=múons e azul=hádrons. Figura extraída de [38]. 


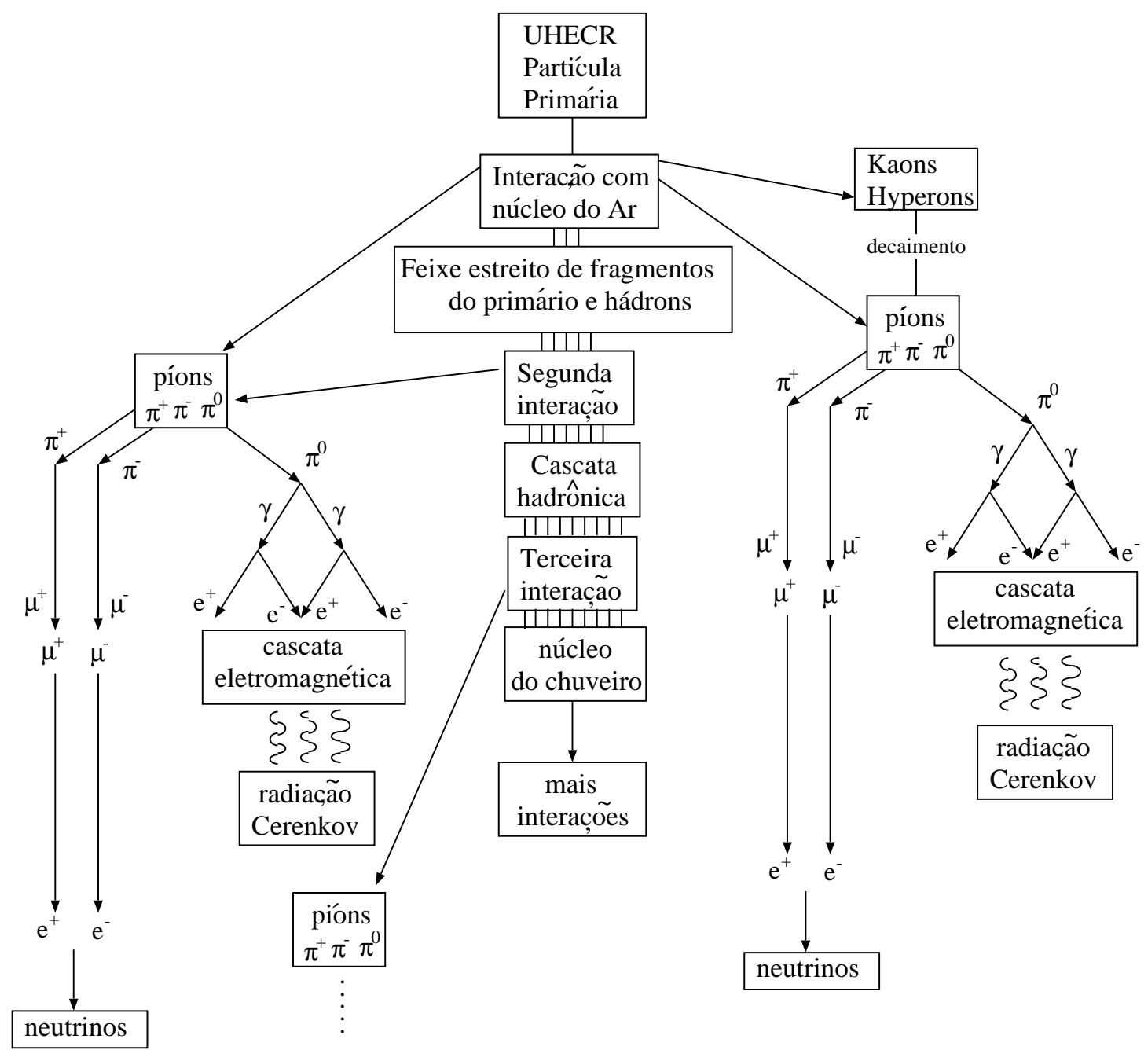

Figura 1.13: Esquema do desenvolvimento de um chuveiro atmosférico.

A partir da primeira interação, o desenvolvimento do EAS é governado pelos processos de decaimento e interação, criando as componentes hadrônica, eletromagnética, muônica e neutrínica do chuveiro. A interação inicial pode gerar, entre outras partículas, káons e píons de alta energia, que podem interagir com a atmosfera ou decair, alimentando as componentes muônica e neutrínica. No caso do $\pi^{0}$, este irá alimentar diretamente a componente eletromagnética (cascata EM), devido a seu rápido decaimento em 2 fótons. A cascata eletromagnética é então governada pelos processos de criação de pares e bremsstrahlung.

Os pares $e^{ \pm}$produzidos nesse processo perdem energia ao gerar fótons de brems- 
strahlung quando são acelerados pelo campo Coulombiano de núcleos. As seções de choque totais desses dois processos podem ser relacionadas da seguinte forma:

$$
\sigma_{\text {par }}=\frac{7}{9} \sigma_{b r e m}
$$

O comprimento de radiação $X_{0}$ é a unidade característica para expressar a espessura de matéria em processos eletromagnéticos, e é definida como a quantidade média de matéria atravessada para que a energia de elétrons de alta energia se degrade até $1 / e$ da energia inicial:

$$
E=E_{0} \cdot \exp \frac{-X}{X_{0}}
$$

onde $E$ e $E_{0}$ são as energias final e inicial do elétron, respectivamente, e $X$ é a quantidade de matéria atravessada pelo elétron. Outro processo que compete com bremsstrahlung para diminuir a energia dos $e^{ \pm}$é a ionização. A taxa de perda de energia por bremsstrahlung é aproximadamente proporcional à energia do $e^{ \pm}$, enquanto que a taxa de perda de energia por ionização varia apenas logaritmicamente com a energia. Desse modo, a perda de energia por bremsstrahlung é dominante a altas energias. A energia média $\epsilon_{c}$ perdida por um elétron de alta energia ao atravessar um comprimento $X_{0}$ de matéria é denominada energia crítica e, no caso do ar, corresponde a $\epsilon_{c}=81 \mathrm{MeV}$. A essa energia, as perdas por ionização passam a ser dominantes e os elétrons são rapidamente absorvidos.

Em 1949, Heitler[39] propôs um "Toy Model” para descrever o desenvolvimento de cascatas eletromagnéticas. Embora extremamente simples, descrevemos esse modelo já que ele ilustra muito bem as características gerais de EAS e a física envolvida. Embora tenha sido inicialmente aplicado no tratamento de cascatas puramente eletromagnéticas, sua estrutura também se aplica a chuveiros criados por hádrons. Inicialmente, vamos assumir que um par $e^{ \pm}$de mesma energia é criado por um fóton após uma distância $\lambda_{\text {par }}=\left(n \sigma_{\text {par }}\right)^{-1}$, onde $n$ é a densidade numérica de núcleos da região atravessada pelo fóton e $\sigma_{p a r}$ a seção de choque total para a produção de pares. Vamos também aproximar 
a seção de choque total de bremsstrahlung $\sigma_{\text {brem }}$ como sendo igual à seção de choque de criação de pares $\sigma_{\text {par }}$. Após a mesma distância $\lambda=\lambda_{\text {par }}=\lambda_{\text {brem }}$, dois fótons de bremsstrahlung de mesma energia são criados, um pelo elétron e outro pelo pósitron.

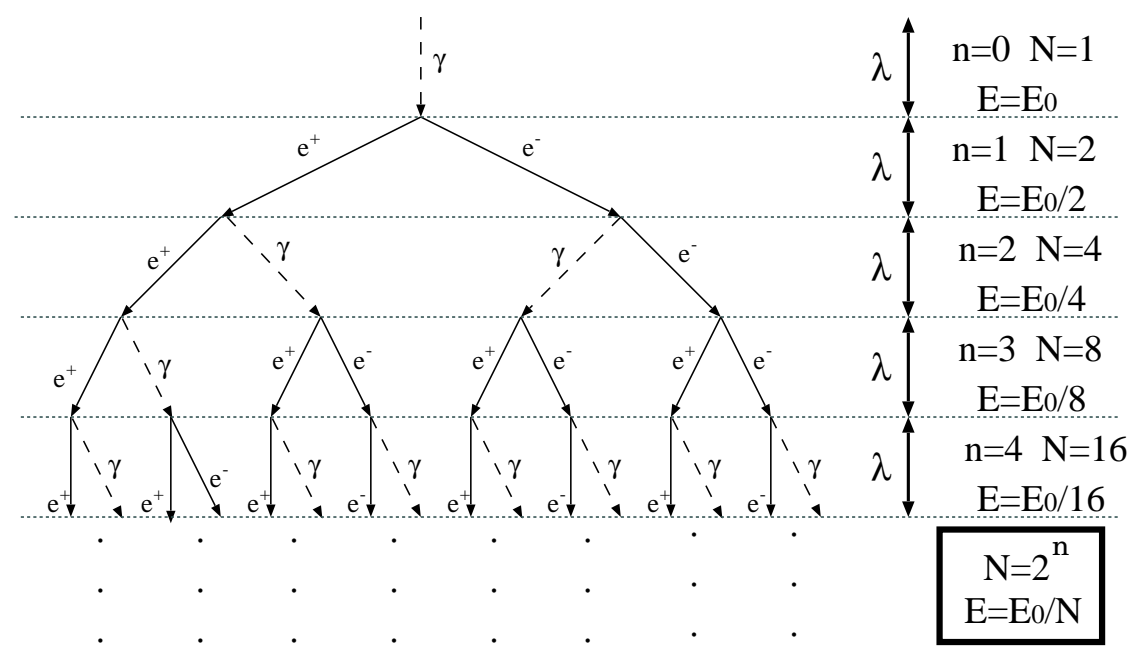

Figura 1.14: Esquema do Toy Model de Heitler.

Assim, após percorrer uma distância $X$ de material, temos $n(X)$ gerações:

$$
n(X)=\frac{X}{\lambda}
$$

Nesse ponto, o número $N(X)$ de partículas é dado por

$$
N(X)=2^{n}=2^{\frac{X}{\lambda}}
$$

cada uma delas com energia

$$
E(X)=\frac{E_{0}}{N(X)}=\frac{E_{0}}{2^{\frac{X}{\lambda}}}
$$

Esse processo continua até a energia das partículas alcançar a energia crítica $E=\epsilon_{c}$, quando as partículas perdem rapidamente toda sua energia por ionização. Nesse ponto, a uma profundidade atmosférica $X_{\max }$, temos o número máximo $N_{\max }$ de partículas no 
chuveiro, cada uma com energia $E=\epsilon_{c}$. Da eq.1.23 temos:

$$
\begin{gathered}
E\left(X_{\max }\right)=\epsilon_{c}=\frac{E_{0}}{N\left(X_{\max }\right)} \Rightarrow \\
N\left(X_{\max }\right)=N_{\max }=\frac{E_{0}}{\epsilon_{c}}, \\
E=\epsilon_{c}=\frac{E_{0}}{2^{\frac{X_{\max }}{\lambda}}} \Rightarrow \\
X_{\max }=\frac{\lambda}{\ln 2} \ln \left(\frac{E_{0}}{\epsilon_{c}}\right) .
\end{gathered}
$$

As eqs. 1.24 e 1.25 ilustram características importantes do chuveiro, e como elas variam com a energia da partícula incidente. Esses resultados são características de cascatas eletromagnéticas e boas aproximações para chuveiros hadrônicos. Vemos que o número de partículas no máximo do chuveiro é diretamente proporcional à energia $E_{0}$, enquanto que a posição do máximo cresce apenas logaritmicamente com $E_{0}$. Uma outra grandeza importante no estudo de EAS é a taxa de elongação, definida como:

$$
D_{10}=\frac{\partial<X_{\max }>}{\partial \log E_{0}} .
$$

Da eq. 1.25, vemos que a taxa de elongação para cascatas eletromagnéticas é uma constante, já que $X_{\max } \propto \log E_{0}$.

No caso de núcleos, podemos utilizar o modelo de superposição, que assume que um núcleo com $A$ nucleons se comporta como um conjunto de $A$ nucleons livres de energia $E_{0} / A$, já que a energia $E_{0}$ é muito maior que a energia de ligação dos nucleons. Assim, um chuveiro criado por um núcleo de massa $A$ se comporta aproximadamente como $A$ chuveiros criados por nucleons de energia $E_{0} / A$. Desse modo, a partir da eq. 1.25 obtemos:

$$
X_{\max } \propto \log \frac{E_{0}}{A}
$$


Essa dependência da posição do máximo do chuveiro em relação à massa do primário é muito importante na determinação da composição dos raios cósmicos.

Embora o Toy Model de Heitler possa exprimir de maneira simples as características básicas de um EAS, esclarecendo a física envolvida no seu desenvolvimento, os detalhes desse desenvolvimento são muito complexos para serem descritos de maneira precisa mesmo por modelos analíticos mais detalhados. Por isso, simulações Monte Carlo, como o Corsika(COsmic Ray SImulation for KAscade)[40] e o Aires(AIR shower Extended Simulation)[8] são utilizadas.

Embora a parte eletromagnética do chuveiro possa ser extremamente bem descrita, já que os processos de criação de pares e bremsstrahlung são muito bem compreendidos e podem ser precisamente calculados através da QED, o mesmo não é verdade em relação à cascata hadrônica. Essa cascata hadrônica é de extrema importância no desenvolvimento do EAS, já que ela alimenta a componente eletromagnética do chuveiro, principalmente através da produção de $\pi^{0} \mathrm{~s}$ (ver fig. 1.13). Os parâmetros essenciais do desenvolvimento de cascatas hadrônicas, como seções de choque, inelasticidade e multiplicidade, ainda não são bem conhecidos na região de altíssimas energias, região esta que está muito acima das energias possíveis com aceleradores. Os modelos de interação hadrônica, como o QGSJET[41] e o Sibyll[7], extrapolam os dados de experimentos para as regiões de altíssimas energias utilizando diferentes modelos, chegando a valores diferentes para esses importantes parâmetros no desenvolvimento do chuveiro e levando a diferenças consideráveis nos resultados. Desse modo, a cascata hadrônica é fonte de grandes incertezas no estudo dos EAS.

A cascata hadrônica é iniciada no topo da atmosfera pela interação com um núcleo do ar. Chamamos de nucleon "líder" aquele que carrega a maior fração de energia da interação. O número de interações desse nucleon mais energético é uma grande fonte de flutuações no desenvolvimento do chuveiro. Outras fontes de flutuação são a multiplicidade da interação, que pode ser entendida como o número médio de partículas produzidas na interação, e a inelasticidade $\kappa$, definida como a fração da energia da 
partícula incidente que não é mantida pelo nucleon "líder":

$$
\kappa=1-\frac{E_{\text {lead }}}{E_{\text {proj }}},
$$

onde $E_{l e a d}$ é a energia do nucleon líder após a interação e $E_{\text {proj }}$ é a energia do projétil.

A seção de choque inelástica p-ar é a soma da seção de choque "quase-elástica", que corresponde aos casos onde o núcleo alvo se quebra sem produzir novas partículas, e a seção de choque de produção $\sigma_{\text {prod }}$, quando pelo menos uma partícula é gerada. O desenvolvimento do EAS[42] é sensível principalmente à seção de choque de produção, que vai determinar o caminho livre médio do nucleon na atmosfera:

$$
\lambda=\left(\sigma_{\text {prod }} n\right)^{-1}
$$

onde $n$ é a densidade numérica de alvos na atmosfera. Por outro lado, como discutido anteriormente, as seções de choque são extrapoladas das regiões de energia mais baixa de maneira diferente em diferentes modelos de interação hadrônica. Assim, para diferentes modelos, teremos diferentes valores para o caminho livre médio $\lambda$. Além das diferenças em $\lambda$, diferentes modelos de interações hadrônicas produzem diferenças na inelasticidade $\kappa$ e na multiplicidade.

Vamos agora analisar, de maneira extremamente simplificada, os efeitos desses parâmetros da cascata hadrônica no desenvolvimento do EAS. Inicialmente vamos utilizar uma aproximação para as interações do nucleon "líder":

$$
p+p \rightarrow p+p+N\left(\pi^{0}+\pi^{+}+\pi^{-}\right)
$$

onde simplesmente ignoramos partículas como $K, \Lambda$, etc... que são produzidas nessas interações a altíssimas energias. Porém, nossas conclusões sobre os píons podem ser aplicadas aos outros hádrons menos numerosos criados nessa interação.

Devido à independência de carga, a energia deve ser igualmente distribuída entre os diferentes tipos de píons. O $\pi^{0}$ alimenta diretamente a componente eletromagnética 
através de seu rápido decaimento e assim $33 \%$ da energia $\kappa E_{\text {proj }}$, liberada pelo nucleon incidente durante a interação, alimenta diretamente a componente eletromagnética. Os píons carregados, por sua vez, irão sofrer um de dois processos que competem: a interação ou o decaimento. A interação é regida pela densidade do ar e pela seção de choque $\pi$-ar, enquanto que o decaimento é regido pelo fator de Lorentz do píon carregado. A probabilidade de interação é igual à probabilidade de decaimento quando a distância média percorrida antes do decaimento for igual à distância média percorrida antes da interação, ou seja[9]:

$$
\gamma \tau c=\frac{\lambda_{\pi}}{\rho}
$$

onde $\gamma$ é o fator de Lorentz e $\tau=2 \times 10^{-8} s$ a vida média em repouso do píon, $c$ é a velocidade da luz, $\lambda_{\pi}$ é o caminho livre médio para píons no ar e $\rho$ a densidade do ar. Para uma densidade de $5 \times 10^{-4} \mathrm{~g} / \mathrm{cm}^{3}$, equivalente a uma altitude de $\sim 5 \mathrm{~km}$, o fator de Lorentz obtido da equação 1.31 leva a píons de energia da ordem de 50GeV. Logo os píons carregados de altíssima energia $E_{\pi^{ \pm}} \gg 50 \mathrm{GeV}$, gerados nas primeiras interações, tenderão a interagir, alimentando com parte dos produtos dessas interações a cascata eletromagnética. Por outro lado, conforme a cascata hadrônica vá perdendo energia, ela passa a gerar cada vez mais píons carregados de energia inferior à energia crítica. Esses píons decaem, alimentando a componente muônica e neutrínica do chuveiro (fig. 1.13). A multiplicidade é um fator importante na determinação da energia dos píons e, conseqüentemente, no número de múons do chuveiro.

A componente muônica do chuveiro não cresce linearmente com a energia inicial $E_{0}$, pois apenas a energia dos píons cresce linearmente com a energia $\left(<E_{\pi}>\propto E_{0}\right)$, enquanto que seu número cresce apenas logaritmicamente com a energia inicial $\left(<N_{\pi}>\propto\right.$ $\left.\log E_{0}\right)$. Logo, o número de píons que alcança a energia crítica e decai gerando múons e neutrinos não cresce linearmente com $E_{0}[18]$. Uma conseqüência importante disso é que o número de múons é muito sensível à composição do primário. No caso de um núcleo 
de massa $A$ e energia $E_{0}$, pelo princípio da superposição, ele se comportará como $A$ chuveiros de nucleons de energia $E_{0} / A$. Assim, devido à não linearidade da componente muônica, um EAS iniciado por um núcleo conterá mais múons que um EAS iniciado por um próton de mesma energia. Desse modo, a componente muônica do chuveiro é uma ferramenta importante na determinação da composição dos raios cósmicos.

Assim, os principais parâmetros da cascata eletromagnética, como a inelasticidade, que rege a energia do primário depositada por interação, o caminho livre médio, que rege a freqüência dessas interações, e a multiplicidade, que rege o número de partículas criadas, vão alterar a distribuição da energia do primário entre as partículas criadas, além do número dessas partículas. Isso, conseqüentemente, irá alterar o número, a posição de criação e a energia dessas partículas, alterando as probabilidades de interação e decaimento, alterando assim a velocidade do desenvolvimento do chuveiro, bem como a razão entre suas componentes.

O desenvolvimento lateral de chuveiros eletromagnéticos é dominado pelo espalhamento Coulombiano das partículas carregadas e pode ser representado pelo raio de Molière $r_{M}$, que é a distância ao núcleo dentro da qual $90 \%$ da energia total do chuveiro está contida. Um valor característico do raio de Molière em chuveiros atmosféricos é $r_{M} \cong 70 m$. Outra contribuição para essa dispersão é o momento transversal associado com as interações hadrônicas.

Ao contrário de elétrons e fótons, os múons são relativamente pouco afetados pelo espalhamento Coulombiano, se estendendo até alguns $\mathrm{km}$ do eixo do chuveiro, dependendo da energia do primário. Desse modo, a sua distribuição lateral ainda contém informação sobre as trajetórias dos píons que os produziram. A maioria dos múons se propaga além da cascata eletromagnética, gerando uma cauda muônica devido à sua propagação retilínea. A grandes distâncias do núcleo, a densidade de múons é aproximadamente uma função exponencial da distância, refletindo a distribuição do momento transversal no final da cascata hadrônica. A figura 1.15 mostra a extensão espacial das diferentes componentes de um EAS. 


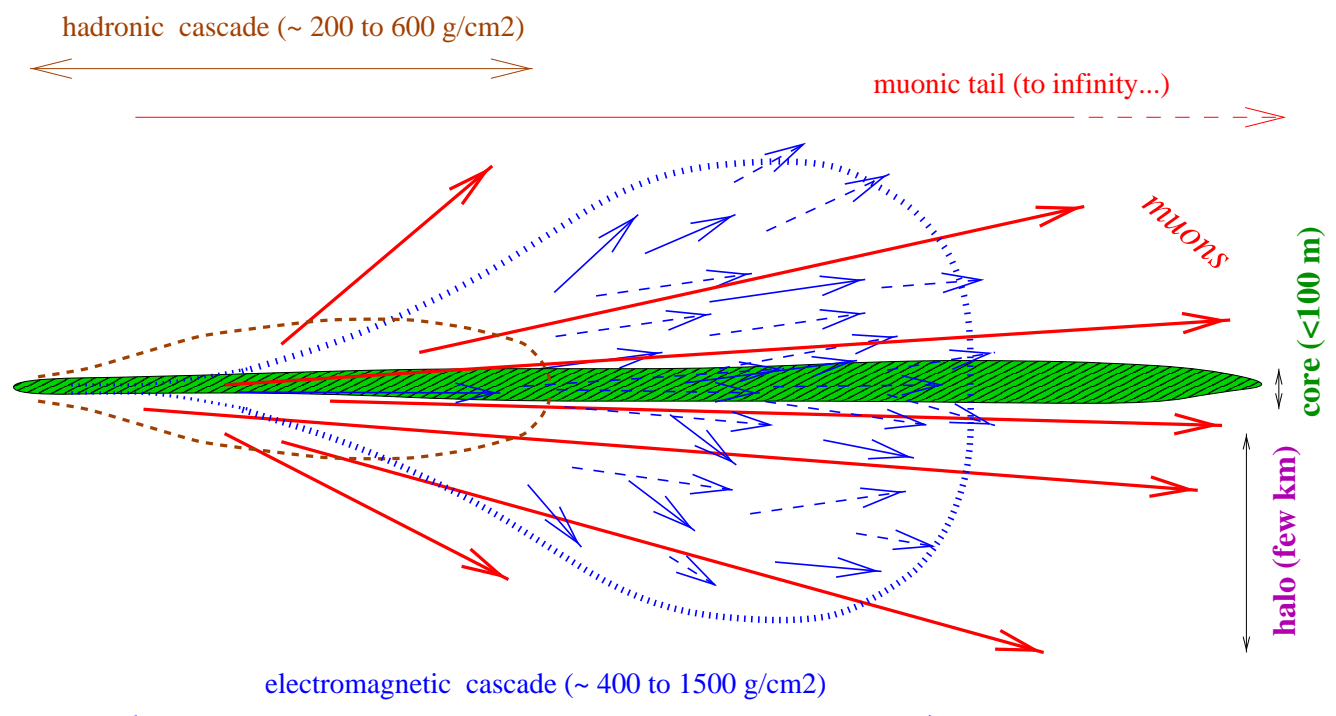

Figura 1.15: Extensão espacial das componentes de um EAS.

\subsection{Simulação do EAS}

Como discutido na seção 1.2, o desenvolvimento de EAS é melhor descrito por simulações Monte Carlo que por métodos analíticos. Isso se deve ao grande número de flutuações intrínsecas a esse desenvolvimento. Dois programas Monte Carlo muito utilizados para a geração de chuveiros de UHECR são o Corsika[40] e o Aires[8]. Esses programas são responsáveis pela simulação da propagação das partículas na atmosfera. Já as interações dependem de modelos hadrônicos que extrapolam os dados de experimentos para as regiões de altíssimas energias, utilizando diferentes modelos. Desse modo, os programas de transporte se utilizam de modelos hadrônicos como os códigos QGSJET[41] e Sibyll[7] para calcular as interações, e a escolha do modelo hadrônico pode alterar sensivelmente os resultados. Assim, a simulação de EAS pode ser dividida em duas partes: a simulação da propagação das partículas, e a simulação das interações.

Como o número de partículas no chuveiro cresce rapidamente com a energia da 
partícula primária, a simulação Monte Carlo completa de chuveiros de alta energia $\left(E_{0} \gtrsim\right.$ $10^{18} \mathrm{eV}$ ) torna-se impraticável devido ao enorme tempo de computação necessário para os cálculos de propagação e interação de todas as partículas secundárias produzidas no EAS. Desse modo, faz-se necessária a utilização de métodos de amostragem estatística, como o desenvolvido por Hillas na década de 80[43], chamado thinning. Esse método se baseia no tratamento Monte Carlo completo apenas de uma fração das partículas do EAS. Somente algumas partículas são simuladas em detalhe e recebem um fator peso. Cada uma delas representará não apenas uma, mas muitas partículas do chuveiro. Por um lado, esse método consegue diminuir o tempo computacional necessário para tratar EAS de alta energia, por outro lado, caso os fatores peso dessas partículas simuladas sejam muito grandes, flutuações artificiais podem ser introduzidas nos observáveis do EAS, como as distribuições laterais e longitudinais. Para minimizar esse problema é possível introduzir um outro parâmetro, que limita os valores dos fatores peso utilizados. Mas essa limitação nos fatores peso tem um impacto significativo no tempo de simulação.

Outros parâmetros que podem ser utilizados para diminuir o tempo necessário para a simulação são limiares de energia para que as partículas continuem sendo propagadas pela simulação. Esses limiares podem ser definidos para cada classe de partícula separadamente, limitando assim o número de interações que devem ser tratadas pela simulação. Todos esses parâmetros devem ser otimizados de modo a obter uma razão qualidade/tempo para a simulação. Por exemplo, como a distribuição lateral de partículas é mais sensível aos cortes estatísticos que a distribuição longitudinal, estudos que dependem apenas dessa última distribuição podem usar parâmetros mais relaxados, diminuindo o tempo de processamento, e vice-versa.

Vale lembrar que a maioria dos códigos disponíveis para a simulação de EAS permitem optar entre vários modelos hadrônicos diferentes, como as várias versões do Sibyll e QGSJET. A seguir, faremos uma descrição sucinta de como o Sibyll trata as interações hádron-hádron e hádron-núcleo. 


\subsubsection{Interações hadrônicas: Sibyll}

O pacote Sibyll[7, 44] é um gerador de eventos para a simulação de EASs. Ele trata as interações hádron-hádron, hádron-núcleo e núcleo-núcleo de maneira fenomenológica. O modelo físico utilizado para tratar todos processos de maneira consistente e permitir a extrapolação para regiões de energia além das medidas experimentais é o Dual Parton model (DPM)[45], com a superposição de modelos de produção de minijets[46, 47]. Muitas das características do modelo são provenientes dos algoritmos Monte Carlo de Lund[48] (programa PYTHIA). Ele utiliza então uma combinação de modelos para interações hádron-hádron "soft", incluindo a possibilidade do alvo e/ou o projétil serem excitados para um estado de maior massa, levando a eventos de dissociação difrativa; modelos para interações "hard", de mais alta energia, com a produção de minijets; e modelos para extrapolar essas interações hádron-hádron para interações hádron-núcleo e núcleo-núcleo (ver [7] e referências ali citadas).

No caso de interações hádron-hádron "soft" a mais baixas energias $(\sqrt{s} \sim 10-$ $20 \mathrm{GeV}$ ), onde o momento transversal $p_{T}$ é baixo, a idéia central é caracterizar essas interações através da produção e subseqüente fragmentação de duas cordas QCD ( $Q C D$ strings)[45]. Vamos tomar como exemplo uma interação nucleon-nucleon. Nesse caso cada nucleon é separado em uma componente quark $q$ e uma componente diquark $q q$. A energia do nucleon é dividida entre suas componentes $q$ e $q q$ seguindo uma função de estrutura. No Sibyll, a fração $x$ da energia do nucleon que é carregada pela componente quark $q$ é dada por uma amostragem Monte Carlo da seguinte função de estrutura:

$$
f_{q}(x)=\frac{(1-x)^{\alpha}}{\left[x^{2}+\mu^{2} / s\right]^{1 / 4}}
$$

onde $\mu=0.36 \mathrm{GeV}$ é uma "massa efetiva do quark" e $\alpha=3.0$. O diquark do projétil então se combina com o quark do alvo e vice versa, criando duas cordas QCD (ver figura $1.16)$.

A energia $E_{\text {str }}$ e o momento transversal $p_{\text {str }}$ de cada corda são dados em função das 


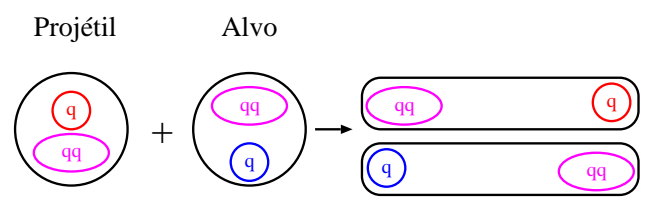

Figura 1.16: Criação de duas cordas QCD a partir da interação de dois nucleons. Cada nucleon é dividido em uma componente $q$ e uma $q q$. O diquark do projétil então se combina com o quark do alvo e vice versa, formando duas cordas QCD.

frações de energia $x_{1}$ da componente do projétil e $x_{2}$ da componente do alvo em suas extremidades:

$$
\begin{aligned}
& E_{s t r}=\frac{\sqrt{s}}{2}\left(x_{1}+x_{2}\right), \\
& p_{s t r}=\frac{\sqrt{s}}{2}\left(x_{1}-x_{2}\right) .
\end{aligned}
$$

No caso da corda superior da figura 1.16, $x_{1}$ seria a fração da energia do projétil carregada por sua componente $q$ (vermelho) e $x_{2}$ a fração da energia do alvo carregada por sua componente $q q$ (rosa).

As cordas então se esticam e se fragmentam, criando hádrons. Essa fragmentação é tratada no sistema do centro de massa $(\mathrm{CM})$ da corda, onde sua massa é dada por $E_{s t r}^{*}=\sqrt{s x_{1} x_{2}}$. A formação e fragmentação das cordas obedece à conservação de energia e momento.

Para a criação de uma partícula, uma das extremidades da corda é então aleatoriamente selecionada e um par $q-\bar{q}$ (ou $q q-\bar{q} \bar{q}$ ) é produzido, gerando um momento transversal $p_{T}$, dado por uma distribuição Gaussiana de média:

$$
\left\langle p_{T}\right\rangle=p_{0}+0.184 \ln \left(\frac{\sqrt{s}}{30 G e V}\right),
$$

onde $p_{0}=0.3 \mathrm{GeV}$ para quarks $u$ e $d, 0.45 \mathrm{GeV}$ para $s$ e $0.6 \mathrm{GeV}$ para diquarks. Momentos $p_{T}$ de mesma intensidade e sentidos opostos são dados a cada componente do par $q-\bar{q}$ (ou $q q-\bar{q} \bar{q})$. O sabor do par criado se combina com o sabor da extremidade escolhida da corda, formando uma nova partícula. A figura 1.17 exemplifica esse processo. 
Em (A) o lado direito da corda foi aleatoriamente selecionado e um par $q-\bar{q}$ é criado, gerando um certo momento transversal $p_{T}$. A corda se fragmenta e o sabor criado se combina com a extremidade direita criando uma nova partícula, que no exemplo da figura 1.17 é um méson. Em (B) temos então uma corda menor (menor massa) e uma nova partícula (méson) criado.

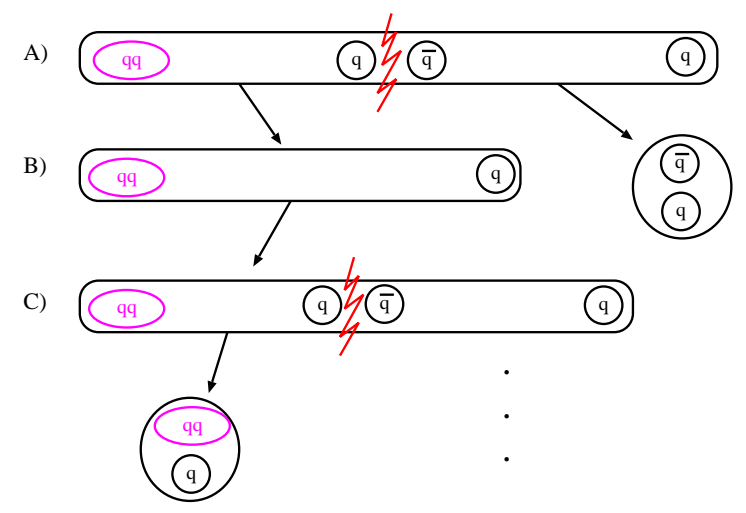

Figura 1.17: Fragmentação de uma corda QCD. Em (A) o lado direito da corda é aleatoriamente selecionado e um par $q-\bar{q}$ é criado. A corda se fragmenta e o sabor criado se combina com a extremidade direita criando uma nova partícula (méson). Em (B) temos então uma corda menor (menor massa) e uma partícula. Em (C) o processo se repete, agora com o lado esquerdo da corda, gerando um bárion. Esse processo se repete até que a massa da corda atinja um certo limiar.

O momento transversal da partícula produzida é a soma vetorial dos momentos transversais de suas componentes, enquanto que sua energia é gerada seguindo a função de fragmentação de Lund[7]:

$$
f(z)=\frac{(1-z)^{a}}{z} \exp \frac{-b m_{T}^{2}}{z}
$$

onde $z$ é a fração da energia do quark ou diquark "pai" que é carregada pela nova partícula, e $m_{T}=\sqrt{p_{T}^{2}+m^{2}}, a=0.5$ e $b=0.8$. Esse processo continua até que a massa (energia) da corda restante seja menor que um certo limiar $M_{t h}$, quando temos a formação de duas partículas na última fragmentação, a partir de ambos os lados da corda.

No caso da criação de uma partícula que contém o diquark original do projétil ou 
do alvo, esta deve conter a maior parte da energia e é então considerada uma partícula líder (leading particle). Nesse caso, uma função de fragmentação mais dura é utilizada para gerar a fração $z$ da energia do quark ou diquark "pai" que é carregada por ela:

$$
f(z)=c+(1-z)^{a}
$$

onde $a=0.667$ e $c=0.60$. Na figura 1.17, a segunda partícula criada, em (C), contém o diquark original do alvo (marcado em rosa), e é considera uma leading particle.

A abordagem utilizada no Sibyll para eventos difrativos também é fenomenológica. A seção de choque difrativa pode ser separada em 3 partes: forward ("feixe"), backward ("alvo") e dupla ("alvo e feixe"). As componentes forward e backward são tomadas como sendo $9 \%$ da seção de choque inelástica a $30 G e V$, a dupla tomada como sendo 4\%, e um termo exponencial é utilizado para ajustar o crescimento da seção de choque difrativa. Em um evento difrativo, uma ou ambas partículas incidentes são excitadas para um estado $X$ de maior massa, que posteriormente decai, gerando um grupo de partículas. A massa do estado excitado é gerada a partir de uma distribuição $\propto M_{X}^{-2}$, com limites $M_{X}^{2}[\mathrm{~min}]=1.5 \mathrm{GeV}^{2}$ para (anti-)nucleons, $0.2 G e V^{2}$ para $\pi^{ \pm}$e $0.6 G e V^{2}$ para káons; e $M_{X}^{2}[\max ]=0.1 s$.

O algoritmo utilizado para o decaimento do estado excitado depende de sua massa. Caso $\left(M_{X}-m_{h}\right) \leq 0.6 G e V$, temos o decaimento:

$$
X \rightarrow h^{\prime}+n \pi
$$

onde $n$ é o número de píons produzidos, amostrado de uma distribuição gaussiana $(\langle n\rangle=$ $2 \sqrt{M_{X}-m_{h}}$ e $\left.\sigma_{n}=0.5\langle n\rangle\right)$ e $h^{\prime}$ é o próprio hádron que foi excitado, ou um relacionado com ele por isospin. Para massas mais altas, o estado $X$ é separado em suas componentes $q-\bar{q}$ (para mésons) ou $q-q q$ (para bárions) e uma corda QCD de massa $M_{X}$ é criada, carregando o momento de $X$. Ela então é fragmentada da maneira usual.

Com o aumento da energia, a produção de minijets torna-se importante. O modelo 
utilizado assume que a produção de minijets está relacionada com o aumento da seção de choque inelástica. Podemos imaginar que um párton do hádron incidente sofre uma colisão "hard" com um párton no hádron alvo. A seção de choque $\sigma_{Q C D}(s)$ para interações "hard" foi calculada utilizando-se QCD perturbativa e encontra-se no Sibyll já na forma de uma tabela. O número $N_{\text {hard }}$ de interações "hard" entre os pártons é então gerado a partir da seção de choque inelástica, criando $N_{\text {hard }}$ pares de minijets. Essas interações são então tratadas independentemente. Um limiar de momento transversal $p_{\perp}^{\text {cutoff }}(s)$, dependente da energia, é utilizado para restringir o cálculo da seção de choque para produção de minijets somente em regiões onde os cálculos pertubativos são válidos. Abaixo desse limiar, as interações são consideradas "soft" e também são tratadas separadamente.

No caso de interações hádron-núcleo, o projétil irá interagir com $N_{W}$ nucleons participantes (wounded nucleons). O número $N_{W}$ de wounded nucleons é gerado a partir da distribuição $P_{N_{W}}=\sigma_{N_{W}} / \sigma_{\text {inel }}^{h A}$ (ver também seção IIIC de [7]). Esse evento é então tratado como uma superposição de $2 N_{W}$ cordas, um par para cada nucleon participante. Cada um desses nucleons é separado em suas componentes $q$ e $q q$, como anteriormente. $N_{W}-1$ pares $q-\bar{q}$ são então excitados do mar do projétil, formando cordas com as componentes $q$ e $q q$ dos nucleons participantes. O projétil também é separado em $q$ e $q q$ e se combina com um dos nucleons participantes, formando as duas últimas cordas. Um esquema desse processo pode ser visto na figura 1.18 . 


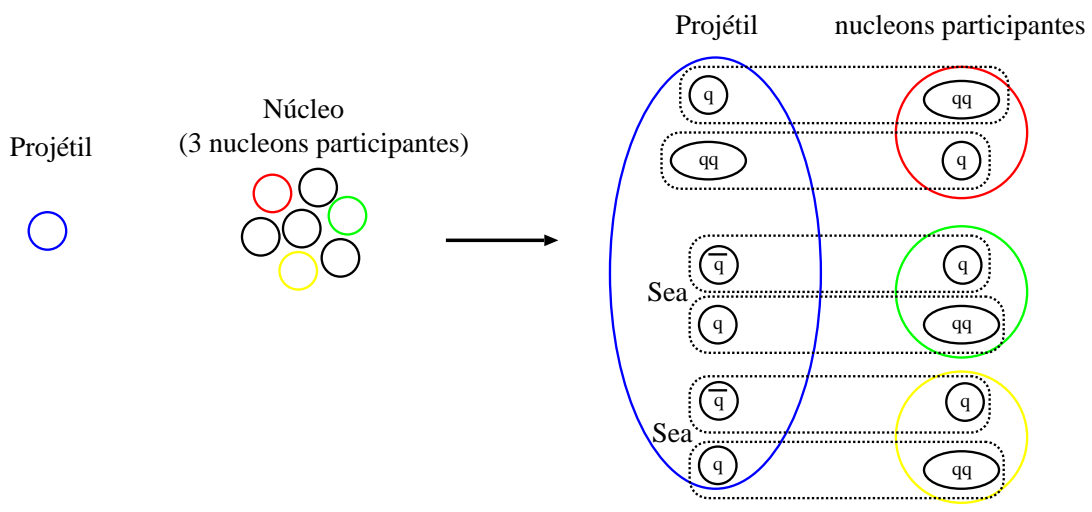

Figura 1.18: Criação de cordas entre projétil e nucleons participantes em uma interação hádron-núcleo $\left(N_{W}=3\right)$.

\subsection{Detecção do EAS}

Existem várias técnicas de detecção de chuveiros atmosféricos extensos, sendo que as duas principais utilizam detetores de superfície (SD) e detetores de fluorescência (FD). Algumas características mensuráveis do EAS são o perfil longitudinal e a distribuição lateral das partículas. O método FD é utilizado para medir o perfil longitudinal do EAS, enquanto que o método que utiliza SDs mede a densidade das partículas no solo em função da distância ao core $^{2}$. A seguir, descreveremos sucintamente o perfil longitudinal e a distribuição lateral, incluindo algumas de suas características que são importantes para a reconstrução da energia do primário, bem como para estudos de composição dos raios cósmicos.

O perfil longitudinal é o número de partículas em função da profundidade atmosférica. Ele representa o desenvolvimento do chuveiro e pode ser utilizado diretamente para estimar a energia depositada na atmosfera pelo EAS. A figura 1.19 mostra a média de 20 chuveiros criados por prótons e 20 por núcleos de ferro, obtidos de simulações com o Aires.

Como discutido na seção 1.2, a profundidade $X_{\max }$ do máximo depende da energia e da composição da partícula primária. A uma mesma energia, um chuveiro criado

\footnotetext{
${ }^{2} \mathrm{O}$ core do EAS é a intersecção do eixo do chuveiro com o plano do solo.
} 


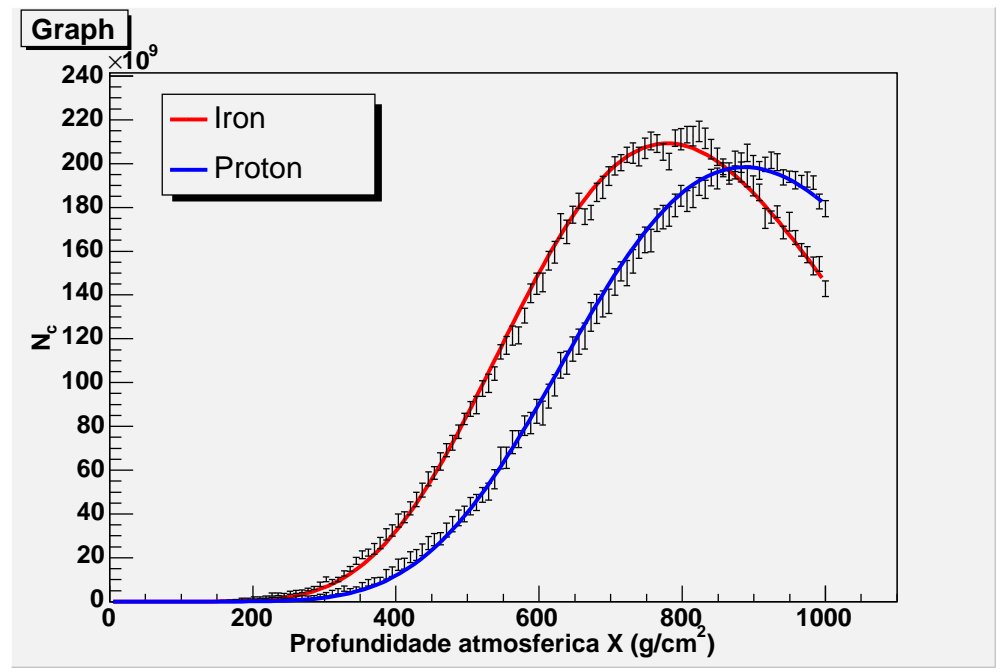

Figura 1.19: Perfil longitudinal da média de 20 chuveiros criados por prótons e 20 por núcleos de ferro, ambos com energia $E=3.2 \cdot 10^{20} \mathrm{eV}$, criados com o Aires. O final abrupto da distribuição representa o nível do solo.

por um núcleo pesado tende a se desenvolver mais rapidamente que um criado por um próton. Isso se deve em parte à sensibilidade do $X_{\max }$ à posição da primeira interação, já que um núcleo pesado tende a interagir antes na atmosfera, pois sua seção de choque é maior que a de um próton. Mas a maior contribuição na variação de $X_{\max }$ com a composição pode ser explicada pelo modelo da superposição (seção 1.2, eq. 1.27), que estima o comportamento de um chuveiro de $F e$ de energia $E_{0}$ como uma superposição de 56 chuveiros de prótons de energia $E_{0} / 56$. Dado que a taxa de elongação (eq. 1.26) de um chuveiro protônico é de pelo menos $55 \mathrm{~g} / \mathrm{cm}^{2}$ por década de energia, esperamos pelo menos uma diferença de $55 \mathrm{~g} / \mathrm{cm}^{2} \cdot \log 56 \cong 100 \mathrm{~g} / \mathrm{cm}^{2}$ entre o $X_{\max }$ do ferro e o do próton. Na figura 1.19 pode-se observar que o chuveiro de ferro se desenvolve mais rapidamente, levando a uma diferença no $X_{\max }$ de aproximadamente $120 \mathrm{~g} / \mathrm{cm}^{2}$ em relação ao chuveiro protônico, ilustrando a dependência do perfil longitudinal com composição do primário. Essa dependência é importante em estudos de composição dos primários em FDs.

Uma função analítica aproximada para o perfil longitudinal muito utilizada foi proposta por Gaisser e Hillas (função GH)[49]: 


$$
N(X)=N_{\max }\left(\frac{X-X_{0}}{X_{\max }-X_{0}}\right)^{\frac{\left(X_{\max }-X_{0}\right)}{\lambda}} \exp \left[\frac{\left(X_{\max }-X\right)}{\lambda}\right]
$$

onde $N(X)$ é o número de partículas na profundidade atmosférica $X, N_{\max }$ é o número de partículas no máximo do chuveiro e $\lambda=70 \mathrm{~g} / \mathrm{cm}^{2}$. A figura 1.20 mostra um ajuste da função GH aos pontos obtidos da simulação de chuveiros iniciados por prótons da figura 1.19. Isso permite estimar o desenvolvimento do chuveiro mesmo após o nível do solo, como se tivéssemos uma atmosfera infinita.

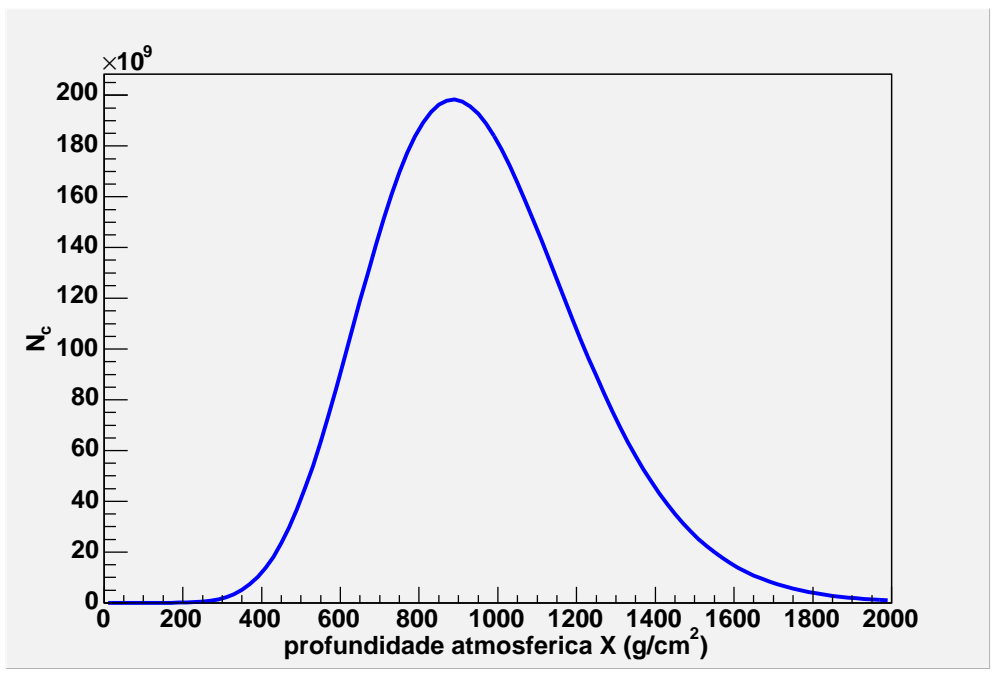

Figura 1.20: Exemplo de perfil longitudinal obtido da simulação com o Aires de um próton com $E=3.2 \cdot 10^{20} \mathrm{eV}$.

Como discutido na seção 1.2 , cerca de $90 \%$ da energia da partícula primária é depositada na atmosfera pela componente eletromagnética do chuveiro. Desse modo, como uma partícula carregada deposita em média $2.2 \mathrm{MeV}$ por intervalo de $1 \mathrm{~g} / \mathrm{cm}^{2}$ na atmosfera[50], a integral do perfil longitudinal é uma medida da energia eletromagnética total do chuveiro:

$$
E_{e m}=2.2 M e V \mathrm{~cm}^{2} / g \times \int_{0}^{\infty} N_{c}(X) d X
$$

onde $N_{c}(X)$ é o número de partículas carregadas na profundidade atmosférica $X$. Aplicandose uma correção a essa energia calorimétrica $E_{e m}$, é possível reconstruir a energia da 
partícula primária.

Como discutido na seção 1.2, a distribuição lateral das partículas do chuveiro é regida pelo espalhamento Coulombiano das partículas carregadas e pelo momento transversal associado às interações hadrônicas durante os estágios iniciais do desenvolvimento.

As partículas que chegam ao solo podem ser detectadas por SDs, o que permite obter um sinal em função da distância ao core do chuveiro no solo. Esses sinais podem ser descritos por funções de distribuição lateral (LDF), cuja forma depende do detetor utilizado, e permite a reconstrução da densidade de partículas no solo. A razão entre as componentes muônica e eletrônica do chuveiro é dependente da composição do primário, e pode ser medida no solo por alguns tipos de SDs, permitindo um estudo mais detalhado de composição.

\subsubsection{Técnica experimental de Fluorescência (FD)}

Essa técnica, utilizada para a obtenção do perfil longitudinal de um EAS, baseia-se na deteç̧ão de luz de fluorescência emitida pelo chuveiro. A figura 1.21 mostra um esquema da detecção de EAS pelo método FD. Os fótons emitidos são detectados por fotomultiplicadoras (PMTs) em um telescópio. Como cada PMT aponta para uma direção específica do céu, é possível não somente medir a intensidade da emissão, mas também a direção do ponto de emissão. Esse método permite observar grande parte do desenvolvimento do chuveiro.

Partículas ionizantes podem excitar as moléculas de $N_{2}$ na atmosfera. Essas, por sua vez, podem emitir fótons de fluorescência, tipicamente entre 10 e $50 \mu s$ após a excitação. A maior parte da emissão de fluorescência ocorre entre 300 e 400 nm[50], como pode ser visto na figura 1.22. A atmosfera é relativamente transparente nessa região de comprimentos de onda, correspondendo a um comprimento de atenuação da ordem de $15 \mathrm{~km}$ para um feixe vertical[52].

Embora o número de fótons de fluorescência emitidos por partícula ionizante seja pequeno, EAS com energia maior que $10^{17} \mathrm{eV}$ apresentam mais de $10^{8}$ partículas no 


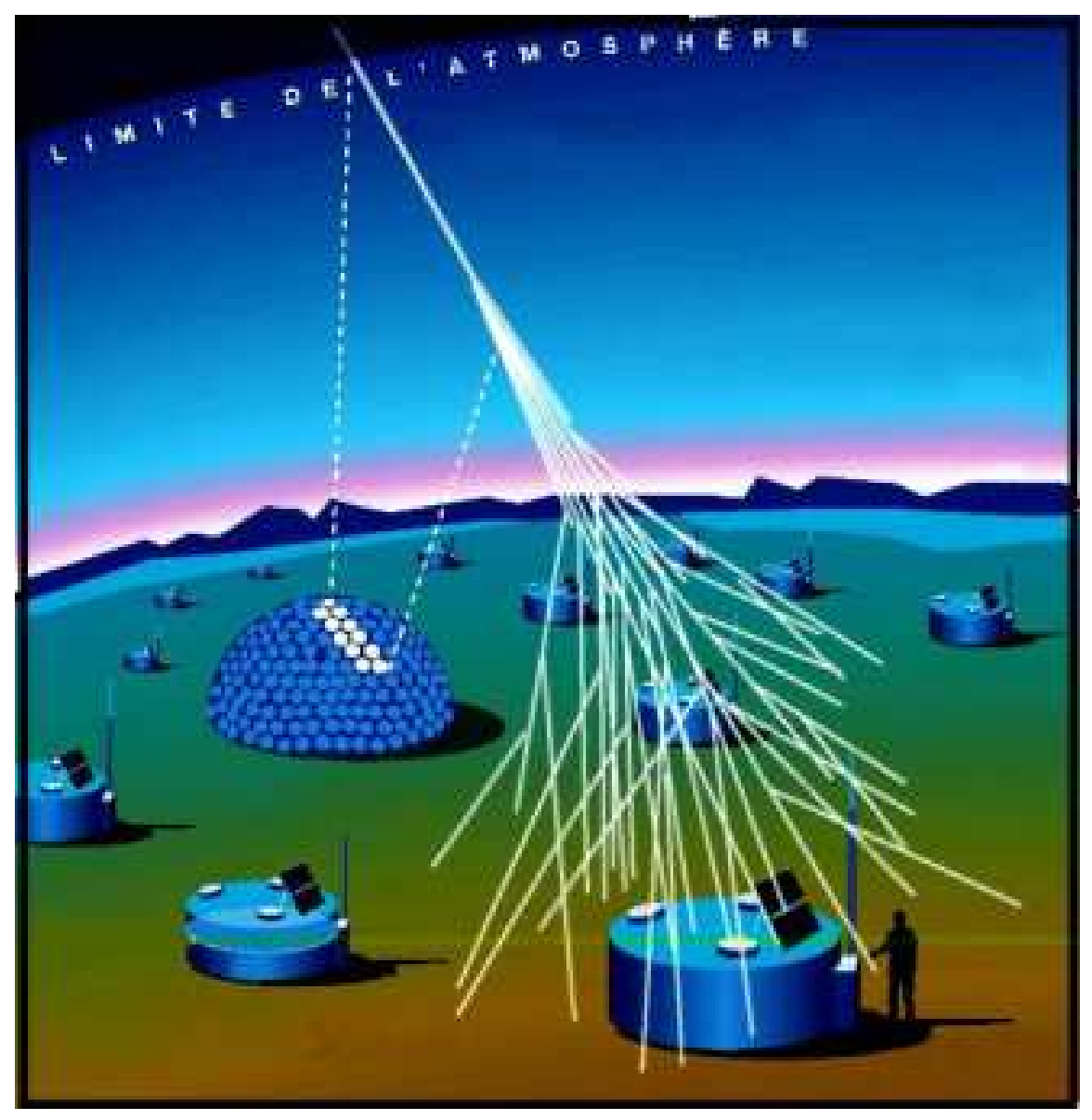

Figura 1.21: Esquema da detecção de EAS pelo método de fluorescência e por tanques Cerenkov (evento híbrido). Extraído de [51]

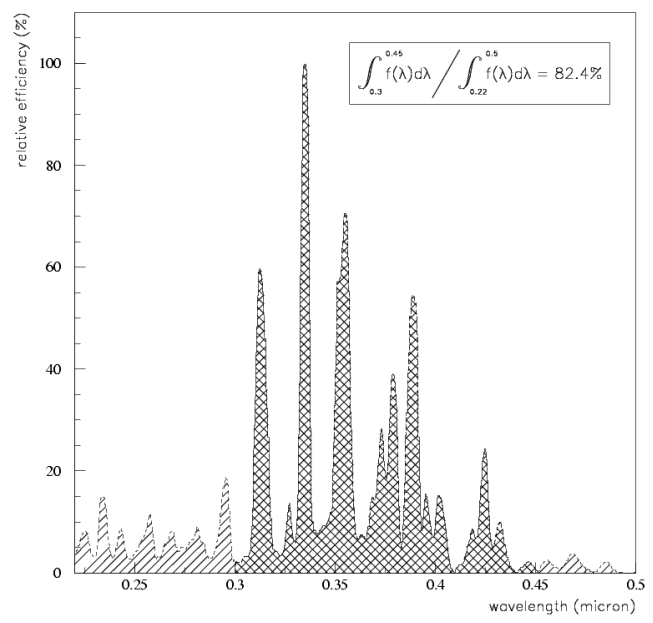

Figura 1.22: Espectro de emissão de fluorescência, extraída de [50]. Cerca de $82 \%$ da emissão ocorre entre 300 e $450 \mathrm{~nm}$. 
máximo. Desse modo, mesmo com uma eficiência de emissão por fluorescência da ordem de $0.5 \%$, um número substancial de fótons é emitido. Essa radiação é emitida isotropicamente e é proporcional ao número de partículas no chuveiro. Desse modo, telescópios de fluorescência podem coletar esses fótons, possibilitando a reconstrução do perfil longitudinal de um EAS.

Um detetor de fluorescência ou "olho" é constituído por um espelho que coleta a luz, tipicamente somente na região entre 300 e 400 nm devido à utilização de um filtro, focando-a em uma matriz de fotomultiplicadoras, que funciona como uma câmera onde cada pixel é uma PMT. Cada uma dessas fotomultiplicadores recebe luz de uma região específica no céu, com uma abertura típica da ordem de $1^{\circ}$. Desse modo, podemos detectar não só a intensidade da luz de fluorescência, mas também a direção no céu de onde ela é proveniente. Para um detetor de fluorescência distante, um EAS é visto como um ponto de luz UV que se move rapidamente em um arco no céu, através de um ruído de fundo constituído por luz espalhada de estrelas, radiação difusa da galáxia, poluição luminosa e reações fotoquímicas na atmosfera. A razão sinal/ruído é de extrema importância nessa técnica de detecção, permitindo sua utilização apenas em noites sem nuvens e sem lua, quando a radiação de fundo é mínima. Outro fator importante nesse aspecto é a luz Cerenkov produzida pelo próprio chuveiro. Essa radiação, também na região de comprimentos de onda observados pelo telescópio, é emitida em um cone estreito na direção do eixo do chuveiro. Embora essa radiação não necessariamente chegue diretamente ao detector, dependendo da direção do chuveiro, ela é espalhada na atmosfera fazendo com que uma fração da luz Cerenkov emitida sempre chegue ao telescópio. Essa contribuição ao sinal deve ser posteriormente subtraída.

Processos de triggering são então aplicados aos sinais das PMTs. O trigger primário é baseado na integral do sinal de cada PMT, com limiares tipicamente da ordem de $4 \sigma$ sobre o fundo médio. Esse procedimento é seguido por um processo de triggering secundário, que leva em conta as posições relativas das PMTs aceitas pelo trigger primário, que devem descrever uma linha na câmera. A figura 1.23 mostra um candidato 
a evento FD do Observatório Auger. À esquerda está uma representação da câmera com as PMTs que passaram pelos triggers primário e secundário. Os sinais das PMTs indicadas por pontos são mostrados na parte superior direita da figura, onde o eixo horizontal é composto por bins de tempo.

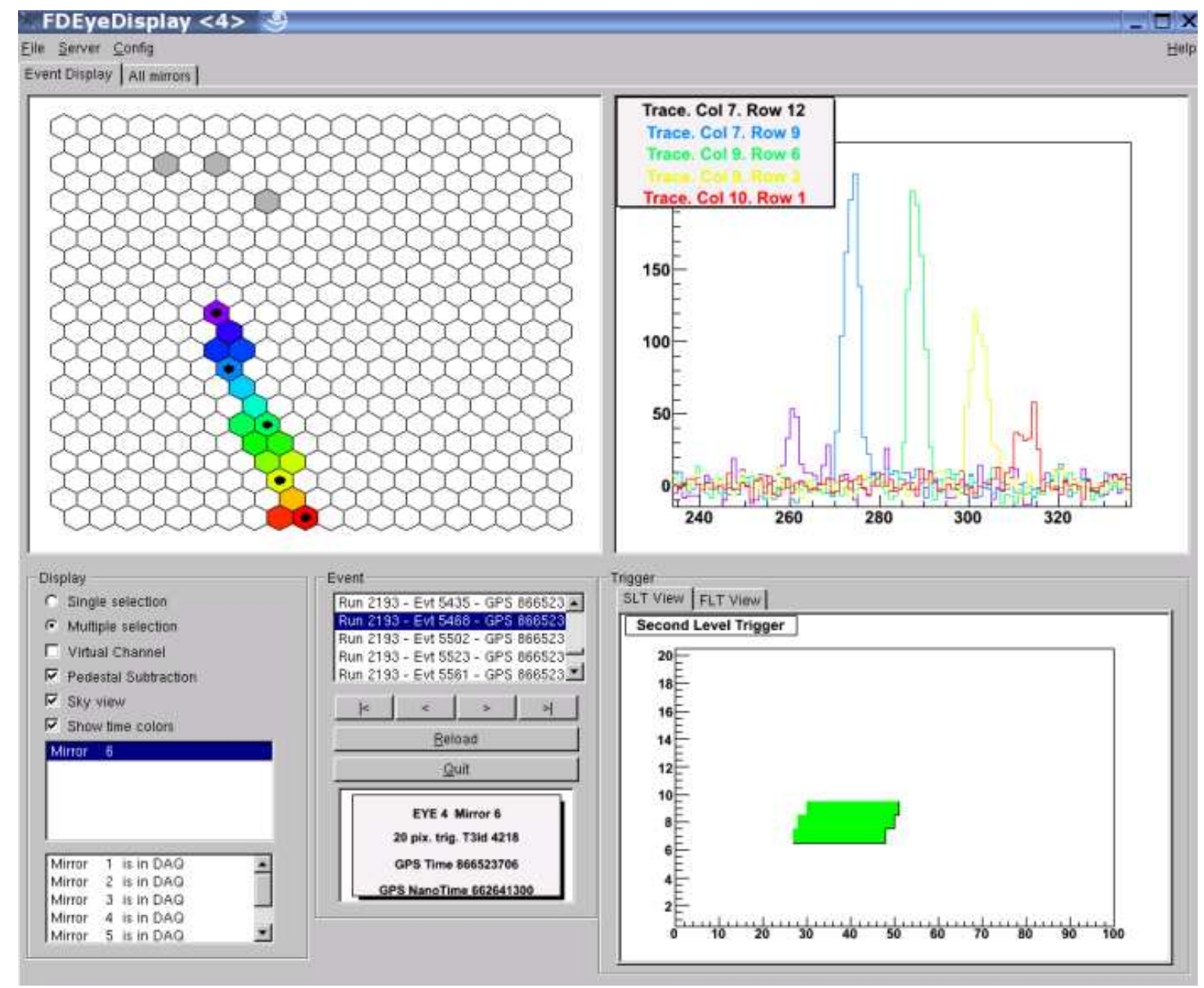

Figura 1.23: Candidato a evento FD do Observatório Auger. À esquerda está uma representação da câmera com as PMTs que passaram pelos triggers primário e secundário. Os sinais das PMTs indicadas por pontos são mostrados na parte superior direita da figura, onde o eixo horizontal é composto por bins de tempo.

O próximo passo na reconstrução do evento é a reconstrução da geometria do EAS. Como cada PMT está relacionada com uma direção no céu, um plano pode ser ajustado às direções das PMTs acionadas, ponderadas pela integral do seu sinal. Esse ajuste pode ser representado por um ajuste linear na câmera de PMTs (ver figura 1.23). Esse plano, mostrado na figura 1.24, é conhecido como plano chuveiro-detetor (SDP) e é 
determinado pelo eixo do chuveiro e pela posição do telescópio.

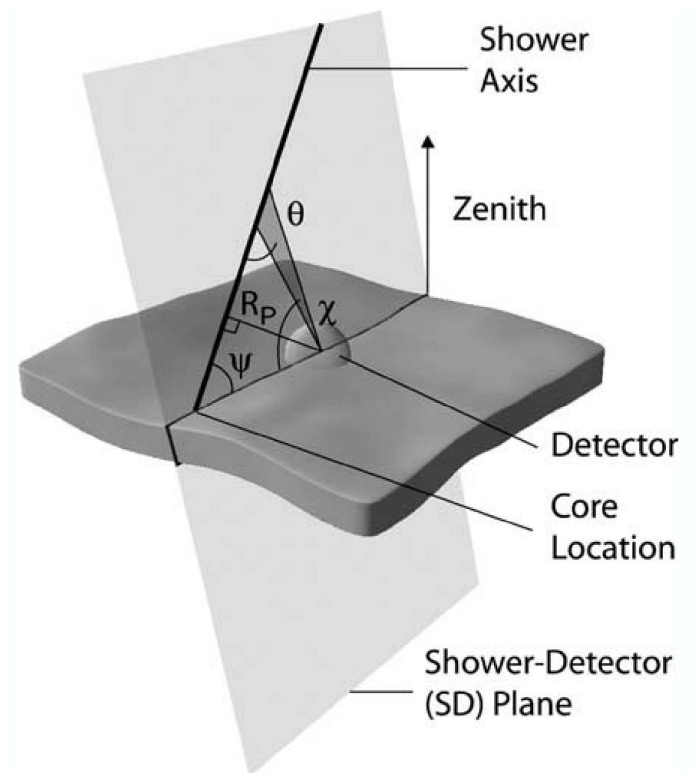

Figura 1.24: Esquema da reconstrução geométrica de um EAS, mostrando o plano chuveiro-detetor, extraído de [53].

Uma vez determinado o SDP, é necessário obter a direção do eixo do chuveiro dentro desse plano. A partir do tempo de subida do sinal em cada PMT, é possível estipular um tempo $t_{i}$ de acionamento para cada PMT. Da direção de cada PMT, obtêm-se os ângulos $\chi_{i}$ em relação ao solo das direções das PMTs projetadas sobre o SDP. Utilizando os valores obtidos para $t_{i}$ e $\chi_{i}$, a seguinte função pode ser ajustada[53]:

$$
t_{i}=t_{0}+\frac{R_{p}}{c} \tan \left(\frac{\pi-\psi-\chi_{i}}{2}\right)
$$

obtendo-se $t_{0}, \psi$ e $R_{p}$, que definem totalmente a geometria reconstruída do EAS. A figura 1.25 mostra um exemplo desse ajuste a dados experimentais. A incerteza relacionada com a determinação do SDP é muito menor que a relacionada com a posição do eixo do chuveiro dentro do SDP, obtida do ajuste da eq. 1.39. A detecção de eventos estéreo, onde dois olhos observam o mesmo chuveiro, leva a uma reconstrução geométrica muito 
melhor. O mesmo acontece em eventos híbridos, onde um mesmo chuveiro é observado simultaneamente por detetores de superfície. Os SDs proporcionam uma medida muito mais precisa da posição do core do chuveiro no solo.

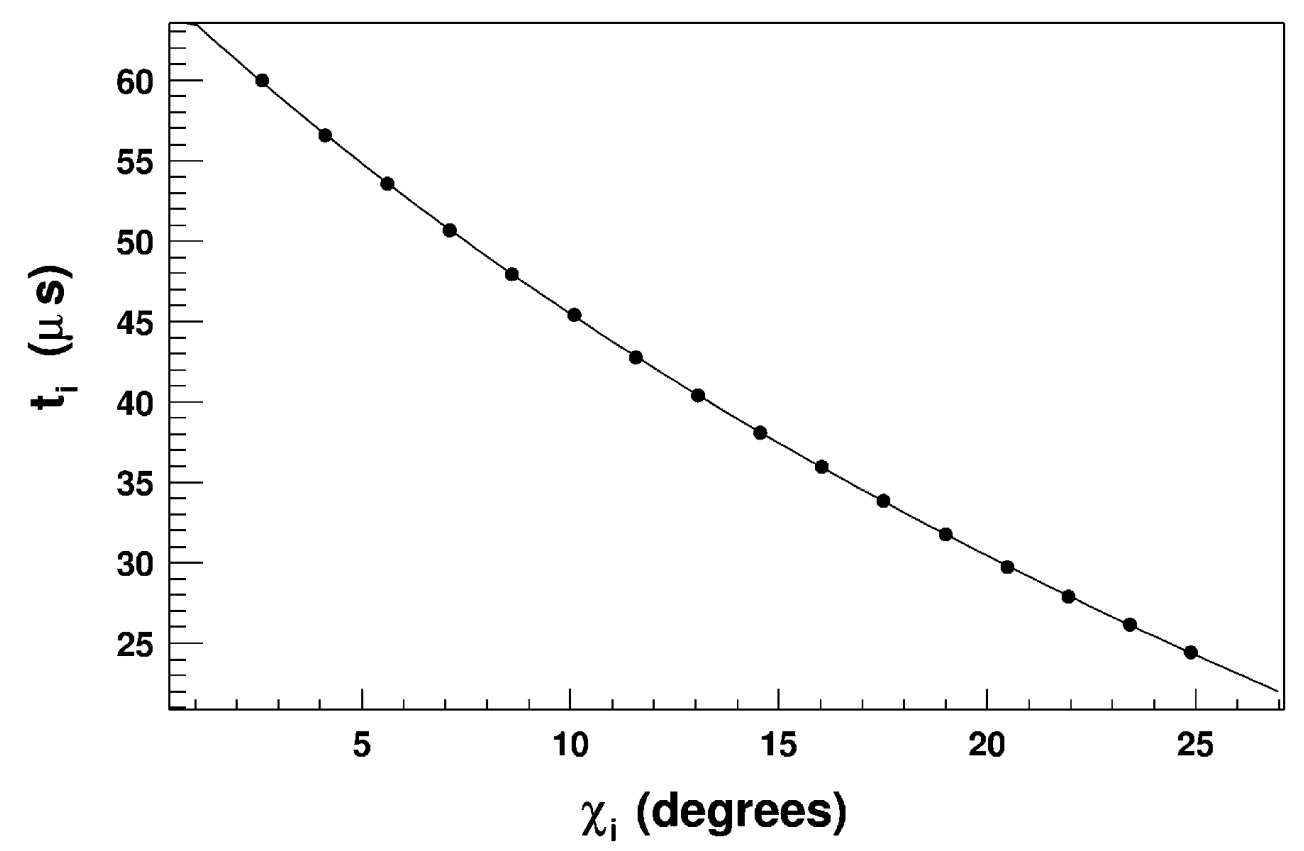

Figura 1.25: Exemplo de reconstrução geométrica de um chuveiro. O tempo $t_{i}$ do pixel é plotado em função de $\chi_{i}$, a direção do pixel projetada no SDP. Figura extraída de [54].

Com a geometria bem definida, é possível identificar os pontos na atmosfera onde foram emitidos os fótons de fluorescência detectados por cada PMT. Por outro lado, o número de fótons detectados é menor que o número de fótons emitidos por fluorescência, pois a emissão é isotrópica e os fótons estão sujeitos a processos de atenuação na atmosfera até serem detectados pelo FD. Os processos de absorção são importantes na região abaixo de $290 \mathrm{~nm}$ e acima de $800 \mathrm{~nm}$ [52]. Na região entre $300-400 \mathrm{~nm}$, onde está a maior parte da emissão por fluorescência, os principais mecanismos de atenuação são o espalhamento dos fótons nas moléculas da atmosfera, chamado espalhamento Rayleigh e nos aerossóis presentes na atmosfera, chamado espalhamento Mie.

O espalhamento Rayleigh é fortemente dependente do comprimento de onda $\lambda$, pois sua seção de choque é proporcional a $\lambda^{-4}$. O coeficiente de atenuação entre um ponto de 
emissão de profundidade atmosférica slant $x_{1}$ e um ponto de detecção de profundidade $x_{2}$ pode ser escrita como[55]:

$$
T_{R}=\exp \left[-\frac{\left|x_{1}-x_{2}\right|}{X_{R}}\left(\frac{400 n m}{\lambda}\right)^{4}\right]
$$

onde o caminho livre médio $X_{R}$ é $2974 \mathrm{~g} / \mathrm{cm}^{2}$ para $\lambda=400 \mathrm{~nm}$.

O espalhamento Mie é extremamente complexo, pois apresenta uma forte dependência no ângulo de espalhamento com o tamanho do aerossol, sua forma e sua constante dielétrica. Essa dependência, juntamente com a também complexa distribuição de aerossóis na atmosfera, faz com que seja extremamente difícil modelar esse processo no caso de altas concentrações de aerossóis. Por esse motivo, observatórios de raios cósmicos que utilizam técnicas ópticas devem se localizar em locais onde o espalhamento por aerossóis é muito menor que o espalhamento Rayleigh, como desertos e altas altitudes. Nessas circunstâncias, um modelo simplificado desenvolvido por Eterman pode ser utilizado. Nesse modelo, a concentração de aerossóis na atmosfera cai exponencialmente com a altitude e uma lei de potência descreve a distribuição de tamanho desses aerossóis. Nesse caso, o coeficiente de atenuação entre um ponto de emissão de altitude $h_{1}$ e um ponto de detecção de altitude $h_{2}$ pode ser escrito como[55]:

$$
T_{M}=\exp \left\{\frac{H_{M}}{L_{M} \cos \theta}\left[\exp \left(-\frac{h_{1}}{H_{M}}\right)-\exp \left(-\frac{h_{2}}{H_{M}}\right)\right] \frac{400 n m}{\lambda}\right\},
$$

onde a altitude de escala $H_{M} \cong 1.2 \mathrm{~km}$ e o comprimento de atenuação horizontal $L_{M}=$ $15 \mathrm{~km}$ para $\lambda=400 \mathrm{~nm}$ e $\theta$ é o ângulo zenital do ponto de emissão em relação ao ponto de detecção. Vale lembrar que os parâmetros dos espalhamentos, como comprimentos de atenuação, variam no tempo e com a localização do detetor. Desse modo, torna-se necessário um monitoramento da atmosfera para diminuir as incertezas relativas aos cálculos de atenuação.

Considerando o espalhamento múltiplo dos fótons desprezível, podemos escrever o coeficiente $\tau$ de transmissão total como: 


$$
\tau=T_{R} T_{M}
$$

Levando em conta a atenuação desses fótons do ponto de emissão até o detector e o ângulo sólido efetivo do telescópio em relação ao ponto de emissão, é possível reconstruir o número de fótons de fluorescência emitidos na região observada por cada PMT. O número de fótons de fluorescência emitidos por unidade de profundidade atmosférica, chamado Fluorescence Yield (FY), é proporcional à energia depositada $d E / d X$ e depende da temperatura $T$ e densidade $\rho$ da atmosfera no ponto de emissão. Foram efetuadas várias medidas experimentais do FY de vários picos de emissão de fluorescência de elétrons no ar e em $N_{2}[56,55,57]$. Esses trabalhos sugerem a seguinte relação entre a deposição de energia $d E / d X$ e o FY na região 300 - 400nm[57] e $300-405 n m[56]$ :

$$
F Y\left(K_{c}, \rho, T\right)=\frac{\left(\frac{d E}{d X}\right)}{\left(\frac{d E}{d X}\right)_{K_{c}}} \times \rho\left(\frac{A_{1}}{1+\rho B_{1} \sqrt{T}}+\frac{A_{2}}{1+\rho B_{2} \sqrt{T}}\right)
$$

onde $A_{1}, A_{2}, B_{1}, B_{2}, K_{c}$ e $(d E / d X)_{K_{c}}$ são constantes obtidas experimentalmente $[57,56]$.

De posse do FY para o ponto de emissão, é possível reconstruir a energia depositada na região do chuveiro observada por cada PMT. Essa energia é proporcional à multiplicidade de partículas. Desse modo, são obtidos pontos no perfil longitudinal de deposição de energia. A esse perfil é ajustada uma função GH (eq. 1.37). A figura 1.26 mostra um exemplo de um perfil longitudinal reconstruído de deposição de energia e um ajuste GH.

A integral da função GH ajustada é a energia calorimétrica total $E_{\text {cal }}$ depositada pelo chuveiro. Como discutido na seção 1.2, essa energia é da ordem de $90 \%$ da energia total $E_{0}$ da partícula primária:

$$
E_{0}=\int_{0}^{\infty} \frac{d E}{d X}(X) d X+M . E .=E_{c a l}+M . E .
$$

onde $(d E / d X)(X)$ é a deposição de energia na profundidade $X$ e M.E. a missing energy. A missing energy é a energia carregada por neutrinos e múons de alta energia que não 


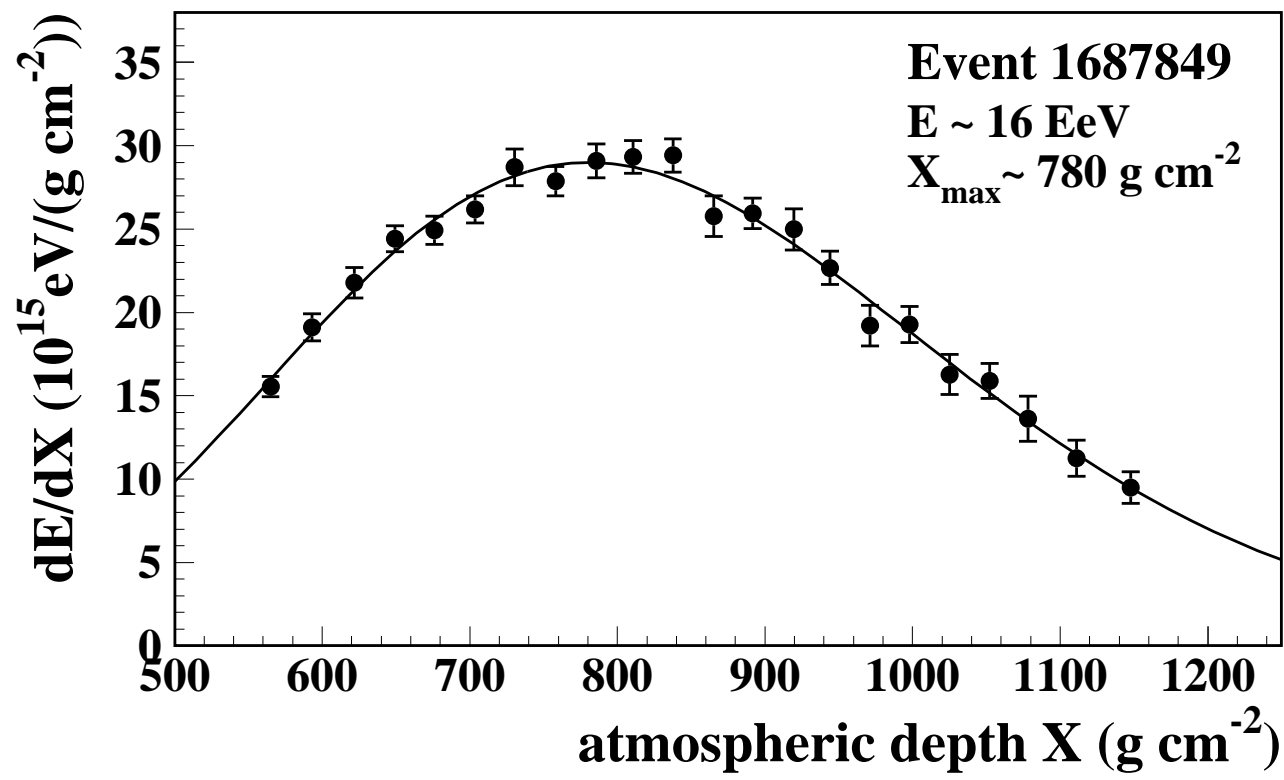

Figura 1.26: Exemplo de um perfil longitudinal reconstruído de deposição de energia (pontos) e um ajuste GH. Figura retirada de [58].

é depositada na atmosfera e pode ser estimada através de simulações.

Uma das maiores vantagens do método FD, em relação a detetores de superfície, é que a reconstrução de energia é praticamente independente de simulações, exceção feita à determinação da missing energy, que representa apenas $\sim 10 \%$ da energia total. Já as desvantagens são um duty cycle muito baixo, da ordem de $10 \%$, já que as medidas devem ser feitas em noites sem nuvens e lua para minimizar a radiação de fundo, além da reconstrução geométrica, que pode ser problemática em alguns casos. Outro fator é que o FY é de extrema importância para a reconstrução do perfil longitudinal em experimentos FD, já que é praticamente proporcional à medida de energia depositada. Acredita-se que possam existir erros sistemáticos nas medidas de energia da ordem de até $20 \%$ devido às incertezas relacionadas ao FY. Um novo experimento chamado AIRFLY[59], já em fase final, promete reduzir a no máximo $10 \%$ as incertezas nesse parâmetro.

Essa técnica de detecção permite a medida do $X_{\max }$ do EAS, que é um dado importante na determinação da composição do primário. A figura 1.27 mostra a profundidade 
média do máximo $\left\langle X_{\max }\right\rangle$ em função da energia do primário, obtida de simulações com distintos modelos hadrônicos, além de dados experimentais. Pode-se observar que os dados mostram que, a energias mais altas, a composição parece ser dominada por nucleons e núcleos leves e parece incompatível com fótons.

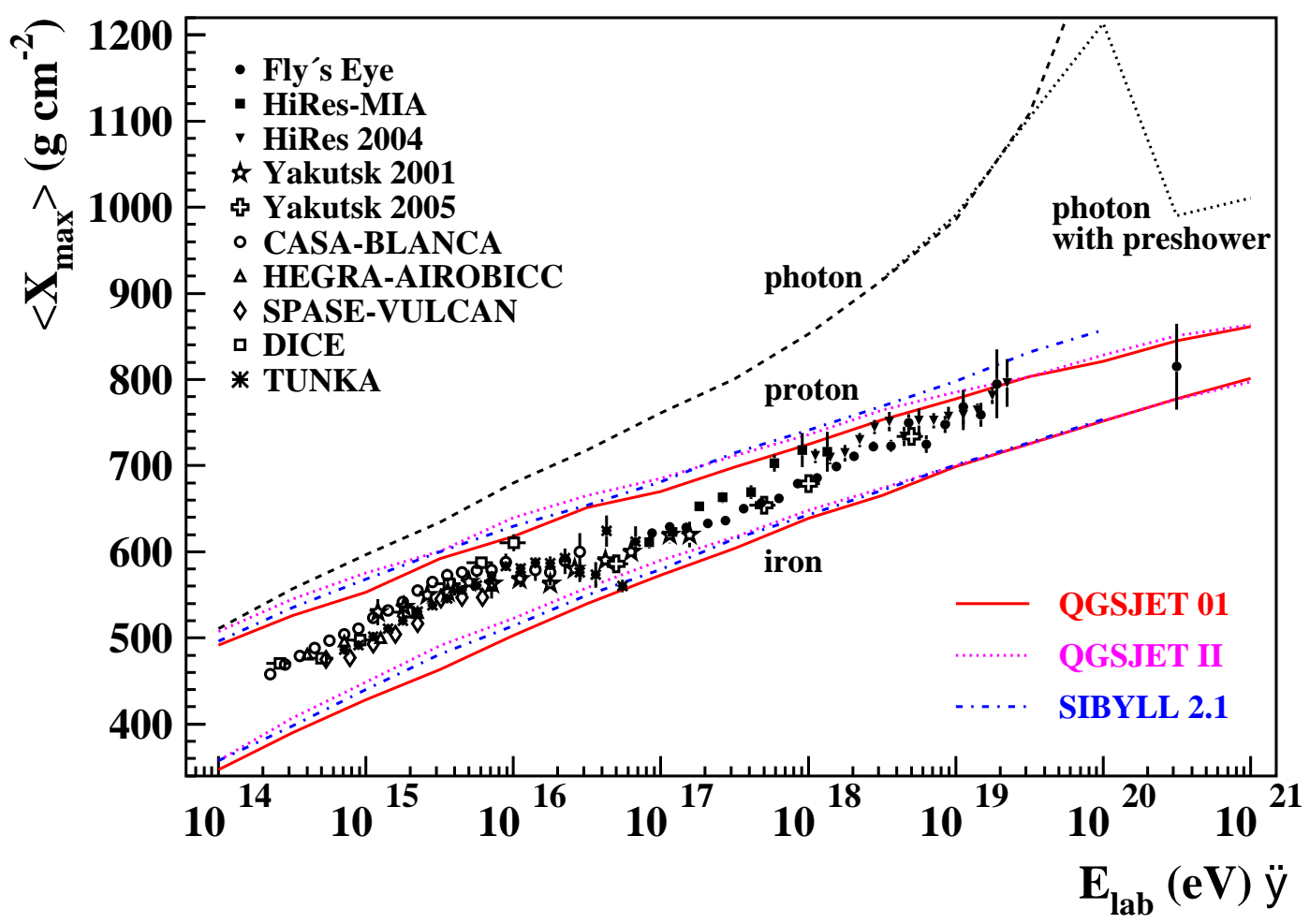

Figura 1.27: Profundidade média do máximo $\left\langle X_{\max }\right\rangle$ em função da energia do primário obtida de simulações com distintos modelos hadrônicos além de dados experimentais. Figura retirada de [58].

\subsubsection{Técnica experimental de Superfície (SD)}

A detecção de EAS pelo método SD é capaz de medir a distribuição lateral das partículas secundárias no solo. Ela se baseia na detecção das partículas secundárias da frente do EAS utilizando uma matriz de detetores de superfície no solo. Esses detetores são capazes de medir o número de partículas carregadas no solo em função do tempo. Com isso, determinam a densidade de partículas secundárias em função da distância ao core do chuveiro, além dos tempos de detecção por diferentes detetores. Para a reconstrução 
do evento, inicialmente uma estimativa da direção de chegada é obtida a partir dos tempos de passagem da frente do chuveiro por vários detetores, enquanto que a posição do core é obtida da distribuição lateral no solo. Quanto maior for a energia do EAS que se deseja medir, maior pode ser o espaçamento entre os detetores no solo. Por outro lado, quanto maior a energia, maior deve ser a área coberta pelos detetores, devido à rápida diminuição do fluxo com a energia.

Existem dois tipos principais de detetores de superfície: tanques Cerenkov e cintiladores. Os tanques Cerenkov são tanques de água com PMTs. Partículas carregadas emitem luz Cerenkov ao atravessar o tanque, e essa luz é medida pelas PMTs. O outro tipo de detetor utiliza cintiladores plásticos ou líquidos, cuja emissão de luz ao serem atravessados por partículas carregadas também é medida por PMTs. Muitos detetores desse tipo possuem duas camadas de cintiladores, separadas por um absorvedor e isoladas opticamente, podendo então separar a componente eletromagnética, que é depositada no cintilador superior, da componente muônica, depositada no cintilador inferior. Essa característica é muito útil em estudos de composição, já que permite uma medida mais precisa da razão $e^{ \pm} / \mu$ do EAS, que é dependente da composição do primário.

Próximo ao core o sinal depende fortemente da profundidade da primeira interação do raio cósmico na atmosfera, resultando em uma grande flutuação no sinal nessa região para vários EAS de mesma energia e composição. Nas regiões mais distantes, a flutuação estatística do sinal é dominante. Desse modo, existe uma distância ótima $r_{\text {opt }}$ entre essas duas regiões, onde a flutuação do sinal, incluindo sua dependência em composição, é mínima. Essa distância depende das características do experimento, como a distância entre os tanques. No caso do experimento Auger, $r_{o p t}=1000 m$. O sinal $S\left(r_{o p t}\right)$ a uma distância $r_{o p t}$ do core proporciona a melhor estimativa para a energia do primário.

Uma das desvantagens do método SD é que a reconstrução de energia é fortemente dependente de simulações, já que estas determinam a relação entre a distribuição lateral no solo e a energia do primário. Por outro lado, o Observatório Pierre Auger utiliza também o método FD, cuja medida de energia independe de simulações. Desse modo, 
a partir de eventos híbridos, é feita uma calibração da energia $E_{S D}$, obtida pelo SD, em função da energia $E_{F D}$ medida pelo FD. Obtém-se assim uma relação entre $S\left(r_{o p t}\right)$ e $E_{F D}$, que pode ser utilizada para minimizar a dependência de simulações na energia reconstruída em eventos puramente SD. Por outro lado, a utilização dessa calibração deixa a medida de energia pelo método SD sujeita a um possível erro sistemático na medida de energia por fluorescência, devido à incerteza no fluorescence yield, como discutido na seção 1.4.1. Desse modo, caso haja um erro relativo $\epsilon$ no FY, espera-se um erro sistemático de $\sim \epsilon$ na reconstrução de energia tanto pelo $\mathrm{FD}$, quanto pelo SD.

Estudos da composição dos raios cósmicos através de dados de SDs são baseados nas características da distribuição lateral dependentes da composição da partícula primária. Enquanto a diferenciação entre chuveiros iniciados por fótons (ou neutrinos) e os por núcleos seja relativamente simples [60], a diferenciação entre diferentes espécies de núcleos é extremamente complicada. A figura 1.28 mostra os números de elétrons e múons reconstruídos do experimento KASCADE-Grande, que utiliza cintiladores que medem as duas componentes separadamente. Os pares de linhas tracejadas indicam linhas de massa e energia constantes obtidas do Corsika.

Por outro lado, no caso de detetores Cerenkov, que não medem separadamente as componentes EM e muônica, a determinação direta da razão $e^{ \pm} / \mu$ é mais complicada. Assim, outros métodos para determinar a composição do primário têm sido intensamente pesquisados recentemente[60]. Alguns desses métodos baseiam-se na estrutura temporal da frente do EAS, que é sensível à composição do primário devido à sua dependência com a altitude do desenvolvimento do chuveiro. 


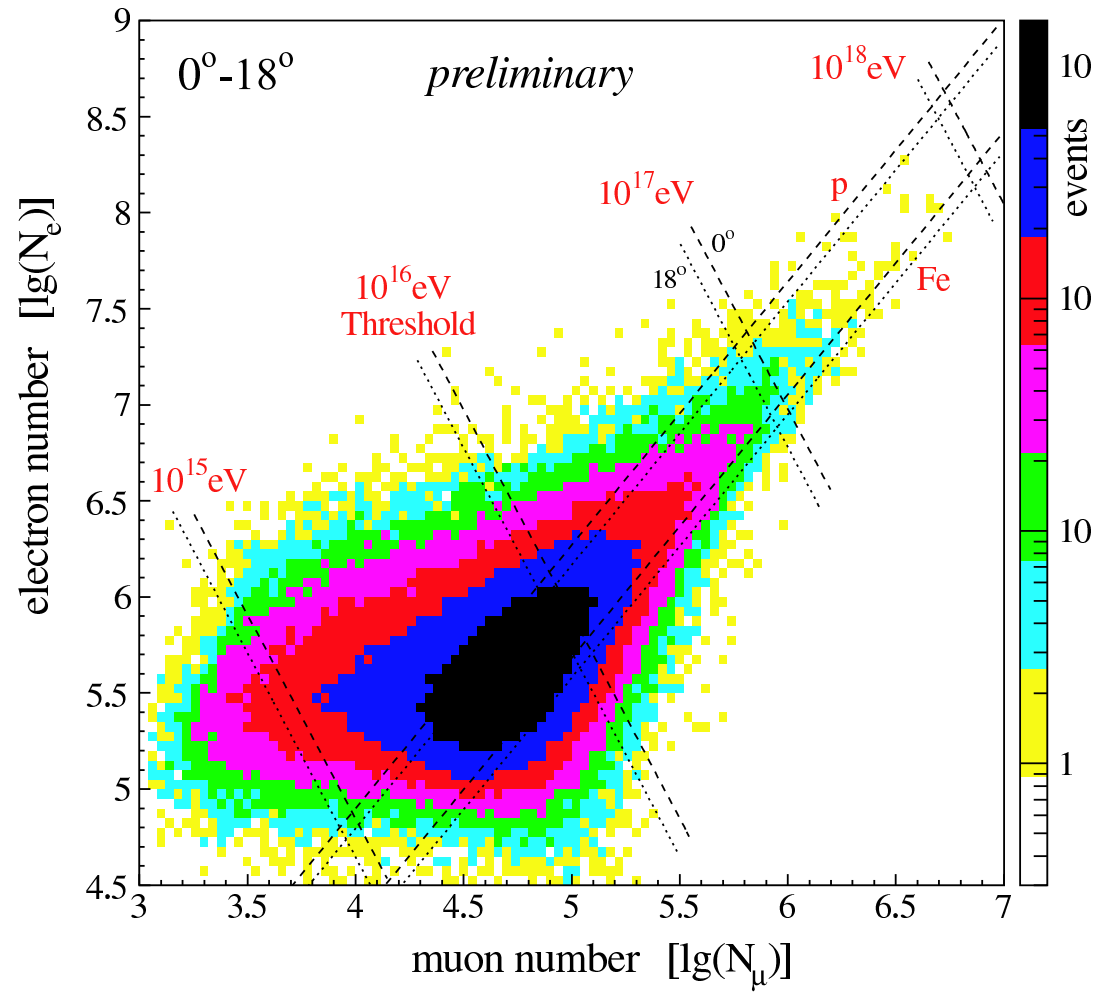

Figura 1.28: Números de elétrons e múons reconstruídos do experimento KASCADEGrande. Os pares de linhas tracejadas indicam linhas de massa e energia constantes obtidas do Corsika. Figura extraída de [61]. 


\section{Capítulo 2}

\section{Simulação da deteç̧ão e reconstrução de eventos pelo método FD.}

Neste capítulo descrevemos o conjunto de ferramentas computacionais que desenvolvemos para a simulação de detetores, reconstrução de eventos e análise de dados, chamado Shower Tools, descrito em detalhes no apêndice A. Utilizando essas ferramentas, foram criadas simulações[6] dos telescópios de fluorescência das colaborações HiRes e Auger, usando as principais características desses detetores, como sua abertura angular (elevação máxima e mínima), sua eficiência (transmitância do filtro, refletância do espelho e eficiência quântica das PMTs), a área efetiva de sua abertura, o tamanho do pixel e sua altitude como parâmetros. A tabela 2.1 mostra os valores dos principais parâmetros dos detetores utilizados na simulação. Essas simulações podem utilizar como entrada chuveiros gerados tanto pelo Aires, quanto pelo Corsika.

\begin{tabular}{|c|c|c|c|}
\hline Parâmetro & Auger & HiRes-I & HiRes-II \\
\hline Altitude $(\mathrm{m})$ & 1500 & 1957 & 1957 \\
\hline Eficiência & $20.0 \%$ & $15.5 \%$ & $20.0 \%$ \\
\hline Elevação mínima $\left(^{\circ}\right)$ & 2 & 3 & 3 \\
\hline Elevação máxima $\left(^{\circ}\right)$ & 32 & 17 & 31 \\
\hline Área da abertura $\left(m^{2}\right)$ & 3.8 & 3.72 & 5.10 \\
\hline Tamanho do Pixel $\left(^{\circ}\right)$ & 1.5 & 1.0 & 1.0 \\
\hline
\end{tabular}

Tabela 2.1: Principais parâmetros dos telescópios utilizados na simulação. 
Inicialmente, definimos a geometria simulada para o EAS: uma direção isotrópica é gerada para o eixo do chuveiro, bem como uma posição para o core no solo, igualmente distribuída em área (seção A.4.1). O perfil longitudinal de deposição de energia, gerado pelo Aires ou pelo Corsika, tem então seu ângulo zenital alterado (seção A.2.3), conforme a geometria amostrada. De posse desse perfil alterado e da geometria do evento, o telescópio é então simulado, seguindo o esquema mostrado na figura 2.1, obtendo-se assim o sinal em cada uma das PMTs. Esse sinal leva em conta o fundo durante a aquisição e características da eletrônica, como freqüência de aquisição e ruído.

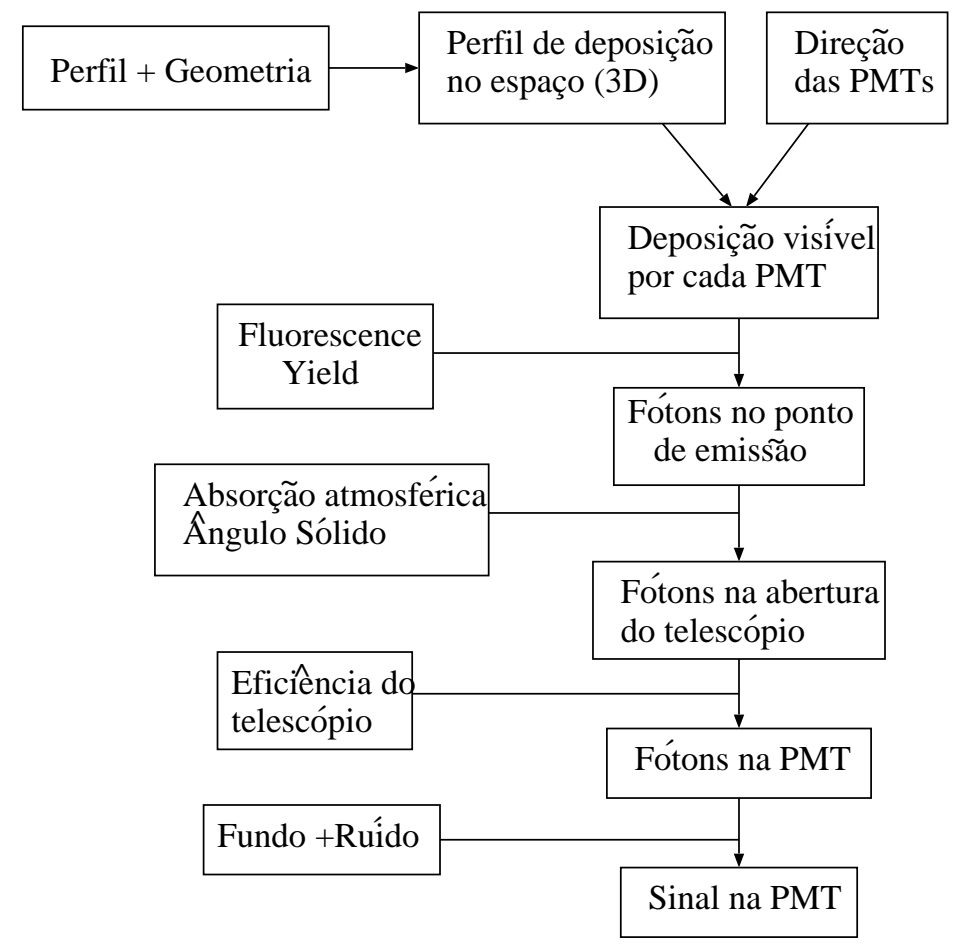

Figura 2.1: Esquema da simulação dos sinais em cada PMT do detetor.

Nesse ponto termina a simulação da detecção do sinal e inicia-se a reconstrução do evento. A geometria reconstruída para o evento é então determinada, levando em conta erros característicos de detetores de fluorescência (seção A.5.4). Para todos os telescópios, foi utilizado um erro gaussiano de desvio-padrão $\sigma=5^{\circ}$ na determinação da direção do eixo do chuveiro sobre o SDP.

Para que o sinal de uma determinada PMT seja utilizado na reconstrução, esta deve 
passar pelo trigger primário, que compara o sinal obtido da PMT com um certo valor de referência (seção A.5.3). No caso dos telescópios HiRes-II e Auger, utilizou-se 4 vezes o fundo médio[50] ( 24 fótons/100ns), e no caso do HiRes-I, 25 fotoelétrons/grau[53].

De posse da geometria reconstruída e do sinal simulado nas PMTs, o perfil longitudinal é reconstruído seguindo os passos mostrados na figura 2.2. Finalmente, esse perfil de deposição reconstruído é analisado (ajuste de função GH, integração e cálculo do missing energy), obtendo-se a energia reconstruída para o evento (seção A.5.5), bem como os outros observáveis do evento, como a deposição máxima $(d E / d X)_{\max }$ e a posição $X_{\max }$ desse máximo. Os resultados da simulação são então armazenados (seção A.6) para posterior análise.

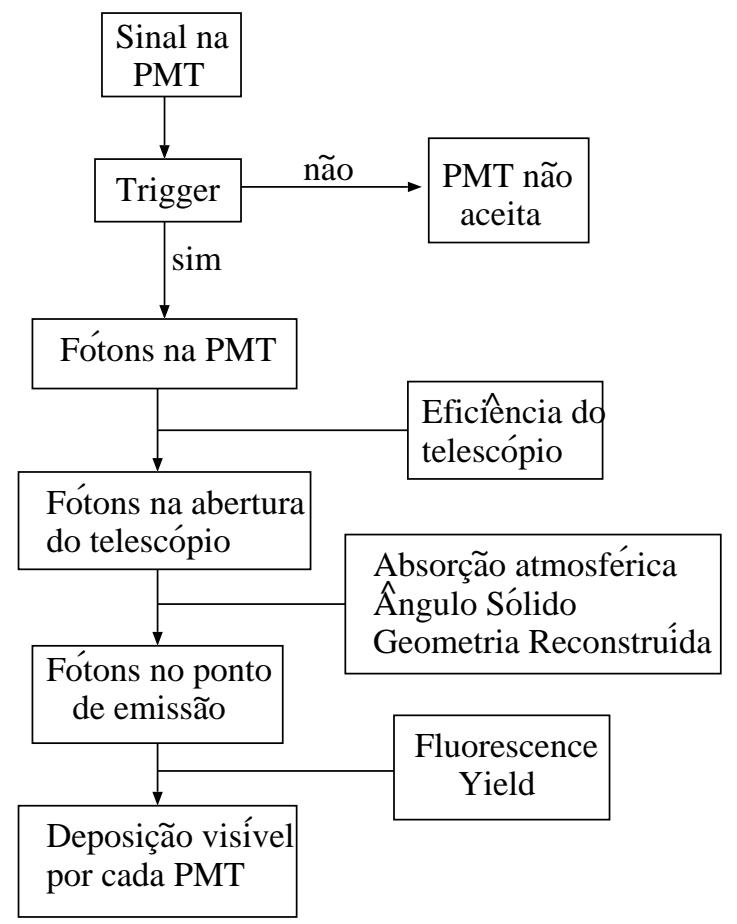

Figura 2.2: Esquema da reconstrução do evento.

Para a análise dos dados da simulação são realizados cortes sobre os parâmetros listados na tabela 2.2, utilizando a parte de análise do shower tools. Uma vez aplicados os cortes é possível obter as distribuições relevantes da simulação, como por exemplo a distribuição da energia reconstruída, a distribuição de erros na energia reconstruída, ou 


\begin{tabular}{|l|c|c|c|}
\hline Corte & HiRes-I[53,62] & HiRes-II[53, 62] & Auger[63] \\
\hline velocidade angular & $<3.33^{\circ} / \mu \mathrm{s}$ & $<11^{\circ} / \mu \mathrm{s}$ & \\
\hline PMTs aceitas pelo trigger & $>7$ & $>7$ & $>5$ \\
\hline Comprimento do Track $\left(<17^{\circ}\right.$ elevation) & & $>7^{\circ}$ & \\
\hline Comprimento do Track $\left(>17^{\circ}\right.$ elevation) & & $>10^{\circ}$ & \\
\hline Comprimento do Track & $8^{\circ}$ & & $>200 \mathrm{~g} / \mathrm{cm}^{2}$ \\
\hline Ângulo zenital & $<60^{\circ}$ & $<60^{\circ}$ & $<60^{\circ}$ \\
\hline$X_{\text {max }}$ & visível & visível & visível \\
\hline Ângulo $\psi$ & $<120^{\circ}$ & & $<132^{\circ}$ \\
\hline$\chi_{\text {red }}^{2}($ ajuste GH) & & $<10$ & $<20$ \\
\hline
\end{tabular}

Tabela 2.2: Cortes aplicados aos resultados da simulação para cada telescópio.

a distribuição do parâmetro de impacto $R_{p}$ do chuveiro (fig. 1.24). Este último é extremamente sensível às características do telescópio e por isso foi utilizado como um teste de nossa simulação, já que no caso do telescópio HiRes-I, existem dados publicados[62] das distribuições de $R_{p}$. A figura 2.3 mostra uma comparação entre nossos resultados e os dados e simulações da colaboração HiRes nas energias $E=10^{19} \mathrm{eV}$ e $E=10^{19.5} \mathrm{eV}$, podendo-se observar um bom acordo entre os resultados em ambas energias.
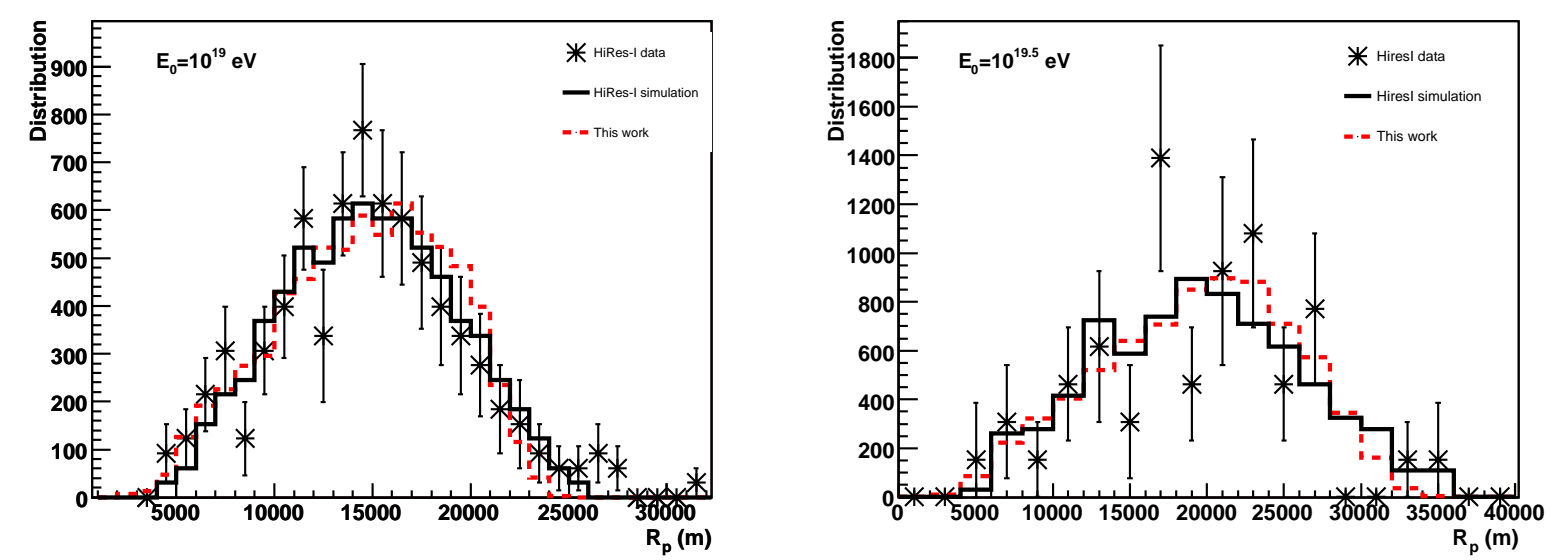

Figura 2.3: Comparação entre nossos resultados para o parâmetro de impacto $R_{p}$ e os dados e simulações da colaboração HiRes, para $E=10^{19} \mathrm{eV}$ e $E=10^{19.5} \mathrm{eV}$.

Nesses testes foi utilizado o programa Corsika[40], juntamente com o modelo hadrônico QGSJET01[41], para a geração dos EAS utilizados como entrada na simulação do telescópio. Para cada uma das quatro energias utilizadas: $10^{19.0}, 10^{19.5}, 10^{20.0}$ e $10^{20.5} \mathrm{eV}$, 
2000 chuveiros iniciados por prótons foram simulados com um ângulo zenital fixo de $60^{\circ}$ e a energia depositada amostrada em intervalos de $5 \mathrm{~g} / \mathrm{cm}^{2}$. O fator de thinning utilizado foi $10^{-5}$, o peso máximo $10^{6}$, e os limiares de energia $0.1 \mathrm{MeV}$ para elétrons e fótons, $0.3 \mathrm{MeV}$ para hádrons e $0.7 \mathrm{MeV}$ para múons. Esses parâmetros são os mesmos que foram utilizados para a criação de uma parametrização do missing energy por Barbosa et al[64], utilizada na análise. Cada um destes chuveiros foi utilizado múltiplas vezes.

A partir da simulação da detecção e reconstrução de chuveiros atmosféricos de determinada energia $E_{0}$, e da subseqüente aplicação de cortes, obtém-se o espectro de energias reconstruídas $E_{r e c}$. A distribuição de erros na energia reconstruída (EED) pode então ser obtida. O erro $\epsilon$ na energia é definido como:

$$
\epsilon=\frac{\left(E_{r e c}-E_{0}\right)}{E_{0}} .
$$

A figura 2.4 mostra a EED para chuveiros de prótons de $10^{19.5} \mathrm{eV}$ após nossa simulação do telescópio HiRes-II, seguida da reconstrução e aplicação dos cortes. Para comparação, foram ajustadas uma Gaussiana e uma Lognormal à parte central da EED. Da figura fica claro que nenhuma dessas funções descreve bem a EED de fluorescência.

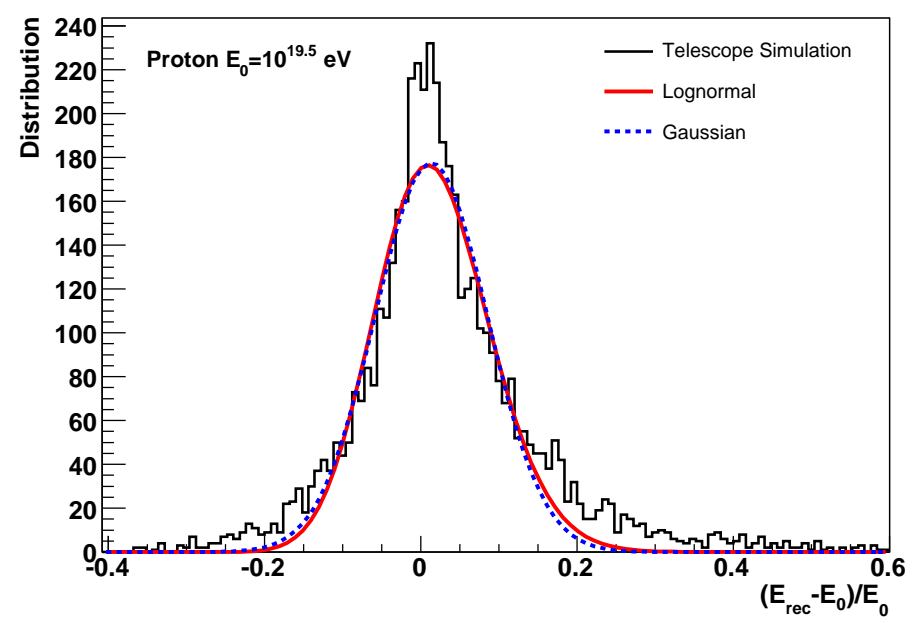

Figura 2.4: EED obtida de nossa simulação do telescópio HiRes-II. Um ajuste Gaussiano e um Lognormal à parte central da distribuição também é mostrado. 
As EEDs obtidas possuem algumas características interessantes: são assimétricas, com caudas para energias maiores, e essa assimetria depende da energia do chuveiro. A figura 2.5 mostra as EEDs obtidas de nossas simulações para chuveiros gerados a partir de prótons de energia $E_{0}=10^{19} \mathrm{eV}$ e $E_{0}=10^{20} \mathrm{eV}$ para os telescópios HiRes-II e Auger, enquanto que a figura 2.6 mostra o skewness em função da energia para as EEDs obtidas de nossas simulações do HiRes-II e Auger. O skewness é uma medida da assimetria da distribuição. Utilizando esse ferramental, investigamos a influência das EEDs de detetores de fluorescência no espectro dos UHECR[6].
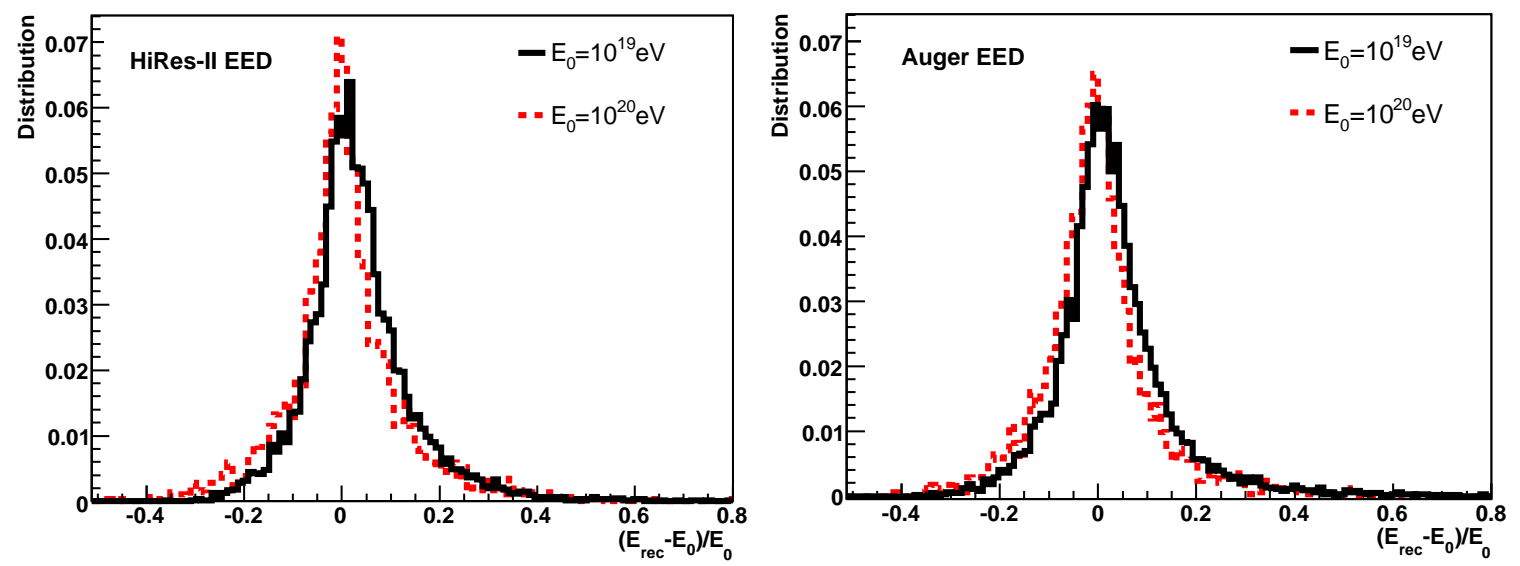

Figura 2.5: Figura extraída de nosso artigo [6] mostrando EEDs obtidas para chuveiros gerados a partir de prótons de energia $E_{0}=10^{19} \mathrm{eV}$ e $E_{0}=10^{20} \mathrm{eV}$ para os telescópios HiRes-II e Auger. 


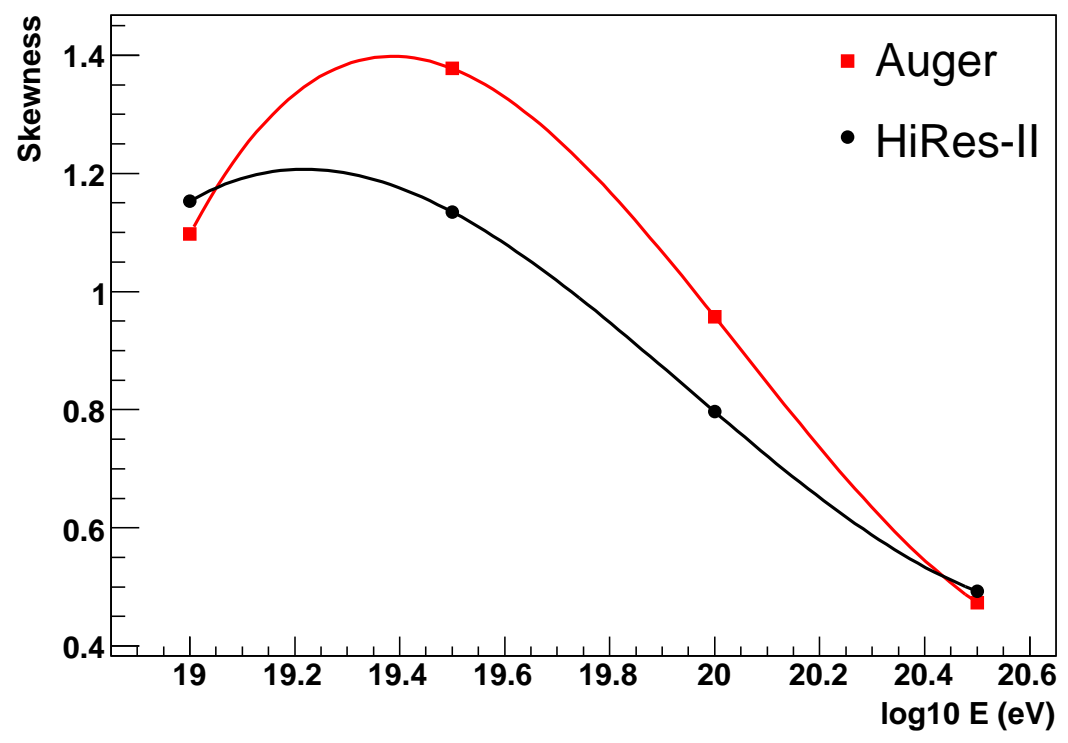

Figura 2.6: Skewness em função da energia para as EEDs obtidas de nossas simulações do HiResII e Auger. Figura extraída de nosso artigo[6] 


\section{Capítulo 3}

\section{Simulação de EAS produzidos por}

\section{uhecrons}

Como discutido anteriormente, um dos objetivos deste trabalho é simular EAS produzidos por uhecrons. Para isto fez-se necessário alterar códigos Monte Carlo de simulação de EAS, bem como modelos hadrônicos. Para fixar o viés devido a diferenças nos modelos hadrônicos, utilizaremos sempre nesse trabalho o Aires em conjunto com o Sibyll para gerar chuveiros iniciados por uhecrons.

A seção 3.0.3 descreve as alterações efetuadas no pacote Sibyll para a inclusão do uhecron, enquanto que a seção 3.0.4 descreve as mudanças no pacote Aires.

\subsubsection{Interações do UHECRON e alterações no Sibyll}

Neste trabalho utilizamos a mesma definição abrangente de uhecron que Albuquerque, Kolb e Farrar[2], isto é, uma partícula composta por um "quark" pesado (doravante denominado $Q$ ) de massa $M$, rodeado por dois quarks leves, estes últimos responsáveis pela interação com a matéria normal. Para incluir as interações do uhecron com partículas usuais, o gerador de eventos Sibyll[7] foi alterado. Uma nova partícula, o uhecron, e um novo "quark", o $Q$, foram incluídos e várias alterações nos algoritmos foram implementadas. Nas seções seguintes descrevemos as alterações principais. 


\section{Seção de choque e massa do UHECRON}

O uhecron não é uma partícula específica, mas uma classe genérica de partículas estáveis, neutras e com um núcleo massivo, suficientemente genérica para englobar partículas previstas por vários modelos além do SM. Nossas alterações no Sibyll foram testadas para massas do uhecron entre $M_{U}=10$ e $50 \mathrm{GeV}$.

A maior contribuição para a seção de choque uhecron-nucleon $\sigma_{U N}$ é devida aos quarks leves que rodeiam o quark pesado. Desse modo, assumimos que essa seção de choque uhecron-nucleon é igual à seção de choque píon-nucleon, ou seja:

$$
\sigma_{U N}=\sigma_{\pi N}
$$

Essa seção de choque mais baixa tem uma grande repercussão no desenvolvimento e flutuação do chuveiro, entre outros motivos porque leva a um caminho livre médio mais longo para interações uhecron-ar. Assim, o número médio de interações de um uhecron durante o desenvolvimento do chuveiro é menor, se comparado ao de um próton.

\section{Funções de estrutura e fragmentação}

Devido à grande massa do quark pesado, os quarks leves, que são os principais responsáveis pela interação com a matéria, carregam apenas uma pequena fração da energia total do uhecron. Desse modo, a energia disponível para as interações é muito menor que no caso de um hádron usual de mesma energia, levando a interações com características diferentes.

Para a criação de cordas QCD durante a interação, o uhecron incidente deve ser quebrado em um quark e um diquark. Assim, quando da quebra do uhecron, as seguintes combinações quark-diquark podem ser criadas: $Q+q q$ e $Q q+q$. No Sibyll, a fração de energia da partícula que é carregada pelo constituinte quark é dada pela função de

estrutura (eq. 1.32). Como a fração da energia do uhecron carregada pelo quark Q deve ser muito maior que a carregada pelos quarks leves, a função de estrutura 1.32 deve ser 
alterada. Assim, no caso do uhecron, ao invés da função 1.32, utilizamos a função de Peterson:

$$
f_{Q}(z)=\frac{1}{z}\left[1-\frac{1}{z}-\frac{\epsilon_{Q}}{1-z}\right]^{-2},
$$

onde z é a fração da energia do uhecron que é carregada pelo seu constituinte pesado. Utilizamos essa função pois ela descreve bem os dados das interações do quark $b$, que é fenomenologicamente mais próximo a um uhecron. Para o cálculo de $\epsilon_{Q}$, utilizamos como base o valor experimental para o quark $b$ obtido pela colaboração ALEPH[65]. Como $\epsilon_{Q} \propto m_{q}^{2} / m_{Q}^{2}$, onde $m_{q}$ e $m_{Q}$ são as massas efetivas do quark leve e pesado, respectivamente, utilizamos:

$$
\epsilon_{Q}=\epsilon_{Q}^{A L E P H} \times \frac{m_{b}^{2}}{m_{Q}^{2}},
$$

onde $\epsilon_{Q}^{A L E P H}=0.003$ é o valor experimental, $m_{b}=4.7 \mathrm{GeV}$ é a massa efetiva do quark $b$ e $M_{Q}$ é a massa do componente massivo do uhecron. A figura 3.1 mostra um histograma de amostragens da função de Peterson obtido de nosso programa, e um ajuste a esse histograma. A função de Peterson possui as características desejáveis de uma função de estrutura para quarks pesados, já que tende a uma função delta para $m_{Q} \rightarrow \infty$. Assim, a maior parte da energia da partícula inicial é levada pelo quark $Q$. No caso da quebra do uhecron em $Q q+q$, o valor de $z$ amostrado é a fração de energia levada pelo diquark $Q q$, que contém o quark pesado.

Após a formação da corda QCD, esta é "esticada" da maneira usual e é posteriormente quebrada, levando à formação de um par $q-\bar{q}$ ou $q q-\bar{q} \bar{q}$. Embora o quark pesado $Q$ tenha sido incluído no Sibyll, sua criação quando da produção desses pares quark anti-quark (ou diquark anti-diquark) não ocorre em interações na atmosfera. Isso automaticamente inibe a produção de outros uhecrons durante a interação. Assim, durante toda a simulação da interação, existe apenas um quark $Q$ e, conseqüentemente, apenas um uhecron. Após a criação desse par, uma das extremidades da corda irá ha- 


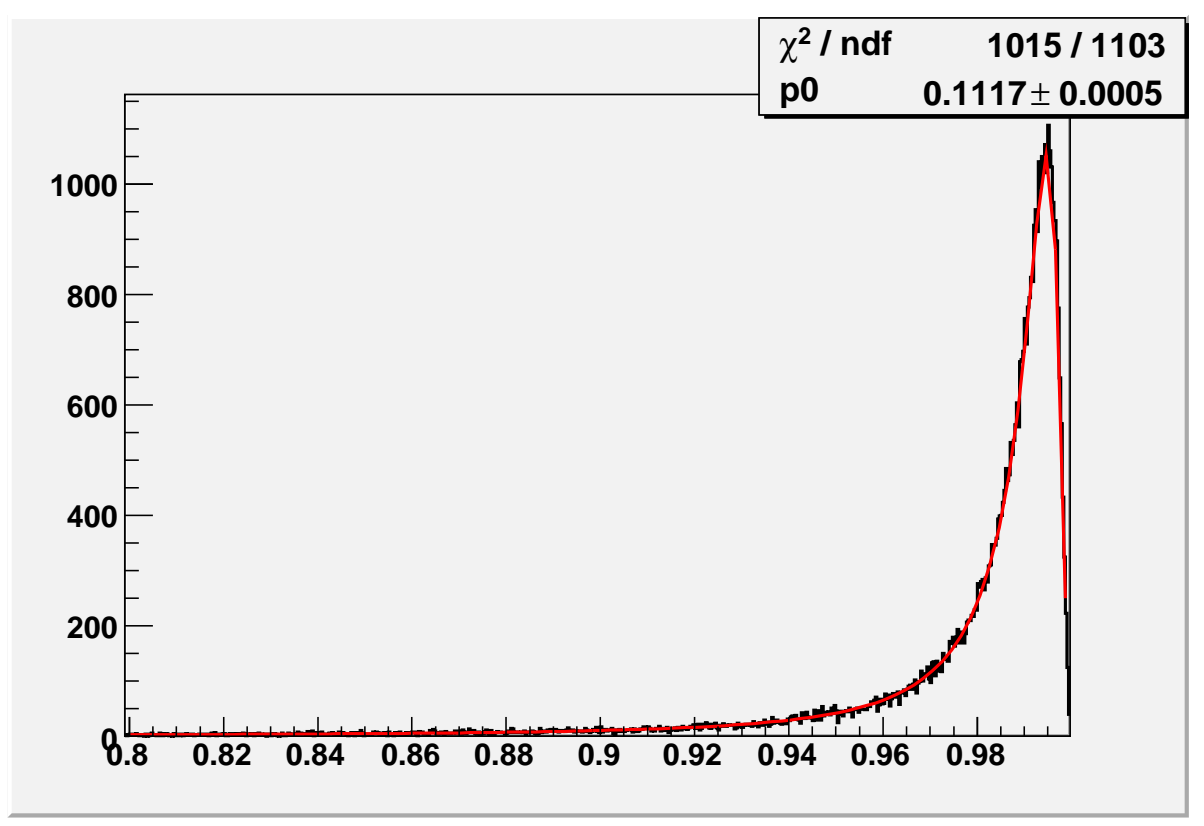

Figura 3.1: Amostragens e ajuste da função de Peterson, obtidas de nosso programa, para $\epsilon_{Q}=2.65 \times 10^{-5}$, valor esse utilizado para $M_{U}=50 \mathrm{GeV}$.

dronizar uma partícula, que será a combinação do sabor nessa ponta da corda com o sabor do (di)quark $q(q q)$ ou $\bar{q}(\bar{q} \bar{q})$ gerado. A fração da energia $z$ do quark pai que é levada por essa partícula formada é usualmente dada pela função de fragmentação de Lund (eq. 1.35). Porém, no caso de uma extremidade que contém o quark pesado $Q$ proveniente do uhecron, também utilizamos a função de Peterson como função de fragmentação. Assim, a partícula formada que contém o quark pesado $Q$, que neste caso é a leading particle, irá levar a maior parte da energia desse quark $Q$, que por sua vez é a maior parte da energia da corda QCD (devido à amostragem da mesma função de Peterson como função de estrutura para esse $Q$ ). Com isso, a inelasticidade do uhecron é fortemente atenuada, ou seja, o uhecron perde muito menos energia por interação que um hádron normal. Desse modo, o desenvolvimento de um chuveiro iniciado por um uhecron deve ser mais lento se comparado com um chuveiro iniciado por um próton.

A massa do uhecron também altera a inelasticidade dos processos de interação. Quanto maior for a massa do uhecron, e conseqüentemente a massa de $Q$, menor será a inelasticidade das interações e mais lento o desenvolvimento do EAS. Isso se deve ao 
fato da função de Peterson (eq. 3.1) se tornar mais dura para valores maiores de $M_{Q}$. Assim, quanto maior a massa do $Q$, maior será a fração da energia do uhecron que ele carregará consigo, tanto na criação da corda, quanto na hadronização do uhecron.

Uma outra diferença em relação ao algoritmo usual do Sibyll é que no caso de uma corda QCD que contém o $Q$ proveniente do uhecron, somente a partícula formada que carrega o $Q$ é considerada leading, e sua fração de energia será amostrada da função de Peterson. Todas outras partículas geradas por essa corda utilizarão a função de fragmentação usual, ou seja, a função de Lund (1.35).

A figura 3.2 mostra um esquema do desenvolvimento de duas cordas: uma contendo o quark massivo $Q$ do uhecron, e outra seguindo os procedimentos usuais do Sibyll.

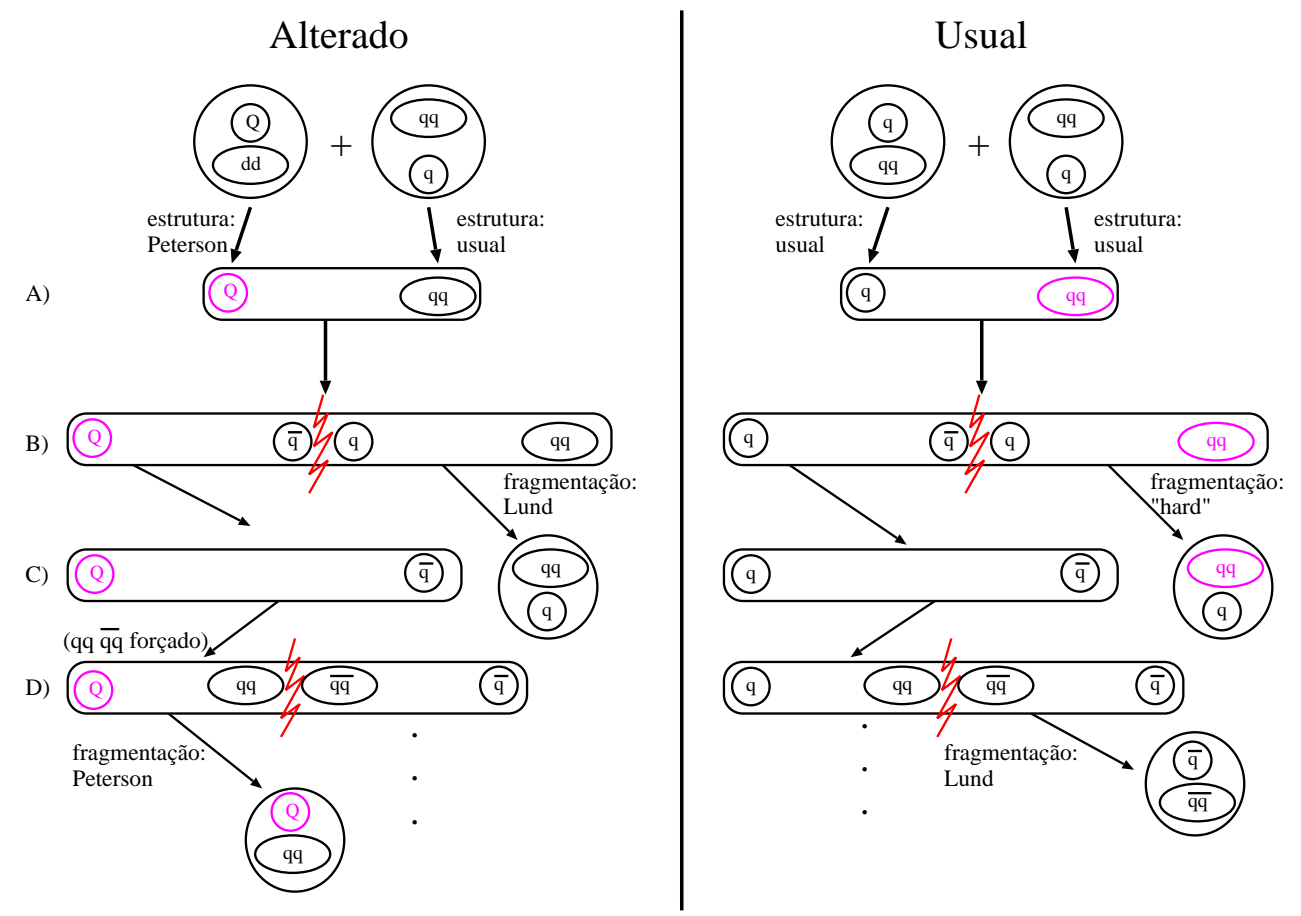

Figura 3.2: Esquema da criação e desenvolvimento da corda QCD no caso usual e no caso do uhecron.

\section{Eventos difrativos e produção de minijets}

Algumas alterações foram implementadas no caso de eventos difrativos. A difração backwards (alvo) foi desabilitada para o uhecron, devido à sua massa. Porém, as outras 
partículas ainda podem sofrer esse tipo de difração. A massa mínima do estado excitado $X$ também foi aumentada de acordo com a massa $M_{U}$ do uhecron. Embora no algoritmo original do Sibyll o estado excitado possa decair ou se quebrar de três maneiras diferentes, dependendo de sua massa, no caso do uhecron forçamos a quebra do estado excitado através da produção de uma corda composta pelos componentes do uhecron. Essa corda se estica e se quebra da maneira usual. Esse tipo de quebra é a usualmente utilizada no caso de um estado excitado $X$ de grande massa, que é o caso do uhecron.

Uma última modificação foi feita na parte "hard" da seção de choque, quando o momento transferido é grande e usualmente há a produção de minijets. No caso do uhecron, inibimos a produção de minijets já que, como vimos, o uhecron sempre interage com baixa energia. Por outro lado, minijets ainda podem ser produzidos pelos hádrons "normais" criados a partir das interações do uhecron.

\subsubsection{Alterações no Aires}

Para a simulação de EAS usamos o Aires (AIR shower Extended Simulation)[8, 66], alterando-o para incluir o uhecron. Estas alterações são bem mais simples e diretas do que as do Sibyll. Ao incluírmos o uhecron, tomamos a seção de choque uhecron-núcleo como sendo igual à seção de choque píon-núcleo, levando a um caminho livre médio (mfp) maior. Dado que o Aires calcula o mfp de determinada partícula a determinada energia através da utilização de parametrizações de resultados obtidos de modelos hadrônicos, como o Sibyll, no caso do uhecron utilizamos a parametrização dos resultados obtidos para píons. Como o uhecron é neutro, não foi necessário alterar o tratamento de interações eletromagnéticas do Aires. 


\section{Capítulo 4}

\section{Resultados e Análise}

Neste capítulo descrevemos a análise dos chuveiros e os métodos desenvolvidos para separar uhecrons das partículas usuais, utilizando o método FD.

A seção 4.1 compara as características dos chuveiros iniciados por uhecrons com chuveiros iniciados por partículas usuais, especialmente prótons. Na seção 4.2 descrevemos métodos para a detecção de sinais de uhecrons em observatórios de UHECR, baseados nas diferenças encontradas entre chuveiros exóticos e normais, incluindo os efeitos de detecção e reconstrução de eventos.

\subsection{Características de chuveiros iniciados por uhecrons.}

As interações do uhecron na atmosfera são diferentes das interações de hádrons normais. Como essas interações regem o desenvolvimento do chuveiro, EAS iniciados por uhecrons terão características distintas dos produzidos por partículas usuais. Nas seções seguintes descreveremos essas características.

Inicialmente, analisamos os chuveiros obtidos diretamente dos pacotes Aires e Sibyll por nós alterados para a simulação de EAS produzidos por uhecrons, sem a inclusão de qualquer efeito de deteç̧ão e reconstrução de eventos. Esta primeira análise mostrará as características físicas intrínsecas dos chuveiros iniciados por uhecrons e como estas 
diferem das características de chuveiros iniciados por partículas usuais.

Em seguida, mostramos as características físicas detectáveis de chuveiros iniciados por uhecrons, após a simulação completa do processo de detecção e reconstrução de eventos pelo método de fluorescência. Analisaremos como as características intrínsecas dos chuveiros iniciados por uhecrons são alteradas pelo processo de detecção e reconstrução e como esses chuveiros observados diferem de EAS iniciados por partículas usuais.

Como vimos no capítulo 3, a inelasticidade das interações do uhecron é muito menor se comparada com a de prótons, e devido à sua seção de choque menor, o número médio de interações do uhecron durante o desenvolvimento do chuveiro também é menor. Com isso, o desenvolvimento de chuveiros iniciados por uhecrons deve ser mais lento e ter flutuações maiores que chuveiros iniciados por prótons.

Para evitar o viés devido a diferentes modelos hadrônicos, nossos resultados são obtidos sempre comparando o uhecron com prótons ou outras partículas usuais, sendo todos gerados com a combinação Aires/Sibyll. Os chuveiros foram gerados utilizando os seguintes parâmetros:

- Ângulo zenital de $60^{\circ}$.

- Thinning relativo de $10^{-5}$ com fator peso 12 (default).

- Injeção da partícula primária a $100 \mathrm{~km}$ de altitude.

- Amostragem do perfil a cada $5 \mathrm{~g} / \mathrm{cm}^{2}$ de profundidade atmosférica vertical, entre $5 \mathrm{~g} / \mathrm{cm}^{2}$ e $1295 \mathrm{~g} / \mathrm{cm}^{2}$.

- Energias de corte de $200 \mathrm{keV}$ para elétrons e gamas, $1 \mathrm{MeV}$ para múons, $1.5 \mathrm{MeV}$ para mésons e $125 \mathrm{MeV}$ para nucleons.

\subsubsection{Características intrínsecas de EAS iniciados por uhecrons.}

Nesta seção analisamos as características intrínsecas dos chuveiros simulados, sem a inclusão de quaisquer efeitos de detecção e reconstrução dos eventos. Nossos resultados 
para chuveiros usuais (próton, Fe, etc.), obtidos a partir de nossas versões alteradas do Aires/Sibyll, foram comparados com resultados obtidos das versões inalteradas e, como esperado, obtivemos os mesmos resultados. Nossos resultados para chuveiros iniciados por uhecrons também são compatíveis com os resultados obtidos por Albuquerque, Farrar e Kolb[2].

\section{Perfil Longitudinal}

Para a análise dos perfis longitudinais, foram efetuadas simulações com primários de energia $E=320 \mathrm{EeV}, E=100 \mathrm{EeV}$ e $E=50 \mathrm{EeV}$. As partículas primárias utilizadas foram núcleos de Ferro, prótons e uhecrons com massas $M_{U}=20 \mathrm{GeV}, M_{U}=30 \mathrm{GeV}$ e $M_{U}=50 \mathrm{GeV}$. Para cada energia e partícula foram gerados 500 chuveiros.

O perfil longitudinal médio das partículas carregadas, obtido diretamente do Aires $/$ Sibyll $^{1}$, foi ajustado com a funções Gaisser-Hillas com $\lambda$ variável:

$$
N(X)=N_{\max }\left(\frac{X-X_{0}}{X_{\max }-X_{0}}\right)^{\frac{\left(X_{\max }-X_{0}\right)}{\lambda_{0}+\lambda_{1} X+\lambda_{2} X^{2}}} \exp \left[\frac{\left(X_{\max }-X\right)}{\lambda_{0}+\lambda_{1} X+\lambda_{2} X^{2}}\right]
$$

onde $N_{\max }$ é o número de partículas carregadas no máximo do chuveiros e $X_{\max }$ é a profundidade atmosférica desse máximo. Os valores de $N_{\max }$ e $X_{\max }$ obtidos estão nas tabelas $4.1,4.2$ e 4.3 .

\begin{tabular}{|c|c|c|}
\hline partícula & $N_{\max }\left(\times 10^{11}\right)$ & $X_{\max }\left(\right.$ slant $\left.\mathrm{g} / \mathrm{cm}^{2}\right)$ \\
\hline Ferro & 2.34 & 797.1 \\
\hline próton & 2.23 & 897.6 \\
\hline uhecron $\left(M_{U}=20 \mathrm{GeV}\right)$ & 1.94 & 997.7 \\
\hline uhecron $\left(M_{U}=30 \mathrm{GeV}\right)$ & 1.92 & 1005.3 \\
\hline uhecron $\left(M_{U}=50 \mathrm{GeV}\right)$ & 1.85 & 1021.5 \\
\hline
\end{tabular}

Tabela 4.1: Valores de $N_{\max }$ e $X_{\max }$ obtidos do ajuste de funções GH aos perfis longitudinais dos primários de energia $E=320 \mathrm{EeV}$.

A figura 4.1 mostra os perfis longitudinais ${ }^{2}$ médios para chuveiros de energias $E=$

\footnotetext{
${ }^{1}$ Tabela 1291 do Aires.

${ }^{2}$ Veja a seção 1.2 para uma definição de profundidade atmosférica slant.
} 


\begin{tabular}{|c|c|c|}
\hline partícula & $N_{\max }\left(\times 10^{10}\right)$ & $X_{\max }\left(\right.$ slant $\left.\mathrm{g} / \mathrm{cm}^{2}\right)$ \\
\hline Ferro & 7.35 & 767.0 \\
\hline próton & 7.11 & 866.2 \\
\hline uhecron $\left(M_{U}=20 \mathrm{GeV}\right)$ & 6.20 & 967.7 \\
\hline uhecron $\left(M_{U}=30 \mathrm{GeV}\right)$ & 5.96 & 981.4 \\
\hline uhecron $\left(M_{U}=50 \mathrm{GeV}\right)$ & 5.91 & 988.2 \\
\hline
\end{tabular}

Tabela 4.2: Valores de $N_{\max }$ e $X_{\max }$ obtidos do ajuste de funções GH aos perfis longitudinais dos primários de energia $E=100 \mathrm{EeV}$.

\begin{tabular}{|c|c|c|}
\hline partícula & $N_{\max }\left(\times 10^{10}\right)$ & $X_{\max }\left(\right.$ slant $\left.\mathrm{g} / \mathrm{cm}^{2}\right)$ \\
\hline Ferro & 3.68 & 749.4 \\
\hline próton & 3.58 & 852.1 \\
\hline uhecron $\left(M_{U}=20 \mathrm{GeV}\right)$ & 3.06 & 953.6 \\
\hline uhecron $\left(M_{U}=30 \mathrm{GeV}\right)$ & 3.00 & 967.4 \\
\hline uhecron $\left(M_{U}=50 \mathrm{GeV}\right)$ & 2.90 & 977.6 \\
\hline
\end{tabular}

Tabela 4.3: Valores de $N_{\max }$ e $X_{\max }$ obtidos do ajuste de funções GH aos perfis longitudinais dos primários de energia $E=50 \mathrm{EeV}$.

$320 \mathrm{EeV}$. Pode-se observar que tanto $N_{\max }$ quanto $X_{\max }$ são diferentes para diferentes partículas. O desenvolvimento de chuveiros iniciados por núcleos de Ferro é mais rápido que os de chuveiros iniciados por prótons de mesma energia. Assim, o máximo de EAS iniciados por Ferro se dá mais alto na atmosfera, levando a um $X_{\max }$ menor e um $N_{\max }$ maior, já que este deve depositar aproximadamente a mesma quantidade de energia em um intervalo menor de profundidade atmosférica. Do mesmo modo, como chuveiros iniciados por uhecrons apresentam um desenvolvimento mais lento que chuveiros iniciados por prótons, EAS iniciados por uhecrons apresentam um $X_{\max }$ mais profundo e um $N_{\max }$ menor do que os iniciados por prótons.

A figura 4.2 mostra os perfis longitudinais médios de energias $E=100 \mathrm{EeV} \mathrm{e}$ $E=50 \mathrm{EeV}$. Observa-se que, embora tanto o $X_{\max }$ quanto o $N_{\max }$ sejam menores para energias menores do primário, a relação entre esses parâmetros e a velocidade do desenvolvimento do chuveiro, dada pelo tipo de partícula primária, continua inalterada. Como os chuveiros iniciados por uhecrons se aproximam mais dos chuveiros iniciados por prótons que os por ferro, a maior parte das figuras comparativas a seguir incluirá 


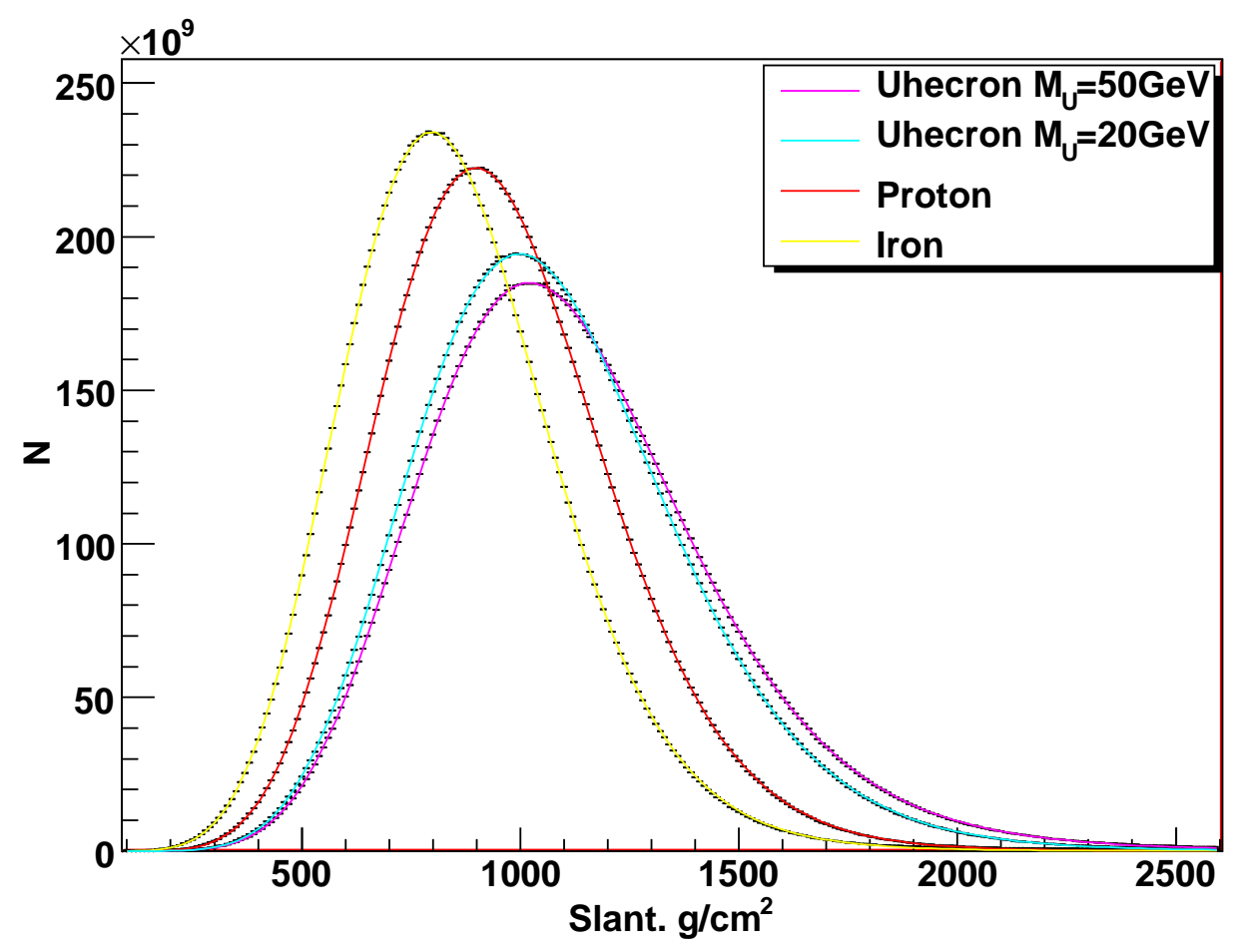

Figura 4.1: Perfis longitudinais médios de 500 chuveiros iniciados por cada tipo de partícula com energia $E=320 \mathrm{EeV}$ : Ferro, prótons, e uhecrons com massas de $50 \mathrm{GeV}$ e $20 \mathrm{GeV}$. Os valores de $N_{\max }$ e $X_{\max }$ podem ser vistos na tabela 4.1.
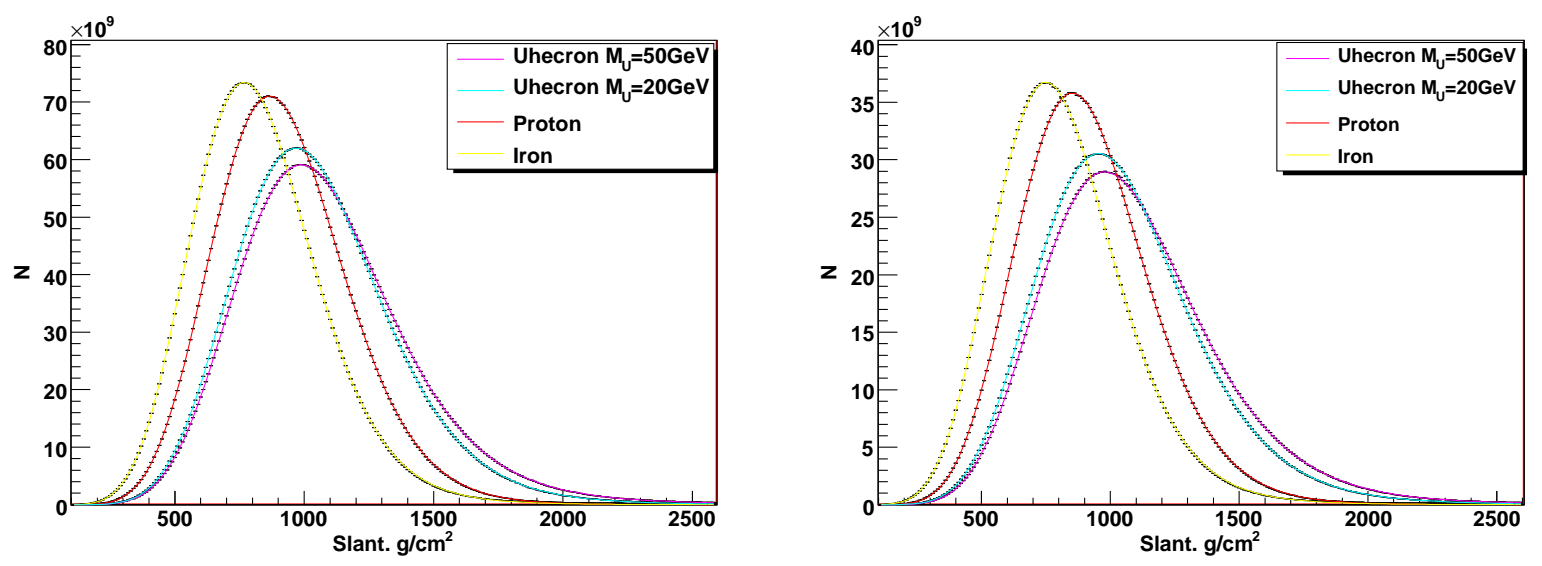

Figura 4.2: Perfis longitudinais médios de 500 chuveiros iniciados por ferro, prótons, e uhecrons com massas de $50 \mathrm{GeV}$ e $20 \mathrm{GeV}$ de energia $E=100 \mathrm{EeV}$ (esquerda) e $E=50 \mathrm{EeV}$ (direita). Os valores de $N_{\max }$ e $X_{\max }$ podem ser vistos nas tabelas $4.2 \mathrm{e}$ 4.3 . 
apenas prótons e uhecrons.

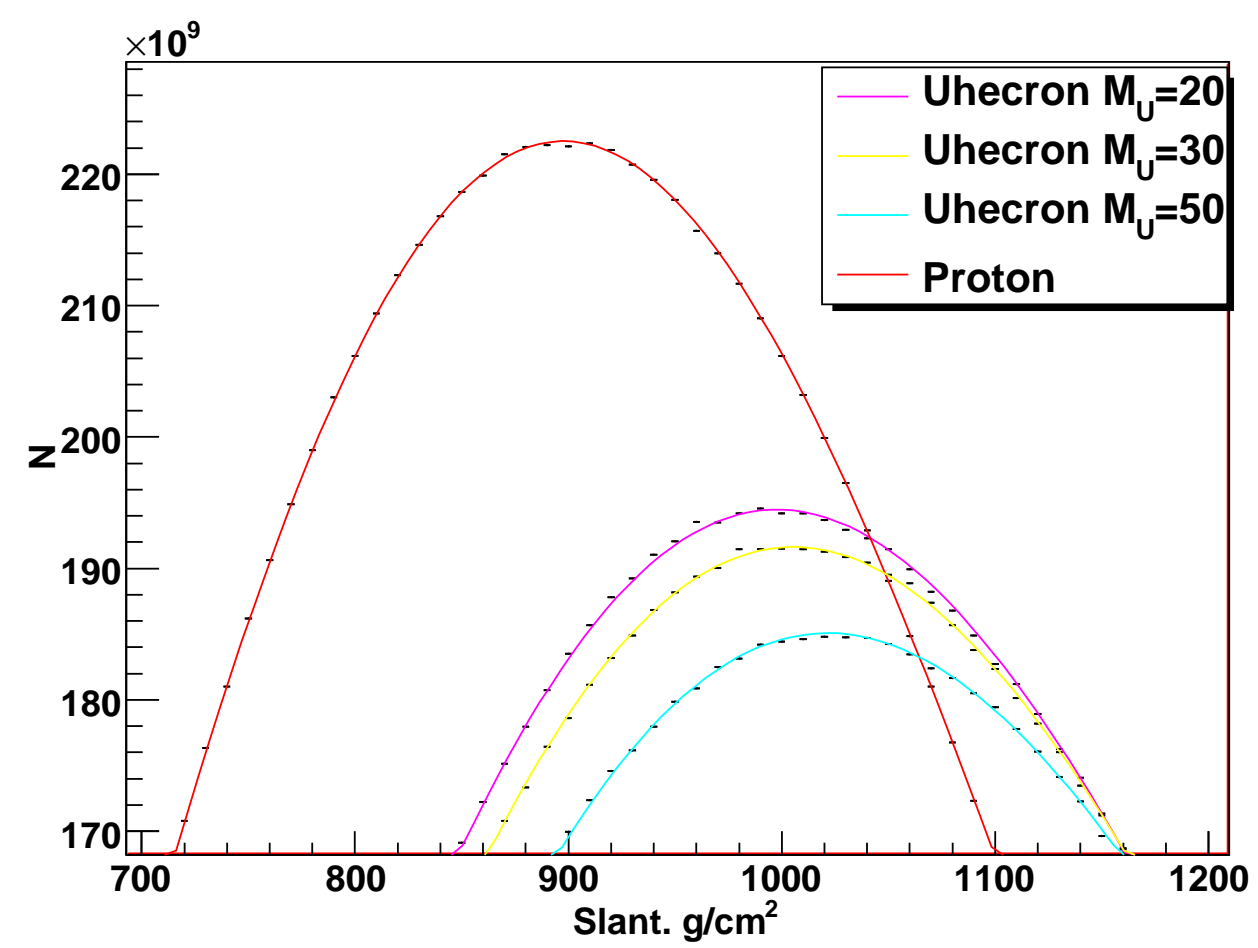

Figura 4.3: Região de $X_{\max }$ dos perfis longitudinais médios de 500 chuveiros iniciados por prótons e uhecrons com massas de $50 \mathrm{GeV}$, 30 GeV e $20 \mathrm{GeV}$ de energia $\mathrm{E}=320 \mathrm{EeV}$. Os valores de $N_{\max }$ e $X_{\max }$ podem ser vistos na tabela 4.1.

A figura 4.3 mostra uma região de $X_{\max }$ dos perfis longitudinais médios de 500 chuveiros iniciados por prótons e uhecrons de energia $E=320 \mathrm{EeV}$. Pode-se observar que a massa do uhecron altera as características do desenvolvimento do chuveiro. Massas maiores levam a desenvolvimentos mais lentos e, conseqüentemente, a $X_{\max }$ maiores e $N_{\max }$ menores, já que uhecrons mais massivos levam a interações de mais baixa energia, retardando o desenvolvimento do chuveiro. Isso se deve à função de estrutura (e fragmentação) mais dura no caso de uhecrons, a função de Peterson (eq. 3.1).

Embora o perfil longitudinal médio possa nos dar uma visão do comportamento médio do desenvolvimento dos chuveiros iniciados por determinada partícula, ele não pode nos fornecer informação das flutuações chuveiro a chuveiro. Para isso, fez-se necessária a análise do perfil de cada chuveiro simulado, separadamente. As figuras 4.4 e 4.5 
mostram as distribuições de $X_{\max }$ e $N_{\max }{ }^{3}$. Pode-se observar que as flutuações nos chuveiros iniciados por uhecrons são muito maiores que as dos iniciados por prótons. Como discutido no capítulo 3, a inelasticidade das interações do uhecron é menor e seu caminho livre médio é maior, se comparados aos do próton, levando não somente a um desenvolvimento mais lento do chuveiro, mas também a flutuações maiores nesse desenvolvimento.
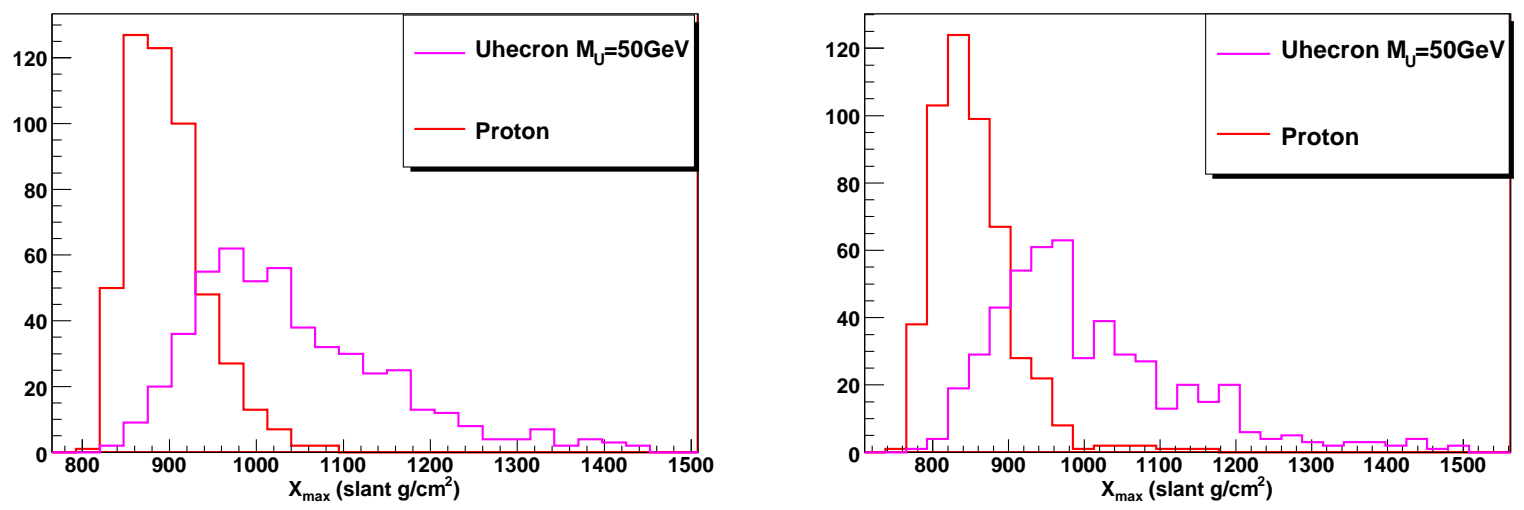

Figura 4.4: Distribuições de $X_{\max }$ obtidos diretamente do Aires para chuveiros iniciados por prótons e uhecrons de massa $M_{U}=50 \mathrm{GeV}$ de energias $E_{0}=320 \mathrm{EeV}$ (esquerda) e $E_{0}=50 \mathrm{EeV}$ (direita). Os valores do RMS das distribuições podem ser vistos na tabela 4.4 .

\begin{tabular}{|c|c|c|c|}
\hline partícula & $E_{0}=320 \mathrm{EeV}$ & $E_{0}=100 \mathrm{EeV}$ & $E_{0}=50 \mathrm{EeV}$ \\
\hline próton & 44.9 & 51.0 & 54.4 \\
\hline uhecron $\left(M_{U}=20 \mathrm{GeV}\right)$ & 86.8 & 89.5 & 101.0 \\
\hline uhecron $\left(M_{U}=30 \mathrm{GeV}\right)$ & 99.1 & 105.4 & 113.2 \\
\hline uhecron $\left(M_{U}=50 \mathrm{GeV}\right)$ & 114.9 & 112.1 & 129.8 \\
\hline
\end{tabular}

Tabela 4.4: Valores do RMS (slant $\mathrm{g} / \mathrm{cm}^{2}$ ) das distribuições de $X_{\max }$ para várias energias e partículas.

Um outro fator que pode contribuir para a maior dispersão dos valores de $X_{\max }$ e $N_{\max }$ no caso do uhecron é o ajuste da função Gaisser-Hillas. Devido a suas características distintas, os chuveiros iniciados por uhecrons podem apresentar uma forma ligeiramente diferente dos chuveiros iniciados por partículas usuais e assim não ser tão

\footnotetext{
${ }^{3}$ Tabela 5501 do Aires
} 

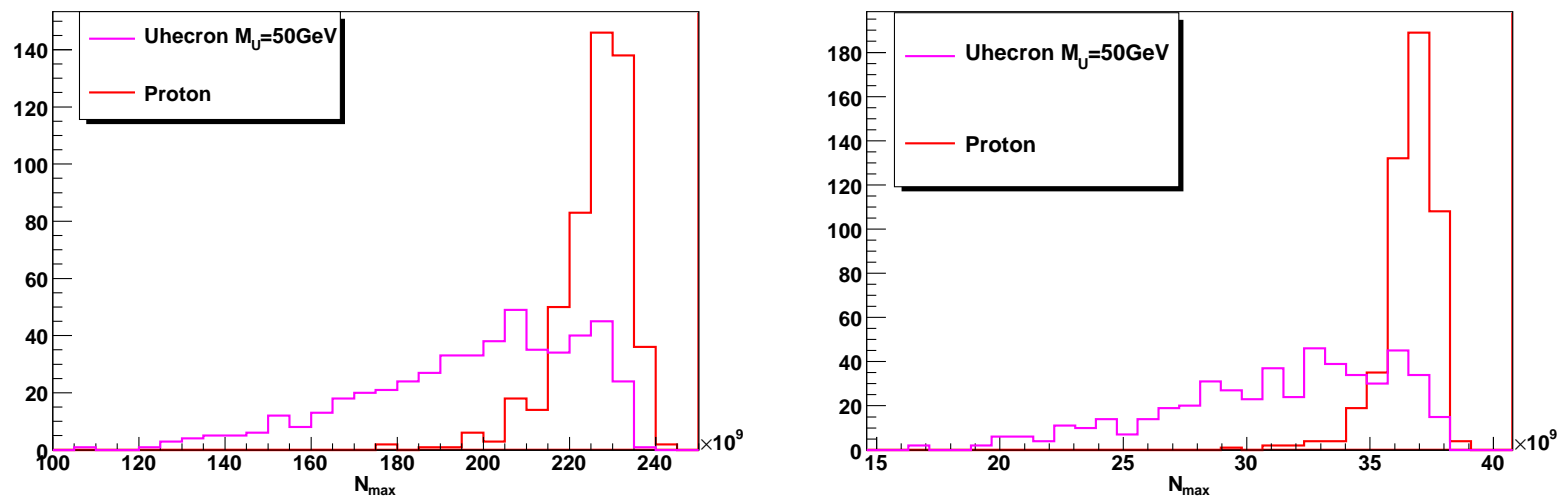

Figura 4.5: Distribuições de $N_{\max }$ obtidos diretamente do Aires para chuveiros iniciados por prótons e uhecrons de massa $M_{U}=50 \mathrm{GeV}$ de energias $E_{0}=320 \mathrm{EeV}$ (esquerda) e $E_{0}=50 \mathrm{EeV}$ (direita). Os valores do RMS das distribuições podem ser vistos na tabela 4.5.

\begin{tabular}{|c|c|c|c|}
\hline partícula & $E_{0}=320 \mathrm{EeV}$ & $E_{0}=100 \mathrm{EeV}$ & $E_{0}=50 \mathrm{EeV}$ \\
\hline próton & $8.60 \times 10^{9}$ & $2.14 \times 10^{9}$ & $1.11 \times 10^{9}$ \\
\hline uhecron $\left(M_{U}=20 \mathrm{GeV}\right)$ & $2.05 \times 10^{10}$ & $6.74 \times 10^{9}$ & $3.86 \times 10^{9}$ \\
\hline uhecron $\left(M_{U}=30 \mathrm{GeV}\right)$ & $2.18 \times 10^{10}$ & $7.74 \times 10^{9}$ & $4.15 \times 10^{9}$ \\
\hline uhecron $\left(M_{U}=50 \mathrm{GeV}\right)$ & $2.52 \times 10^{10}$ & $8.35 \times 10^{9}$ & $4.51 \times 10^{9}$ \\
\hline
\end{tabular}

Tabela 4.5: Valores do RMS das distribuições de $N_{\max }$ para várias energias e partículas.

bem representado pela função GH, levando a ajustes piores que, por sua vez, levam a uma dispersão maior dos valores ajustados. Esse ponto será discutido em mais detalhes na seção 4.1.2, quando analisaremos a influência dos processos de detecção e reconstrução de eventos nos observáveis dos EAS.

\section{Distribuição Lateral}

Embora o foco desta tese seja nas características de EAS observados por detetores de fluorescência, nessa seção comparamos algumas características dos chuveiros de uhecrons no solo com chuveiros iniciados por partículas usuais. Embora não entremos nos detalhes da detecção das partículas no solo, mostramos algumas diferenças na distribuição lateral que, a princípio, poderiam ser detectadas por detetores de superfície.

A distribuição lateral das partículas no solo depende da "idade" do chuveiro no solo. 
A figura 4.6 mostra o perfil longitudinal médio dos 500 chuveiros verticais utilizados para o estudo da distribuição lateral de partícula no solo para ferro, prótons e uhecrons de energia $E_{0}=320 \mathrm{EeV}$ e $E_{0}=50 \mathrm{EeV}$. O final do gráfico coincide com a profundidade atmosférica $X \cong 865 \mathrm{~g} / \mathrm{cm}^{2}$ do solo no Observatório Pierre Auger. Pode-se observar que para $E_{0}=320 E e V$ apenas o Ferro atingiu seu máximo desenvolvimento, enquanto que para $E_{0}=50 \mathrm{EeV}$ os prótons atingem o máximo pouco antes do solo. Por outro lado, os EAS iniciados por uhecrons, com seu desenvolvimento mais lento, não atingem o máximo antes do solo em nenhum dos casos. Vale lembrar que no caso de chuveiros inclinados, a profundidade atmosférica (slant) do solo aumenta com o ângulo zenital $\theta$, logo chuveiros inclinados se desenvolverão mais que os seus equivalentes verticais antes de atingirem o solo.
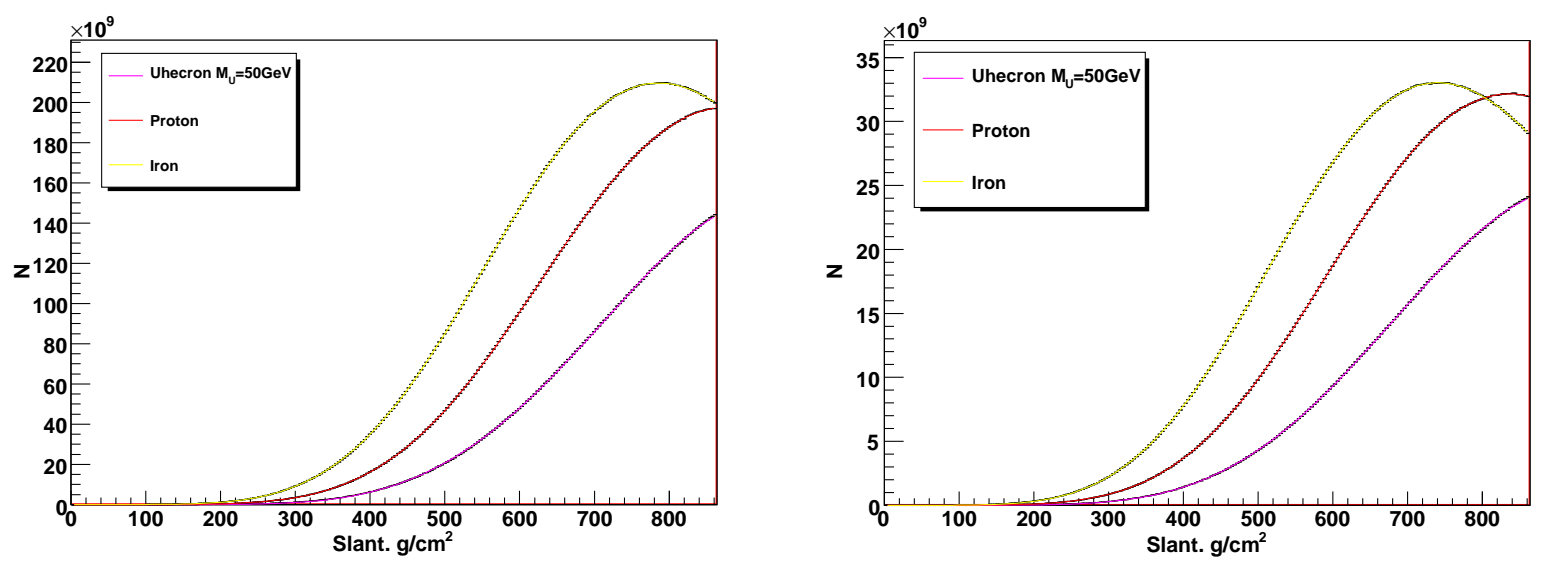

Figura 4.6: Perfil longitudinal médio dos 500 chuveiros verticais utilizados para o estudo da distribuição lateral de partículas no solo para ferro, prótons e uhecrons de energia $E_{0}=320 \mathrm{EeV}$ (esquerda) e $E_{0}=50 \mathrm{EeV}$ (direita). O final do gráfico coincide com a profundidade atmosférica $X \cong 865 \mathrm{~g} / \mathrm{cm}^{2}$ do solo no Observatório Pierre Auger.

Como discutido anteriormente na seção 1.2, a razão entre as componentes EM e muônica do chuveiro é fortemente dependente da composição do primário. Assim, esta razão pode, a princípio, ser utilizada em estudos de composição utilizando detetores de superfície. A figura 4.7 mostra a densidade de $e \pm$ e $\mu \pm$ no solo em função da distância ao core do chuveiro para prótons e uhecrons de energia $E_{0}=320 \mathrm{EeV}$ e $E_{0}=$ 
$50 \mathrm{EeV}$. Essas densidades foram calculadas do número de $e \pm$ e $\mu \pm$ obtidos diretamente do Aires ${ }^{4}$. Pode-se observar que o número de partículas é sistematicamente menor no caso de uhecrons, para ambas as energias estudadas. Vale lembrar também que esses resultados se restringem a apenas um caso específico, e podem ser alterados com a idade do chuveiro. Por exemplo, para chuveiros inclinados ou de mais baixa energia, que chegam mais "velhos" ao solo, os chuveiros iniciados por prótons poderiam chegar com sua componente EM já bem degradada, devido a seu desenvolvimento mais rápido se comparado a uhecrons, levando a uma inversão nos resultados aqui mostrados, para este caso específico.
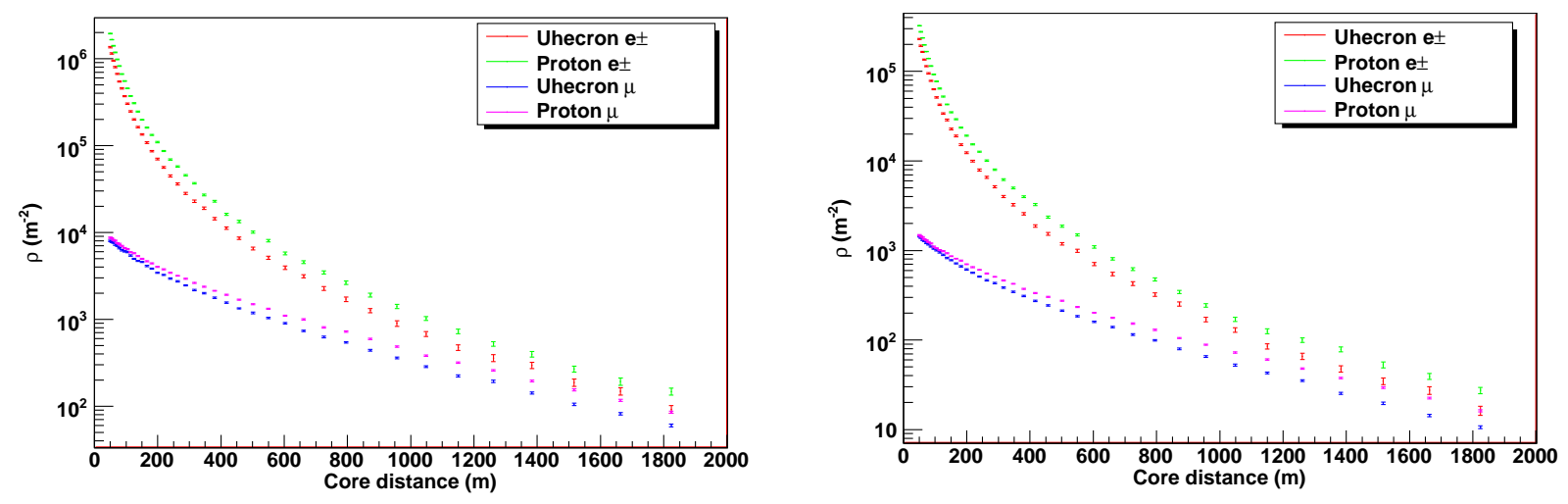

Figura 4.7: Densidade média de $e \pm$ e $\mu \pm$ no solo em função da distância ao core do chuveiro para prótons e uhecrons de energia $E_{0}=320 \mathrm{EeV}$ (esquerda) e $E_{0}=50 \mathrm{EeV}$ (direita).

Nessa seção mostramos apenas algumas características das partículas no solo para chuveiros verticais iniciados por uhecrons, prótons e ferro. Na seção 4.2 descreveremos métodos para a separação de prótons e uhecrons utilizando o FD. Devido ao baixíssimo fluxo a altíssimas energias, devemos minimizar os cortes que separam estes dois tipos de partícula, levando a uma pequena contaminação por prótons dos candidatos a uhecrons separados por esse método. Por outro lado, no caso de eventos híbridos (detectados pelo FD e SD simultaneamente), as características dos chuveiros no solo que dependem da composição do primário podem, em princípio, ser utilizadas pelo SD para diminuir a

\footnotetext{
${ }^{4}$ Tabelas 2205(e土) e 2207( $\left.\mu \pm\right)$ do Aires.
} 
contaminação de prótons na subamostra de candidatos a uhecrons obtida pelo FD.

\subsubsection{Características detectáveis de EAS iniciados por uhecrons.}

Nessa seção analisaremos como os processos de detecção e reconstrução pelo método de fluorescência alteram as características dos chuveiros iniciados por uhecrons e por partículas usuais e faremos uma comparação entre as características desses dois tipos de EAS, levando em conta esses processos.

Como vimos na seção 1.4.1, a técnica de fluorescência permite estimar o perfil longitudinal do chuveiro através da detecção de fótons de fluorescência gerados na atmosfera. Vale lembrar que a grandeza que é efetivamente medida por telescópios de fluorescência é a deposição de energia das partículas do chuveiro na atmosfera, e que essa deposição é proporcional ao número de partículas no chuveiro. Desse modo, os perfis longitudinais mostrados a partir dessa seção são perfis longitudinais de deposição de energia, ou seja, a deposição de energia $d E / d X$ em função da profundidade atmosférica $X$.

Vimos também que a energia da partícula primária é reconstruída através do ajuste de uma função Gaisser-Hillas aos pontos do perfil longitudinal obtidos pelo telescópio. Essa função é então integrada além da profundidade atmosférica do solo, obtendo-se a energia total que seria depositada em uma atmosfera que continuasse além do nível do solo. Esse método de reconstrução da energia depende fortemente do ajuste de uma função tipo GH aos dados de deposição de energia obtidos do telescópio. Inicialmente, discutiremos os efeitos desse tipo de ajuste nos observáveis dos EAS.

\section{Efeitos devido ao ajuste da função GH}

Nossas simulações da reconstrução de eventos utilizam duas funções GH diferentes: Uma com $\lambda$ variável, utilizada quando temos um perfil longitudinal completo e com muitos pontos, como os obtidos diretamente da simulação do EAS pelo Aires/Sibyll. A forma dessa função GH se molda de acordo com a forma do perfil longitudinal ao qual está sendo ajustada, já que o valor efetivo de $\lambda$ é dado por um polinômio, variando com a 
profundidade atmosférica $X$ e com os valores ajustados dos parâmetros $\lambda_{0}, \lambda_{1}$ e $\lambda_{2}$ :

$$
\left(\frac{d E}{d X}\right)(X)=\left(\frac{d E}{d X}\right)_{\max }\left(\frac{X-X_{0}}{X_{\max }-X_{0}}\right)^{\frac{\left(X_{\max }-X_{0}\right)}{\lambda_{0}+\lambda_{1} X+\lambda_{2} X^{2}}} \exp \left[\frac{\left(X_{\max }-X\right)}{\lambda_{0}+\lambda_{1} X+\lambda_{2} X^{2}}\right]
$$

A outra função GH (eq. 4.3) possui $\lambda$ fixo e é utilizada no ajuste dos pontos do perfil longitudinal parcial, ou seja, o perfil obtido da região da atmosfera que é vista pelo telescópio. Os parâmetros ajustados da função GH com $\lambda$ fixo são somente $X_{\max }$ e $(d E / d X)_{\max }$, ou seja, o ponto do máximo do perfil. Assim, a forma da função ajustada é definida somente por esse ponto de máximo.

$$
\left(\frac{d E}{d X}\right)(X)=\left(\frac{d E}{d X}\right)_{\max }\left(\frac{X-X_{0}}{X_{\max }-X_{0}}\right)^{\frac{\left(X_{\max }-X_{0}\right)}{\lambda}} \exp \left[\frac{\left(X_{\max }-X\right)}{\lambda}\right] .
$$

Embora a função com $\lambda$ variável produza ajustes de melhor qualidade (apêndice A.2.4), no sentido de um $\chi_{\text {red }}^{2}$ menor, a forma da curva ajustada é passível de grande alteração devido a flutuações locais no perfil longitudinal, levando a uma grande variação em sua integral, que é a energia calorimétrica que estamos tentando medir. Já a função função GH com $\lambda$ fixo, cuja forma é determinada somente pelos parâmetros ajustados $X_{\max }$ e $(d E / d X)_{\max }$, leva a flutuações menores na medida de energia quando temos perfis longitudinais com poucos pontos e/ou grandes incertezas ou flutuações, como é o caso dos perfis obtidos do FD. Desta forma, utilizamos a GH $\operatorname{com} \lambda$ fixo para a reconstrução dos eventos após a simulação do telescópio, lembrando que este é o tipo de função GH utilizada nos experimentos.

Porém, verificamos que a forma da função GH $\operatorname{com} \lambda$ fixo causa alguns efeitos na reconstrução de chuveiros iniciados por uhecrons. Para isolar esses efeitos de reconstrução dos efeitos de detecção pelo telescópio, utilizamos os dados de deposição de energia obtidos diretamente do Aires/Sibyll, ou seja, sem a simulação do telescópio, e fizemos uma comparação entre os resultados da reconstrução utilizando ambos os tipos de função 
GH, com $\lambda$ fixo e com $\lambda$ variável, tanto para prótons, quanto para uhecrons.

A figura 4.8 mostra as distribuições de $X_{\max }$ e $(d E / d X)_{\max }$ para os ajustes de funções Gaisser-Hillas com $\lambda$ fixo e $\lambda$ variável para 2000 chuveiros de prótons e uhecrons de massa $M_{U}=50 \mathrm{GeV}$, ambos com $E_{0}=320 \mathrm{EeV}$. Pode-se observar que a distribuição desses parâmetros não é fortemente alterada pelo tipo de função utilizada, havendo apenas um pequeno deslocamento para valores menores do máximo da distribuição de $(d E / d X)_{\max }$ quando a GH de $\lambda$ fixo é utilizada.
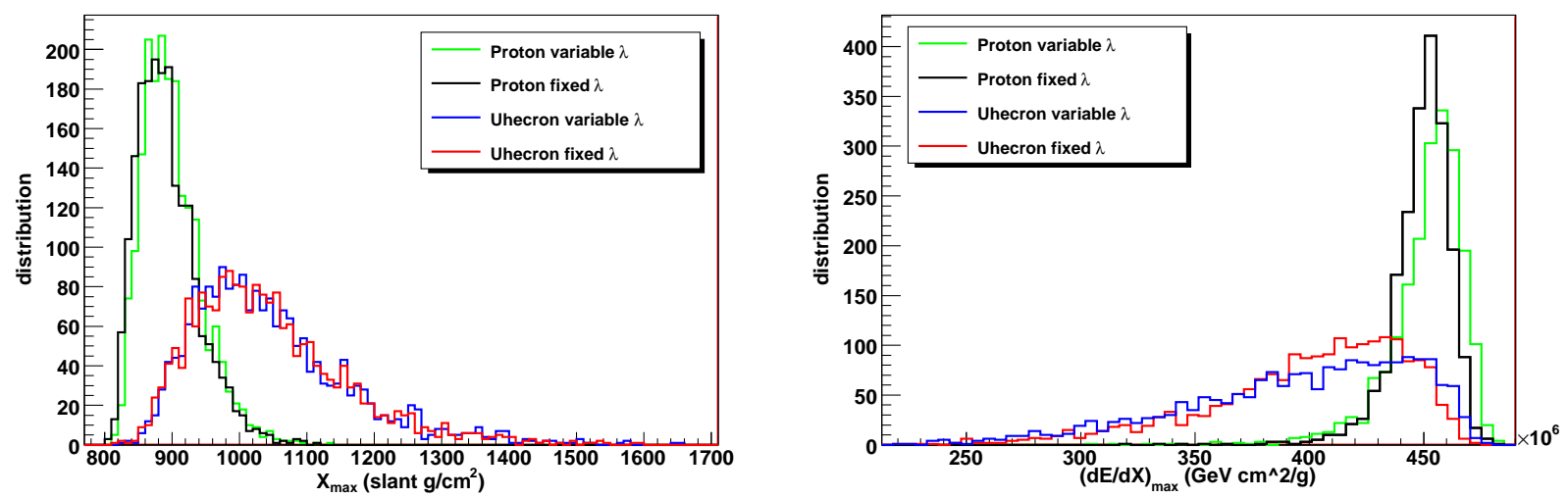

Figura 4.8: Distribuições de $X_{\max }$ (esquerda) e $(d E / d X)_{\max }$ (direita) para os ajustes de funções Gaisser-Hillas com $\lambda$ fixo e $\lambda$ variável para prótons e uhecrons de massa $M_{U}=50 \mathrm{GeV}$, ambos com $E_{0}=320 \mathrm{EeV}$.

Por outro lado, a distribuição da integral da função GH após o ajuste, que é a energia calorimétrica reconstruída, é mais larga no caso da utilização da GH $\operatorname{com} \lambda$ fixo. Especificamente no caso de EAS iniciados por uhecrons, esse alargamento da distribuição é extremamente grande, como pode ser visto na figura 4.9, que mostra as distribuições do "missing energy" ( $E_{0}-$ integral $) / E_{0}$. Os valores da média e RMS dessas distribuições podem ser vistos na tabela $4.6^{5}$ Essa distribuição nada mais é que a diferença entre a energia calorimétrica reconstruída e a energia inicial do primário utilizado na simulação. Pode-se observar que, mesmo no caso dos ajustes com $\lambda$ variável, a energia calorimétrica reconstruída do máximo da distribuição é aproximadamente $10 \%$ menor que a energia

\footnotetext{
${ }^{5}$ No caso de uhecrons de massas $M_{U}=20 \mathrm{GeV}$ e $M_{U}=30 \mathrm{GeV}$, foram utilizados apenas 500 chuveiros para a análise.
} 
inicial. Isso se deve principalmente à energia do chuveiro que é carregada por partículas que não depositam sua energia na atmosfera, como neutrinos e múons de alta energia, chamada de missing energy (ver seção 1.4.1).

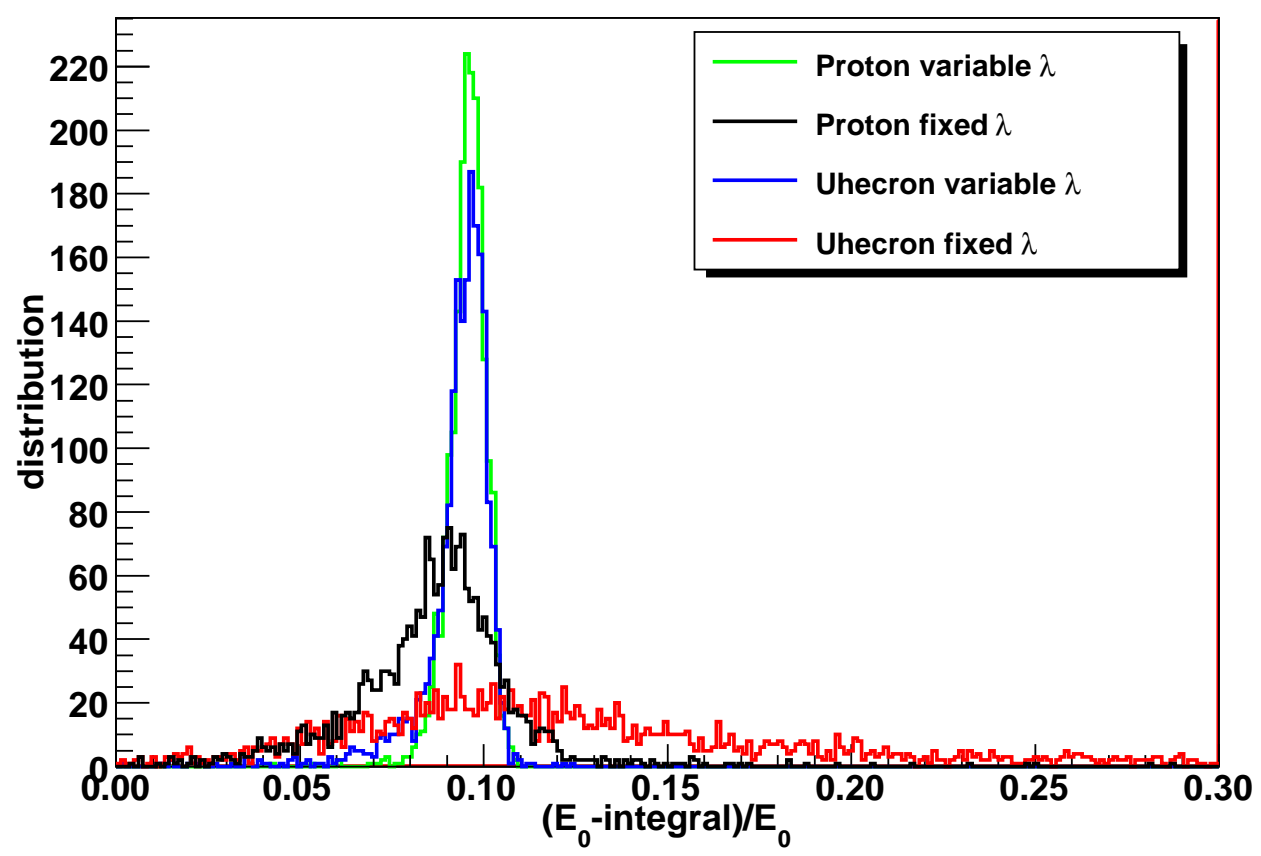

Figura 4.9: Distribuições do "missing energy" $\left(E_{0}-\right.$ integral $) / E_{0}$ para os ajustes de funções Gaisser-Hillas com $\lambda$ fixo e $\lambda$ variável para prótons e uhecrons de mass $M_{U}=$ $50 \mathrm{GeV}$, ambos com $E_{0}=320 \mathrm{EeV}$. Os valores da média e RMS dessas distribuições podem ser vistas na tabela 4.6 .

\begin{tabular}{|c|c|c|c|c|}
\hline \multirow{2}{*}{ partícula } & \multicolumn{2}{|c|}{$\lambda$ variável } & \multicolumn{2}{c|}{$\lambda$ fixo } \\
\cline { 2 - 5 } & média & RMS & média & RMS \\
\hline próton & 0.0955 & 0.00530 & 0.0866 & 0.0230 \\
\hline uhecron $\left(M_{U}=20 \mathrm{GeV}\right)$ & 0.0954 & 0.00612 & 0.1170 & 0.0480 \\
\hline uhecron $\left(M_{U}=30 \mathrm{GeV}\right)$ & 0.0943 & 0.00849 & 0.1173 & 0.0542 \\
\hline uhecron $\left(M_{U}=50 \mathrm{GeV}\right)$ & 0.0930 & 0.01068 & 0.1218 & 0.0589 \\
\hline
\end{tabular}

Tabela 4.6: Valores da média e RMS das distribuições do missing energy $\left(E_{0}-\right.$ integral $) / E_{0}$ para os ajustes com $\lambda$ variável e $\lambda$ fixo para vários primários de energia $E_{0}=320 \mathrm{EeV}$.

Observa-se também que as distribuições de $\left(E_{0}-\right.$ integral $) / E_{0}$ obtidas com ajustes da GH com $\lambda$ variável para prótons e para uhecrons são semelhantes, enquanto que o 
aumento da dispersão da distribuição no caso de ajustes da GH $\operatorname{com} \lambda$ fixo é muito maior no caso dos uhecrons, mesmo com a pequena variação observada na distribuição dos parâmetros ajustados $X_{\max }$ e $(d E / d X)_{\max }$ em relação ao tipo de GH ajustada (ver fig. 4.8). Essa variação vem da forma da GH de $\lambda$ fixo, que é ligeiramente inadequada para descrever a forma real do perfil de EAS iniciados por uhecrons: $\mathrm{Na}$ GH com $\lambda$ fixo, a forma do perfil ajustado é determinada somente pelo ponto do máximo, $\left(X_{\max },(d E / d X)_{\max }\right)$. Essa forma fixa é mais adequada para descrever perfis longitudinais de EAS iniciados por partículas usuais que EAS iniciados por uhecrons, que possuem uma grande variação intrínseca em $X_{\max }$ e $(d E / d X)_{\max }$, como pode ser visto

pelas distribuições (fig. 4.8). Essa variação de $X_{\max }$ e $(d E / d X)_{\max }$, sem uma variação correspondente na forma do perfil, leva a uma distribuição larga da integral da GH com $\lambda$ fixo, enquanto que no caso da GH com $\lambda$ variável, cuja forma varia de acordo com o perfil como um todo, e não somente com o ponto máximo ajustado, a distribuição da integral é similar à distribuição da integral no caso de prótons.

Um estudo mais aprofundado da forma do perfil longitudinal pode levar a outras maneiras de distinguir prótons e uhecrons. Esse estudo pode ser baseado na utilização de vários tipos de função para o ajuste do perfil longitudinal, ou na utilização de novos métodos para a determinação da composição que levam em conta a forma do perfil longitudinal, como os descritos em [67] e [68].

\section{Inclusão dos efeitos de detecção.}

Para a análise dos efeitos da detecção dos EAS, os 2000 chuveiros simulados pelo Aires/Sibyll para cada tipo de partícula e energia foram utilizados como entrada da simulação do telescópio de fluorescência, descrita no capítulo 2, utilizando os parâmetros do telescópio de fluorescência do Auger, que podem ser vistos nas tabelas 2.1 e A.3.

Para cada tipo de partícula e energia, foram simulados 40000 eventos FD, ou seja, cada um dos 2000 chuveiros simulados pelo Aires/Sibyll foi utilizado 20 vezes como entrada da simulação do telescópio. Esses chuveiros foram alterados de acordo com 


\begin{tabular}{|l|c|}
\hline Corte & Auger $[63]$ \\
\hline PMTs aceitas pelo trigger & $>5$ \\
\hline Comprimento do Track & $>200 \mathrm{~g} / \mathrm{cm}^{2}$ \\
\hline Angulo zenital & $<60^{\circ}$ \\
\hline$X_{\max }$ & visível \\
\hline Angulo $\psi$ & $<132^{\circ}$ \\
\hline$\chi_{\text {red }}^{2}($ ajuste $\mathrm{GH})$ & $<50$ \\
\hline
\end{tabular}

Tabela 4.7: Cortes de qualidade inicialmente aplicados aos resultados da simulação.

os procedimentos descritos no capítulo 2 e em nosso artigo[6]. Para cada evento foi gerada uma direção isotrópica, com ângulo zenital máximo de $60^{\circ}$, e uma posição do core do chuveiro no solo igualmente distribuída em área, com uma distância máxima ao telescópio de $60 \mathrm{~km}$. A emissão de fótons de fluorescência, seu transporte pela atmosfera e sua detecção pela eletrônica foram então simulados, obtendo-se os sinais nas PMTs do telescópio (ver fig. 2.1). Os triggers foram então aplicados e a geometria dos eventos aceitos reconstruída, possibilitando a reconstrução da energia depositada na região da atmosfera que é vista por cada PMT (ver fig. 2.2), obtendo-se a reconstrução do perfil longitudinal de deposição de energia.

A esses eventos simulados foram então aplicados cortes de qualidade[63], que podem ser vistos na tabela 4.7. Esses cortes são os cortes mínimos de qualidade que permitem separar eventos mal reconstruídos. O corte de $\chi_{\text {red }}^{2}$ foi relaxado em relação a [63], devido aos efeitos do ajuste da GH com $\lambda$ fixo aos perfis de uhecrons, descritos anteriormente nessa seção. Doravante vamos nos referir a esse cortes como cortes iniciais. A figura 4.10 mostra as distribuições normalizadas dos $\chi_{\text {red }}^{2}$ dos ajustes da função GH de $\lambda$ fixo aos perfis longitudinais reconstruídos de prótons e uhecrons de energia $E_{0}=320 \mathrm{EeV}$. Pode-se observar que os $\chi_{\text {red }}^{2}$ dos ajustes de EAS iniciados por uhecrons tendem a ser maiores que os iniciados por prótons, já que a forma fixa da função GH de $\lambda$ fixo descreve melhor chuveiros iniciados por partículas usuais.

A deteç̧ão e reconstrução dos eventos geram fontes de erros como a reconstrução geométrica do eixo do chuveiro, ruído das PMTs, número de PMTs acionadas e o campo 


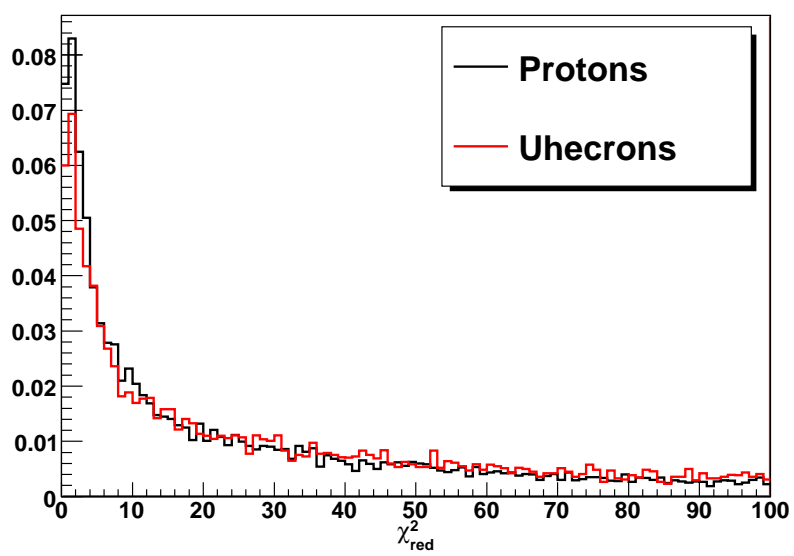

Figura 4.10: Distribuições normalizadas dos $\chi_{r e d}^{2}$ dos ajustes da função GH de $\lambda$ fixo aos perfis longitudinais reconstruídos de prótons e uhecrons de energia $E_{0}=320 \mathrm{EeV}$.

de visão do telescópio. Essas incertezas resultam em uma amostragem mais esparsa do perfil longitudinal, levando a um perfil reconstruído com menos pontos, mais flutuações e possíveis erros sistemáticos. A esses erros no perfil longitudinal ainda somam-se os erros nos ajustes da função GH. A contribuição de cada um desses erros nas medidas desses observáveis é de difícil separação.

Uma maneira de investigar a influência desses erros nas medidas dos observáveis é a comparação das distribuições desses observáveis antes e após a simulação do telescópio. A figura 4.11 mostra as distribuições de $X_{\max }$ antes e após a inclusão dos efeitos de detecção para prótons e uhecrons de massa $M_{U}=50 \mathrm{GeV}$, ambos primários com energia $E_{0}=320 \mathrm{EeV}$, enquanto que a figura 4.12 mostra as mesmas distribuições para $E_{0}=$ $100 \mathrm{EeV}$. Com o intuito de facilitar a comparação da forma das distribuições antes e após a inclusão dos efeitos de deteç̧ão, incluímos também nos gráficos a distribuição de $X_{\max }$ após o telescópio, normalizada para o número de eventos da distribuição antes do telescópio. Os valores médios, RMS, e o número de eventos nessas distribuições, bem como a variação da média antes e após a inclusão dos efeitos do telescópio podem ser vistos na tabela 4.8 .

Podemos observar que as distribuições de $X_{\max }$ após o telescópio têm seu máximo deslocado para valores menores, e que esse deslocamento é menor para prótons que para 

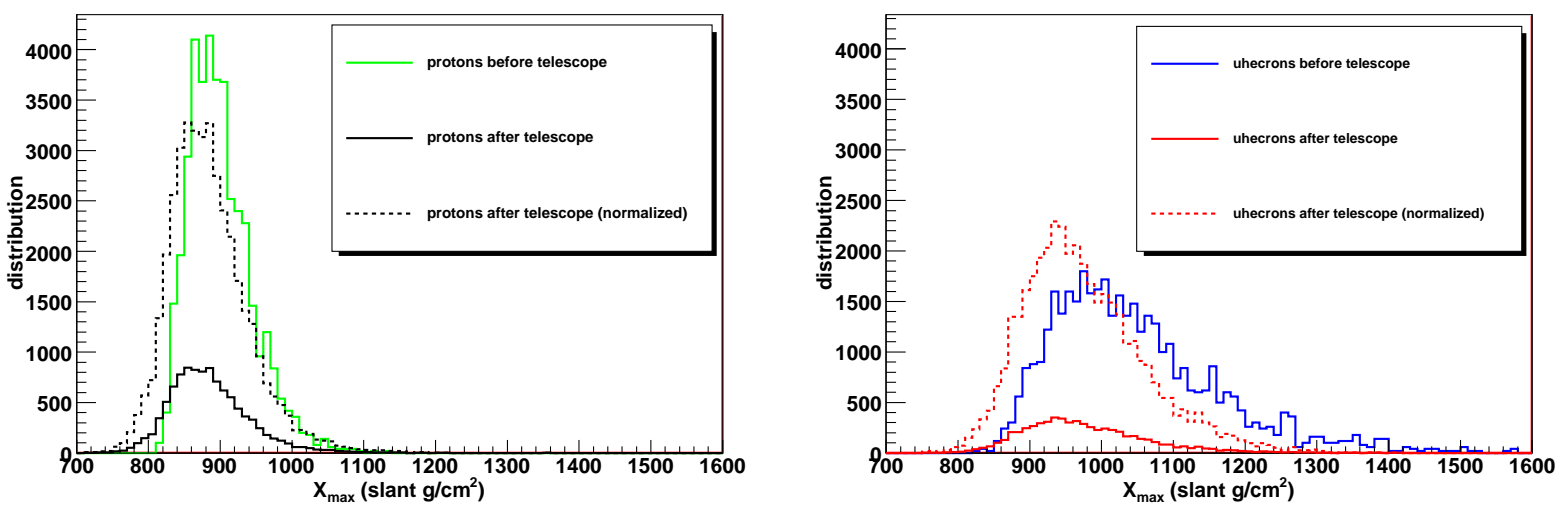

Figura 4.11: Comparação entre as distribuições de $X_{\max }$ antes e após a inclusão dos efeitos de detecção. À esquerda prótons antes da detecção (verde), após a detecção (preto) e após a detecção, normalizada para o número de eventos de entrada da simulação (preto tracejado). À direita uhecrons $\left(M_{U}=50 \mathrm{GeV}\right)$ antes da detecção (azul), após a detecção (vermelho) e após a detecção, normalizada para o número de eventos de entrada da simulação (vermelho tracejado). Ambos primários com energia $E_{0}=320 \mathrm{EeV}$.
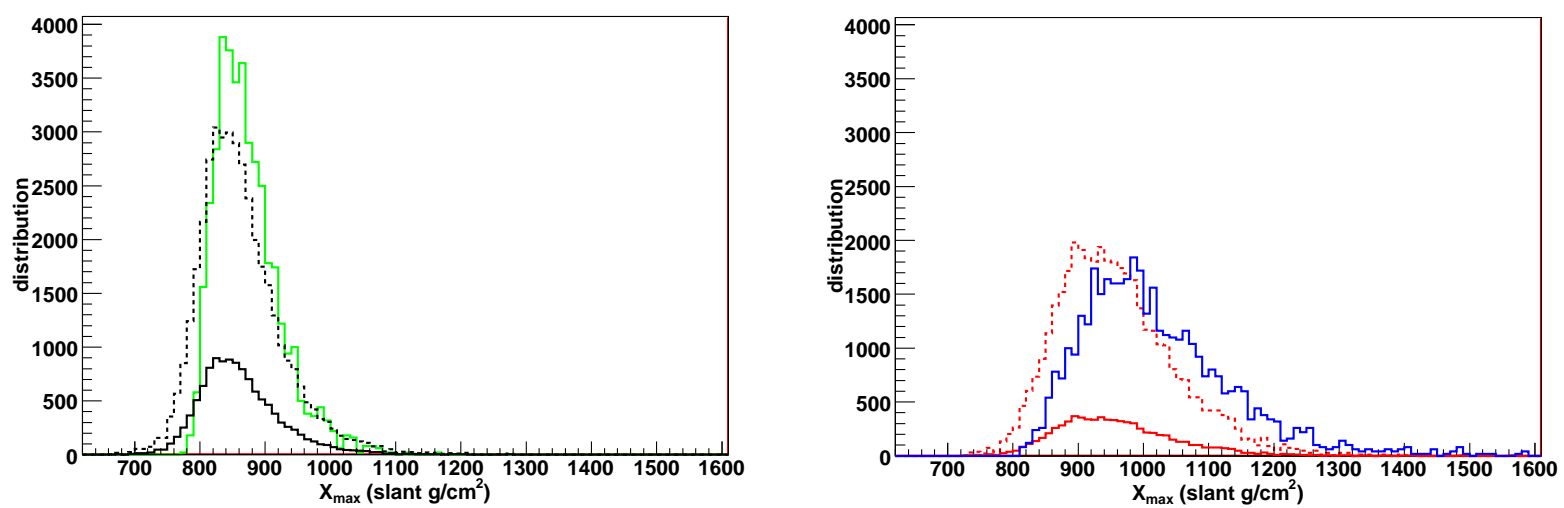

Figura 4.12: Comparação entre as distribuições de $X_{\max }$ antes e após a inclusão dos efeitos de detecção. À esquerda prótons antes da detecção (verde), após a detecção (preto) e após a detecção, normalizada para o número de eventos de entrada da simulação (preto tracejado). À direita uhecrons $\left(M_{U}=50 \mathrm{GeV}\right)$ antes da detecção (azul), após a detecção (vermelho) e após a detecção, normalizada para o número de eventos de entrada da simulação (vermelho tracejado). Ambos primários com energia $E_{0}=100 \mathrm{EeV}$.

uhecrons. Vemos também que esse deslocamento tende a diminuir ao se diminuir a energia do primário. No caso do próton observamos que, como esperado, a distribuição após a simulação do telescópio é mais larga que antes da simulação. Por outro lado, esse alargamento se dá somente na direção de valores menores de $X_{\max }$. Porém, no caso do 


\begin{tabular}{|c|c|c|c|c|c|c|}
\hline \multirow{2}{*}{ partícula } & \multicolumn{2}{|c|}{ antes do telescópio } & \multicolumn{4}{|c|}{ após o telescópio } \\
\cline { 2 - 7 } & $\left\langle X_{\max }\right\rangle$ & RMS & $\left\langle X_{\max }\right\rangle$ & RMS & $N\left(N / N_{0} \%\right)$ & $\Delta\left\langle X_{\max }\right\rangle(\%)$ \\
\hline próton $320 \mathrm{EeV}$ & 900.2 & 44.5 & 884.8 & 55.9 & $10296(25.7 \%)$ & $-15.4(-1.7 \%)$ \\
\hline uhecron $320 \mathrm{EeV}$ & 1047.5 & 119.4 & 975.6 & 84.8 & $6104(15.3 \%)$ & $-71.9(-6.9 \%)$ \\
\hline próton $100 \mathrm{EeV}$ & 872.7 & 50.7 & 862.2 & 64.4 & $11791(29.5 \%)$ & $-10.5(-1.2 \%)$ \\
\hline uhecron $100 \mathrm{EeV}$ & 1020.8 & 120.0 & 958.5 & 91.5 & $7415(18.5 \%)$ & $-62.3(-6.1 \%)$ \\
\hline
\end{tabular}

Tabela 4.8: Valores da média e RMS (slant $\mathrm{g} / \mathrm{cm}^{2}$ ) das distribuições de $X_{\max }$ antes e após a inclusão dos efeitos de detecção. $N$ refere-se ao número de eventos detectados que passaram pelos triggers e cortes de qualidade, $N_{0}=40000$ ao número total de eventos simulados e $\Delta\left\langle X_{\max }\right\rangle$ à variação na média das distribuições antes e após a inclusão dos efeitos de detecção.

uhecron, observamos uma diminuição na largura da distribuição e um forte deslocamento para a esquerda. Vemos também que a fração dos eventos que passam pelos triggers e cortes é menor que no caso de prótons. Essas características podem ser explicadas através de duas premissas: as incertezas de detecção tendem a alargar a distribuição, enquanto que a aceitância do telescópio tende a privilegiar valores menores de $X_{\max }$, como pode ser visto na figura $4.13^{6}$. Assim, como os valores de $X_{\max }$ no caso de uhecrons tendem a ser maiores, a aceitância do detetor para uhecrons é menor que para prótons, o que pode ser diretamente observado pelo menor número de eventos de uhecrons aceitos. Com a diminuição da energia, diminuímos $X_{\max }$, aumentando então a aceitância do detetor para ambas as partículas (ver tabela 4.8). O alargamento da distribuição, esperado devido às incertezas de detecção, só se dá do lado esquerdo (valores menores de $X_{\max }$ ) devido à aceitância do detetor, que corta a maior parte dos eventos do lado direito da distribuição, especialmente no caso de uhecrons, que apresentam uma longa cauda para valores maiores de $X_{\max }$. Esse corte de eventos do lado direito, juntamente com o alargamento da distribuição devido aos erros experimentais, leva ao deslocamento do máximo da distribuição para a esquerda após a inclusão dos efeitos de detecção. Todos esses efeitos diminuem com a diminuição da energia e, conseqüentemente, de $X_{\max }$.

A figura 4.14 mostra as distribuições normalizadas dos valores reconstruídos da de-

\footnotetext{
${ }^{6}$ No caso de chuveiros com inclinação até $60^{\circ}$, essa aceitância cai mais rapidamente, já que o máximo do chuveiro deve ser visível, portanto acima do solo. A $60^{\circ}$, o solo no observatório Auger se encontra a aproximadamente 1700 slant $\mathrm{g} / \mathrm{cm}^{2}$, quando a aceitância passa a ser nula.
} 


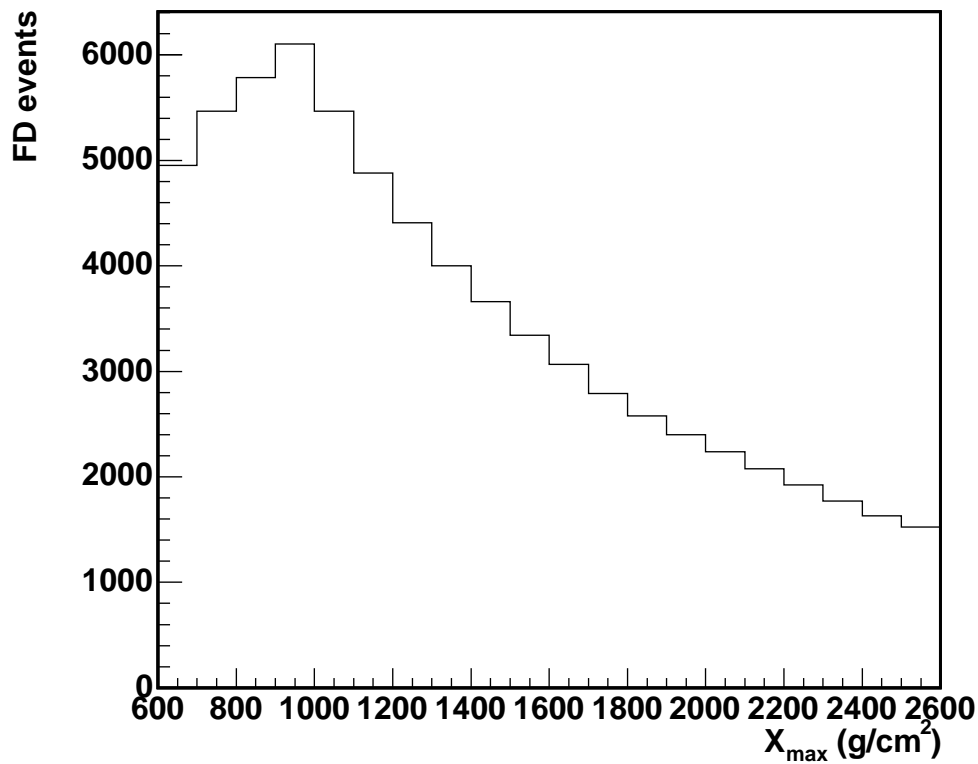

Figura 4.13: Aceitância em função de $X_{\max }$ do detetor de fluorescência do Observatório Pierre Auger. Figura extraída de [69].

posição máxima $(d E / d X)_{\max }$ para prótons e uhecrons. Pode-se observar que há um deslocamento do máximo da distribuição para a esquerda (valores menores de $(d E / d X)_{\max }$ ) em ambos os casos. No caso de prótons, é possível observar o alargamento da distribuição devido aos erros experimentais. Por outro lado, no caso de chuveiros iniciados por uhecrons, o efeito desse alargamento é mínimo, especialmente do lado esquerdo da distribuição. É possível que isso se dê pela grande flutuação intrínseca da deposição máxima de chuveiros iniciados por uhecrons (azul), se comparada à flutuação intrínseca no caso de prótons (verde).

Para a reconstrução da energia, a função GH de $\lambda$ fixo ajustada ao perfil longitudinal reconstruído (parâmetros $X_{\max }$ e $\left.(d E / d X)_{\max }\right)$ é integrada, obtendo-se a energia calorimétrica total $E_{c a l}$ reconstruída. A essa energia, soma-se o valor do missing energy, calculado através da parametrização de Barbosa et al. [64] para prótons (eq. A.6 e tabela A.1), obtendo-se a energia reconstruída $E_{r e c}$. Mais detalhes sobre essa reconstrução podem ser vistos na seção A.2.5. A figura 4.15 mostra a distribuição do erro na energia reconstruída, dada por $\left(E_{r e c}-E_{0}\right) / E_{0}$, antes e após a inclusão dos efeitos de deteç̧ão 

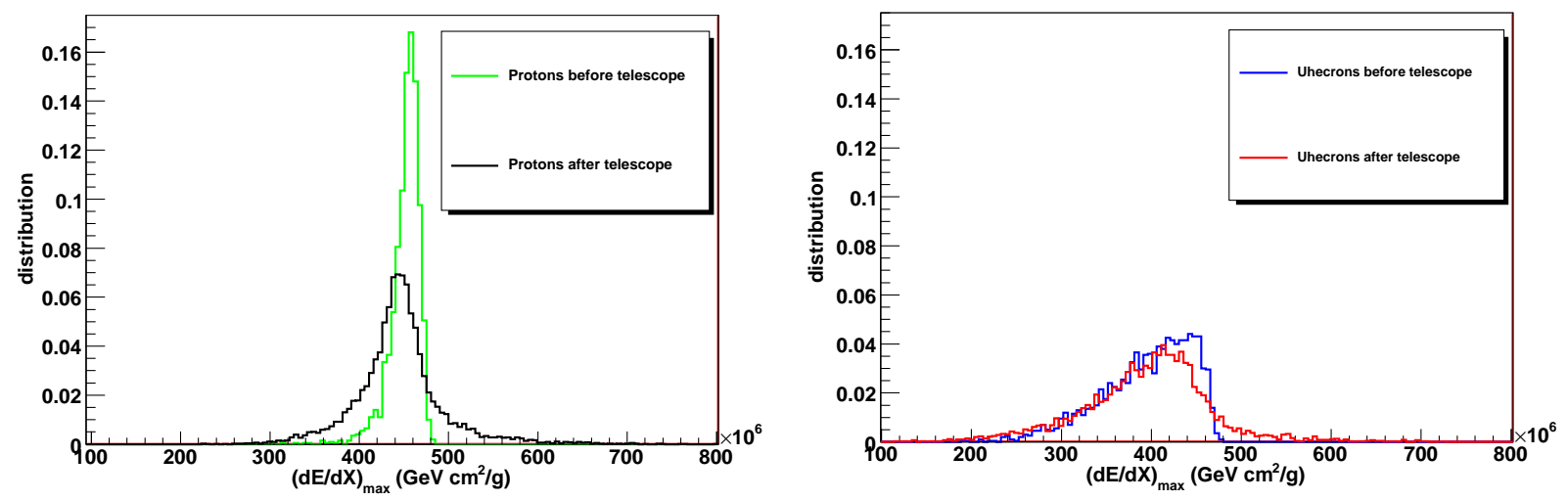

Figura 4.14: Comparação entre as distribuições normalizadas de $(d E / d X)_{\max }$ antes e após a inclusão dos efeitos de deteç̧ão. À esquerda prótons antes da detecção (verde) e após a detecção (preto). À direita uhecrons antes da deteç̧ão (azul) e após a detecção (vermelho). Ambos primários com energia $E_{0}=320 \mathrm{EeV}$.

para prótons e uhecrons de $E_{0}=320 \mathrm{EeV}$. A figura 4.16 mostra as mesmas distribuições para $E_{0}=100 \mathrm{EeV}$. Os valores da média e RMS dessas distribuições podem ser vistos na tabela 4.9 .
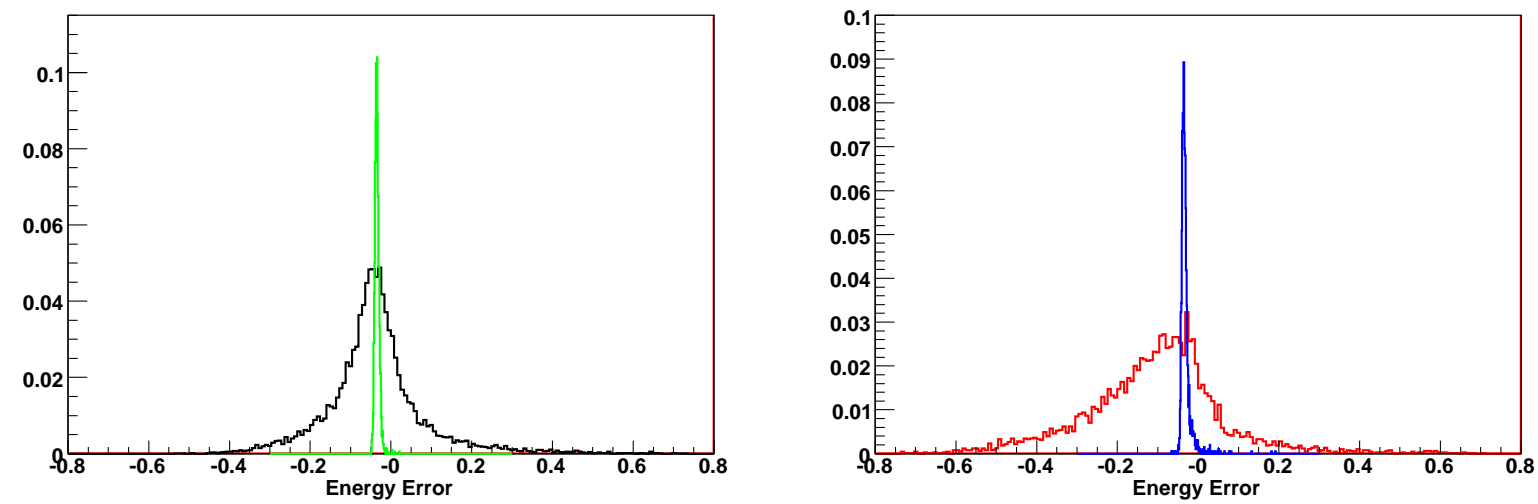

Figura 4.15: Comparação entre as distribuições normalizadas de erro na energia antes e após a inclusão dos efeitos de deteç̧ão. À esquerda prótons antes da detecção (verde) e após a detecção (preto). À direita uhecrons antes da detecção (azul) e após a detecção (vermelho). Ambos primários com energia $E_{0}=320 \mathrm{EeV}$.

Podemos observar que, mesmo antes da inclusão dos efeitos de detecção, existe um erro sistemático da ordem de 3\% na medida de energia. Esse erro sistemático pode ser explicado devido à utilização da parametrização do missing energy[64], criada a par- 

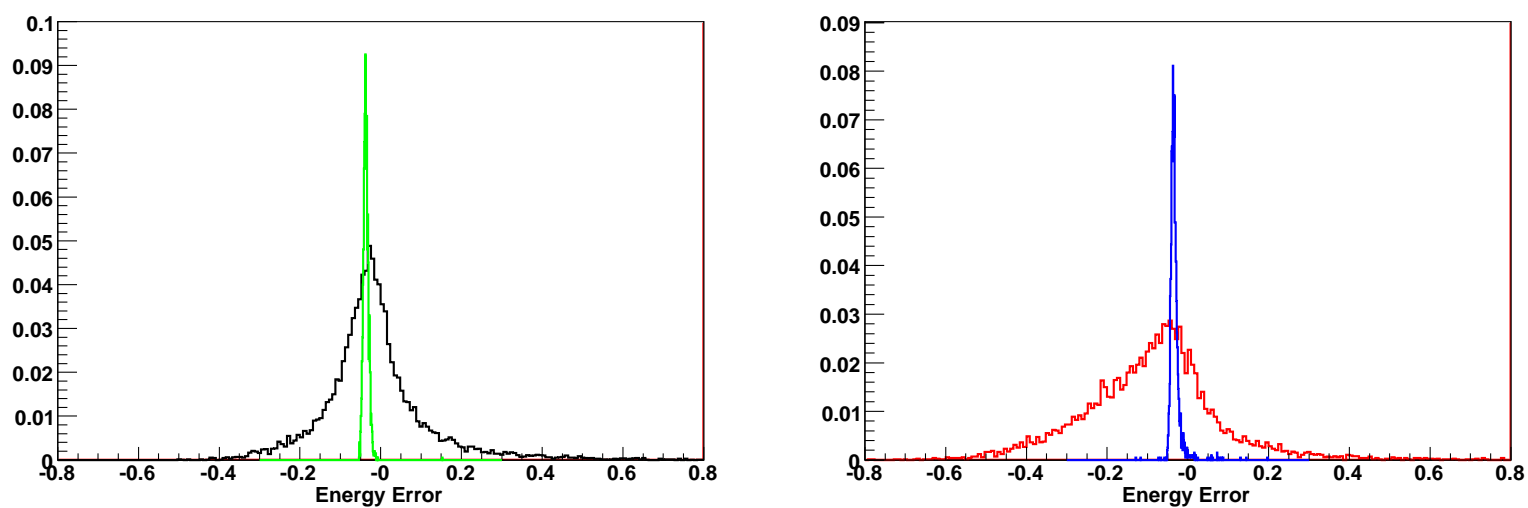

Figura 4.16: Comparação entre as distribuições normalizadas de erro na energia antes e após a inclusão dos efeitos de detecção. À esquerda prótons antes da detecção (verde) e após a detecção (preto). À direita uhecrons antes da detecção (azul) e após a detecção (vermelho). Ambos primários com energia $E_{0}=100 \mathrm{EeV}$.

\begin{tabular}{|l|c|c|c|c|}
\hline \multirow{2}{*}{ partícula } & \multicolumn{2}{|c|}{ antes do telescópio } & \multicolumn{2}{c|}{ após o telescópio } \\
\cline { 2 - 5 } & média $\left(\times 10^{-2}\right)$ & RMS $\left(\times 10^{-2}\right)$ & média $\left(\times 10^{-2}\right)$ & RMS $\left(\times 10^{-2}\right)$ \\
\hline próton $320 \mathrm{EeV}$ & -3.4 & 0.56 & -3.8 & 12.4 \\
\hline uhecron $320 \mathrm{EeV}$ & -3.1 & 1.45 & -10.7 & 17.3 \\
\hline próton $100 \mathrm{EeV}$ & -3.6 & 0.77 & -1.4 & 13.2 \\
\hline uhecron $100 \mathrm{EeV}$ & -3.3 & 1.48 & -9.0 & 17.0 \\
\hline
\end{tabular}

Tabela 4.9: Valores da média e RMS das distribuições do erro na energia reconstruída $\left(E_{\text {rec }}-E_{0}\right) / E_{0}$ antes e após a inclusão dos efeitos de detecção. Os gráficos dessas distribuições podem ser vistos nas figuras 4.15 e 4.16 .

tir de simulações do Corsika/QGSJET. Essa parametrização apresenta grande acuidade quando utilizamos chuveiros simulados pelo Corsika/QGSJET. Porém, quando chuveiros simulados pelo Aires/Sibyll são analisados, essa acuidade diminui, levando a esse erro sistemático. Essa discrepância ilustra as diferenças entre os chuveiros simulados por diferentes pacotes. Observa-se também que a inclusão dos efeitos de detecção não altera significativamente a posição do máximo da distribuição do erro na energia reconstruída em ambas as energias e partículas. Por outro lado, enquanto que no caso de prótons a média da distribuição permanece relativamente inalterada, a forte assimetria das distribuições no caso de uhecrons após a inclusão dos efeitos de detecção diminui significativamente sua média. Vemos que a média do erro na energia no caso de uhecrons 
após a simulação do telescópio é da ordem de $-10 \%$. Trata-se de um erro sistemático que será levado em conta em nosso método de separação entre sinais de uhecrons e prótons, que será descrito na próxima seção.

\subsection{Método para separação de prótons e uhecrons}

Nessa seção descreveremos métodos para a separação de sinais de uhecrons e prótons em telescópios de fluorescência. Esses métodos são baseados nas distribuições de alguns observáveis de EAS obtidos de nossas simulações da detecção e reconstrução de eventos FD.

Como vimos anteriormente, os observáveis de prótons são os que mais se aproximam dos de uhecrons, exceção feita ao $X_{\max }$ de fótons, mais profundos que os de prótons, aproximando-se dos $X_{\max }$ de uhecrons. Por outro lado, o limite superior para a fração de fótons é relativamente baixo $^{7}, 2 \%$ para energias acima de $10^{19} \mathrm{eV}[24]$. Embora a análise que leva esses resultados para o limite superior da fração de fótons também se baseie na influência do perfil longitudinal do chuveiro no tempo de subida (espessura) e curvatura da frente do chuveiro, medidos pelo detetor de superfície do Observatório Pierre Auger, é de se esperar que sinais provenientes de uhecrons sejam distintos dos de fótons, por exemplo, devido à menor componente muônica de EAS iniciados por fótons. Uma análise mais elaborada da distinção entre uhecrons e fótons será abordada posteriormente. Aqui desenvolvemos métodos para a separação entre sinais de uhecrons e prótons usando o FD, lembrando que EAS iniciados por primários mais pesados que prótons seriam ainda mais distintos dos iniciados por uhecrons, facilitando ainda mais a separação desses sinais de primários pesados.

Para essa análise utilizamos os resultados da simulação de detecção e reconstrução de 40000 eventos por tipo de partícula, seguida da aplicação dos cortes iniciais (tabela 4.7). A figura 4.17 (esquerda) mostra as distribuições de $X_{\max }$ para prótons e uhecrons

\footnotetext{
${ }^{7} 2 \%$ para energias acima de $10^{19} \mathrm{eV}, 5.1 \%$ acima de $2 \times 10^{19} \mathrm{eV}$ e $31 \%$ acima de $4 \times 10^{19} \mathrm{eV}$, com nível de confiança de $95 \%[24]$.
} 
de energia $E_{0}=320 E e V$, após a detecção e reconstrução de eventos e a aplicação dos cortes iniciais. Pode-se observar que uhecrons tendem a ter um $X_{\max }$ maior que prótons. Assim, a aplicação de um corte nesse observável, como o que aceita $X_{\max }>912 \mathrm{~g} / \mathrm{cm}^{2}$ indicado pela seta azul, descartaria mais prótons que uhecrons.
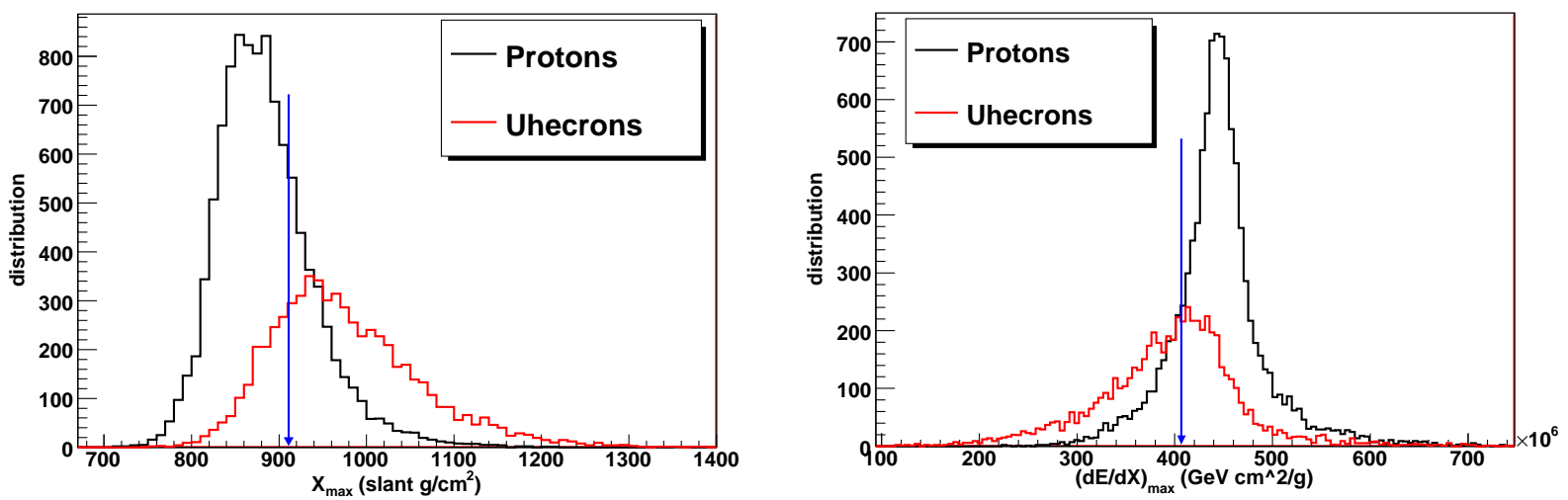

Figura 4.17: Distribuições de $X_{\max }$ (esquerda) e $(d E / d X)_{\max }$ (direita) para prótons e uhecrons de energia $E_{0}=320 \mathrm{EeV}$, após a detecção e reconstrução de eventos e a aplicação dos cortes iniciais. As setas azuis representam a posição dos cortes que aceitam $X_{\max }>912 \mathrm{~g} / \mathrm{cm}^{2}$ (esquerda) e $(d E / d X)_{\max }<4.08 \times 10^{8} \mathrm{GeV} \mathrm{cm}^{2} / \mathrm{g}$ (direita).

Outro observável que permite discernir entre prótons e uhecrons é a deposição máxima $(d E / d X)_{\max }$, que tende a ser menor para EAS iniciados por uhecrons que por prótons. A figura 4.17 (direita) mostra as distribuições de $(d E / d X)_{\max }$ para prótons e uhecrons de energia $E_{0}=320 E e V$, após a detecção e reconstrução de eventos e a aplicação dos cortes iniciais. A aplicação de outro corte nesse observável, como o que aceita $(d E / d X)_{\max }<4.08 \times 10^{8} \mathrm{GeV} \mathrm{cm}^{2} / \mathrm{g}$, também ajudaria a descartar mais prótons que uhecrons.

Ainda outros dois observáveis, o ângulo zenital $\theta$ e a altitude $H_{\max }$, que dependem do desenvolvimento longitudinal do chuveiro e estão relacionados com a detecção pelo FD, podem ser utilizados para a separação de sinais de prótons e uhecrons. A inclinação $\theta$ dos chuveiros detectados cresce com $X_{\max }$ devido a argumentos geométricos, já que o máximo do chuveiro deve ser visível pelo telescópio. Desse modo, EAS iniciados por uhecrons que passaram pelos cortes iniciais tendem a ter inclinações zenitais $\theta$ maiores se 
comparados com prótons. Isso pode ser visto na figura 4.18, que mostra as distribuições de $\theta$ para prótons e uhecrons de energia $E_{0}=320 \mathrm{EeV}$, após a detecção e reconstrução de eventos e aplicação dos cortes iniciais. A aplicação de um corte nesse observável, como o que aceita $\theta>0.571 \mathrm{rad}$, representado pela seta azul pode, em alguns casos, ajudar a separação de prótons e uhecrons. A altitude $H_{\max }$ do primeiro ponto detectado pelo telescópio, que nada mais é do que a mínima profundidade atmosférica vertical do perfil longitudinal detectado transformada em altitude (eq. A.9 na seção A.4.2), também é relevante. Como o desenvolvimento de EAS iniciados por uhecrons é mais lento, o limiar da emissão de fluorescência que é detectável pelo FD deve se dar a altitudes menores (profundidades $X$ maiores). A figura 4.18 mostra as distribuições de $H_{\text {max }}$ para prótons e uhecrons de energia $E_{0}=320 \mathrm{EeV}$, após a detecção e reconstrução de eventos e aplicação dos cortes iniciais. No caso da aplicação de um corte, como o que aceita $H_{\text {max }}<12.61 \mathrm{~km}$ representado pela seta azul, teríamos mais prótons que uhecrons descartados.
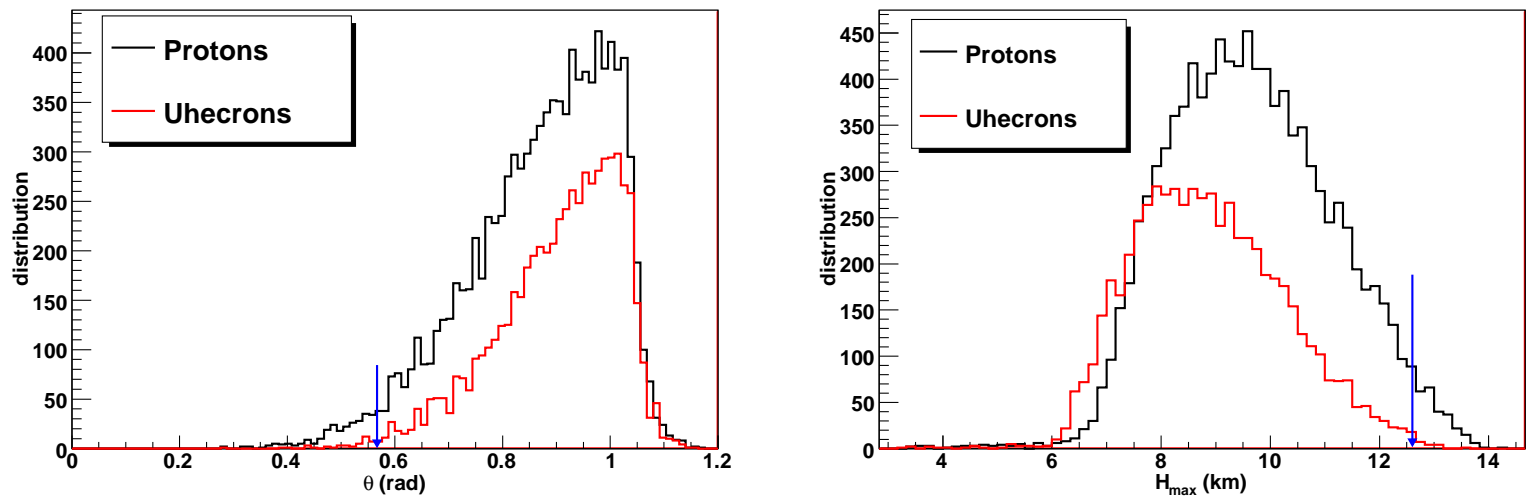

Figura 4.18: Distribuições de $\theta$ (esquerda) e $H_{\text {max }}$ (direita) para prótons e uhecrons de energia $E_{0}=320 E e V$, após a detecção e reconstrução de eventos e aplicação dos cortes iniciais. As setas azuis representam a posição dos cortes que aceitam $\theta>0.571 \mathrm{rad}$ (esquerda) e $H_{\max }<12.61 \mathrm{~km}$ (direita). 


\section{Otimização de cortes offline}

As distribuições dos observáveis descritos acima podem ser utilizadas para a análise evento a evento da composição do primário de EAS detectados pelo FD. Esse método direto de comparação dos observáveis de um determinado chuveiro com as distribuições para prótons e uhecrons obtidas das simulações pode ser utilizado para a criação de uma subamostra de eventos candidatos a uhecrons. Por outro lado, com o intuito de determinar a possibilidade de separação entre prótons e uhecrons, seria interessante optimizar valores de corte para cada um desses observáveis. Para isso criamos um método para a otimização desses novos cortes, que doravante serão chamados de cortes offline.

O objetivo dos cortes é minimizar a contaminação de prótons em uma subamostra de candidatos a uhecron, maximizando também o número de eventos de uhecrons nessa subamostra, ou seja, queremos maximizar a fração de uhecrons, bem como o número de uhecrons nessa subamostra final. Para isso criamos um fator de qualidade $q$, utilizado para a otimização desses cortes:

$$
q=\left(\frac{N_{U}^{\prime}}{N_{U}^{\prime}+N_{p}^{\prime}}\right) \times\left(N_{U}^{\prime}\right)^{A},
$$

onde $N_{U}^{\prime}$ e $N_{p}^{\prime}$ são o número de uhecrons e prótons na amostra final, respectivamente, e $A$ é uma constante.

Esse parâmetro $q$ pode ser maximizado em função dos cortes em $(d E / d X)_{\max }, \theta$, $H_{\max }$ e $X_{\max }$. Vale notar que, quanto maior for o parâmetro $A$, mais forte será a contribuição de $N_{U}^{\prime}$ no fator de qualidade $q$, e mais fracos serão os cortes ótimos, ou seja, menos eventos serão descartados por esses cortes e, conseqüentemente, maior será a contaminação de prótons na amostra final. Na análise descrita a seguir, utilizamos o parâmetro $A=0.2$ (eq. 4.4).

Para a otimização dos cortes offline, consideramos como a amostra inicial os eventos após a simulação da detecção e reconstrução e aplicação dos cortes iniciais, descritos na 
tabela 4.7. Em seguida, para cada uma das distribuições, definimos valores mínimos e máximos para os cortes offline. Essa região relevante para a aplicação dos cortes é então dividida, obtendo-se vários valores para cada um dos cortes. Todas as combinações ${ }^{8}$ desses cortes são então aplicados à amostra inicial e, ao final de cada combinação, obtemos as distribuições dos observáveis. Para cada conjunto dessas distribuições, o valor de $q$ é então calculado. O maior valor de $q$ obtido indica o conjunto ótimo desses cortes.

Para o caso de prótons e uhecrons de massa $M_{U}=50 \mathrm{GeV}$, ambos com energia $E_{0}=320 \mathrm{EeV}$, a aplicação dos cortes offline otimizados levou a uma subamostra de candidatos a uhecrons com cerca de $8 \%$ de contaminação de prótons. Cerca de $42 \%$ dos uhecrons da amostra inicial foram aceitos pelos cortes offline, enquanto que apenas $2 \%$ dos prótons passaram pelos cortes (ver primeira linha da tabela 4.10). O efeitos dos cortes offline nas distribuições de $X_{\max }$ e $(d E / d X)_{\max }$ podem ser vistos nas figuras 4.19 e 4.20, respectivamente, enquanto que a figura 4.21 mostra os efeitos nas distribuições de $\theta$ e $H_{\max }$. Pode-se observar que nas regiões de máximo das distribuições de $(d E / d X)_{\max }$ e $X_{\max }$ para prótons, as distribuições desses mesmos observáveis para uhecrons já estão em queda (ver figuras 4.19 e 4.20). Isso torna os cortes em $(d E / d X)_{\max }$ e $X_{\max }$ muito mais eficientes que os cortes em $\theta$ e $H_{\text {max }}$.

\section{Correção de energia para uhecrons}

O objetivo desses métodos é separar sinais de uhecrons a partir de dados reais obtidos pelos FDs do Observatório Pierre Auger. Como todos os observáveis são fortemente dependentes da energia do primário, esses dados devem ser separados por energia, e cada energia analisada separadamente. Por outro lado, vimos que os efeitos de deteção e reconstrução introduzem um erro sistemático da ordem de $10 \%$ na energia reconstruída de EAS iniciados por uhecrons. Desse modo, com o intuito de levar esses erros

\footnotetext{
${ }^{8}$ Após alguns testes, verificou-se que a ordem mais adequada para a aplicação dos cortes é $(d E / d X)_{\max }, \theta, H_{\max }$ e $X_{\max }$. Em nossa maximização de $q$, combinamos todos os valores possíveis dos vários cortes, porém sempre aplicados nessa ordem.
} 


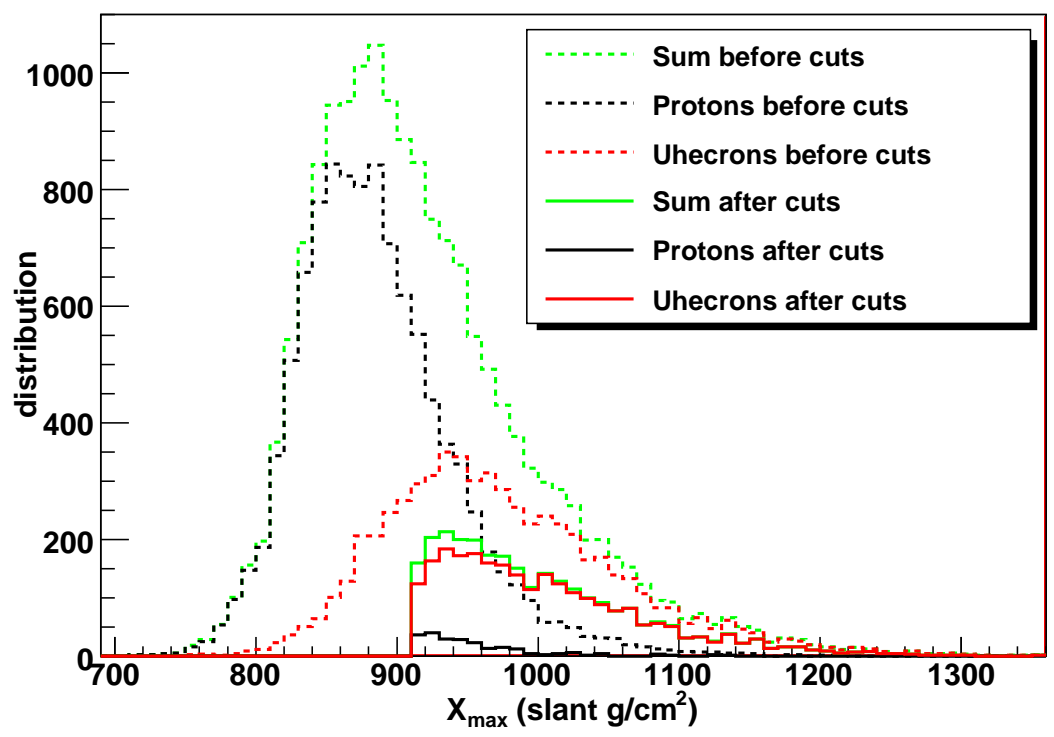

Figura 4.19: Distribuição de $X_{\max }$ para prótons e uhecrons de massa $M_{U}=50 \mathrm{GeV}$, ambos com energia $E_{0}=320 \mathrm{EeV}$, antes e após a aplicação dos cortes offline otimizados.

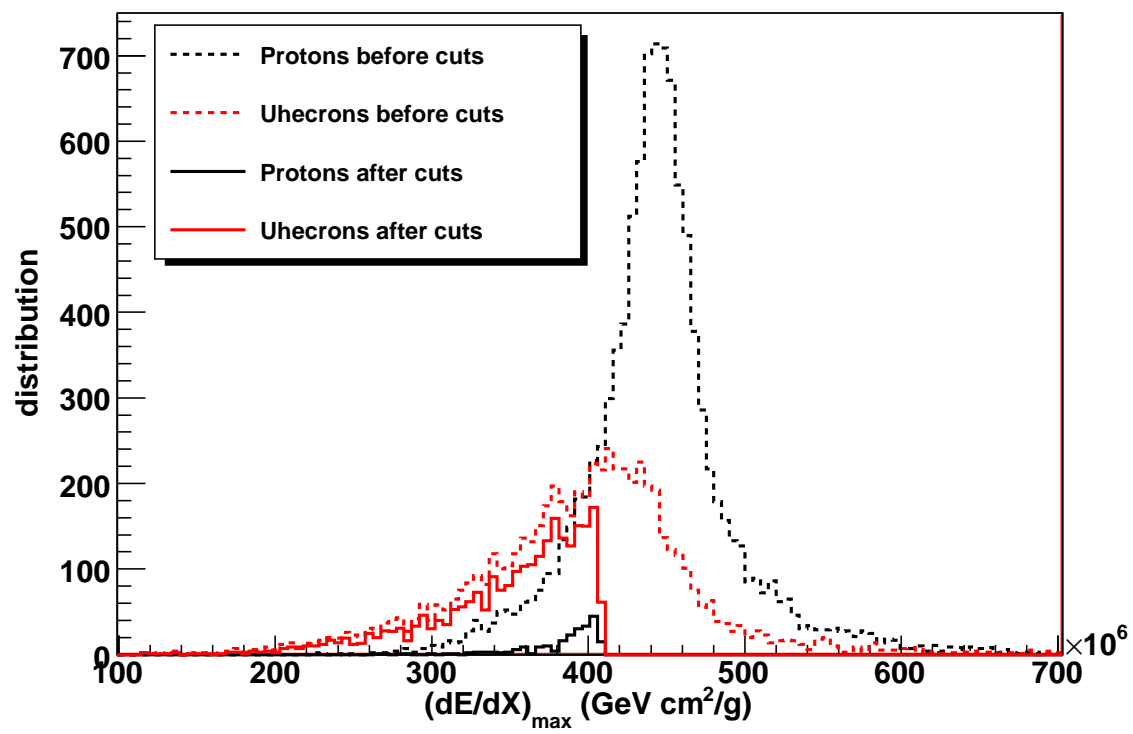

Figura 4.20: Distribuição de $(d E / d X)_{\max }$ para prótons e uhecrons de massa $M_{U}=$ $50 \mathrm{GeV}$, ambos com energia $E_{0}=320 \mathrm{EeV}$, antes e após a aplicação dos cortes offline otimizados.

sistemáticos em conta na nossa análise, utilizamos chuveiros iniciados por uhecrons com energias entre 8 e $10 \%$ maiores que os chuveiros de prótons para a criação das distri- 

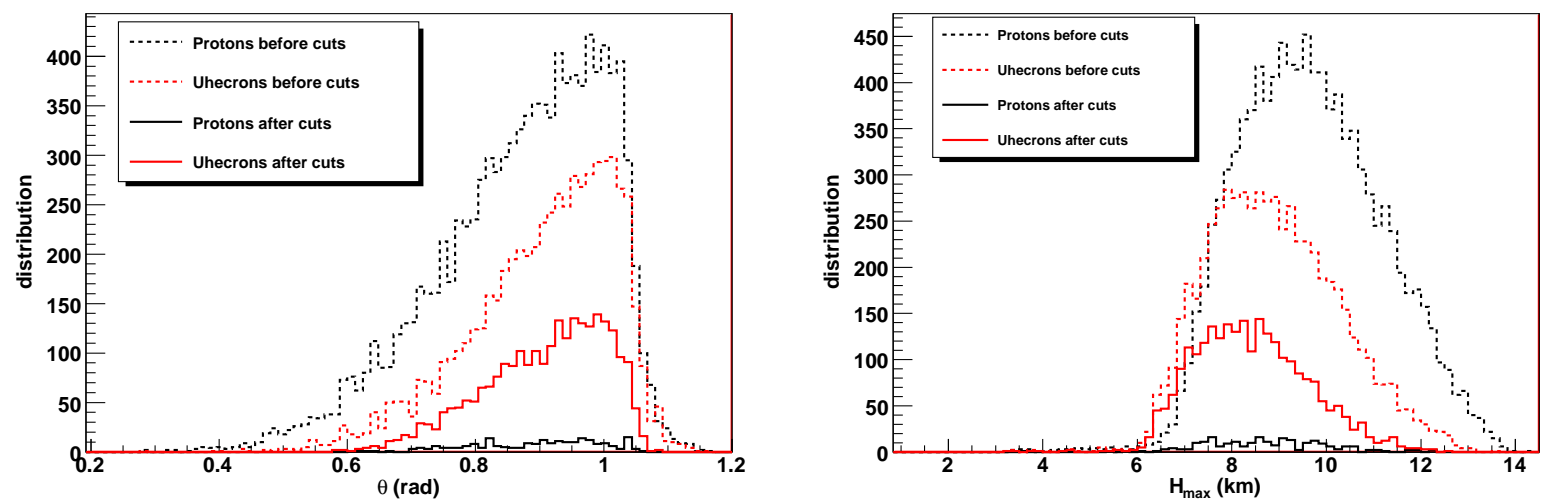

Figura 4.21: Distribuições de $\theta$ e $H_{\text {max }}$ para prótons e uhecrons de massa $M_{U}=50 \mathrm{GeV}$, ambos com energia $E_{0}=320 \mathrm{EeV}$, antes e após a a aplicação dos cortes offline otimizados.

buições dos observáveis. Assim, os chuveiros de prótons de energias 50, 100 e $320 \mathrm{EeV}$ foram comparados com chuveiros iniciados por uhecrons de energias 54, 108 e $352 \mathrm{EeV}$, respectivamente. A otimização dos cortes offline foi feita separadamente para cada caso. Os resultados obtidos para uhecrons de massas 50, 30 e $20 \mathrm{GeV}$ podem ser vistos nas tabelas $4.10,4.11$ e 4.12 .

Os EAS iniciados por uhecrons de energia maior, após a inclusão da correção, tendem a ter $X_{\max }$ maiores e, conseqüentemente, $\theta$ maiores, e portanto tenderiam a separar ainda mais uhecrons de prótons. Por outro lado, vimos que a aceitância do telescópio diminui com $X_{\text {max }}$, levando a um menor número de uhecrons detectados pelo telescópio, além de um deslocamento maior da distribuição de $X_{\max }$ para a esquerda, efeito discutido na seção 4.1.2. Desse modo, após a simulação do telescópio, as distribuições de $X_{\max }$ dos uhecrons com e sem a correção de energia são muito similares, como pode ser visto na figura 4.22. Esses chuveiros de energia corrigida tendem também a ter $(d E / d X)_{\max }$ maiores, levando a $H_{\max }$ maiores, devido à maior emissão de fluorescência. Assim, os valores maiores de $(d E / d X)_{\max }$ e $H_{\max }$ desses uhecrons mais energéticos aproximam-se ainda mais dos valores para prótons, como pode ser visto na distribuição de $(d E / d X)_{\max }$ mostrada na figura 4.22, dificultando a separação entre prótons e uhecrons de energia corrigida. Desse modo, o efeito total da correção da energia de uhecrons é dificultar 
sensivelmente sua separação de prótons, como pode ser observado nas duas primeiras linhas da tabela 4.10. A primeira linha mostra o caso de prótons e uhecrons de $320 \mathrm{EeV}$, ou seja, sem a correção da energia dos uhecrons, enquanto que a segunda linha mostra o caso com a correção de energia. Pode-se observar que, embora a fração $N_{u}^{\prime} / N_{u}$ de uhecrons que passam pelos cortes offline não seja substancialmente alterada, a fração $N_{p}^{\prime} / N_{p}$ de prótons que passam pelos cortes praticamente dobra, levando a quase o dobro de contaminação de prótons $N_{p}^{\prime} / N_{T}^{\prime}$ na subamostra final de candidatos a uhecrons. Isso se deve, principalmente, ao aumento substancial no valor de corte de $(d E / d X)_{\max }$, devido aos maiores valores desse observável nos chuveiros com energia corrigida, levando a um corte menos eficiente.
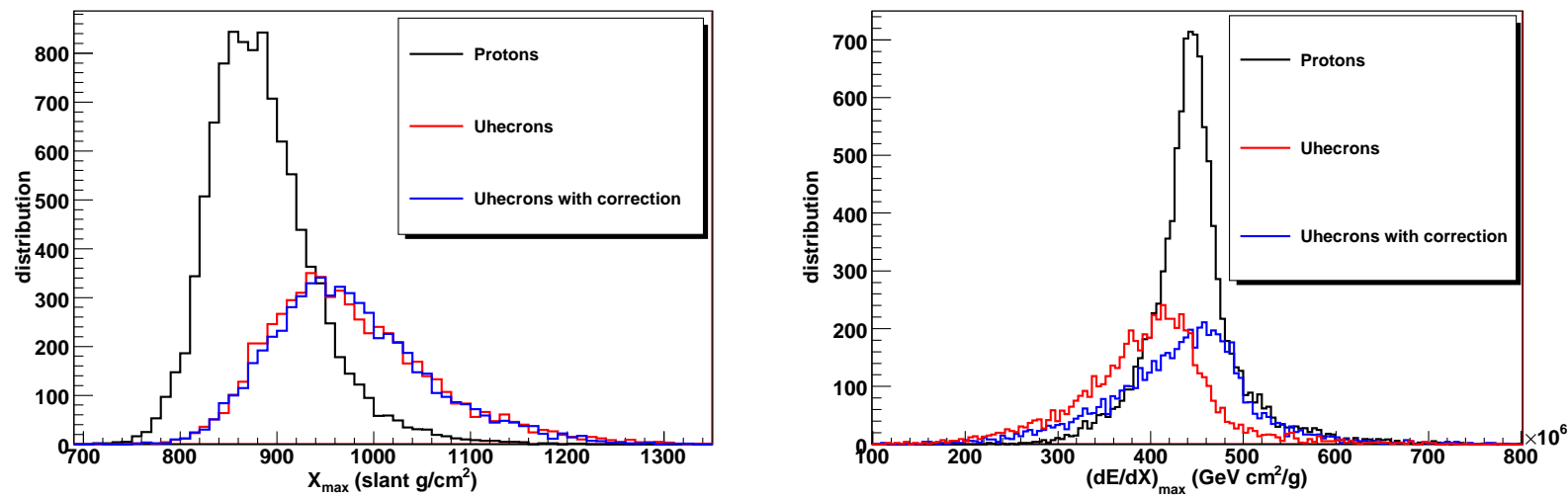

Figura 4.22: Distribuições de $X_{\max }$ (esquerda) e $(d E / d X)_{\max }$ (direita) para prótons de energia $E_{0}=320 \mathrm{EeV}$ (preto) e uhecrons de energias $E_{0}=320 \mathrm{EeV}$ (vermelho) e $E_{0}=352 \mathrm{EeV}$ (azul), após a simulação do telescópio e cortes iniciais.

\begin{tabular}{|c|c|c|c|c|c|c|c|c|}
\hline$E_{U}$ & $E_{p}$ & $N_{u}^{\prime} / N_{u}$ & $N_{p}^{\prime} / N_{p}$ & $N_{p}^{\prime} / N_{T}^{\prime}$ & $(d E / d X)_{\max }<$ & $\theta>$ & $H_{\max }<$ & $X_{\max }>$ \\
\hline 320 & 320 & 0.417 & 0.022 & 0.081 & $4.08 \mathrm{e}+08$ & 0.571 & 12.61 & 912.2 \\
\hline 352 & 320 & 0.402 & 0.043 & 0.152 & $5.20 \mathrm{e}+08$ & 0.633 & 11.50 & 973.3 \\
\hline 108 & 100 & 0.366 & 0.039 & 0.143 & $1.57 \mathrm{e}+08$ & 0.637 & 11.44 & 956.3 \\
\hline 54 & 50 & 0.299 & 0.016 & 0.080 & $6.64 \mathrm{e}+07$ & 0.400 & 11.41 & 882.8 \\
\hline
\end{tabular}

Tabela 4.10: Resultados após a aplicação dos cortes offline para uhecrons de massa $50 \mathrm{GeV} . E_{U}$ e $E_{p}$ indicam a energia inicial (EeV) dos uhecrons e prótons, respectivamente. $N_{u}\left(N_{u}^{\prime}\right)$ e $N_{p}\left(N_{p}^{\prime}\right)$ indicam o número de eventos antes (após) a aplicação dos cortes offline. $N_{T}^{\prime}=N_{u}^{\prime}+N_{p}^{\prime}$. As últimas 4 colunas indicam os valores que são aceitos após a otimização dos cortes ( $G e V \mathrm{~cm}^{2} / \mathrm{g}, \mathrm{rad}, \mathrm{km}$ e $\mathrm{g} / \mathrm{cm}^{2}$, respectivamente). 


\begin{tabular}{|c|c|c|c|c|c|c|c|c|}
\hline$E_{U}$ & $E_{p}$ & $N_{u}^{\prime} / N_{u}$ & $N_{p}^{\prime} / N_{p}$ & $N_{p}^{\prime} / N_{T}^{\prime}$ & $(d E / d X)_{\max }<$ & $\theta>$ & $H_{\max }<$ & $X_{\max }>$ \\
\hline 352 & 320 & 0.400 & 0.053 & 0.178 & $5.18 \mathrm{e}+08$ & 0.726 & 11.26 & 962.2 \\
\hline 108 & 100 & 0.344 & 0.043 & 0.159 & $1.57 \mathrm{e}+08$ & 0.400 & 11.18 & 952.8 \\
\hline 54 & 50 & 0.257 & 0.015 & 0.078 & $6.61 \mathrm{e}+07$ & 0.428 & 11.26 & 881.1 \\
\hline
\end{tabular}

Tabela 4.11: Resultados após a aplicação dos cortes cortes offline para uhecrons de massa $30 \mathrm{GeV}$ (ver legenda da tabela 4.10).

\begin{tabular}{|c|c|c|c|c|c|c|c|c|}
\hline$E_{U}$ & $E_{p}$ & $N_{u}^{\prime} / N_{u}$ & $N_{p}^{\prime} / N_{p}$ & $N_{p}^{\prime} / N_{T}^{\prime}$ & $(d E / d X)_{\max }<$ & $\theta>$ & $H_{\max }<$ & $X_{\max }>$ \\
\hline 352 & 320 & 0.390 & 0.062 & 0.198 & $5.54 \mathrm{e}+08$ & 0.712 & 11.41 & 961.4 \\
\hline 108 & 100 & 0.359 & 0.057 & 0.188 & $1.74 \mathrm{e}+08$ & 0.616 & 10.85 & 951.7 \\
\hline 54 & 50 & 0.411 & 0.071 & 0.198 & $8.12 \mathrm{e}+07$ & 0.300 & 10.90 & 922.3 \\
\hline
\end{tabular}

Tabela 4.12: Resultados após a aplicação dos cortes cortes offline para uhecrons de massa $20 \mathrm{GeV}$ (ver legenda da tabela 4.10).

A influência da energia e da massa do uhecron na eficiência dos cortes está relacionada com a diferença intrínseca entre os chuveiros analisados e a aceitância do detetor para determinado tipo de partícula. Vimos que essa aceitância pode distorcer as características intrínsecas dos EAS de uhecrons, aproximando-as das características de prótons, e que essa distorção aumenta para $X_{\max }$ maiores, relacionados com energias maiores e/ou massas maiores do uhecron. Além disso, para $X_{\max }$ menores (na região estudada) a aceitância do detetor cresce, levando a um maior número de eventos detectados. Assim, uma combinação de todos esses fatores altera a eficiência do método de separação.

Fixando-se a massa do uhecron, a diminuição da energia $\left(X_{\max }\right.$ menores $)$ não deve modificar significativamente as diferenças intrínsecas relativas entre uhecrons e prótons. Por outro lado, no caso das características efetivamente detectadas, essas diferenças aumentam com a diminuição da energia, devido à menor distorção das características intrínsecas causada pela detecção, distorção essa que aproximaria prótons e uhecrons. Essa diminuição de energia também aumentará a aceitância do detetor para uhecrons mais rapidamente que para prótons, levando a uma fração de uhecrons maior na amostra inicial no caso de energias menores ${ }^{9}$. Assim, esperamos uma maior eficiência do método

\footnotetext{
${ }^{9}$ Por exemplo, para uhecrons de massa $50 \mathrm{GeV}$, a fração de uhecrons na amostra inicial cresce
} 
para energias menores, como pode ser visto nas tabelas 4.10, 4.11 e 4.12, que mostram que a contaminação de prótons na amostra final tende a diminuir com a energia, ou seja, os cortes tornam-se mais eficientes com essa diminuição.

De modo análogo, fixando-se a energia estudada, a diminuição na massa do uhecron diminui sensivelmente as diferenças intrínsecas entre os dois tipos de chuveiro. Embora os $X_{\max }$ menores de uhecrons mais leves levem a uma distorção menor das características desses chuveiros e a um aumento na fração de uhecrons na amostra inicial, as diferenças intrínsecas menores entre os chuveiros de prótons e uhecrons levará a uma eficiência menor do método, como pode ser visto através de uma comparação entre as tabelas 4.10, 4.11 e 4.12, onde podemos observar que, em geral, a contaminação da sub-amostra de candidatos a uhecrons cresce com a diminuição da massa do uhecron.

Em suma, a eficiência dos cortes é maior para energias menores e maiores massas do uhecron, pelo menos na região de energias e massas analisadas neste trabalho.

\section{Influência da razão entre os fluxos de uhecrons e prótons}

Em nossa análise até agora geramos o mesmo número de eventos de uhecrons e prótons como entrada da nossa simulação do detetor de fluorescência. Isso é equivalente a um fluxo igual de prótons e uhecrons. Por outro lado, fluxos menores de uhecrons em relação a prótons devem diminuir a eficiência dos cortes offline, dificultando a separação entre as duas partículas.

Assim, com o intuito de analisar a influência desses fluxos diferentes na capacidade do método de distinguir prótons e uhecrons, variamos a razão entre os fluxos de uhecrons e prótons obtendo, após a simulação do telescópio e a aplicação dos cortes iniciais, novas amostras iniciais. Em seguida utilizamos essas novas amostras para a otimização dos cortes offline, como descrito anteriormente. Nessa nova análise, fatorizamos o fluxo de uhecrons a $10 \%, 5 \%$ e $1 \%$ em relação a prótons.

Com um número bem menor de uhecrons na amostra inicial, devemos minimizar a de $37 \%$ para $39 \%$ com a diminuição da energia dos prótons (uhecrons) de $320 E e V(352 \mathrm{EeV})$ para $50 \mathrm{EeV}(54 \mathrm{EeV})$. 
perda de uhecrons devido à aplicação dos cortes offline. Por isso, variamos o valor de $A$ no fator de qualidade $q$ (eq. 4.4), de forma a aumentar o peso do número final de uhecrons $N_{U}^{\prime}$ em $q$. A tabela 4.13 mostra alguns resultados para várias energias e vários valores de $A$. A figura 4.23 mostra as distribuições de $X_{\max }$ no caso de uma razão de 0.1 entre os fluxos de uhecrons e prótons de energia $E_{0}=352 \mathrm{EeV}$ e $E_{0}=320 \mathrm{EeV}$, respectivamente, antes e após a inclusão dos cortes offline.

\begin{tabular}{|c|c|c|c|c|c|c|}
\hline$E_{U}$ & $E_{p}$ & $\phi_{U} / \phi_{p}$ & $A$ & $N_{u}^{\prime} / N_{u}$ & $N_{p}^{\prime} / N_{p}$ & $N_{p}^{\prime} / N_{T}^{\prime}$ \\
\hline \hline 352 & 320 & 0.1 & 0.6 & 0.150 & 0.003 & 0.270 \\
\hline 352 & 320 & 0.05 & 0.5 & 0.111 & 0.001 & 0.261 \\
\hline \hline 108 & 100 & 0.05 & 0.6 & 0.084 & 0.0008 & 0.221 \\
\hline 108 & 100 & 0.05 & 0.7 & 0.141 & 0.030 & 0.430 \\
\hline \hline 54 & 50 & 0.05 & 0.6 & 0.145 & 0.001 & 0.213 \\
\hline 54 & 50 & 0.01 & 0.8 & 0.109 & 0.0003 & 0.356 \\
\hline
\end{tabular}

Tabela 4.13: Resultados após a aplicação dos cortes offline para uhecrons de massa $50 \mathrm{GeV} . E_{U}$ e $E_{p}$ indicam a energia inicial (EeV) dos uhecrons e prótons, respectivamente, $\phi_{U} / \phi_{p}$ é a razão entre os fluxos de uhecrons e prótons. $N_{u}\left(N_{u}^{\prime}\right)$ e $N_{p}\left(N_{p}^{\prime}\right)$ indicam o número de eventos antes (após) a aplicação dos cortes offline. $N_{T}^{\prime}=N_{u}^{\prime}+N_{p}^{\prime}$.
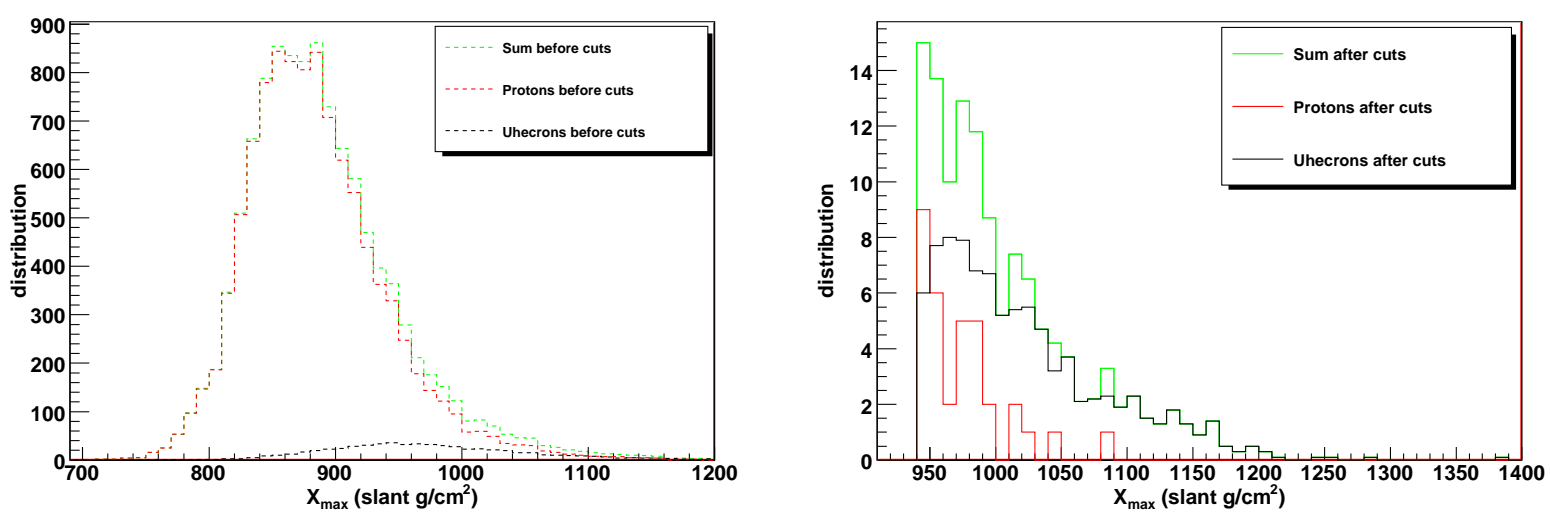

Figura 4.23: Distribuições de $X_{\max }$ no caso de uma razão de 0.1 entre os fluxos de uhecrons e prótons de energia $E_{0}=352 \mathrm{EeV}$ e $E_{0}=320 \mathrm{EeV}$, respectivamente, antes (esquerda) e após (direita) a inclusão dos cortes offline.

Dos resultados pode-se observar que ainda é possível distinguir entre prótons e uhecrons de massa $50 \mathrm{GeV}$ com uma razão entre os fluxos de 1\%, embora a fração de uhecrons aceitos pelos cortes offline seja apenas da ordem de $11 \%$ e a contaminação de prótons 
na amostra final da ordem de $37 \%$. O objetivo dessa análise simples é demonstrar que é possível separar sinais de uhecrons e prótons utilizando os cortes offline, mesmo no caso de fluxos de uhecrons ordens de grandeza menores que o fluxo de prótons. Uma análise mais detalhada no caso de baixos fluxos de uhecrons pode levar a cortes de melhor qualidade, onde o número de uhecrons aceitos é maior, e a contaminação por prótons menor do que os resultados aqui apresentados. É importante ressaltar que a razão entre os fluxos de prótons e uhecrons acima e abaixo do limite GZK pode variar sensivelmente devido à menor perda de energia dos uhecrons em relação a prótons acima desse limite, durante sua propagação da fonte até a Terra, levando a um fluxo muito maior de uhecrons a energias mais altas. 


\section{Capítulo 5}

\section{Discussão e conclusão}

Vimos que os EAS iniciados por uhecrons apresentam características marcantemente diferentes dos chuveiros iniciados por partículas usuais, e que mesmo após a deteç̧ão e reconstrução de eventos FD, ainda é possível observar essas diferenças.

Essa análise determinou as diferenças básicas que distinguem uhecrons de prótons. Dentre as partículas usuais, os prótons parecem ter os chuveiros mais parecidos com os iniciados por uhecrons. Vimos que EAS iniciados por núcleos se desenvolvem muito mais rapidamente, facilitando ainda mais sua separação de EAS de uhecrons. Espera-se que as características de EAS fotônicos também sejam bem diferentes, facilitando sua separação, porém uma análise mais detalhada nesse aspecto é necessária.

A razão entre os fluxos de prótons e uhecrons é uma incógnita, e sua influência em nossa capacidade de separar prótons e uhecrons é grande. Por outro lado, vimos que mesmo com um fluxo de uhecrons duas ordens de grandeza mais baixo que o de prótons, ainda é possível fazer uma distinção entre esses primários, embora a análise nesse caso não seja trivial. Essa razão entre os fluxos deve depender fortemente da energia. Acima do limite GZK, esperamos que o fluxo de uhecrons, caso presente, seja bem maior que o de prótons, devido à sua menor perda de energia durante a propagação. Esperase que esse fluxo de prótons presente acima do limite GZK seja devido apenas a fontes próximas do ponto de vista astrofísico, portanto menos numerosas que as possíveis fontes 
de uhecrons, que podem ser bem mais distantes. Por outro lado, vimos que a eficiência de nosso método de separação é menor a essas energias mais altas, especialmente devido à aceitância do FD. No caso de energias abaixo do limite GZK, esperamos que o fluxo de prótons seja dominante, dificultando a separação de uhecrons. Porém, nessa região de energia, nosso método de separação é mais eficiente.

Devido ao baixíssimo fluxo de UHECR, cuidados especiais devem ser dados aos cortes utilizados para a separação de sinais de uhecrons. Ao mesmo tempo que queremos eliminar prótons, os cortes aplicados devem aceitar um número significativo dos uhecrons presentes na amostra inicial, número este que pode ser extremamente baixo. Assim, somente a aplicação de cortes, embora muito eficiente para separar uhecrons de prótons, pode vir a ser inadequada para uma análise com tão baixa estatística. Por outro lado, as distribuições dos observáveis de chuveiros obtidas nesse trabalho podem ser utilizadas em outros tipos de análise mais refinadas, como a utilização de PCA (principal component analysis). Exemplos desse tipo de análise podem ser vistos em [67, 68].

Vimos também que as densidades de partículas carregadas no solo são diferentes para chuveiros iniciados por uhecrons. Assim, pode ser possível aliar nossos métodos de separação desses sinais, que utilizam detetores de fluorescência, com outros métodos de separação utilizando detetores de superfície, no caso de eventos híbridos.

Existem partículas descritas por modelos além do modelo padrão que se encaixam na classe de uhecrons, como o massive gluino LSP[4] e algumas classes de WIMPless dark matter[5], com massas entre $10 \mathrm{GeV}$ e $50 \mathrm{GeV}$. Ao se escolher um modelo específico para a busca de sinais dessas partículas em observatórios de UHECR, determinamos a massa específica do uhecron utilizado nessa busca. É possível, através de uma análise inicial utilizando os métodos descritos nesse trabalho, efetuar uma busca por sinais destas partículas nos dados reais do Observatório Pierre Auger, criando uma sub-amostra de candidatos a essas partículas.

Em resumo, através de alterações no pacote Aires de simulação de EAS e no modelo hadrônico Sibyll, foram gerados chuveiros iniciados por uhecrons, uma classe geral de 
partículas exóticas, que engloba várias partículas descritas por modelos além do modelo padrão. Um pacote de programas para a simulação da detecção e reconstrução de eventos pelo método de fluorescência também foi desenvolvido e, após a simulação da detecção e reconstrução dos chuveiros gerados pelos pacotes Aires/Sibyll alterados, foi possível obter distribuições dos observáveis de EAS iniciados por uhecrons. A partir da comparação entre as características de chuveiros iniciados uhecrons e prótons, desenvolvemos métodos para a separação de sinais entre esses dois tipos de partículas. Esses métodos podem ser utilizados em uma análise inicial, com o intuito de procurar por sinais de partículas exóticas nos dados reais de observatórios de UHECR. 


\section{Referências Bibliográficas}

[1] Chung DJH, Farrar GR, Kolb EW (1998) Are ultrahigh energy cosmic rays signals of supersymmetry? Phys Rev D57:4606-4613. doi:10.1103/PhysRevD.57.4606. astro-ph/9707036.

[2] Albuquerque I, Farrar G, Kolb E (1999) Exotic massive hadrons and ultrahigh energy cosmic rays. Phys Rev D 59:015021.

[3] Raby S (1998) Gauge-mediated SUSY breaking with a gluino LSP. Phys Lett B 422:158.

[4] Mafi A, Raby S (2000) Analysis of a heavy gluino LSP at CDF: The heavy gluino window. Phys Rev D 62:035003.

[5] Feng JL, Kumar J (2008) The WIMPless miracle hep-ph/0803.4196v1.

[6] W Carvalho Jr, IFM Albuquerque and V de Souza (2007) Effects of the energy error distribution of fluorescence telescopes on the UHECR energy spectrum. Astropart Phys 28:89-97. doi:10.1016/j.astropartphys.2007.04.010. astro-ph/0702123.

[7] Engel J, Gaisser TK, Stanev T, Lipari P (1992) Nucleus-nucleus collisions and interpretation of cosmic ray cascades. Phys Rev D46:5013-5025. doi: 10.1103/PhysRevD.46.5013.

[8] Sciutto SJ (1999). AIRES: A system for air shower simulations (Version 2.2.0). astro-ph/9911331. 
[9] Watson A (2002). Extensive air showers and ultra high energy cosmic rays. URL http://www . ast. leeds.ac.uk/Auger/augerthesis/mexlects3.pdf.

[10] Greisen K (1966) End to the cosmic ray spectrum? Phys Rev Lett 16:748-750. doi:10.1103/PhysRevLett.16.748.

[11] Zatsepin GT, Kuz'min VA (1966) ZhETF Pis'ma Eksp 4:114.

[12] Zatsepin GT, Kuzmin VA (1966) Upper limit of the spectrum of cosmic rays. JETP Lett 4:78-80.

[13] Bhattacharjee P, Sigl U (2000) Origin and propagation of extremely high-energy cosmic rays. Phys Rep 327:109-247.

[14] Berezinsky V, Gazizov AZ, Grigorieva SI (2006) On astrophysical solution to ultra high energy cosmic rays. Phys Rev D74:043005. hep-ph/0204357.

[15] Aharonian FA, Cronin JW (1994) Influence of the universal microwave background radiation on the extragalactic cosmic ray spectrum. Phys Rev D50:1892-1900. doi:10.1103/PhysRevD.50.1892.

[16] Cronin JW (2005) The highest-energy cosmic rays. Nucl Phys Proc Suppl 138:465491. astro-ph/0402487.

[17] De Marco D (2005) Propagation of UHECRs astro-ph/0506412.

[18] Letessier-Selvon A (2000) Theoretical and experimental topics on ultra high energy cosmic rays astro-ph/0006111.

[19] Sigl G (2004) Some current theoretical issues around ultra-high energy cosmic rays. Acta Phys Polon B35:1845-1862. astro-ph/0404074.

[20] Hooper D, Sarkar S, Taylor AM (2007) The intergalactic propagation of ultra-high energy cosmic ray nuclei. Astropart Phys 27:199-212. astro-ph/0608085. 
[21] Hillas AM (1984) The Origin of Ultrahigh-Energy Cosmic Rays. Ann Rev Astron Astrophys 22:425-444. doi:10.1146/annurev.aa.22.090184.002233.

[22] Sigl G, Schramm DN, Bhattacharjee P (1994) On the origin of highest energy cosmic rays. Astropart Phys 2:401-414. doi:10.1016/0927-6505(94)90029-9. astro-ph/9403039.

[23] Aharonian FA, Bhattacharjee P, Schramm DN (1992) Photon/proton ratio as a diagnostic tool for topological defects as the sources of extremely high-energy cosmic rays. Phys Rev D 46:4188-4192. doi:10.1103/PhysRevD.46.4188.

[24] The Pierre Auger Collaboration (2008) Upper limit on the cosmic-ray photon flux above $10^{19} \mathrm{eV}$ using the surface detector of the Pierre Auger Observatory. Astropart Phys 29:243-256. doi:doi:10.1016/j.astropartphys.2008.01.003.

[25] Blasi P (2003) Theoretical aspects of ultra high energy cosmic rays astro-ph/0304206.

[26] Norman CA, Melrose DB, Achterberg A (1995) The Origin of Cosmic Rays above $10^{18.5} \mathrm{eV}$. Astrophys J 454:60.

[27] Elbert JW, Sommers P (1995) In search of a source for the $320 \mathrm{EeV}$ Fly's Eye cosmic ray. Astrophys J 441:151-161. astro-ph/9410069.

[28] Bird DJ, et al. (1995) Detection of a cosmic ray with measured energy well beyond the expected spectral cutoff due to cosmic microwave radiation. Astrophys J 441:144-150.

[29] Hayashida N, et al. (1994) Observation of a very energetic cosmic ray well beyond the predicted 2.7-K cutoff in the primary energy spectrum. Phys Rev Lett 73:34913494. doi:10.1103/PhysRevLett.73.3491.

[30] Bergman DR, for the HiRes Collaboration (2007) Observation of the GZK cutoff using the HiRes detector. Nucl Phys Proc Suppl 165:19-26. astro-ph/0609453. 
[31] Abbasi R, et al. (2008) Observation of the GZK cutoff by the HiRes experiment. Phys Rev Lett 100:101101. doi:10.1103/PhysRevLett.100.101101. astro-ph/0703099.

[32] Roth M, et al. (2007) Measurement of the UHECR energy spectrum using data from the Surface Detector of the Pierre Auger Observatory arXiv:0706.2096 [astro-ph].

[33] Perrone L, et al. (2007) Measurement of the UHECR energy spectrum from hybrid data of the Pierre Auger Observatory arXiv:0706.2643 [astro-ph].

[34] Facal San Luis P (2007) Measurement of the UHECR spectrum above $10 \mathrm{EeV}$ at the Pierre Auger Observatory using showers with zenith angles greater than 60 degrees arXiv:0706.4322 [astro-ph].

[35] Abraham J, et al. (2007) Correlation of the highest energy cosmic rays with nearby extragalactic objects. Science 318:938-943. doi:10.1126/science.1151124. 0711.2256.

[36] Abraham J, et al. (2008) Correlation of the highest-energy cosmic rays with the positions of nearby active galactic nuclei. Astropart Phys 29:188-204. doi: 10.1016/j.astropartphys.2008.01.002. 0712.2843.

[37] U.S. Standard Atmosphere 1976 URL http://modelweb.gsfc.nasa.gov/atmos/us_standard.html.

[38] Schmidt F Corsika shower images URL http://www.ast.leeds.ac.uk/ fs/showerimages.html.

[39] Heitler W (1949) Theory of meson production. Rev Mod Phys 21:113-121. doi: 10.1103/RevModPhys.21.113. 
[40] Heck D, Knapp J, Capdevielle J, Schatz G, Thouw T (1998) A Monte-Carlo Code to Simulate Extensive Air Showers - Report FZKA 6019. Technical report, Forschungszentrum Karlsruhe, www.ik.fzk.de/角k/corsika.

[41] Kalmykov NN, Ostapchenko SS, Pavlov AI (1997) Quark-gluon string model and EAS simulation problems at ultra-high energies. Nucl Phys Proc Suppl 52B:17-28.

[42] Anchordoqui L, et al. (2004) High energy physics in the atmosphere: Phenomenology of cosmic ray air showers. Ann Phys 314:145-207. doi: 10.1016/j.aop.2004.07.003. hep-ph/0407020.

[43] Hillas A (1985) Study of model dependence of EAS simulations at $E \geq 10^{19} \mathrm{eV}$. In: Proc. $19^{\text {th }}$ Int. Cosmic Ray Conf., La Jolla (USA). p. 155.

[44] Engel R, Gaisser T, Lipari P, Stanev T (1999) Air Shower Calculations With the New Version of SIBYLL. In: $26^{\text {th }}$ Int. Cosmic Ray Conf. Salt Lake City, volume 1, p. 415 .

[45] Capella A, Krzywicki A (1978) Theoretical model for soft hadron-nucleus collisions at high energies. Phys Rev D 18:3357.

[46] Gaisser T, Halzen F (1985) "Soft" Hard Scattering in the Teraelectronvolt Range. Phys Rev Lett 54:1754.

[47] Durand L, Pi H (1987) QCD and Rising Cross Sections. Phys Rev Lett 58:303.

[48] Bengtsson H, Sjostrand T (1987) The Lund Monte Carlo for hadronic processes PYTHIA version 4.8. Comp Phys Commun 46:43-82.

[49] Gaisser TK, Hillas AM (1977) In: $15^{\text {th }}$ Int. Cosmic Ray Conf. Salt Lake City, volume 8, p. 353 .

[50] The Pierre Auger Collaboration (1997) Auger Project Design Report. Technical report, www.auger.org/reports/design_report.html. 
[51] Auger-LAL. URL http://auger.lal.in2p3.fr/.

[52] Sokolsky P (1989) Introduction to Ultrahigh Energy Cosmic Ray Physics. AddisonWesley Publishing Company.

[53] Abbasi R, et al. (2005) Monocular Measurement of the Spectrum of UHE Cosmic Rays by the FADC detector of the HiRes Experiment. Astropart Phys 23:157-174.

[54] The Pierre Auger Collaboration (2004) Properties and performance of the prototype instrument for the Pierre Auger observatory. Nucl Instr and Meth A523:50-95.

[55] Nagano M, Kobayakawa K, Sakaki N, Ando K (2004) New measurement on photon yields from air and the application to the energy estimation of primary cosmic rays. Astropart Phys 22:235. astro-ph/0406474.

[56] Nagano M, Kobayakawa K, Sakaki N, Ando K (2003) Photon yields from nitrogen gas and dry air excited by electrons. Astropart Phys 20:293. astro-ph/0303193.

[57] Kakimoto F, et al. (1996) A measurement of the air fluorescence yield. Nucl Instrum Meth A372:527-533.

[58] Abraham J, et al. (2007) An upper limit to the photon fraction in cosmic rays above $10^{19} \mathrm{eV}$ from the Pierre Auger observatory. Astropart Phys 27:155-168. doi: 10.1016/j.astropartphys.2006.10.004. astro-ph/0606619.

[59] AIRFLY Collaboration (2007). Measurement of the pressure dependence of air fluorescence emission induced by electrons. astro-ph/0703132.

[60] Healy MD, et al. (2007). Composition-sensitive parameters measured with the surface detector of the Pierre Auger Observatory. URL http://www. citebase .org/abstract?id=oai : arXiv .org:0706.1569.

[61] Kampert KH, for the KASCADE-Grande Collaboration (2006). Recent Results from Kascade-Grande. astro-ph/0608340. 
[62] Abbasi R, et al. (2004) Measurement of the flux of ultrahigh energy cosmic ray from monocular observations by the High Resolution Fly's Eye Experiment. Physical Review Letters 92:151101-1.

[63] The Pierre Auger Collaboration (2005) First estimate of the primary cosmic ray energy spectrum above $3 \mathrm{EeV}$ form the Pierre Auger Observatory. In: $29^{\text {th }}$ Int. Cosmic Ray Conf. Usa-sommers-P-abs1-he14-oral.

[64] Barbosa HMJ, Catalani F, Chinellato JA, Dobrigkeit C (2004) Determination of the calorimetric energy in extensive air showers. Astropart Phys 22:159-166.

[65] ALEPH collaboration (1995) Measurement of the effective b quark fragmentation function at the $\mathrm{z}$ resonance. Phys Lett B 357:699-714. 28 p.

[66] Sciutto SJ (2001) The AIRES system for air shower simulations. An update astro-ph/0106044.

[67] Abbasi R, et al. (2006) A likelihood method for measuring the ultrahigh energy cosmic ray composition. Astropart Phys 26:28-40. astro-ph/0604558.

[68] Catalani F, Chinellato JA, de Souza V, Takahashi J, Vasconcelos GMS (2007) Statistical methods applied to composition studies of ultrahigh energy cosmic rays. Astropart Phys 28:357-365. astro-ph/0703582.

[69] Chou A (2006) Deep shower interpretation of the cosmic ray events observed in excess of the Greisen-Zatsepin-Kuzmin energy. Phys Rev D 74:103001. astro-ph/0606742.

[70] ROOT System - An Object-Oriented Data Analysis Framework URL http://root.cern.ch/.

[71] Friedberg S, Insel A (1986) Introduction to linear algebra with applications. Prentice-Hall. 
[72] Goldstein H (1980) Classical Mechanics. Addison-Wesley Publishing Company.

[73] de Souza V, Medina-Tanco G, Ortiz JA (2006) On the fluctuations of the fluorescence photon yield of electrons in extensive air showers for different atmospheric conditions. Astropart Phys 25:84-92. doi:10.1016/j.astropartphys.2005.12.001.

[74] Boyer JH, et al. (2002) FADC-based DAQ for HiRes Fly's Eye. Nuclear Instruments and Methods in Physics Research A 482:457-474.

[75] L Prado Jr, et al. (2005) Simulation of the fluorescence detector of the Pierre Auger Observatory. Nucl Instr and Meth A 545:632-642. 


\section{Apêndice A}

\section{Shower Tools.}

OShower Tools é um pacote de ferramentas que desenvolvemos para a análise e simulação de detecção de chuveiros atmosféricos. Ele é escrito em $\mathrm{C}++$ e utiliza o ROOT System [70]. O Shower Tools é constituído por classes $^{1}$ que armazenam e operam sobre elementos de um chuveiro atmosférico e classes que simulam detetores. A seguir, descrevemos as principais classes implementadas. Estas incluem todas as ferramentas necessárias para simular a detecção e reconstrução de eventos FD, e para a sua análise.

\section{A.1 Sistemas de coordenadas utilizados na simulação}

Na simulação foram utilizados três sistemas de coordenadas relacionados entre si por transformações lineares[71]: Sistema do telescópio (sistema Tel), sistema da atmosfera (sistema Atm) e sistema do eixo do chuveiro (sistema $S A$ ). O sistema do telescópio é utilizado para todos os cálculos geométricos em relação ao telescópio. O sistema da atmosfera é utilizado para obter as profundidades atmosféricas corretas para os pontos de emissão de luz de fluorescência, pois leva em conta a altitude do telescópio. Finalmente,

\footnotetext{
${ }^{1}$ Uma classe é um pedaço de código que armazena variáveis relacionadas entre si e os métodos que operam sobre essas variáveis, ou seja, é a unidade de definição de dados e comportamento (funcionalidade) para "alguma coisa". Uma instância específica de uma classe é chamada objeto, e geralmente é utilizado para modelar objetos do mundo real, como por exemplo um perfil longitudinal de deposição ou um conjunto de fotomultiplicadoras. Uma classe é a base da modularidade e estrutura da programação orientada a objetos.
} 
o sistema do eixo do chuveiro é utilizado para gerar uma direção reconstruída para o eixo do chuveiro.

A origem do sistema Tel é o telescópio e o eixo $z$ é vertical, logo os eixos $x$ e $y$ se encontram num plano horizontal, paralelo à superfície terrestre. No sistema Atm a origem é o ponto de intersecção da linha vertical que passa pelo telescópio com o plano do nível do mar (Fig. A.1). Todos os eixos de coordenadas do sistema Atm são paralelos aos eixos do sistema Tel. Esses dois sistemas são ligados por uma translação:

$$
\vec{I}^{a t m}=\vec{I}^{t e l}+A \hat{z}
$$

onde $A$ é a altitude do telescópio acima do nível do mar.

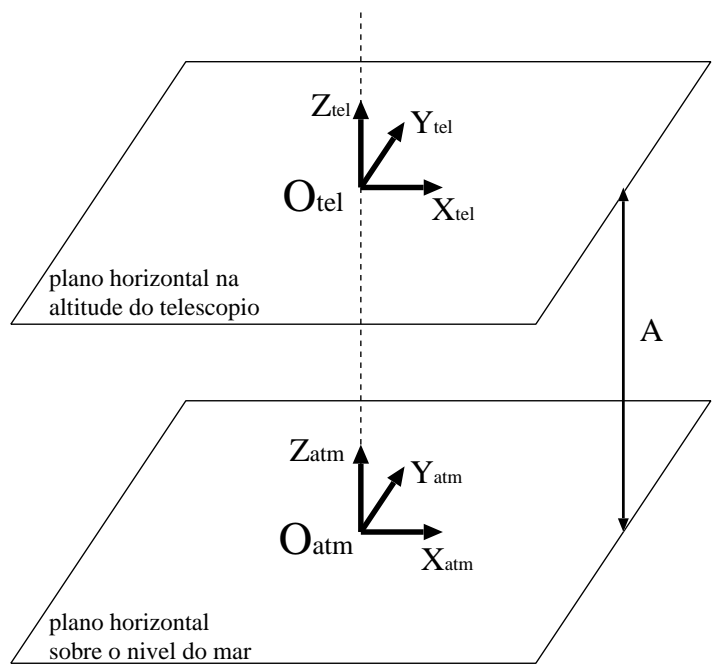

Figura A.1: Esquema da relação entre o sistema do telescópio $\left(O_{t e l}\right)$ e o sistema da atmosfera $\left(O_{\text {atm }}\right)$.

No sistema $S A$ o eixo $z$ coincide com a direção $\vec{D}$ do eixo do chuveiro. Esse sistema está relacionado com o sistema Tel por duas rotações: uma rotação em torno do eixo $z$ de $\phi_{d i r}$ e outra em torno do novo eixo $y$ de $\theta_{d i r}$, onde $\phi_{d i r}$ e $\theta_{\text {dir }}$ são os ângulos que definem a direção do eixo do chuveiro no sistema Tel. Como esse sistema somente é utilizado para gerar novas direções, a posição de sua origem é irrelevante. As duas rotações que relacionam os sistemas $T e l$ ao sistema $S A$ podem ser descritas pela matriz 
de rotação[71, 72]:

$$
R\left(\theta_{d i r}, \phi_{d i r}\right)=\left(\begin{array}{ccc}
\cos \theta_{d i r} \cos \phi_{d i r} & -\sin \phi_{d i r} & \sin \theta_{d i r} \cos \phi_{d i r} \\
\cos \theta_{d i r} \sin \phi_{d i r} & \cos \phi_{d i r} & \sin \theta_{d i r} \sin \phi_{d i r} \\
-\sin \theta_{d i r} & 0 & \cos \theta_{d i r}
\end{array}\right)
$$

que é utilizada nas transformações entre os sistemas Tel e $S A$ :

$$
\begin{gathered}
\vec{V}_{S A}=R\left(\theta_{d i r}, \phi_{d i r}\right) \cdot \vec{V}_{T e l} \\
\mathrm{e} \\
\vec{V}_{T e l}=R^{-1}\left(\theta_{d i r}, \phi_{d i r}\right) \cdot \vec{V}_{S A},
\end{gathered}
$$

onde $\vec{V}_{S A}$ e $\vec{V}_{T e l}$ são vetores nos sistemas $S A$ e $T e l$, respectivamente.

Para simplificar a nomenclatura, já que a maioria dos cálculos descritos são efetuados no sistema Tel, os vetores e pontos nesse sistema não conterão nenhuma marca, enquanto que os vetores nos sistemas Atm e $S A$ conterão os superescritos Atm e $S A$, respectivamente.

\section{A.2 Classe Energy Deposition}

Este classe é responsável pelas variáveis e elementos que constituem a deposição de energia ao longo do desenvolvimento longitudinal do chuveiro atmosférico. A seguir, descrevemos algumas de suas funções e os métodos utilizados.

\section{A.2.1 Leitura dos dados do perfil de deposição de energia}

O método ReadCorsika é responsável pela leitura dos dados de deposição de energia de um arquivo de saída do Corsika ou do Aires. Esse tipo de arquivo contém a energia total depositada em cada passo de profundidade atmosférica. O comprimento desse passo, bem como se é descrito em profundidade atmosférica vertical ou slant, depende dos 
parâmetros utilizados no arquivo de entrada. O método ${ }^{2}$ ReadCorsika reconhece automaticamente o tipo de profundidade atmosférica utilizado (vertical ou slant) e divide a energia total depositada no passo pelo tamanho do passo, criando um perfil longitudinal de deposição $d E / d X \times X$ que é marcado ${ }^{3}$ como vertical ou slant e armazenado em um objeto TGraphErrors do ROOT System. A incerteza em $d E / d X$ é tomada como sendo unitária, para finalidades de ajuste. Outras variáveis lidas pelo ReadCorsika são:

- $E_{0}$ : Energia $(\mathrm{GeV})$ de entrada do Corsika.

- $\theta, \varphi$ : direção do chuveiro simulado.

- Step: Tamanho do passo utilizado no perfil longitudinal de deposição.

- $N_{p}$ : Número de pontos no perfil longitudinal.

Para o caso da utilização do Aires, um método semelhante, chamado ReadAires é utilizado. Através desses métodos é possível criar um arquivo .root com os dados de deposição do Corsika ou Aires. Este arquivo possui uma série de vantagens em relação à utilização do arquivo de saída original do Corsika, entre elas um tamanho menor, pois além de conter somente a informação necessária para a simulação, é um arquivo automaticamente comprimido pelo Root; e maior facilidade de manuseio por ser o formato nativo de arquivos utilizado no Root. Este arquivo possui um TTree[70] com o perfil de deposição em um TGraphErrors, que é marcado como vertical ou slant, além das variáveis descritas acima. Uma vez criado este arquivo com os dados de deposição, estes podem ser lidos utilizando o método ReadEDTree, muito mais rápido e eficiente que os métodos ReadCorsika ou ReadAires.

Perfis longitudinais provenientes da simulação do telescópio (objetos ShowerGeometry e PMT) também podem ser utilizados como entrada. Para isso foi criado o método ReadRec, que lê um TGraphErrors com o perfil longitudinal simulado e suas incertezas,

\footnotetext{
${ }^{2}$ Um método designa uma função que opera sobre as variáveis ou elementos armazenados em uma classe.

${ }^{3}$ Essa marcação é feita utilizando-se um flag que durante todo programa indica que tipo de perfil está sendo utilizado.
} 
sua unidade de profundidade atmosférica $\left(\mathrm{g} / \mathrm{cm}^{2}\right.$ vertical ou slant), além da direção do eixo do chuveiro $(\theta$ e $\varphi)$.

\section{A.2.2 Transformações entre profundidade atmosférica vertical e slant}

Os métodos SlanttoVert e VerttoSlant permitem transformar os perfis de deposição entre os dois tipos de profundidade atmosférica, utilizando a relação 1.18. Vale notar que não somente a profundidade atmosférica $X$ deve ser transformada, mas também a deposição $d E / d X$, pois o elemento $d X$ é alterado pela transformação e a integral entre profundidades equivalentes deve permanecer constante. Assim foram utilizadas as seguintes relações:

$$
\begin{gathered}
X_{v}=X_{s} \cos \theta, \quad X_{s}=\frac{X_{v}}{\cos \theta} \\
\left(\frac{d E}{d X}\right)_{v}=\frac{\left(\frac{d E}{d X}\right)_{s}}{\cos \theta} \text { e }\left(\frac{d E}{d X}\right)_{s}=\left(\frac{d E}{d X}\right)_{v} \cos \theta
\end{gathered}
$$

onde $\theta$ é a inclinação azimutal do chuveiro e $v$ e $s$ indicam unidades verticais e slant de profundidade atmosférica, respectivamente.

\section{A.2.3 Transformação da inclinação zenital do chuveiro}

A simulação de chuveiros atmosféricos é extremamente cara computacionalmente, especialmente para altas energias. Além disso, uma simulação que leva em conta a geometria de detecção requer um grande número de perfis de deposição simulados com diferentes inclinações zenitais para análise. Embora os raios cósmicos apresentem uma distribuição isotrópica, a geometria de detecção altera a distribuição de inclinação dos chuveiros que são efetivamente detectados, bem como a parte do perfil de deposição desses chuveiros que são utilizados na análise (ver seção A.4.2). Desse modo, se utilizarmos uma saída do Corsika com chuveiros isotrópicos, a maior parte desses não seria efetivamente 
analisada, levando a um extremo desperdício de processamento e tempo.

O perfil longitudinal de um chuveiro em profundidade atmosférica slant leva em conta a quantidade de matéria atravessada por este chuveiro. Desse modo é possível utilizar, com um mínimo de impacto nos resultados da simulação, a deposição simulada de um chuveiro de certa inclinação como a deposição de um chuveiro de inclinação diferente. Também, como apenas a parte desse perfil de deposição vista pelo telescópio é utilizada na análise, parte essa determinada pela geometria simulada para esse chuveiro, um mesmo perfil de deposição simulado pode ser utilizado múltiplas vezes na simulação. Esse método é amplamente utilizado em simulações que incluem algum tipo de geometria, como no caso da simulação do telescópio do experimento HiRes [53].

Para implementar esse método é necessário alterar o ângulo de inclinação zenital do chuveiro. No caso de perfis de deposição expressos em profundidade atmosférica slant, essa transformação é trivial, bastando modificar o ângulo zenital que será utilizado na geometria de detecção, sem nenhuma alteração do perfil de deposição. Porém, no caso de perfis de deposição expressos em profundidade atmosférica vertical, é necessário transformar o perfil de deposição. A figura A.2 é um esquema que ilustra essa transformação. Ao se alterar o ângulo de inclinação de um certo chuveiro, um determinado ponto no perfil de deposição em profundidade atmosférica slant permanece inalterado $\left(X_{s}=X_{s}^{\prime}\right)$, porém a profundidade atmosférica vertical desse ponto é alterada ao se alterar a inclinação $\left(X_{v}^{\prime} \neq X_{v}\right)$. Desse modo, utilizamos as seguintes relações para transformar o perfil vertical $(d E / d X)_{v} \times X_{v}$ ao se alterar a inclinação de um chuveiro:

$$
X_{v}^{\prime}=X_{v} \frac{\cos \theta_{t}}{\cos \theta_{0}} \quad \text { e }\left(\frac{d E}{d X}\right)_{v}^{\prime}=\left(\frac{d E}{d X}\right)_{v} \frac{\cos \theta_{0}}{\cos \theta_{t}}
$$

onde $\theta_{0}$ é a inclinação original do chuveiro, $\theta_{t}$ é a nova inclinação e ' indica grandezas transformadas para o novo ângulo. 


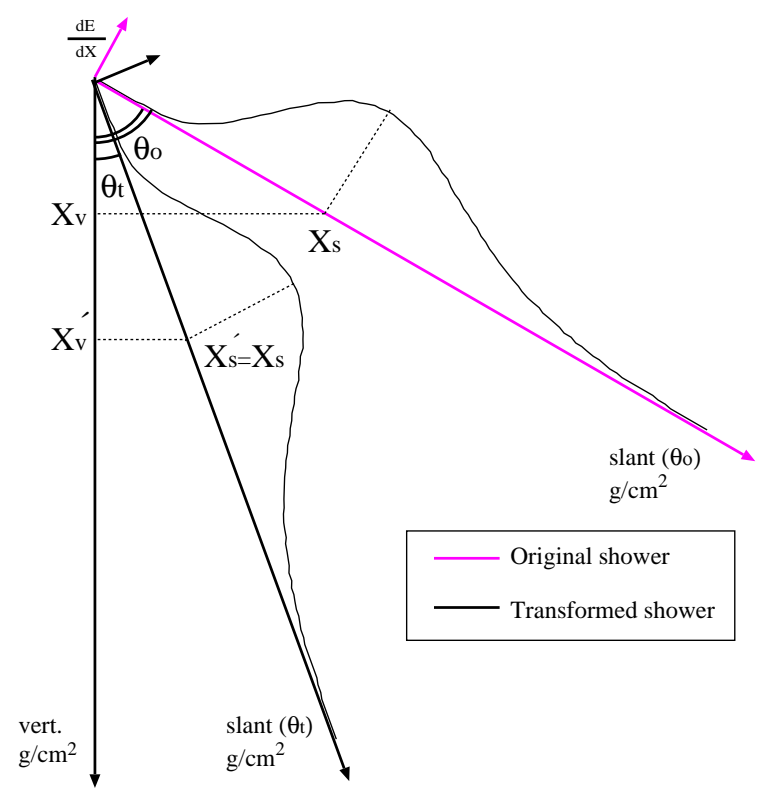

Figura A.2: Esquema ilustrativo da transformação da inclinação zenital do perfil longitudinal de deposição de um chuveiro atmosférico. O perfil de deposição em profundidade atmosférica slant permanece inalterado $\left(X_{s}=X_{s}^{\prime}\right)$.

\section{A.2.4 Ajuste da função Gaisser-Hillas ao perfil longitudinal de deposição de energia}

Como discutido na seção 1.4, a deposição de energia na atmosfera é proporcional ao número de partículas (eq. 1.38). Assim, o perfil longitudinal de deposição de energia está intimamente ligado ao perfil longitudinal "normal". Desse modo, a função GaisserHillas (eq. 1.37) também pode ser utilizada para descrever o comportamento médio do perfil longitudinal de deposição de energia de um chuveiro atmosférico. Uma de duas variantes dessa função é ajustada ao perfil de deposição, dependendo das características desse perfil. A primeira variante utilizada é a forma clássica da função Gaisser-Hillas, onde o número de partículas $N(X)$ é substituído pela deposição de energia $d E / d X$ :

$$
\left(\frac{d E}{d X}\right)(X)=\left(\frac{d E}{d X}\right)_{\max }\left(\frac{X-X_{0}}{X_{\max }-X_{0}}\right)^{\frac{\left(X_{\max }-X_{0}\right)}{\lambda}} \exp \left[\frac{\left(X_{\max }-X\right)}{\lambda}\right]
$$


Em nosso programa, essa função é utilizada para ajustar perfis longitudinais parciais $^{4}$ de deposição, que devem ser necessariamente expressos em termos de profundidade atmosférica slant. Os parâmetros $X_{0}$ e $\lambda$ são fixados em $-60 \mathrm{~g} / \mathrm{cm}^{2}$ e $70 \mathrm{~g} / \mathrm{cm}^{2}$, respectivamente, que são os valores utilizados nos ajustes do experimento HiRes [53], enquanto que os parâmetros ajustados $(d E / d X)_{\max }$ e $X_{\max }$ são limitados nos intervalos $\left[D_{\max }-3 \%, D_{\max }+3 \%\right]$ e $\left[P_{\max }-70 \mathrm{~g} / \mathrm{cm}^{2}, P_{\max }+70 \mathrm{~g} / \mathrm{cm}^{2}\right]$, onde $D_{\max }$ é a máxima deposição de energia presente nos dados e $P_{\max }$ é a profundidade atmosférica desse dado com deposição $D_{\max }$.

A segunda variante utiliza um polinômio de segundo grau na profundidade atmosférica $X$ para descrever a variável $\lambda$, que pode ser interpretada como o livre caminho médio de um elétron no ar:

$$
\left(\frac{d E}{d X}\right)(X)=\left(\frac{d E}{d X}\right)_{\max }\left(\frac{X-X_{0}}{X_{\max }-X_{0}}\right)^{\frac{\left(X_{\max }-X_{0}\right)}{\lambda_{0}+\lambda_{1} X+\lambda_{2} X^{2}}} \exp \left[\frac{\left(X_{\max }-X\right)}{\lambda_{0}+\lambda_{1} X+\lambda_{2} X^{2}}\right]
$$

Essa variante é utilizada por nosso programa somente para o ajuste de perfis longitudinais completos, como os obtidos diretamente do Corsika. O parâmetro $X_{0}$ é fixado em $-60 \mathrm{~g} / \mathrm{cm}^{2}$ e os parâmetros ajustados $(d E / d X)_{\max }$ e $X_{\max }$ são limitados nos intervalos $\left[D_{\max }-3 \%, D_{\max }+3 \%\right]$ e $\left[P_{\max }-100 \mathrm{~g} / \mathrm{cm}^{2}, P_{\max }+100 \mathrm{~g} / \mathrm{cm}^{2}\right]$, respectivamente.

A necessidade da utilização de funções diferentes para o ajuste de perfis longitudinais completos e parciais está relacionada com a integral da função ajustada, que é a medida da energia calorimétrica do chuveiro. Embora a função $\operatorname{com} \lambda$ variável (eq. A.5) produza ajustes de melhor qualidade $\left(\chi_{\text {red }}^{2}\right.$ menor $)$, mesmo no caso de perfis parciais, como temos mais parâmetros ajustados, devido ao polinômio que representa $\lambda$, a forma da curva ajustada é passível de grande alteração devido a flutuações locais no perfil longitudinal. Essas flutuações na forma, por sua vez, levam a uma grande flutuação na integral da função, que é a energia calorimétrica que estamos tentando medir. Por outro lado, a

\footnotetext{
${ }^{4}$ Perfis parciais designam aqui perfis de deposição onde somente a parte visível, isto é, a parte que é efetivamente detectada por um telescópio de fluorescência é analisada (veja seção A.4.2). Um perfil longitudinal completo obtido do Corsika pode ser limitado utilizando-se o método SetLimits da classe Energy Deposition.
} 
função com $\lambda$ fixo (eq. A.4), cujos parâmetros ajustados são somente $(d E / d X)_{\max }$ e $X_{\max }$, mantém sua forma estável devido ao valor fixo de $\lambda=70 \mathrm{~g} / \mathrm{cm}^{2}$, levando a uma flutuação muito menor na medida da energia calorimétrica.

Em todos os ajustes foi utilizado o "pacote" de minimização MINUIT ${ }^{5}$, parte do ROOT System[70] e o valor de $\chi_{\text {red }}^{2}$ calculado usando os métodos GetChisquare e GetNDF, da classe TF1 do Root system. Nosso programa diferencia automaticamente perfis parciais de perfis completos, e no caso de um perfil parcial descrito em profundidade atmosférica vertical, esse é automaticamente transformado para uma descrição em profundidade atmosférica slant, antes do ajuste. A figura A.3 mostra um exemplo de ajuste a um perfil longitudinal de deposição completo, e a figura A.4 mostra um ajuste ao mesmo perfil, limitado entre 250 e $600 \mathrm{~g} / \mathrm{cm}^{2}$ na vertical. Note que o perfil de deposição foi transformado automaticamente para profundidade atmosférica slant antes do ajuste e que os valores de $\chi_{\text {red }}^{2}$ são muito grandes devido à incerteza unitária definida para perfis provenientes diretamente do Corsika ou Aires.

\section{A.2.5 Integração da função GH e missing energy}

Para a reconstrução da energia da partícula primária, a função Gaisser-Hillas, que foi ajustada ao perfil longitudinal e representa o comportamento médio de $(d E / d X)(X)$, é integrada utilizando o método Integral(xmin,xmax) da classe TF1 do ROOT System. Para minimizar problemas com precisão numérica, a função é inicialmente integrada de $X=0$ até $X=1000 \mathrm{~g} / \mathrm{cm}^{2}$ e, a partir desse ponto, a integral é feita em passos de $5 \mathrm{~g} / \mathrm{cm}^{2}$. A integral de cada passo é somada às integrais anteriores e é comparada com o valor total obtido. Quando a integral do passo for menor que $0.0001 \%$ do valor total, a integral é considerada completa.

A integral do perfil longitudinal de deposição representa a energia calorimétrica $E_{c a l}$, que é utilizada para se obter a energia reconstruída $E_{0}$ do primário (eq. 1.43). Nessa

\footnotetext{
${ }^{5} \mathrm{O}$ MINUIT foi originalmente desenvolvido em FORTRAN, porém foi transformado em uma classe $\mathrm{C}++$ e incluído no ROOT System.
} 


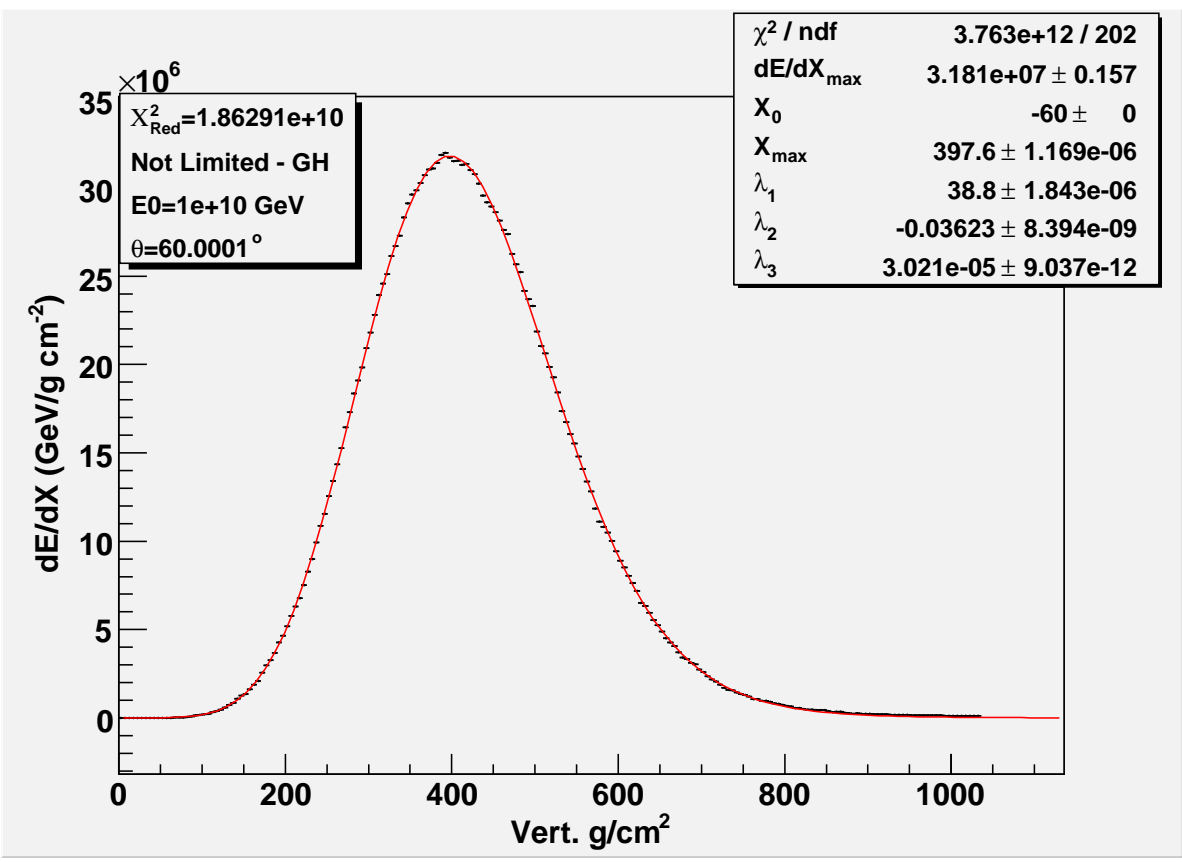

Figura A.3: Exemplo de ajuste da função A.5 a um perfil longitudinal de deposição completo obtido diretamente do Corsika. As incertezas nesse caso são tomadas como sendo unitárias.

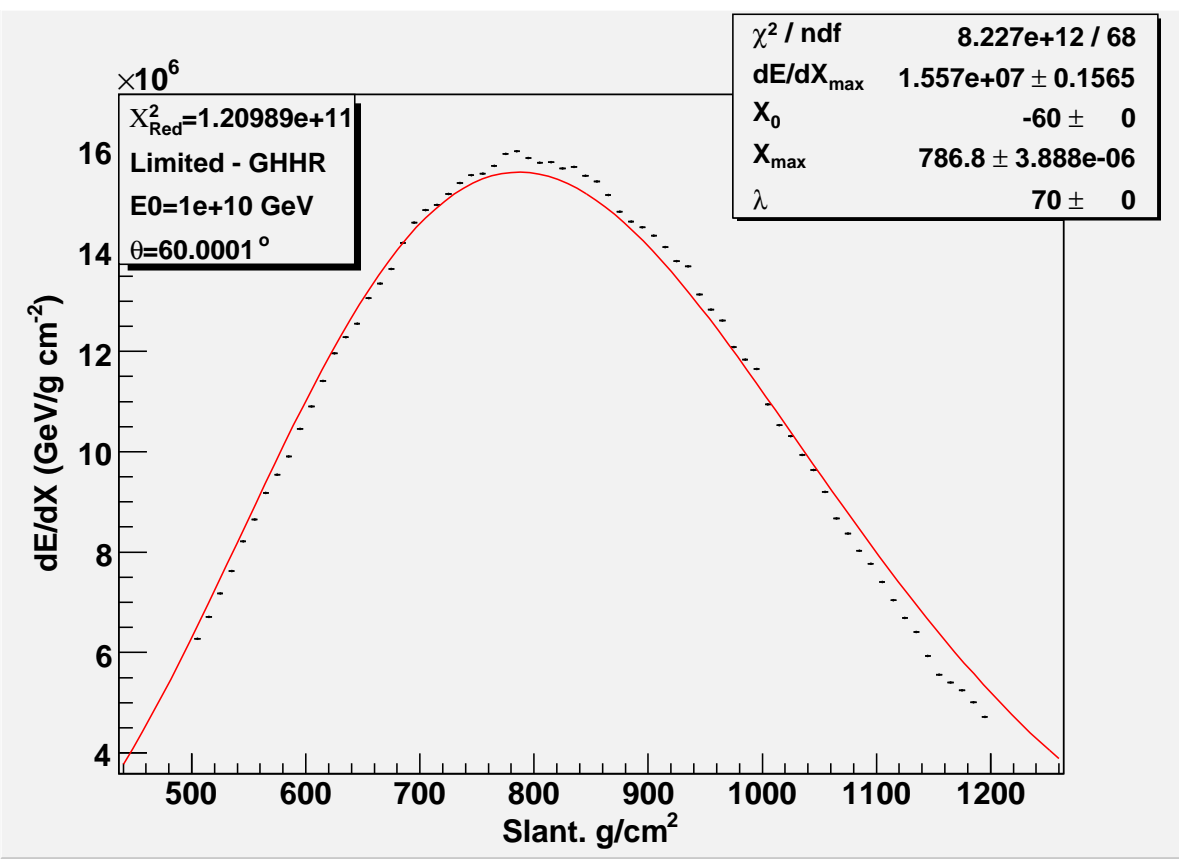

Figura A.4: Exemplo de ajuste da função A.4 a um perfil longitudinal de deposição parcial. As incertezas nesse caso são tomadas como sendo unitárias. 
equação, M.E. representa a missing energy, que é a energia não detectada carregada por neutrinos e múons de alta energia que chegam ao solo. Barbosa et al[64] criaram uma parametrização para a missing energy em função da composição da partícula primária e da inclinação do chuveiro, expressa como a razão da energia calorimétrica pela energia do primário, a partir de chuveiros simulados pelo Corsika:

$$
\frac{E_{c a l}}{E_{0}}=A-B\left(\frac{E_{c a l}}{1 E e V}\right)^{-C} \Rightarrow E_{0}=\frac{E_{c a l}}{\left[A-B\left(\frac{E_{c a l}}{1 E e V}\right)^{-C}\right]}
$$

onde os parâmetros $A, B$ e $C$ para prótons e cada inclinação do chuveiro estão na tabela A.1.

\begin{tabular}{|c|c|c|c|}
\hline Angulo & $\mathrm{A}$ & $\mathrm{B}$ & $\mathrm{C}$ \\
\hline $0^{\circ}$ & 0.984 & 0.071 & 0.089 \\
\hline $30^{\circ}$ & 0.986 & 0.074 & 0.088 \\
\hline $45^{\circ}$ & 0.958 & 0.048 & 0.162 \\
\hline $60^{\circ}$ & 0.942 & 0.035 & 0.337 \\
\hline
\end{tabular}

Tabela A.1: Parâmetros $A, B$ e $C$ da expressão da missing energy para prótons e cada inclinação do chuveiro[64].

A figura A.5 mostra um ajuste a um perfil longitudinal do telescópio HiRes-II simulado para um chuveiro de $E_{0}=10^{19} \mathrm{eV}$. A integral da função GH para esse chuveiro, a energia reconstruída, o tipo de função ajustada $(\mathrm{GH} \text { ou GHHR})^{6}$ e o $\chi_{\text {red }}^{2}$ do ajuste, entre outras informações, são automaticamente impressas na figura.

\footnotetext{
${ }^{6} \mathrm{GH}$ refere-se à função Gaisser-Hillas $\operatorname{com} \lambda$ variável (eq. A.5) e GHHR (Gaisser-Hillas - HiRes) à função $\operatorname{com} \lambda$ fixo (eq. A.4)
} 


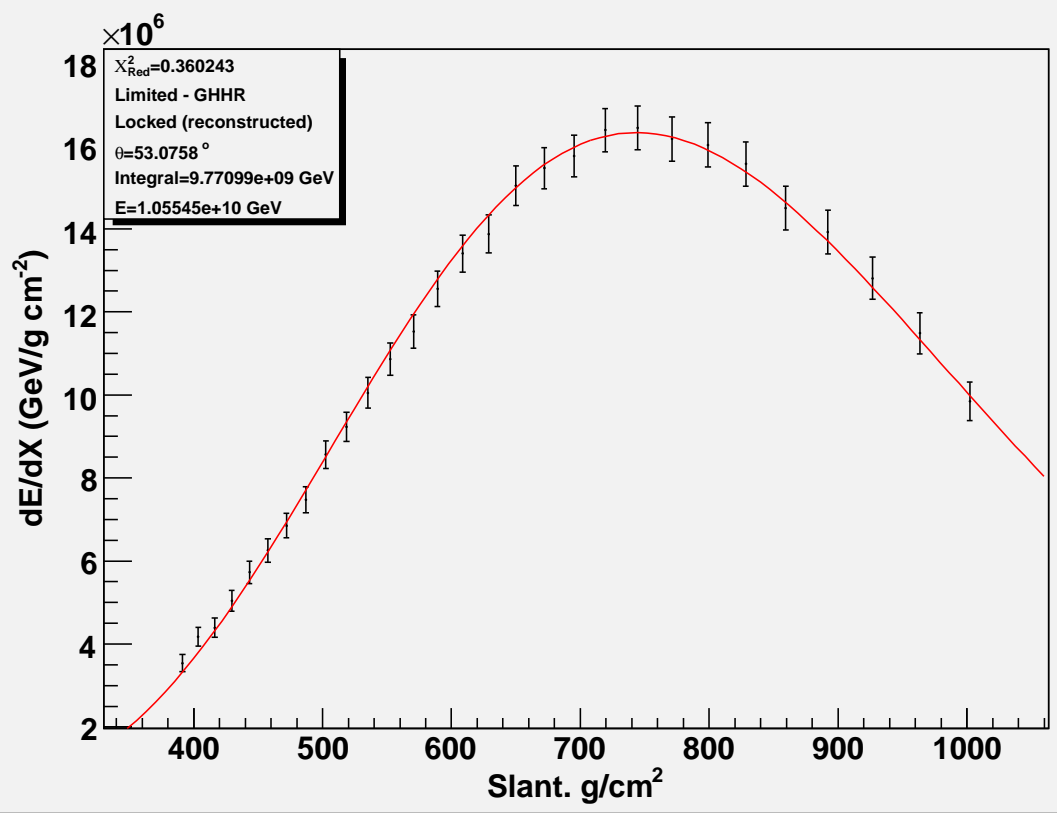

Figura A.5: Exemplo de ajuste da função A.4 a um perfil longitudinal de deposição proveniente da simulação do telescópio HiRes-II. A integral da função, a energia reconstruída (com missing energy), além de outras informações são impressas automaticamente.

\section{A.3 Classe Longitudinal Profile}

Esta classe é responsável pelas variáveis e elementos que constituem o perfil longitudinal do chuveiro em número de partículas. Ela herda a maior parte dos métodos da classe Energy Deposition. A maior diferença é a utilização de funções $\mathrm{GH}$ em número de partículas, ao invés de energia depositada, tanto $\operatorname{com} \lambda$ fixo (eq. A.8) quanto $\operatorname{com} \lambda$ variável (eq. A.7):

$$
\begin{gathered}
N(X)=N_{\max }\left(\frac{X-X_{0}}{X_{\max }-X_{0}}\right)^{\frac{\left(X_{\max }-X_{0}\right)}{\lambda_{0}+\lambda_{1} X+\lambda_{2} X^{2}}} \exp \left[\frac{\left(X_{\max }-X\right)}{\lambda_{0}+\lambda_{1} X+\lambda_{2} X^{2}}\right] \\
N(X)=N_{\max }\left(\frac{X-X_{0}}{X_{\max }-X_{0}}\right)^{\frac{\left(X_{\max }-X_{0}\right)}{\lambda}} \exp \left[\frac{\left(X_{\max }-X\right)}{\lambda}\right]
\end{gathered}
$$

O método e os parâmetros iniciais utilizados nos ajustes de ambas funções GH são iguais ao método FitGH da classe Energy Deposition, porém utilizam o número de 
partículas ao invés da energia depositada.

\section{A.4 Classe Shower Geometry}

Esta classe é responsável pelas variáveis e elementos que constituem a geometria do chuveiro, como sua direção e a posição de seu core sobre o solo, e a relação dessa geometria com um detetor. A seguir, descrevemos algumas de suas funções e os métodos utilizados.

\section{A.4.1 Geração da geometria do chuveiro.}

A classe ShowerGeometry, além de permitir a definição de uma geometria específica para a análise, possui métodos que possibilitam a geração aleatória de geometrias para o chuveiro atmosférico, utilizando métodos Monte Carlo. O sistema de coordenadas utilizado tem sua origem no telescópio (sistema Tel).

O método SetGenCore gera uma posição $\vec{P}_{\text {core }}$ do core do chuveiro sobre o solo a partir de um parâmetro $R_{\text {max }}^{g e n}$, que é a distância máxima à origem. Como o raio da região no solo de um observatório de raios cósmicos é desprezível em relação ao raio da Terra, utilizamos uma aproximação plana para a superfície terrestre. Geramos então $\vec{P}_{c o r e}$ igualmente distribuído na área do círculo de raio $R_{m a x}^{g e n}$, centrado no telescópio, utilizando coordenadas esféricas, da seguinte forma:

$$
r_{\text {core }}=\sqrt{R_{\text {max }}^{\text {gen }} \cdot \xi_{1}}, \theta_{\text {core }}=\pi / 2(\text { solo }) \text { e } \varphi_{\text {core }}=2 \pi \cdot \xi_{2}
$$

onde $\xi_{1}$ e $\xi_{2}$ são números pseudo-aleatórios no intervalo ]0,1].

O método SetGenDir gera uma direção isotrópica para a direção $\vec{D}$ do chuveiro atmosférico, com um ângulo zenital entre 0 e o parâmetro $\theta_{\text {max }}^{\text {gen }}$, da seguinte forma:

$$
r_{d i r}=1, \quad \theta_{d i r}=\arccos \left\{\left[1-\left(1-\cos \theta_{\max }^{\text {gen }}\right)\right] \cdot \xi_{1}\right\} \text { e } \varphi_{\text {dir }}=2 \pi \cdot \xi_{2} .
$$




\section{A.4.2 Determinação da parte visível do chuveiro.}

Somente parte do desenvolvimento longitudinal do chuveiro pode ser detectado pelo telescópio. O tamanho e posição desta parte visível depende das características do telescópio e da geometria de cada chuveiro. Nesta parte do programa definimos um volume na atmosfera pelos parâmetros $\theta_{m a x}^{t e l}, \theta_{\min }^{\text {tel }}$ e $R_{m a x}^{\text {tel }}$. Essa região (Fig. A.6) é a parte de uma semi-esfera de raio $R_{\max }^{t e l}$ centrada na origem do sistema Tel (posição do telescópio) delimitada por dois cones: um cone superior, definido pelo ângulo zenital $\theta_{\text {min }}^{t e l}$ e um cone inferior, definido pelo ângulo zenital $\theta_{\max }^{t e l}$.

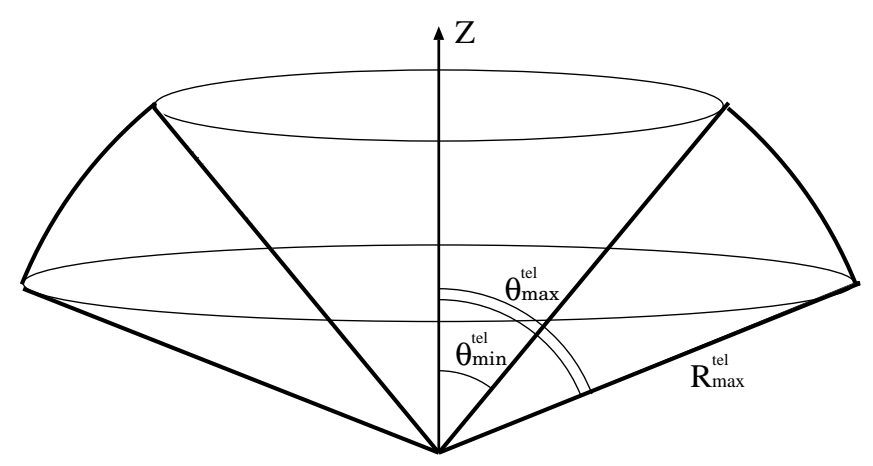

Figura A.6: Região na atmosfera que representa o limite máximo de visibilidade do telescópio. Toda deposição de energia do chuveiro dentro desta região pode posteriormente ser analisada pela classe PMT.

Essa região representa o limite máximo de visibilidade do telescópio. Toda deposição de energia dentro dessa região pode posteriormente ser analisada pela classe PMT (ver seção A.5), levando em conta todas características relevantes do telescópio e eletrônica de deteç̧ão.

Dados a direção do chuveiro $\vec{D}=\left(V_{x}, V_{y}, V_{z}\right)$, onde $\|\vec{D}\|=1$, e a posição do core do chuveiro sobre o solo $\vec{P}_{\text {core }}=\left(x_{c}, y_{c}, 0\right)$, podemos encontrar a intersecção do chuveiro com as superfícies que definem a região visível, utilizando um parâmetro $t$, que é a distância do core a um certo ponto $\vec{P}(t)$ ao longo da direção do chuveiro:

$$
\vec{P}(t)=\vec{P}_{\text {core }}+t \vec{D}=\left(x_{c}+t V_{x}, y_{c}+t V_{y}, t V_{z}\right) .
$$


No caso da superfície esférica $x^{2}+y^{2}+z^{2}=R_{\max }^{2}$, substituindo $x, y$ e $z$ pelas componentes de $\vec{P}(t)$, obtemos uma equação de segundo grau em $t, A t^{2}+B t+C=0$, onde:

$$
A=V_{x}^{2}+V_{y}^{2}+V_{z}^{2}, \quad B=2 x_{c} V_{x}+2 y_{c} V_{y} \text { e } C=x_{c}^{2}+y_{c}^{2}-R_{\max }^{2} .
$$

Para que $\vec{P}(t)$ esteja na região da superfície esférica delimitada pelos cones, temos que (ver Fig. A.6) sua componente $z, P_{z}(t)$, deve estar na região:

$$
R_{\max } \cos \theta_{\max }^{t e l} \leq P_{z}(t)=t V_{z} \leq R_{\max } \cos \theta_{\min }^{t e l}
$$

levando aos limites para a aceitação das raízes $t$ da equação de segundo grau:

$$
\frac{R_{\max } \cos \theta_{\max }^{t e l}}{V_{z}} \leq t \leq \frac{R_{\max } \cos \theta_{\min }^{t e l}}{V_{z}}
$$

No caso das superfícies cônicas $\left(x^{2}+y^{2}\right) / z^{2}=\tan ^{2} \theta_{\text {min,max }}^{\text {tel }}$, de modo análogo obte$\operatorname{mos} A t^{2}+B t+C=0$, onde:

$$
A=\frac{V_{x}^{2}+V_{y}^{2}}{\tan ^{2} \theta_{\min , \max }^{t e l}}-V_{z}^{2}, \quad B=\frac{2 x_{c} V_{x}+2 y_{c} V_{y}}{\tan ^{2} \theta_{\min , \max }^{t e l}} \text { e } C=\frac{x_{c}^{2}+y_{c}^{2}}{\tan ^{2} \theta_{\min , \max }^{\text {tel }}}
$$

Para que $\vec{P}(t)$ esteja na região da superfície cônica delimitada pela superfície esférica, temos:

$$
0 \leq t \leq \frac{R_{\max } \cos \theta_{\min , \max }^{t e l}}{V_{z}}
$$

As raízes $t$ obtidas desta forma são então colocadas em ordem crescente, levando aos pontos $\vec{I}_{i}$ de intersecção do eixo do chuveiro com as superfícies que definem a região visível da atmosfera, em ordem crescente de altitude. O número de intersecções possíveis é 0,2 ou 4, levando a 0, 1 ou 2 regiões visíveis do desenvolvimento longitudinal, respectivamente. Pode-se mostrar que, caso as direções dos chuveiros sejam geradas com um ângulo zenital máximo $\theta_{\max }^{\text {gen }} \leq \theta_{\min }^{\text {tel }}$, o número máximo de intersecções possíveis é 2 , 
levando a apenas uma região visível.

Uma vez determinados os pontos $\vec{I}_{i}$ de intersecção no sistema Tel, esses são transformados para o sistema da atmosfera (Atm) utilizando a expressão A.1. Essa transformação é feita para levar em conta a altitude do telescópio em relação ao nível do mar e permite que as altitudes em $\mathrm{km}$ dos pontos $\vec{I}_{i}^{A t m}$ obtidos sejam transformadas em $\mathrm{g} / \mathrm{cm}^{2}$ verticais.

Para essa transformação, utilizamos a parametrização de Linsley para a U.S Standard Atmosphere 1976 [37], que relaciona uma profundidade atmosférica $X$ em $\mathrm{g} / \mathrm{cm}^{2}$ a uma altitude $H$ em $\mathrm{km}$ :

$$
X(H)=\left\{\begin{array}{rr}
-1.86556 \cdot 10^{2}+1.2227 \cdot 10^{3} \exp \left(\frac{-H}{9.9419}\right) & \text { para } \quad-5.8 \leq H<4.0 \\
-94.919+1.1449 \cdot 10^{3} \exp \left(\frac{-H}{8.7815}\right) & \text { para } 4.0 \leq H<10.0 \\
6.1289 \cdot 10^{-1}+1.3056 \cdot 10^{3} \exp \left(\frac{-H}{6.3814}\right) & \text { para } 10.0 \leq H<40.0 \\
5.4018 \cdot 10^{2} \exp \left(\frac{-H}{7.7217}\right) & \text { para } \quad 40.0 \leq H<100.0 \\
1.12829 \cdot 10^{-2}-\frac{H}{10^{4}} & \text { para } 100.0 \leq H<112.8 \\
0 & \text { para } \quad H \geq 112.8
\end{array}\right.
$$

Utilizando-se essa parametrização, as altitudes em $\mathrm{km}$ dos pontos $\vec{I}_{i}^{A t m}$ obtidos são transformadas em $\mathrm{g} / \mathrm{cm}^{2}$ verticais, obtendo-se assim os limites $X_{i}$, em profundidade atmosférica vertical, da região visível do desenvolvimento completo do chuveiro. Posteriormente, o comprimento dessa região visível pode ser calculado em $\mathrm{km}, \mathrm{g} / \mathrm{cm}^{2}$ e $\mathrm{rad}$ em relação ao telescópio (no plano definido pelo eixo do chuveiro e telescópio). 


\section{A.5 Classe PMT}

A classe PMT é responsável pela simulação da detecção de um chuveiro atmosférico extenso por um telescópio de fluorescência, levando em conta os parâmetros relevantes da atmosfera e do telescópio, incluindo alguns efeitos da eletrônica de detecção. Ela calcula, armazena e opera sobre os sinais das fotomultiplicadoras de um detetor de fluorescência. Um perfil longitudinal de deposição simulado, cuja geometria é bem definida, é a base para a simulação da emissão de fótons de fluorescência na atmosfera. Esses fótons são então propagados até o telescópio, e sinais em fotomultiplicadoras são então simulados. A partir desses sinais, o evento é analisado e a energia do primário é reconstruída, utilizando métodos usuais em experimentos que utilizam a técnica de fluorescência.

A entrada da classe $P M T$ é a parte visível do perfil longitudinal, já alterado para a geometria simulada pela classe ShowerGeometry. Um esquema da entrada da classe PMT pode ser visto na figura A.7.

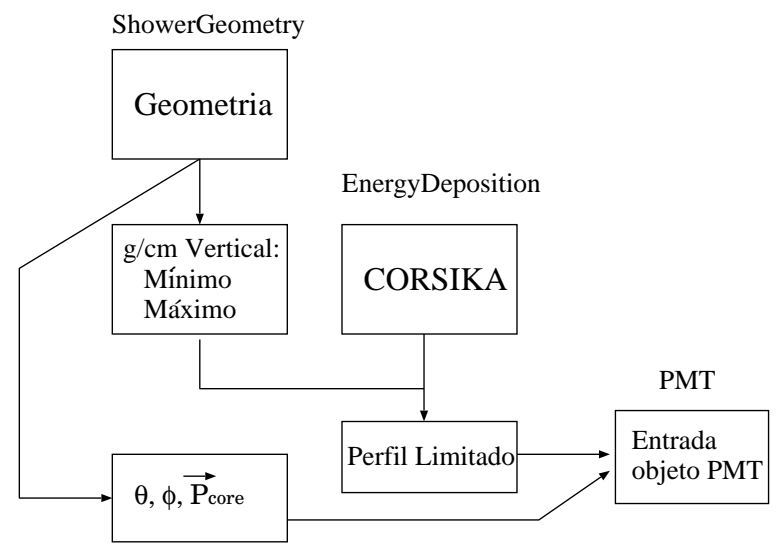

Figura A.7: Esquema de entrada para a classe PMT. 


\section{A.5.1 Simulação do campo de visão das fotomultiplicadoras do telescópio e cálculo da energia depositada na atmosfera.}

Um telescópio de fluorescência (ver seção 1.4.1) utiliza várias fotomultiplicadoras (PMTs) para transformar os fótons de fluorescência gerados na atmosfera em sinais que podem ser analisados. Cada fotomultiplicadora aponta para uma direção específica, subtendendo assim seu próprio ângulo sólido no céu. Essa parte do programa recebe um perfil parcial de deposição de energia, que contém somente a parte visível do chuveiro (ver seção A.4.2), e separa esse perfil em regiões que são detectadas por diferentes PMTs do telescópio. As PMTs simuladas, ao contrário das PMTs de um telescópio real, estão sempre alinhadas com o eixo do chuveiro. Desse modo obtemos uma "linha" composta por várias PMTs, cujos sinais serão posteriormente simulados. Cada PMT abrange um ângulo dado pelo parâmetro $\Theta$ (HiRes: $1^{\circ}$ Auger:1.5 $5^{\circ}$. O início da região observada pela primeira PMT é tomado como sendo o ponto geométrico $\vec{I}_{2}$ na atmosfera, que é o ponto mais alto de intersecção com a região visível do telescópio (ver seção A.4.2). A figura A.8(A) mostra um esquema da separação do perfil de deposição nas regiões visíveis por cada PMT sobre o plano do chuveiro, que é definido pelo eixo do chuveiro e pela posição do telescópio. Os pontos $\vec{P}_{i}$ sobre o eixo do chuveiro definem as intersecções das regiões observadas por uma PMT e sua PMT vizinha.

Para se obter os pontos $\vec{P}_{i}$, utilizamos um algoritmo capaz de calcular pontos sobre o eixo que definem um certo ângulo $\theta$ com o ponto inicial. Dado um ponto inicial $\vec{P}_{0}=\left(x_{0}, y_{0}, z_{0}\right)$ e a direção $\vec{D}=\left(V_{x}, V_{y}, V_{z}\right)$ do chuveiro, podemos encontrar um ponto $\vec{P}=(x, y, z)$ (ver figura A.8(B) ) que define um ângulo $\theta$ com $\vec{P}_{0}$ utilizando uma variável $m(\theta), \operatorname{com} \vec{P}=\vec{P}_{0}+m \vec{D}$, utilizando uma equação de segundo grau em $m: A m^{2}+B m+$ 


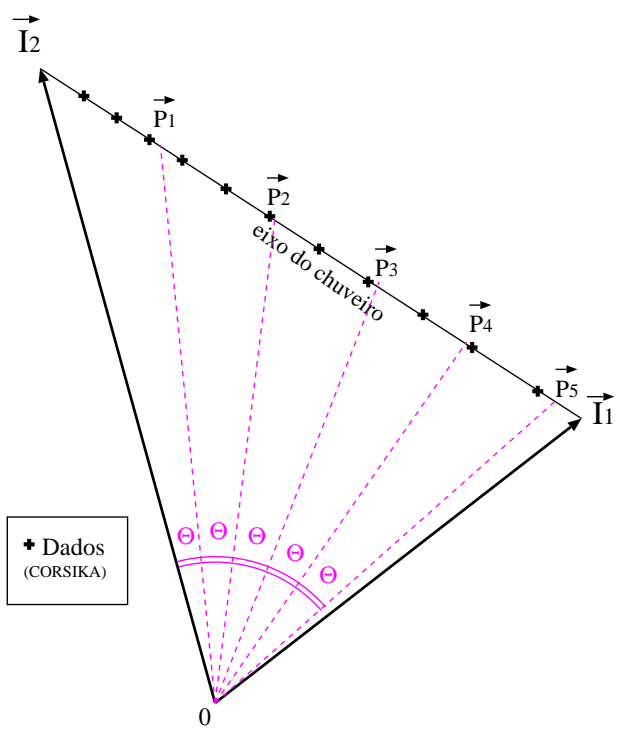

(A)

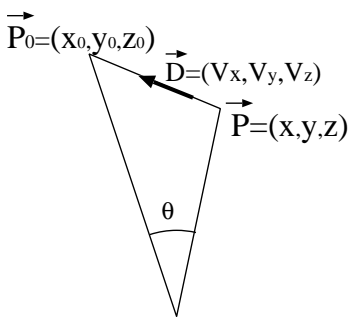

(B)

Figura A.8: (A) Esquema da divisão do perfil longitudinal nas regiões observadas por cada PMT. $\Theta$ é a aceitância angular de cada PMT. (B) Esquema geométrico para o cálculo de um ponto $\vec{P}$ ao longo do eixo do chuveiro que faz um ângulo $\theta$ com o ponto $\vec{P}_{0}$, no plano do chuveiro.

$C=0$ :

$$
\begin{aligned}
& A m^{2}+B m+C=0, \\
& m=\left(-B+\sqrt{B^{2}-4 A C}\right) / 2 A
\end{aligned}
$$

onde:

$$
\begin{aligned}
& A=\left(x_{0} V_{x}\right)^{2}+\alpha^{2}+2 x_{0} V_{x} \alpha-R^{2} \cos ^{2} \theta, \\
& B=2 R^{2}\left(1-\cos ^{2} \theta\right)\left(x_{0} V_{x}+\alpha\right), \\
& C=R^{4}\left(1-\cos ^{2} \theta\right), \\
& \alpha=\left(y_{0} V_{y}+z_{0} V_{z}\right) \quad \text { e } \quad R^{2}=x_{0}^{2}+y_{0}^{2}+z_{0}^{2} .
\end{aligned}
$$

Desse modo, encontramos os pontos $\vec{P}_{i}$ :

$$
\vec{P}_{i}=\vec{I}_{2}+m(i \Theta) \vec{D}
$$

Um outro conjunto de pontos relevantes para a simulação são os pontos $\vec{C}_{i}$ de interseç̧ão entre a direção definida pelo centro da $i$-ésima PMT e o eixo do chuveiro. Estes 
pontos representam os pontos de emissão de fluorescência para finalidades de propagação na atmosfera, e são calculados da seguinte forma:

$$
\vec{C}_{i}=\vec{I}_{2}+m\left(\left[i+\frac{1}{2}\right] \Theta\right) \vec{D}
$$

Para permitir que os pontos geométricos $\vec{P}_{i}$, que definem a região geométrica observada por cada PMT no sistema Tel, possam ser transformados em profundidades atmosféricas, esses devem ser inicialmente transformados para o sistema da atmosfera, utilizando a expressão A.1, obtendo-se os pontos $\vec{P}_{i}^{A t m}{ }^{7}$. As altitudes desses pontos podem então ser transformadas em profundidades atmosféricas slant $X_{i}$ utilizando-se a parametrização de Linsley e o ângulo $\theta$ de inclinação do chuveiro (seção A.2.3). Assim podemos calcular a energia $E_{i}$ depositada dentro da região da atmosfera observada pela i-ésima PMT (Fig. A.9), utilizando o perfil longitudinal de deposição de energia obtido do Corsika ou Aires:

$$
E_{i}=\int_{X_{i}}^{X_{(i+1)}} \frac{d E}{d X} d X
$$

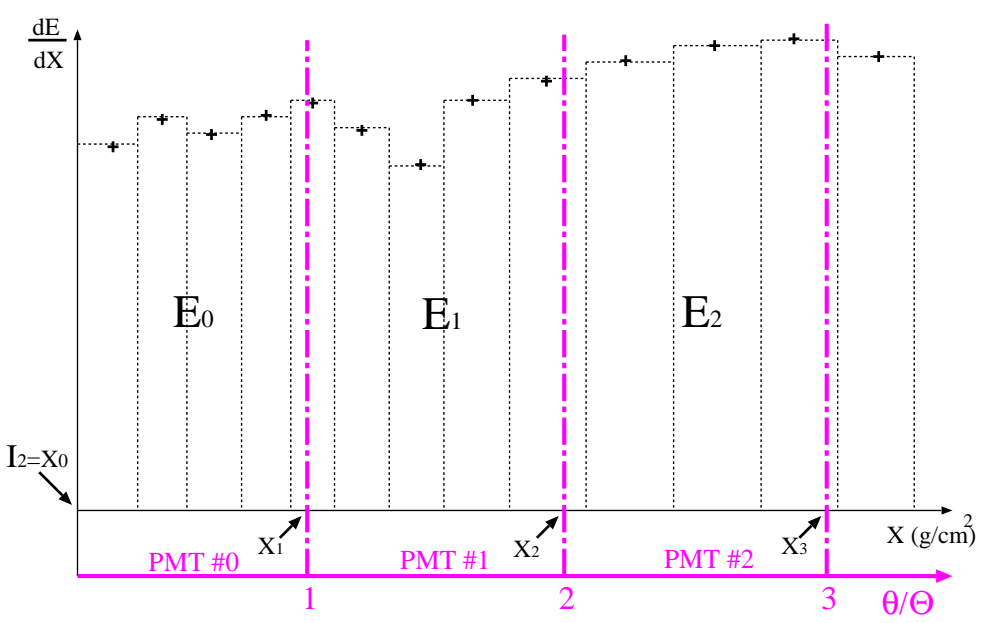

Figura A.9: Esquema da integração da deposição de energia na região observada por cada PMT.

\footnotetext{
${ }^{7}$ Os pontos $\vec{C}_{i}$ também sofrem essa transformação, obtendo-se os pontos $\vec{C}_{i}^{A t m}$.
} 
Ainda outro conjunto de grandezas relevantes na simulação são os tempos $T_{i}$ de aquisição de cada PMT, que representam o tempo entre o início e o fim da deposição de energia na região observada pela $i$-ésima PMT. Esses tempos foram estimados a partir das distâncias entre os pontos $\vec{P}_{i}$, assumindo que a frente do chuveiro se propaga à velocidade da luz ao longo da direção do eixo do chuveiro. Assim temos:

$$
T_{i}=\frac{\left\|\vec{P}_{i+1}-\vec{P}_{i}\right\|}{c}
$$

onde $c$ é a velocidade da luz.

\section{A.5.2 Cálculo do número de fótons de fluorescência emitidos e transporte através da atmosfera.}

Para o cálculo do número de fótons emitidos é necessário o cálculo do fluorescence yield (ver seção 1.4.1) nos pontos de emissão. Trabalhos recentes sugerem a seguinte relação entre a deposição $d E / d X$ e o FY na região 300 - 400nm[57] e 300 - 405nm[56]:

$$
F Y\left(K_{c}, \rho, T\right)=\frac{\left(\frac{d E}{d X}\right)}{\left(\frac{d E}{d X}\right)_{K_{c}}} \times \rho\left(\frac{A_{1}}{1+\rho B_{1} \sqrt{T}}+\frac{A_{2}}{1+\rho B_{2} \sqrt{T}}\right)
$$

onde as constantes utilizadas por Kakimoto et al.[57] (utilizadas em nossos cálculos) e Nagano et al.[56] podem ser vistas na tabela A.2.

\begin{tabular}{|c|c|c|}
\hline Constante & Kakimoto et al.[57] & Nagano et al.[56] \\
\hline \hline$A_{1}\left(\mathrm{~m}^{2} / \mathrm{kg}\right)$ & $89.0 \pm 1.7$ & $147.4 \pm 4.3$ \\
\hline$A_{2}\left(\mathrm{~m}^{2} / \mathrm{kg}\right)$ & $55.0 \pm 2.2$ & $69.8 \pm 12.2$ \\
\hline$B_{1}\left(\mathrm{~m}^{2} \mathrm{~kg}^{-1} \mathrm{~K}^{-0.5}\right)$ & $1.85 \pm 0.04$ & $2.40 \pm 0.18$ \\
\hline$B_{2}\left(\mathrm{~m}^{2} \mathrm{~kg}^{-1} \mathrm{~K}^{-0.5}\right)$ & $6.50 \pm 0.33$ & $20.1 \pm 6.9$ \\
\hline$K_{c}(\mathrm{MeV})$ & 1.4 & 0.85 \\
\hline$(d E / d X)_{K_{c}}\left(\mathrm{MeV} / \mathrm{g} / \mathrm{cm}^{2}\right)$ & 1.65 & 1.67 \\
\hline
\end{tabular}

Tabela A.2: Constantes da equação A.10 utilizadas por Kakimoto et al. e Nagano et al..

Dado um certo modelo para a atmosfera, que relaciona uma altitude $h$ com uma den- 
sidade $\rho$ e uma temperatura $T$, o último termo da equação A.10 pode ser parametrizado em função da altitude $h$, temos então[73]:

$$
F Y(d E / d X, h)=\frac{\left(\frac{d E}{d X}\right)}{\left(\frac{d E}{d X}\right)_{K_{c}}} \times F_{a t m}(h)
$$

A figura A.10 mostra nosso cálculo de $F_{a t m}(h)$ para altitudes até $30 k m$, que são relevantes para o estudo de EASs, a partir da U.S. Atmosphere 1976 (eq. A.9).

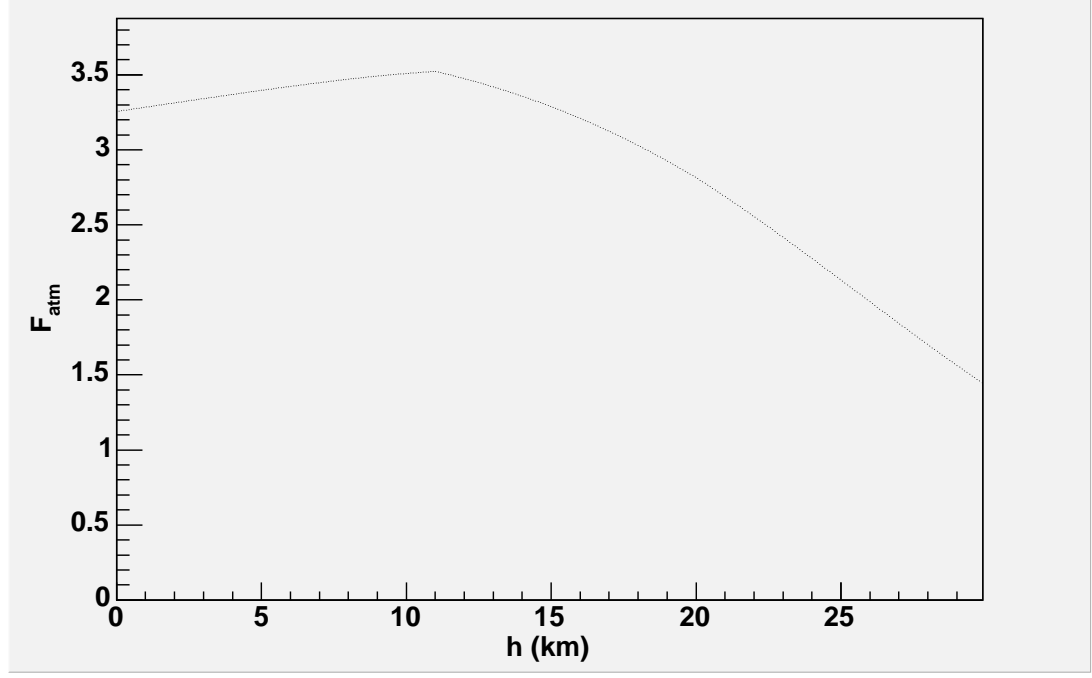

Figura A.10: $F_{\text {atm }}(h)$ calculado a partir da U.S. Atmosphere 1976 para altitudes até $30 \mathrm{~km}$.

Em cada PMT simulada, consideramos o ponto $\vec{C}_{i}^{A t m}$ de intersecção da direção do centro da $i$-ésima PMT com o eixo do chuveiro como sendo o ponto de emissão de fluorescência. Assim, a partir dos valores obtidos de $E_{i}, X_{i}$ e da componente $z C_{i z}^{A t m}$ de $\vec{C}_{i}^{A t m}$ (ver seção A.5.1), o valor médio de $d E / d X$ e o fluorescence yield FY[56, 55, 57] na região observada pela $i$-ésima PMT são dados por:

$$
\begin{gathered}
\left(\frac{d E}{d X}\right)_{i}=\frac{E_{i}}{\left(X_{(i+1)}-X_{i}\right)}, \\
F Y_{i}=\frac{\left(\frac{d E}{d X}\right)_{i}}{\left(\frac{d E}{d X}\right)_{K c}} \times F_{a t m}\left(C_{i z}^{A t m}\right) .
\end{gathered}
$$


Logo o número $N_{i}^{\text {emit }}$ de fótons emitidos na região observada pela PMT é:

$$
N_{i}^{e m i t}=F Y_{i}\left(X_{(i+1)}-X_{i}\right)=\frac{E_{i}}{\left(\frac{d E}{d X}\right)_{K c}} \times F_{a t m}\left(C_{i z}^{A t m}\right)
$$

Em seguida são calculados os valores dos coeficientes de transmissão do espalhamento Rayleigh e Mie, $T_{R}$ e $T_{M}$ (eqs. 1.40 e 1.41), respectivamente, para a trajetória entre $\vec{C}_{i}^{A t m}$ e o telescópio. O ângulo sólido definido pela área $A$ da abertura do telescópio a partir do ponto de emissão $\vec{C}_{i}$ (no sistema Tel) é dado por:

$$
\Omega=\frac{A}{\left\|\vec{C}_{i}\right\|^{2}}
$$

Desse modo, o número de fótons que chega à abertura do telescópio, proveniente da região observada pela $i$-ésima PMT é:

$$
N_{i}^{\text {mouth }}=N_{i}^{\text {emit }} \frac{\Omega}{4 \pi} T_{R} T_{M}
$$

\section{A.5.3 Eficiência do telescópio, inclusão do fundo, simulação da eletrônica e trigger.}

A eficiência $\alpha_{t e l}$ do telescópio é a razão entre o número de fótons que chegam à sua abertura e o sinal em foto-elétrons que esses fótons produzem na PMT. Essa eficiência leva em conta características do telescópio, como a transmitância do filtro, refletância do espelho e eficiência quântica das PMTs. Essa eficiência foi estimada em 20\% para os telescópios das colaborações HiRes-II e Auger e 15.5\% no caso do HiRes-I.

Assim, o sinal inicial $N_{p e}^{\text {NoNoise }}$ em foto-elétrons pode ser estimado por:

$$
N_{p e}^{\text {NoNoise }}=N_{i}^{\text {mouth }} \times \alpha_{t e l}
$$

A partir do sinal sem ruído e do tempo de aquisição de cada PMT, o sinal final de cada PMT é obtido. Esse sinal final inclui o fundo de fótons que não são produzidos 
por fluorescência e os efeitos da eletrônica (ruído eletrônico e do ADC). A inclusão desse fundo, constituído principalmente por luz espalhada de estrelas, radiação difusa da galáxia e reações foto-químicas na atmosfera é muito importante, pois o trigger aplicado ao sinal em cada PMT baseia-se na comparação de contagens ADC com um valor de referência. Esse fundo é de aproximadamente 40 fótons $/ m^{2}{ }^{\circ} \mu s[50,74]$. A variância $\sigma_{p e}^{2}$ do ruído de fundo em foto-elétrons pode ser dada por[75]:

$$
\sigma_{p e}^{2}=\bar{n}_{p e}\left(1+V_{G}\right)
$$

onde $\bar{n}_{p e}$ é a média em foto-elétrons do ruído de fundo para um intervalo de $100 n s$ e $V_{G}$ é o fator variância de ganho da PMT, fator esse que representa o alargamento Gaussiano da distribuição Poissoniana devido aos dinodos da PMT. Assim, a variância do ruído de fundo pode ser vista como tendo duas contribuições: um ruído Poissoniano devido a foto-elétrons, com variância $\sigma_{P}^{2}=\bar{n}_{p e}$, convoluído com um ruído Gaussiano de média zero e variância $\sigma_{G}^{2}=\bar{n}_{p e} V_{G}[75]$. Além do fundo, incluímos um ruído Gaussiano de média zero e variância $\sigma_{A D C}^{2}$, que representa o ruído na conversão ADC e o ruído eletrônico.

Nos telescópios de fluorescência HiRes-II e Auger, o sinal de cada PMT é digitalizado a uma taxa de $10 \mathrm{MHz}[50,74]$, desse modo todo o processo de inclusão do fundo e ruídos é feito em intervalos de 100ns. O sinal de fluorescência, sem ruído, foi tomado como sendo constante (sinal quadrado) e dividido em bins de 100ns (ver figura A.11). A intensidade $S_{0}$ do sinal por unidade de tempo é calculada a partir do número total de foto-elétrons $N_{p e}^{\text {NoNoise }}$ do sinal sem ruído e do tempo $T$ de aquisição de determinado pixel (PMT); $N_{0}$ é o número de foto-elétrons em cada bin ${ }^{8}$

$$
S_{0}=\frac{N_{p e}^{N o N o i s e}}{T}, \quad N_{0}=S_{0} \times 100 n s
$$

Para cada bin de $100 n s$, a partir do valor $N_{0}$, o número de foto-elétrons final $N_{i}^{p e}$ é

\footnotetext{
${ }^{8}$ com exceção do último bin, que é calculado separadamente, pois tem tamanho menor que 100ns.
} 


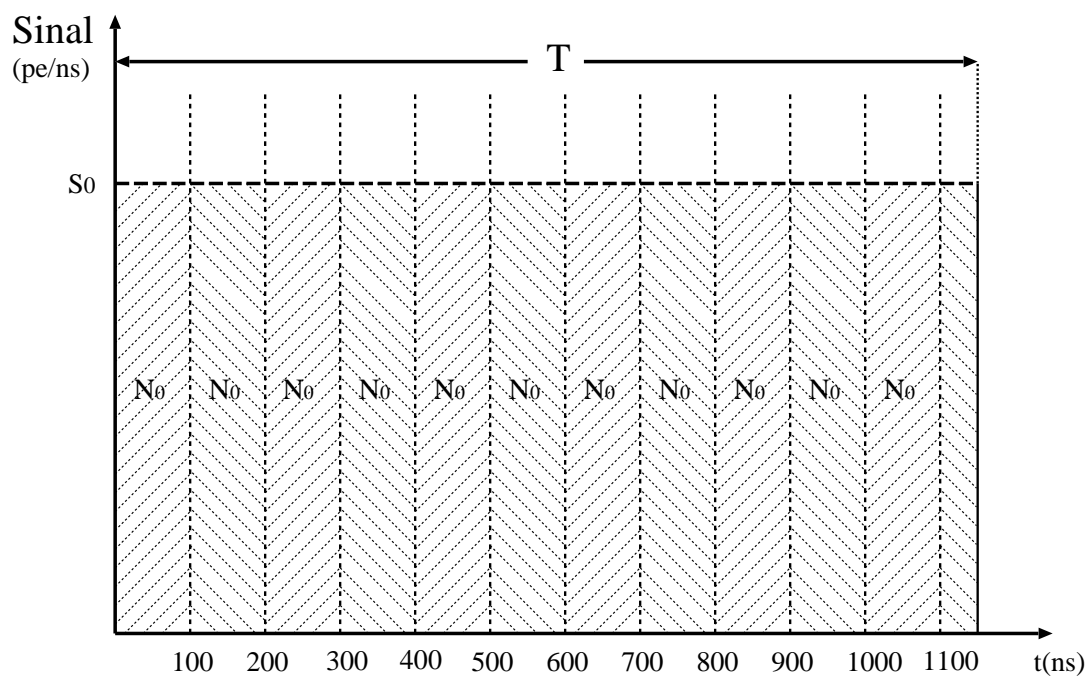

Figura A.11: Esquema do sinal sem ruído dividido em bins de 100ns. A intensidade $S_{0}$ é calculada a partir da integral do sinal sem ruído e do tempo de aquisição $T$. $N_{0}$ é o número de foto-elétrons em cada bin.

gerado da seguinte forma: inicialmente geramos o número de foto-elétrons do fundo que chega à PMT em um intervalo de 100ns, seguindo a variância $\sigma_{p e}^{2}$. O fundo médio $\bar{n}_{p e}$ é então subtraído desse valor:

$$
N_{B c k g}=S_{G}+S_{P}-\bar{n}_{p e}
$$

onde $S_{G}$ é amostrado de uma distribuição Gaussiana de média zero e variância $\sigma_{G}^{2}=$ $\bar{n}_{p e} V_{G}$ e $S_{P}$ é amostrado de uma Poissoniana de variância $\sigma_{P}^{2}=\bar{n}_{p e}$.

Em seguida, esse fundo é transformado em contagens ADC, utilizando um fator de conversão $C_{A D C}$ :

$$
N_{B c k g}^{A D C}=C_{A D C} \times N_{B c k g},
$$

e os ruídos eletrônico e da conversão ADC são acrescentados:

$$
N_{\text {Noise }}^{A D C}=\operatorname{int}\left(N_{B c k g}^{A D C}+E N_{A D C}\right),
$$

onde $E N_{A D C}$ é amostrado de uma distribuição Gaussiana de média zero e variância 
$\sigma_{A D C}^{2}$ e o símbolo int representa a parte inteira da soma. Essas contagens ADC são então transformadas de volta para foto-elétrons e são somadas ao número inicial de foto-elétrons $N_{0}$ do sinal sem ruído, obtendo-se assim o número de foto-elétrons final para o $i$-ésimo bin de tempo (ver figura A.12):

$$
N_{i}^{p e}=\frac{N_{\text {Noise }}^{A D C}}{C_{A D C}}+N_{0}
$$

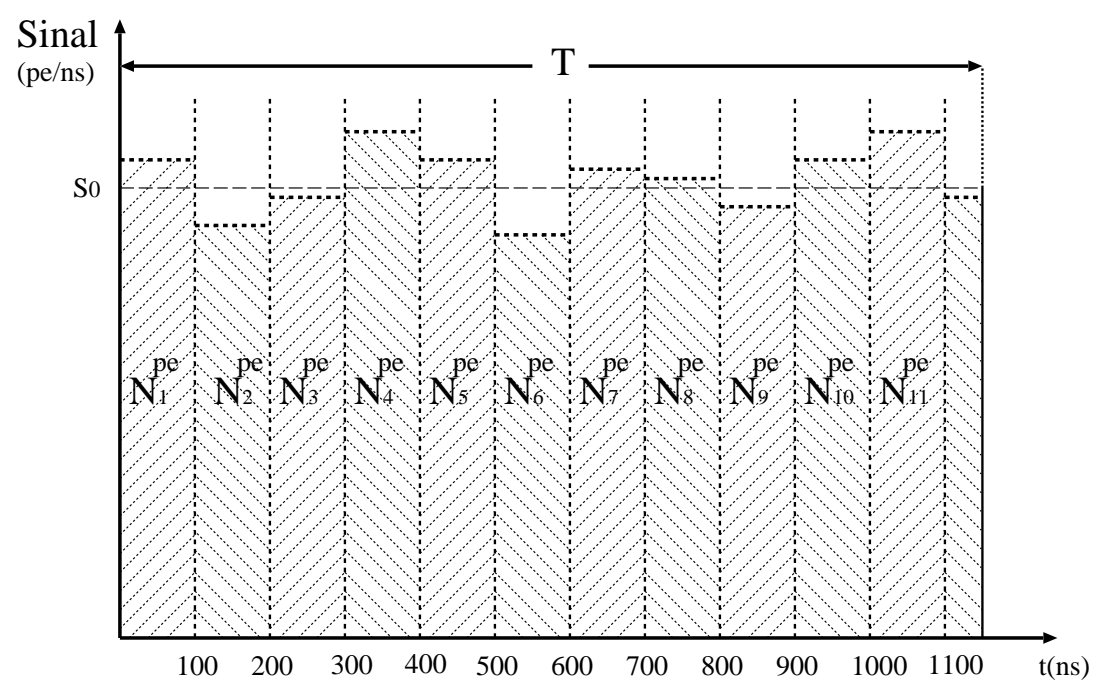

Figura A.12: Esquema do sinal com ruído gerado a cada bin de $100 n s . N_{i}^{p e}$ é o número de foto-elétrons em cada bin, já com a inclusão do fundo e ruído e a subtração do fundo médio.

O sinal final total $N_{f}$ da PMT em foto-elétrons é dado pela somatória:

$$
N_{f}=\sum_{i} N_{i}^{p e}
$$

Para estimar a incerteza em $N_{f}$, os erros no sinal final total foram tomados como sendo Poissonianos, utilizamos então:

$$
\sigma_{N_{f}}=\sqrt{N_{f}}
$$

O trigger utilizado para cada PMT é uma simplificação do trigger primário de [75] 
que compara o sinal final total da PMT com um certo limiar. O limiar utilizado ${ }^{9}$ foi 4 vezes o fundo médio esperado para o tempo de aquisição $T$, ou seja, se:

$$
N_{f} \geq 4 \times \frac{\bar{n}_{p e}}{100 n s} \times T
$$

essa determinada PMT é utilizada na análise. Caso contrário, a PMT é descartada.

A tabela A.3 mostra valores padrão utilizados para a geração do fundo e simulação da eletrônica no caso da simulação do telescópio de fluorescência do Observatório Pierre Auger.

\begin{tabular}{|c|c|}
\hline Parâmetro & Valor \\
\hline $\bar{n}_{p e}$ & 6 foto-elétrons \\
\hline$V_{G}$ & 0.4 \\
\hline$\sigma_{A D C}$ & $\sqrt{3.3}$ contagens \\
\hline$C_{A D C}$ & $1.0 / 1.8$ \\
\hline
\end{tabular}

Tabela A.3: Valores padrão dos parâmetros utilizados na simulação do fundo e da eletrônica no caso da simulação do telescópio de fluorescência do Observatório Pierre Auger.

Nesse ponto acaba a parte de simulação do programa. A partir dos sinais finais em cada PMT, obtidos da simulação, é feita a reconstrução do evento.

\section{A.5.4 Reconstrução da geometria}

A reconstrução da geometria do chuveiro na técnica de fluorescência, como descrito na seção 1.4.1, tem uma eficiência muito maior na determinação do plano do chuveiro que na determinação da direção do eixo do chuveiro sobre esse plano. Para a determinação do plano do chuveiro, as direções de todas PMTs aceitas pelo trigger são utilizadas para o ajuste de um plano, ponderadas pelo tamanho do sinal total. Para a determinação da direção do eixo do chuveiro é necessária a utilização dos tempos $t_{i}$ de acionamento das PMTs, o que introduz uma outra contribuição para os erros na determinação dessa

\footnotetext{
${ }^{9}$ No caso da simulação de alguns telescópios, esse limiar é alterado.
} 
direção. Assim, desprezamos os erros na determinação do plano do chuveiro, e apenas incluímos um erro na direção do eixo do chuveiro sobre esse mesmo plano. A figura A.13 mostra um esquema geométrico da inclusão desse erro na direção.

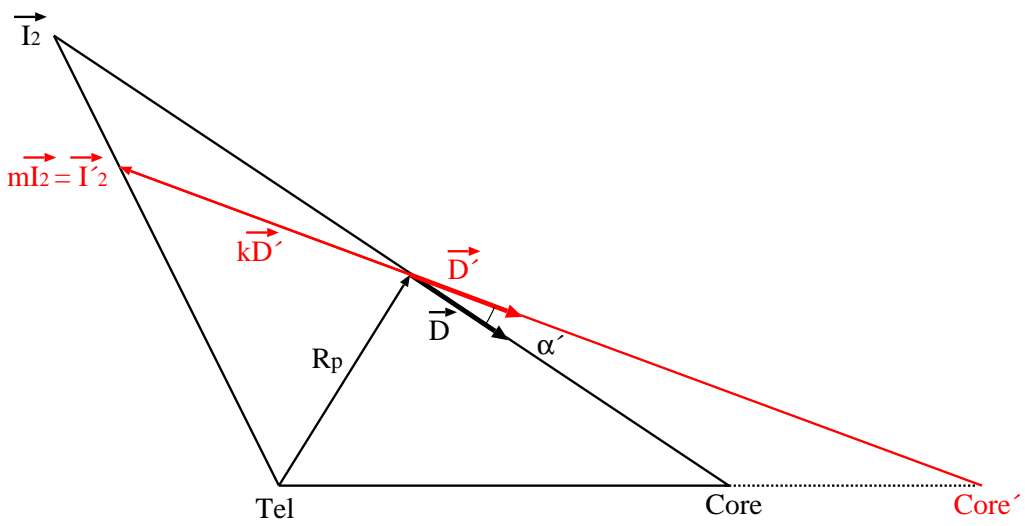

Figura A.13: Esquema geométrico da inclusão do erro na direção do eixo no plano do chuveiro. O erro angular gerado é $\alpha^{\prime}$.

O erro angular $\alpha^{\prime}$ é amostrado de uma Gaussiana de média 0 e desvio-padrão ${ }^{10}$ $\sigma_{\angle}=5^{\circ}$. A direção reconstruída $\vec{D}^{\prime}$ do chuveiro é então obtida rotacionando-se a direção "real" $\vec{D}$ pelo ângulo $\alpha^{\prime}$ no plano do chuveiro em torno do ponto de maior aproximação $R_{P}$. Com isso é possível obter o core reconstruído $\left(C_{\text {ore }}^{\prime}\right)$ e obter as novas intersecções das direções das PMTs com o novo eixo, que são os pontos de emissão reconstruídos.

Para facilitar os cálculos, foi utilizado o sistema do eixo do chuveiro (sistema $S A$ ver seção A.1). Nesse sistema, a direção "real" do chuveiro é dada por $\vec{D} A=(r=1, \theta=$ $0, \phi=0)$. Para definir o plano do chuveiro, utilizamos um segundo vetor pertencente a esse plano, especificamente o vetor $\vec{I}_{2}$ que liga o telescópio ao ponto visível mais alto do eixo do chuveiro(ver figura A.13 e seção A.4.2). Esse vetor é transformado para o sistema $S A$ utilizando-se a relação A.3, obtendo-se $\vec{I}_{2}^{S A}=\left(r_{I 2}, \theta_{I 2}, \phi_{I 2}\right)$. Nesse sistema, o plano definido por $\phi=\phi_{I 2}$ é o plano do chuveiro. A direção reconstruída do eixo é então dada por $\vec{D}^{\prime S A}=\left(r=1, \theta=\alpha^{\prime}, \phi=\phi_{I 2}\right)^{11}$. Essa direção reconstruída é então

\footnotetext{
${ }^{10}$ Esse desvio-padrão de $5^{\circ}$ é representativo das distribuições de erros na direção do chuveiro em telescópios de fluorescência. Essas distribuições de erros podem ser estimadas através da utilização de eventos estéreo e/ou híbridos, onde dois telescópios e/ou um telescópio e um detetor de superfície observam o mesmo evento, permitindo uma reconstrução geométrica muito mais precisa.

${ }^{11}$ Caso $\alpha^{\prime}<0$ usamos o módulo desse ângulo e $\phi=\pi-\phi_{I 2}$ ou $\phi=\phi_{I 2}-\pi$.
} 
transformada de volta para o sistema Tel, obtendo-se $\vec{D}^{\prime}=\left(V_{x}^{\prime}, V_{y}^{\prime}, V_{z}^{\prime}\right)$.

De posse de $\vec{D}^{\prime}$, utilizamos as seguintes relações para obter o vetor $\vec{I}_{2}^{\prime}$ (ver figura A.13):

$$
\vec{I}_{2}^{\prime}=m \vec{I}_{2}=\vec{R}_{p}+k \vec{D}^{\prime} \Rightarrow \begin{cases}\text { Se } V_{z}^{\prime} I_{x}-V_{x}^{\prime} I_{z} \neq 0 & k=\frac{I z R_{p x}-I_{x} R_{p z}}{V_{x}^{\prime} I_{x}-V_{x}^{\prime} I_{z}} \\ \text { Senão } & k=\frac{I_{z} R_{p y}-I_{y}-R_{p z}}{V_{z}^{\prime} I_{y}-V_{y}^{\prime} I_{z}}\end{cases}
$$

A partir de $\vec{I}_{2}^{\prime}$ calculamos os pontos de emissão reconstruídos $\vec{C}_{i}^{\prime}$, utilizando os mesmos métodos descritos em A.5.1.

\section{A.5.5 Reconstrução da energia}

Com a geometria reconstruída, os pontos de emissão $\vec{C}_{i}^{\prime}$ são transformados para o sistema Atm e a profundidade atmosférica de cada um deles é calculada utilizando a parametrização de Linsley, o que permite também o cálculo do tamanho de cada região de emissão em profundidade atmosférica, isto é, o tamanho da região vista por cada PMT .

O sinal em foto-elétrons de cada PMT é analisado pelo trigger (Eq. A.12) e caso essa $i$-ésima PMT seja aceita, seu sinal em foto-elétrons é transformado de volta para o número de fótons na abertura do telescópio, utilizando-se a eficiência do telescópio:

$$
N_{i}^{\prime \text { mouth }}=\frac{N_{f_{i}}}{\alpha_{\text {tel }}}
$$

e esses fótons são então propagados até os pontos de emissão reconstruídos, levandose em conta os espalhamentos Mie e Rayleigh (coeficientes de transmissão $T_{R}^{\prime}$ e $T_{M}^{\prime}$ recalculados para a nova geometria), e o novo ângulo sólido $\Omega^{\prime}$ para o ponto de emissão reconstruído $\vec{C}_{i}^{\prime}$ :

$$
N_{i}^{\prime \text { emit }}=\frac{N_{i}^{\prime \text { mouth }}}{T_{R}^{\prime} T_{M}^{\prime}} \frac{4 \pi}{\Omega^{\prime}}
$$

Utilizando a definição de Fluorescence Yield podemos obter a deposição de energia 
por unidade de profundidade atmosférica:

$$
\begin{gathered}
F Y_{i}=\frac{N_{i}^{\prime}{ }^{\text {emit }}}{\left(X_{(i+1)}-X_{i}\right)}=\frac{\left(\frac{d E}{d X}\right)_{i}}{\left(\frac{d E}{d X}\right)_{K c}} \times F_{a t m}\left(C_{i z}^{\prime}\right) \Rightarrow \\
\left(\frac{d E}{d X}\right)_{i}=\frac{N_{i}^{\prime} \text { emit }}{\left(X_{(i+1)}-X_{i}\right)} \frac{\left(\frac{d E}{d X}\right)_{K c}}{F_{a t m}\left(C_{i z}^{\prime}\right)} .
\end{gathered}
$$

A incerteza na deposição de energia foi estimada a partir da incerteza no sinal total final da PMT:

$$
\sigma_{\left(\frac{d E}{d X}\right)_{i}}=\frac{\sigma_{N_{f}}}{\alpha_{t e l} T_{R}^{\prime} T_{M}^{\prime}} \cdot \frac{4 \pi}{\Omega^{\prime}} \cdot \frac{\left(\frac{d E}{d X}\right)_{K c}}{F_{a t m}\left(C_{i z}\right)}
$$

Após a análise de todas as PMTs que passaram pelo trigger, obtemos o perfil longitudinal de deposição reconstruído e suas respectivas incertezas. Esse perfil é então armazenado em um TGraphErrors e analisado pelo objeto EnergyDeposition através do ajuste de uma função Gaisser-Hillas, da integração dessa função ajustada e da inclusão da missing energy, como descrito anteriormente na seção A.2, obtendo-se assim a energia reconstruída $E$.

\section{A.6 Classe EventManager}

A classe EventManager é responsável pelo armazenamento dos resultados das simulações. Ela cria um arquivo .root com as variáveis relevantes da simulação. Esse arquivo é composto de um TTree com três TBranches, cada um com os resultados obtidos das classes EnergyDeposition, ShowerGeometry e PMT, separadamente. No caso da classe EnergyDeposition, temos tanto os resultados obtidos para o perfil longitudinal de entrada, proveniente do Corsika ou Aires, quanto os obtidos para o perfil longitudinal de saída, proveniente da simulação do telescópio. 


\section{A.6.1 Variáveis armazenadas}

O método SaveEvent da classe EventManager é chamado do programa principal com ponteiros para os objetos que compõem a simulação (instâncias das classes EnergyDeposition, ShowerGeometry e PMT) e grava automaticamente todas variáveis relevantes. As tabelas A.4, A.5 e A.6 mostram uma breve descrição das variáveis armazenadas, provenientes das classes EnergyDeposition, ShowerGeometry e PMT, respectivamente. Vale notar que em uma simulação completa do telescópio são utilizadas duas instâncias da classe EnergyDeposition, uma com o perfil longitudinal completo, proveniente do Corsika ou Aires e outra com o perfil longitudinal reconstruído após a simulação completa do detetor de fluorescência.

\begin{tabular}{|l|c|}
\hline \multicolumn{2}{|c|}{ EnergyDeposition } \\
\hline Variável & Descrição \\
\hline deposition. $\theta$ & ângulo $\theta$ do eixo reconstruído \\
\hline deposition. $\varphi$ & ângulo $\varphi$ do eixo reconstruído \\
\hline deposition. $E_{0}$ & Energia de entrada do Corsika \\
\hline deposition. $E$ & Energia reconstruída após a simulação completa \\
\hline deposition. $X_{\max }$ & $X_{\max }$ do ajuste após a simulação completa \\
\hline deposition. $(d E / d X)_{\max }$ & $(d E / d X)_{\max }$ do ajuste após a simulação completa \\
\hline deposition. $\chi_{\text {red }}^{2}$ & $\chi_{\text {red }}^{2}$ do ajuste após a simulação completa \\
\hline deposition. $\ln _{\text {tegral }}$ & Entegral da função GH ajustada após a simulação completa \\
\hline deposition. $\epsilon_{E}$ & Erro na energia: $\left(E-E_{0}\right) / E_{0}$ \\
\hline deposition. $\epsilon_{X_{\max }} g c m 2$ & Erro em $X_{\max }$ em $g / c m^{2}: X_{\max }-X_{\max 0}$ \\
\hline deposition. $\epsilon_{X_{\max }}$ & Erro em $X_{\max }:\left(X_{\max }-X_{\max 0}\right) / X_{\max 0}$ \\
\hline deposition. $\epsilon_{(d E / d X)_{\max }}$ & Erro em $(d E / d X)_{\max }:\left[(d E / d X)_{\max }-(d E / d X)_{\max }\right] /(d E / d X)_{\max }$ \\
\hline deposition. $g c m 2_{\min }$ & Prof. atmosf. mínima no perfil de deposição reconstruído \\
\hline deposition. $g c m 2_{\max }$ & Prof. atmosf. máxima no perfil de deposição reconstruído \\
\hline deposition. $H_{\max }^{k m}$ & Altitude referente a $g c m 2_{\min }$ \\
\hline deposition. $H_{\min }^{k m}$ & Altitude referente a $g c m 2_{\max }$ \\
\hline
\end{tabular}

Tabela A.4: Descrição das variáveis armazenadas pela classe EventManager provenientes da classe EnergyDeposition.

Para o cálculo dos erros $\epsilon_{X_{\max }} g c m 2, \epsilon_{X_{\max }}$ e $\epsilon_{(d E / d X)_{\max }}$ (ver tabela A.4), os valores de $X_{\max 0}$ e $(d E / d X)_{\max _{0}}$ são obtidos através de um ajuste da função Gaisser-Hillas com $\lambda$ variável (eq. A.5) ao perfil longitudinal completo, proveniente do Corsika, que 
é utilizado para a simulação do evento em questão. Esse ajuste representa a melhor estimativa da posição de $X_{\max }$ e $(d E / d X)_{\max }$ para este perfil longitudinal que é a entrada da simulação.

\begin{tabular}{|c|c|}
\hline \multicolumn{2}{|r|}{ ShowerGeometry } \\
\hline Variável & Descrição \\
\hline geometry.P $P_{\text {Core }-r}$ & Componente $r$ do Core do chuveiro no solo \\
\hline geometry.P $P_{\text {Core }-\theta}$ & Componente $\theta$ do Core do chuveiro no solo \\
\hline geometry.P $P_{\text {Core }-\varphi}$ & Componente $\varphi$ do Core do chuveiro no solo \\
\hline geometry.P $P_{\text {Core }-x}$ & Componente $x$ do Core do chuveiro no solo \\
\hline geometry.P $P_{\text {Core }-y}$ & Componente $y$ do Core do chuveiro no solo \\
\hline geometry.PCore-z & Componente $z$ do Core do chuveiro no solo \\
\hline geometry. $D_{\text {Core }-r}$ & Componente $r$ da direção do chuveiro \\
\hline geometry. $D_{\text {Core }-\theta}$ & Componente $\theta$ da direção do chuveiro \\
\hline geometry. $D_{\text {Core }-\varphi}$ & Componente $\varphi$ da direção do chuveiro \\
\hline geometry. $D_{\text {Core }-x}$ & Componente $x$ da direção do chuveiro \\
\hline geometry. $D_{\text {Core }-y}$ & Componente $y$ da direção do chuveiro \\
\hline geometry. $D_{\text {Core }-z}$ & Componente $z$ da direção do chuveiro \\
\hline geometry.Vislengthkm & Comprimento da parte visível do eixo do chuveiro em $\mathrm{km}$ \\
\hline geometry.Vislengthgcm 2 & Comprimento da parte visível do eixo do chuveiro em $\mathrm{g} / \mathrm{cm}^{2}$ \\
\hline geometry.Vislengthrad & Ângulo descrito pela parte visível do eixo do chuveiro em relação à origem \\
\hline geometry.gcm $2_{\min }$ & Prof. atmosf. mínima da parte visível do chuveiro em $\mathrm{g} / \mathrm{cm}^{2}$ (vert.) \\
\hline geometry.gcm $2_{\max }$ & Prof. atmosf. máxima da parte visível do chuveiro em $\mathrm{g} / \mathrm{cm}^{2}$ (vert.) \\
\hline geometry. $H_{m a x}^{k m}$ & Altitude referente a $g c m 2_{\min }$ \\
\hline geometry. $H_{\min }^{k m}$ & Altitude referente a $g c m 2_{\max }$ \\
\hline geometry. $R_{p}$ & Parâmetro de impacto do eixo do chuveiro \\
\hline geometry. $\Psi$ & Ângulo entre o solo e o eixo do chuveiro no plano do chuveiro \\
\hline geometry. $A$ & Altitude do telescópio acima do nível do mar em $\mathrm{km}$ \\
\hline
\end{tabular}

Tabela A.5: Descrição das variáveis armazenadas pela classe EventManager provenientes da classe ShowerGeometry.

A utilização da classe EventManager implica em várias vantagens: O arquivo de saída .root é nativo ao Root system e é automaticamente comprimido; torna mais fácil a análise de dados por permitir a utilização de vários métodos do Root[70] desenvolvidos especialmente para essas finalidades. Entre eles está a aplicação de cortes nativos do Root (TCut) posteriormente à simulação, o que permite o estudo da influência de vários cortes diferentes a partir de um mesmo arquivo de saída da simulação, simulação essa efetuada apenas uma vez, sem cortes. É possível também definir eixos de scatter plots e 


\begin{tabular}{|c|c|}
\hline \multicolumn{2}{|r|}{$P M T$} \\
\hline Variável & Descrição \\
\hline telescope.P.Pore Cor $-r^{r e c}$ & Componente $r$ do Core reconstruído no solo \\
\hline telescope.P.Pore Cor $-\theta^{\text {rec }}$ & Componente $\theta$ do Core reconstruído no solo \\
\hline telescope.P.Pore Cor $^{\prime}-\varphi$ & Componente $\varphi$ do Core reconstruído no solo \\
\hline telescope.P.Pore Cor $^{\prime}-x$ & Componente $x$ do Core reconstruído no solo \\
\hline telescope.P.Pore'-y & Componente $y$ do Core reconstruído no solo \\
\hline telescope.P.Pore Cor $^{\text {rec }}$ & Componente $z$ do Core reconstruído no solo \\
\hline telescope. $D_{r}^{\prime}$ & Componente $r$ da direção reconstruída do chuveiro \\
\hline telescope. $D_{\theta}^{\prime}$ & Componente $\theta$ da direção reconstruída do chuveiro \\
\hline telescope. $D_{\varphi}^{\prime}$ & Componente $\varphi$ da direção reconstruída do chuveiro \\
\hline telescope. $D_{x}^{\prime}$ & Componente $x$ da direção do reconstruída do chuveiro \\
\hline telescope. $D_{y}^{\prime}$ & Componente $y$ da direção do reconstruída do chuveiro \\
\hline telescope. $D_{z}^{\prime}$ & Componente $z$ da direção reconstruída do chuveiro \\
\hline telescope.gcm $2_{\min }^{r e c}$ & Prof. atmosf. reconstruída do ponto mais alto detectado em $\mathrm{g} / \mathrm{cm}^{2}$ (vert) \\
\hline telescope. $H_{\max }^{k m}$ & Altitude reconstruída referente a $g c m 2_{\min }^{r e c}$ \\
\hline telescope. $\alpha^{\prime}$ & Erro angular utilizado na reconstrução da geometria \\
\hline telescope. $R_{p}^{r e c}$ & Parâmetro de impacto do eixo reconstruído em $\mathrm{km}$ \\
\hline telescope. $\Psi^{\text {rec }}$ & Ângulo entre o solo e o eixo reconstruído do chuveiro no plano do chuveiro \\
\hline telescope. $T^{\text {total }}$ & Tempo total de aquisição \\
\hline telescope. $N_{P M T}$ & Numero de PMTs aceitas pelo trigger \\
\hline telescope.AngSpeed & Velocidade angular média da detecção \\
\hline telescope.Elev $\max$ & Elevação do ponto mais alto detectado \\
\hline
\end{tabular}

Tabela A.6: Descrição das variáveis armazenadas pela classe EventManager provenientes da classe $P M T$.

histogramas a partir de quaisquer variáveis gravadas no TTree, inclusive a utilização de interfaces gráficas (ver fig. A.14) para a rápida visualização e verificação dos dados. Uma outra possibilidade é também salvar os pontos do perfil longitudinal reconstruído pelo telescópio, com incertezas, em um objeto TGraph. Isso permite que, posteriormente, se faça uma análise diferente do evento, por exemplo utilizando funções GH diferentes das utilizadas quando da simulação do telescópio. 


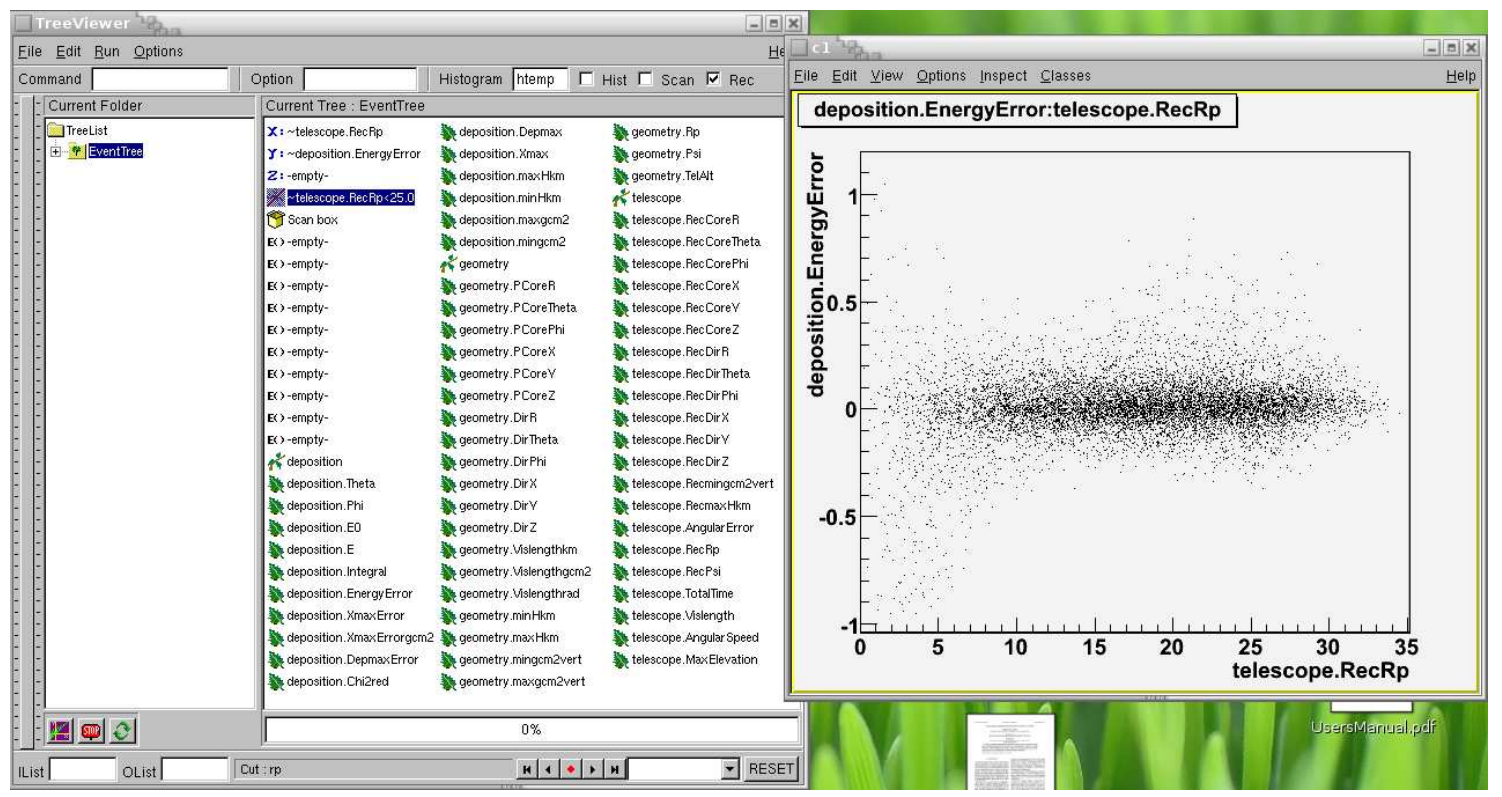

Figura A.14: Screenshot da interface gráfica do Root para TTrees. Com alguns cliques do mouse é possível plotar quaisquer variáveis em função de outras, inclusive com a utilização de cortes. 


\section{Lista de Tabelas}

2.1 Principais parâmetros dos telescópios utilizados na simulação. ..... 69

2.2 Cortes aplicados aos resultados da simulação para cada telescópio. . . . . 72

4.1 Valores de $N_{\max }$ e $X_{\max }$ obtidos do ajuste de funções GH aos perfis longitudinais dos primários de energia $E=320 \mathrm{EeV}$. . . . . . . . . . 85

4.2 Valores de $N_{\max }$ e $X_{\max }$ obtidos do ajuste de funções GH aos perfis longitudinais dos primários de energia $E=100 E e V . \quad \ldots . . .86$

4.3 Valores de $N_{\max }$ e $X_{\max }$ obtidos do ajuste de funções GH aos perfis longitudinais dos primários de energia $E=50 E e V$. . . . . . . . . . . . 86

4.4 Valores do RMS (slant $\mathrm{g} / \mathrm{cm}^{2}$ ) das distribuições de $X_{\max }$ para várias energias e partículas. ................... 89

4.5 Valores do RMS das distribuições de $N_{\max }$ para várias energias e partículas. 90

4.6 Valores da média e RMS das distribuições do missing energy ( $E_{0}-$ integral $) / E_{0}$ para os ajustes com $\lambda$ variável e $\lambda$ fixo para vários primários

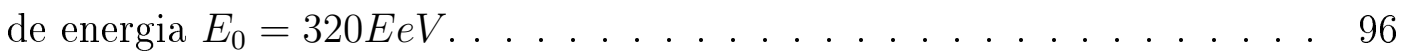

4.7 Cortes de qualidade inicialmente aplicados aos resultados da simulação. . 98

4.8 Valores da média e RMS (slant $\mathrm{g} / \mathrm{cm}^{2}$ ) das distribuições de $X_{\max }$ antes e após a inclusão dos efeitos de detecção. $N$ refere-se ao número de eventos detectados que passaram pelos triggers e cortes de qualidade, $N_{0}=40000$ ao número total de eventos simulados e $\Delta\left\langle X_{\max }\right\rangle$ à variação na média das distribuições antes e após a inclusão dos efeitos de detecção. . . . . . . . . 101 
4.9 Valores da média e RMS das distribuições do erro na energia reconstruída $\left(E_{r e c}-E_{0}\right) / E_{0}$ antes e após a inclusão dos efeitos de detecção. Os gráficos dessas distribuições podem ser vistos nas figuras 4.15 e 4.16 . . . . . . . . 104

4.10 Resultados após a aplicação dos cortes offline para uhecrons de massa $50 \mathrm{GeV} . E_{U}$ e $E_{p}$ indicam a energia inicial (EeV) dos uhecrons e prótons, respectivamente. $N_{u}\left(N_{u}^{\prime}\right)$ e $N_{p}\left(N_{p}^{\prime}\right)$ indicam o número de eventos antes (após) a aplicação dos cortes offline. $N_{T}^{\prime}=N_{u}^{\prime}+N_{p}^{\prime}$. As últimas 4 colunas indicam os valores que são aceitos após a otimização dos cortes $\left(\mathrm{GeV} \mathrm{cm}^{2} / \mathrm{g}, \mathrm{rad}, \mathrm{km}\right.$ e $\mathrm{g} / \mathrm{cm}^{2}$, respectivamente). . . . . . . . . . . 112

4.11 Resultados após a aplicação dos cortes cortes offline para uhecrons de massa $30 \mathrm{GeV}$ (ver legenda da tabela 4.10). . . . . . . . . . . . . . 113

4.12 Resultados após a aplicação dos cortes cortes offline para uhecrons de massa $20 \mathrm{GeV}$ (ver legenda da tabela 4.10). . . . . . . . . . . . . 113

4.13 Resultados após a aplicação dos cortes offline para uhecrons de massa $50 \mathrm{GeV} . E_{U}$ e $E_{p}$ indicam a energia inicial (EeV) dos uhecrons e prótons, respectivamente, $\phi_{U} / \phi_{p}$ é a razão entre os fluxos de uhecrons e prótons. $N_{u}\left(N_{u}^{\prime}\right)$ e $N_{p}\left(N_{p}^{\prime}\right)$ indicam o número de eventos antes (após) a aplicação dos cortes offline. $N_{T}^{\prime}=N_{u}^{\prime}+N_{p}^{\prime} \ldots \ldots \ldots$. . . . . . . 115

A.1 Parâmetros $A, B$ e $C$ da expressão da missing energy para prótons e cada inclinação do chuveiro[64]. . . . . . . . . . . . . . . . . . 139

A.2 Constantes da equação A.10 utilizadas por Kakimoto et al. e Nagano et

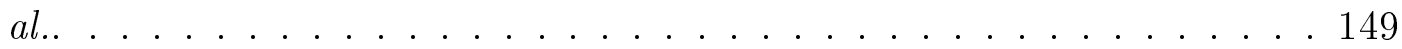

A.3 Valores padrão dos parâmetros utilizados na simulação do fundo e da eletrônica no caso da simulação do telescópio de fluorescência do Observatório Pierre Auger. . . . . . . . . . . . . . . . . . . . . . 155

A.4 Descrição das variáveis armazenadas pela classe EventManager provenientes da classe EnergyDeposition. . . . . . . . . . . . . . . . . . 159 
A.5 Descrição das variáveis armazenadas pela classe EventManager provenientes da classe ShowerGeometry. . . . . . . . . . . . . . . . . 160

A.6 Descrição das variáveis armazenadas pela classe EventManager provenientes da classe PMT. . . . . . . . . . . . . . . . . . 161 


\section{Lista de Figuras}

1.1 Espectro observado dos raios cósmicos. Figura extraída de [9]. . . . . . . 18

1.2 Seção de choque total para fotoprodução de píons no caso de prótons (linha cheia) e nêutrons (linha tracejada) em função da energia do fóton no sistema de repouso do nucleon. O primeiro pico, próximo ao limiar, é devido à ressonância associada à produção do $\Delta^{+}$. Figura extraída de [13]. 20

1.3 Relação entre os sistemas LAB e REST para uma partícula de energia $E$ e massa $M$ se movendo na direção $z$ no sistema LAB, e um fóton do CMB de energia $\epsilon$ incidindo com uma direção $(\theta, \phi)$ sobre o raio cósmico. 20

1.4 Taxa de perda de energia para prótons em $z=0$. A linha "red-shift" representa a perda adiabática de energia. Para $E=6.05 \times 10^{19} \mathrm{eV}$ as perdas devido à fotoprodução de píons e criação de pares são iguais. Figura extraída de $[14] \ldots \ldots \ldots \ldots \ldots \ldots \ldots$

1.5 Energia média em função da distância (tempo) de propagação para prótons com energia inicial indicada. Figura extraída de [15] . . . . . . . . . 24 
1.6 Panorama das interações das partículas primárias de raios cósmicos com o CMB. As curvas marcadas como " $p+\gamma_{C M B} \rightarrow e^{+} e^{-}+\mathrm{p}$ " e "Fe+ $+\gamma_{C M B} \rightarrow$ $e^{+} e^{-}+\mathrm{Fe}$ " são comprimentos de atenuação. A curva marcada como " $p+$ $\gamma_{C M B} \rightarrow \pi^{+} \mathrm{n}$ ou $\pi^{0} \mathrm{p}$ " é o caminho livre médio para fotoprodução de píons no CMB. A curva marcada "Fe+ $+\gamma_{C M B} \rightarrow$ núcleo + n ou 2 n" é o caminho livre médio para reações fotonucleares onde o ferro perde um ou dois nucleons. A curva marcada " $\gamma+\gamma_{C M B} \rightarrow e^{+} e^{-"}$ é o caminho livre

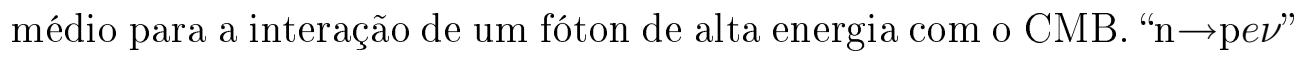
é o comprimento de decaimento médio para nêutrons. Figura extraída de

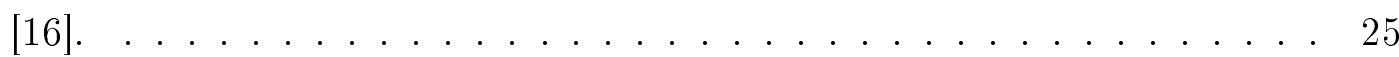

1.7 Diagrama de Hillas mostrando limites de Campo Magnético e tamanho do objeto astrofísico para acelerar partículas a $10^{20} \mathrm{eV}$. . . . . . . . 29

1.8 Integral dos dois espectros monoculares do HiRes dividido por um ajuste da parte final do espectro, antes do corte. Apenas os valores do HiResI(vermelho) são utilizados para a estimativa de $E_{1 / 2}$. Figura extraída de

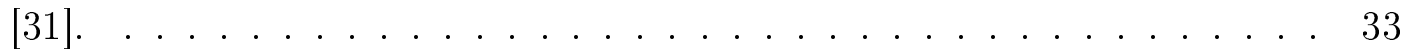

1.9 Razão entre o espectro reconstruído pelo SD do Auger e um espectro $\propto E^{-2.6}$ em função da energia. Figura extraída de [32]. . . . . . . . . . . 34

1.10 Cascata (ou chuveiro) produzido por um próton de $10 G e V$ em uma câmara de núvens contendo placas de chumbo. Figura extraída de [9]. . . . 35

1.11 Relação entre profundidade atmosférica vertical (vertical $\mathrm{g} / \mathrm{cm}^{2}$ ) e profundidade atmosférica slant $\left(\right.$ slant $\left.\mathrm{g} / \mathrm{cm}^{2}\right) \ldots \ldots$. . . . . . . . 37

1.12 Simulação de um EAS produzido por um próton de $10^{15} \mathrm{eV}$. As cores representam diferentes partículas: vermelho=elétrons, pósitrons e gamas, verde $=$ múons e azul $=$ hádrons. Figura extraída de [38]. . . . . . . . . . . 37

1.13 Esquema do desenvolvimento de um chuveiro atmosférico. . . . . . . . . 38

1.14 Esquema do Toy Model de Heitler. . . . . . . . . . . . . . . . . . . . . . 40

1.15 Extensão espacial das componentes de um EAS. . . . . . . . . . . . . . 46 
1.16 Criação de duas cordas QCD a partir da interação de dois nucleons. Cada nucleon é dividido em uma componente $q$ e uma $q q$. O diquark do projétil então se combina com o quark do alvo e vice versa, formando duas cordas

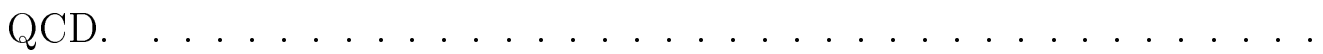

1.17 Fragmentação de uma corda QCD. Em (A) o lado direito da corda é aleatoriamente selecionado e um par $q-\bar{q}$ é criado. A corda se fragmenta e o sabor criado se combina com a extremidade direita criando uma nova partícula (méson). Em (B) temos então uma corda menor (menor massa) e uma partícula. Em (C) o processo se repete, agora com o lado esquerdo da corda, gerando um bárion. Esse processo se repete até que a massa da corda atinja um certo limiar. . . . . . . . . . . . . . . . 50

1.18 Criação de cordas entre projétil e nucleons participantes em uma interação hádron-núcleo $\left(N_{W}=3\right) \ldots \ldots \ldots \ldots \ldots$

1.19 Perfil longitudinal da média de 20 chuveiros criados por prótons e 20 por núcleos de ferro, ambos com energia $E=3.2 \cdot 10^{20} \mathrm{eV}$, criados com o Aires. O final abrupto da distribuição representa o nível do solo. . . . . . . . . . 54

1.20 Exemplo de perfil longitudinal obtido da simulação com o Aires de um próton com $E=3.2 \cdot 10^{20} \mathrm{eV}$. . . . . . . . . . . . . . . . 55

1.21 Esquema da detecção de EAS pelo método de fluorescência e por tanques Cerenkov (evento híbrido). Extraído de [51] . . . . . . . . . . . . . 57

1.22 Espectro de emissão de fluorescência, extraída de [50]. Cerca de $82 \%$ da emissão ocorre entre 300 e $450 n m$. . . . . . . . . . . . . . . . 57

1.23 Candidato a evento FD do Observatório Auger. À esquerda está uma representação da câmera com as PMTs que passaram pelos triggers primário e secundário. Os sinais das PMTs indicadas por pontos são mostrados na parte superior direita da figura, onde o eixo horizontal é composto por bins de tempo. . . . . . . . . . . . . . . . . . 59 
1.24 Esquema da reconstrução geométrica de um EAS, mostrando o plano chuveiro-detetor, extraído de [53]. . . . . . . . . . . . . . 60

1.25 Exemplo de reconstrução geométrica de um chuveiro. O tempo $t_{i}$ do pixel é plotado em função de $\chi_{i}$, a direção do pixel projetada no SDP. Figura extraída de [54]. . . . . . . . . . . . . . . . . . . . . . 6 61

1.26 Exemplo de um perfil longitudinal reconstruído de deposição de energia (pontos) e um ajuste GH. Figura retirada de [58]. . . . . . . . . . . . . . 64

1.27 Profundidade média do máximo $\left\langle X_{\max }\right\rangle$ em função da energia do primário obtida de simulações com distintos modelos hadrônicos além de dados experimentais. Figura retirada de [58]. . . . . . . . . . . . . . 65

1.28 Números de elétrons e múons reconstruídos do experimento KASCADEGrande. Os pares de linhas tracejadas indicam linhas de massa e energia constantes obtidas do Corsika. Figura extraída de [61]. . . . . . . . . . . 68

2.1 Esquema da simulação dos sinais em cada PMT do detetor. . . . . . . . . 70

2.2 Esquema da reconstrução do evento. . . . . . . . . . . . . . . 71

2.3 Comparação entre nossos resultados para o parâmetro de impacto $R_{p}$ e os dados e simulações da colaboração HiRes, para $E=10^{19} \mathrm{eV}$ e $E=10^{19.5} \mathrm{eV} .72$

2.4 EED obtida de nossa simulação do telescópio HiRes-II. Um ajuste Gaussiano e um Lognormal à parte central da distribuição também é mostrado. 73

2.5 Figura extraída de nosso artigo [6] mostrando EEDs obtidas para chuveiros gerados a partir de prótons de energia $E_{0}=10^{19} \mathrm{eV}$ e $E_{0}=10^{20} \mathrm{eV}$ para os telescópios HiRes-II e Auger. . . . . . . . . . . . . . . . . . . 74

2.6 Skewness em função da energia para as EEDs obtidas de nossas simulações do HiResII e Auger. Figura extraída de nosso artigo[6] . . . . . . . . 75

3.1 Amostragens e ajuste da função de Peterson, obtidas de nosso programa, para $\epsilon_{Q}=2.65 \times 10^{-5}$, valor esse utilizado para $M_{U}=50 \mathrm{GeV} . \ldots$. . . 80 
3.2 Esquema da criação e desenvolvimento da corda QCD no caso usual e no caso do uhecron. ....................... . . 81

4.1 Perfis longitudinais médios de 500 chuveiros iniciados por cada tipo de partícula com energia $E=320 \mathrm{EeV}$ : Ferro, prótons, e uhecrons com massas de $50 G e V$ e $20 G e V$. Os valores de $N_{\max }$ e $X_{\max }$ podem ser vistos na tabela $4.1 . \ldots \ldots \ldots \ldots$. . . . . . . . . . . . . 8

4.2 Perfis longitudinais médios de 500 chuveiros iniciados por ferro, prótons, e uhecrons com massas de $50 \mathrm{GeV}$ e $20 \mathrm{GeV}$ de energia $E=100 \mathrm{EeV}$ (esquerda) e $E=50 E e V$ (direita). Os valores de $N_{\max }$ e $X_{\max }$ podem ser vistos nas tabelas 4.2 e $4.3 \ldots \ldots \ldots \ldots \ldots$

4.3 Região de $X_{\max }$ dos perfis longitudinais médios de 500 chuveiros iniciados por prótons e uhecrons com massas de $50 \mathrm{GeV}, 30 \mathrm{GeV}$ e $20 \mathrm{GeV}$ de energia $E=320 E e V$. Os valores de $N_{\max }$ e $X_{\max }$ podem ser vistos na tabela 4.1 .

4.4 Distribuições de $X_{\max }$ obtidos diretamente do Aires para chuveiros iniciados por prótons e uhecrons de massa $M_{U}=50 \mathrm{GeV}$ de energias $E_{0}=$ $320 \mathrm{EeV}$ (esquerda) e $E_{0}=50 \mathrm{EeV}$ (direita). Os valores do RMS das distribuições podem ser vistos na tabela 4.4 . . . . . . . . . . . . . .

4.5 Distribuições de $N_{\max }$ obtidos diretamente do Aires para chuveiros iniciados por prótons e uhecrons de massa $M_{U}=50 \mathrm{GeV}$ de energias $E_{0}=$ $320 \mathrm{EeV}$ (esquerda) e $E_{0}=50 \mathrm{EeV}$ (direita). Os valores do RMS das distribuições podem ser vistos na tabela 4.5. . . . . . . . . . . . . . . . 90

4.6 Perfil longitudinal médio dos 500 chuveiros verticais utilizados para o estudo da distribuição lateral de partículas no solo para ferro, prótons e uhecrons de energia $E_{0}=320 \mathrm{EeV}$ (esquerda) e $E_{0}=50 \mathrm{EeV}$ (direita). O final do gráfico coincide com a profundidade atmosférica $X \cong 865 \mathrm{~g} / \mathrm{cm}^{2}$ do solo no Observatório Pierre Auger. . . . . . . . . . . . . . . . 91 
4.7 Densidade média de $e \pm$ e $\mu \pm$ no solo em função da distância ao core do chuveiro para prótons e uhecrons de energia $E_{0}=320 \mathrm{EeV}$ (esquerda) e $E_{0}=50 \mathrm{EeV}$ (direita). . . . . . . . . . . . . . . 92

4.8 Distribuições de $X_{\max }$ (esquerda) e $(d E / d X)_{\max }$ (direita) para os ajustes de funções Gaisser-Hillas com $\lambda$ fixo e $\lambda$ variável para prótons e uhecrons de massa $M_{U}=50 \mathrm{GeV}$, ambos com $E_{0}=320 \mathrm{EeV}$. . . . . . . . . 95

4.9 Distribuições do "missing energy" $\left(E_{0}-\right.$ integral $) / E_{0}$ para os ajustes de funções Gaisser-Hillas com $\lambda$ fixo e $\lambda$ variável para prótons e uhecrons de mass $M_{U}=50 \mathrm{GeV}$, ambos com $E_{0}=320 \mathrm{EeV}$. Os valores da média e RMS dessas distribuições podem ser vistas na tabela 4.6. . . . . . . . . . 96

4.10 Distribuições normalizadas dos $\chi_{\text {red }}^{2}$ dos ajustes da função GH de $\lambda$ fixo aos perfis longitudinais reconstruídos de prótons e uhecrons de energia

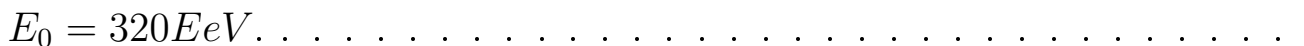

4.11 Comparação entre as distribuições de $X_{\max }$ antes e após a inclusão dos efeitos de detecção. À esquerda prótons antes da detecção (verde), após a detecção (preto) e após a detecção, normalizada para o número de eventos de entrada da simulação (preto tracejado). À direita uhecrons $\left(M_{U}=\right.$ $50 \mathrm{GeV}$ ) antes da detecção (azul), após a detecção (vermelho) e após a detecção, normalizada para o número de eventos de entrada da simulação (vermelho tracejado). Ambos primários com energia $E_{0}=320 \mathrm{EeV}$. . . 100

4.12 Comparação entre as distribuições de $X_{\max }$ antes e após a inclusão dos efeitos de detecção. À esquerda prótons antes da detecção (verde), após a detecção (preto) e após a detecção, normalizada para o número de eventos de entrada da simulação (preto tracejado). À direita uhecrons $\left(M_{U}=\right.$ $50 \mathrm{GeV}$ ) antes da detecção (azul), após a detecção (vermelho) e após a detecção, normalizada para o número de eventos de entrada da simulação (vermelho tracejado). Ambos primários com energia $E_{0}=100 \mathrm{EeV}$. . . . 100 
4.13 Aceitância em função de $X_{\max }$ do detetor de fluorescência do Observatório Pierre Auger. Figura extraída de [69]. . . . . . . . . . . . . . . . . . . . . 102

4.14 Comparação entre as distribuições normalizadas de $(d E / d X)_{\max }$ antes e após a inclusão dos efeitos de detecção. À esquerda prótons antes da detecção (verde) e após a detecção (preto). À direita uhecrons antes da detecção (azul) e após a detecção (vermelho). Ambos primários com energia $E_{0}=320 \mathrm{EeV}$. . . . . . . . . . . . . . . 103

4.15 Comparação entre as distribuições normalizadas de erro na energia antes e após a inclusão dos efeitos de detecção. À esquerda prótons antes da detecção (verde) e após a detecção (preto). À direita uhecrons antes da detecção (azul) e após a detecção (vermelho). Ambos primários com energia $E_{0}=320 E e V . \ldots \ldots \ldots$

4.16 Comparação entre as distribuições normalizadas de erro na energia antes e após a inclusão dos efeitos de detecção. À esquerda prótons antes da detecção (verde) e após a detecção (preto). À direita uhecrons antes da detecção (azul) e após a detecção (vermelho). Ambos primários com energia $E_{0}=100 \mathrm{EeV}$. . . . . . . . . . . . . . . . . 104

4.17 Distribuições de $X_{\max }$ (esquerda) e $(d E / d X)_{\max }$ (direita) para prótons e uhecrons de energia $E_{0}=320 E e V$, após a detecção e reconstrução de eventos e a aplicação dos cortes iniciais. As setas azuis representam a posição dos cortes que aceitam $X_{\max }>912 \mathrm{~g} / \mathrm{cm}^{2}$ (esquerda) e $(d E / d X)_{\max }<4.08 \times 10^{8} \mathrm{GeV} \mathrm{cm}^{2} / \mathrm{g}$ (direita) . . . . . . . . . . 106

4.18 Distribuições de $\theta$ (esquerda) e $H_{\max }$ (direita) para prótons e uhecrons de energia $E_{0}=320 E e V$, após a detecção e reconstrução de eventos e aplicação dos cortes iniciais. As setas azuis representam a posição dos cortes que aceitam $\theta>0.571 \mathrm{rad}$ (esquerda) e $H_{\max }<12.61 \mathrm{~km}$ (direita). 107 
4.19 Distribuição de $X_{\max }$ para prótons e uhecrons de massa $M_{U}=50 \mathrm{GeV}$, ambos com energia $E_{0}=320 E e V$, antes e após a aplicação dos cortes

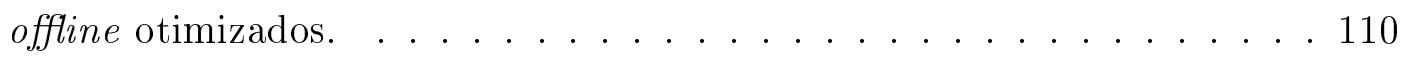

4.20 Distribuição de $(d E / d X)_{\max }$ para prótons e uhecrons de massa $M_{U}=$ $50 \mathrm{GeV}$, ambos com energia $E_{0}=320 \mathrm{EeV}$, antes e após a aplicação dos cortes offline otimizados. . . . . . . . . . . . . . . . . 110

4.21 Distribuições de $\theta$ e $H_{\max }$ para prótons e uhecrons de massa $M_{U}=$ $50 \mathrm{GeV}$, ambos com energia $E_{0}=320 \mathrm{EeV}$, antes e após a a aplicação dos cortes offline otimizados. . . . . . . . . . . . . 111

4.22 Distribuições de $X_{\max }$ (esquerda) e $(d E / d X)_{\max }$ (direita) para prótons de energia $E_{0}=320 \mathrm{EeV}$ (preto) e uhecrons de energias $E_{0}=320 \mathrm{EeV}$ (vermelho) e $E_{0}=352 E e V$ (azul), após a simulação do telescópio e cortes iniciais. . . . . . . . . . . . . . . . . . . . . 112

4.23 Distribuições de $X_{\max }$ no caso de uma razão de 0.1 entre os fluxos de uhecrons e prótons de energia $E_{0}=352 \mathrm{EeV}$ e $E_{0}=320 \mathrm{EeV}$, respectivamente, antes (esquerda) e após (direita) a inclusão dos cortes offline. . . . 115

A.1 Esquema da relação entre o sistema do telescópio $\left(O_{t e l}\right)$ e o sistema da

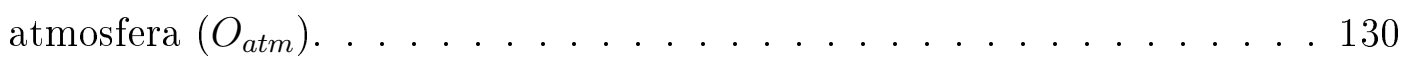

A.2 Esquema ilustrativo da transformação da inclinação zenital do perfil longitudinal de deposição de um chuveiro atmosférico. O perfil de deposição em profundidade atmosférica slant permanece inalterado $\left(X_{s}=X_{s}^{\prime}\right)$. . . 135

A.3 Exemplo de ajuste da função A.5 a um perfil longitudinal de deposição completo obtido diretamente do Corsika. As incertezas nesse caso são tomadas como sendo unitárias. . . . . . . . . . . . . . . . . 138

A.4 Exemplo de ajuste da função A.4 a um perfil longitudinal de deposição parcial. As incertezas nesse caso são tomadas como sendo unitárias. . . . 138 
A.5 Exemplo de ajuste da função A.4 a um perfil longitudinal de deposição proveniente da simulação do telescópio HiRes-II. A integral da função, a energia reconstruída (com missing energy), além de outras informações são impressas automaticamente. . . . . . . . . . . . . . . . 140

A.6 Região na atmosfera que representa o limite máximo de visibilidade do telescópio. Toda deposição de energia do chuveiro dentro desta região pode posteriormente ser analisada pela classe PMT. . . . . . . . . . . . . 142

A.7 Esquema de entrada para a classe PMT. . . . . . . . . . . . . . . . . 145

A.8 (A) Esquema da divisão do perfil longitudinal nas regiões observadas por cada PMT. $\Theta$ é a aceitância angular de cada PMT. (B) Esquema geométrico para o cálculo de um ponto $\vec{P}$ ao longo do eixo do chuveiro que faz um ângulo $\theta$ com o ponto $\vec{P}_{0}$, no plano do chuveiro. . . . . . . . 147

A.9 Esquema da integração da deposição de energia na região observada por cada PMT. . . . . . . . . . . . . . . . . . . . . 148

A.10 $F_{\text {atm }}(h)$ calculado a partir da U.S. Atmosphere 1976 para altitudes até $30 k m . \ldots \ldots \ldots \ldots \ldots \ldots \ldots \ldots \ldots$

A.11 Esquema do sinal sem ruído dividido em bins de 100ns. A intensidade $S_{0}$ é calculada a partir da integral do sinal sem ruído e do tempo de aquisição T. $N_{0}$ é o número de foto-elétrons em cada bin. . . . . . . . . . . . 153

A.12 Esquema do sinal com ruído gerado a cada bin de $100 n s . N_{i}^{\text {pe }}$ é o número de foto-elétrons em cada bin, já com a inclusão do fundo e ruído e a subtração do fundo médio. . . . . . . . . . . . . . . . . . . . . . 154

A.13 Esquema geométrico da inclusão do erro na direção do eixo no plano do chuveiro. O erro angular gerado é $\alpha^{\prime}$. . . . . . . . . . . . . 156

A.14 Screenshot da interface gráfica do Root para TTrees. Com alguns cliques do mouse é possível plotar quaisquer variáveis em função de outras, inclusive com a utilização de cortes. . . . . . . . . . . . . 162 